DISSERTAÇÃO DE MESTRADO

\title{
AVALIAÇÃO DE PARÂMETROS QUE AFETAM A EFETIVIDADE DA COMPARAÇÃO BALÍSTICA AUTOMATIZADA
}

$$
\text { Por, }
$$

Lehi Sudy dos Santos

\section{UNIVERSIDADE DE BRASÍLIA}

\author{
Faculdade de Tecnologia
}

Departamento de Engenharia Mecânica 
UNIVERSIDADE DE BRASILIA

Faculdade de Tecnologia

Departamento de Engenharia Mecânica

Programa de Pós-Graduação em Ciências Mecânicas

\title{
DISSERTAÇÃO DE MESTRADO
}

\section{AVALIAÇÃO DE PARÂMETROS QUE AFETAM A EFETIVIDADE DA COMPARAÇÃO BALÍSTICA AUTOMATIZADA}

\author{
Por, \\ Lehi Sudy dos Santos \\ Dissertação submetida ao Programa de Pós-Graduação em \\ Ciências Mecânicas da Universidade de Brasília como parte dos \\ requisitos necessários para a obtenção do grau de Mestre em \\ Engenharia Mecânica.
}

Banca Examinadora

Prof $^{\mathrm{a}}$. Dr ${ }^{\mathrm{a}}$. Palloma Vieira Muterlle, UnB/ ENM

Orientadora

Prof. Dr. Edson Paulo da Silva, UnB/ ENM

Examinador Externo

Prof. Dr. Cosme Roberto Moreira da Silva, UnB/ ENM

Examinador Interno

Brasília, 27 de novembro de 2015 


\section{FICHA CATALOGRÁFICA}

\section{SANTOS, LEHI SUDY DOS}

Avaliação de Parâmetros que Afetam a Efetividade da Comparação Balística Automatizada. 139p., 297 mm (ENM/FT/UnB, Mestre, Ciências Mecânicas, 2015). Dissertação de Mestrado - Universidade de Brasília.

Faculdade de Tecnologia.

Departamento de Engenharia Mecânica.

1. Comparação Balística Automatizada 2. Dureza Brinell de Projéteis

3. Rugosidade de Projéteis

4. Armas de Fogo

I. ENM/FT/UnB

II. Título ENM.DM-236/2015

\section{REFERÊNCIA BIBLIOGRÁFICA}

SANTOS, L. S. (2015). Avaliação de Parâmetros que Afetam a Efetividade da Comparação Balística Automatizada. Dissertação de Mestrado em Ciências Mecânicas, Publicação ENM.DM-236/2015, Departamento de Engenharia Mecânica, Universidade de Brasília, Brasília, DF, 139p.

\section{CESSÃO DE DIREITOS}

NOME DO AUTOR: Lehi Sudy dos Santos.

TÍTULO: Avaliação de Parâmetros que Afetam a Efetividade da Comparação Balística Automatizada.

\section{GRAU: Mestre ANO: 2015}

É concedida à Universidade de Brasília permissão para reproduzir cópias desta dissertação de mestrado e para emprestar ou vender tais cópias somente para propósitos acadêmicos e científicos. O autor reserva outros direitos de publicação e nenhuma parte desta dissertação de mestrado pode ser reproduzida sem a autorização por escrito do autor.

\section{Lehi Sudy dos Santos}

lehisudy@gmail.com

Al. Das Acácias Q 107 Bloco C ap 803, Aguas Claras; 71920-540; Brasília/DF - Brasil. 
À minha esposa Vanessa e ao meu filho Pietro, e aos meus pais Antônio Vasco (em memória) e Ivoni Meireles.

Lehi Sudy dos Santos 


\section{AGRADECIMENTOS}

Primeiramente a Deus, a quem atribuo a existência das leis da natureza, que permitem a nossa existência e evolução.

À minha esposa Vanessa, e ao meu filho Pietro, que são a razão de me esforçar a ser uma pessoa melhor a cada dia; aos meus pais e irmãos, que me proporcionaram um lar em que pude crescer com segurança, alegria e apoio em todos os sentidos.

A minha orientadora, Prof ${ }^{a}$. Dr ${ }^{a}$. Palloma Vieira Muterlle, por acreditar no projeto, disponibilizar-se a orientar e ajudar no estudo.

A todos meus professores de Pós-Graduação da FT-UnB, pelos quais tenho muito respeito e gratidão pelos ensinamentos acadêmicos.

Ao colega Paulo, sempre solícito e disposto a orientar no uso de aparelhos do laboratório.

Aos alunos de graduação Caio, Jéssica, Matheus, Bernardo, Alyson, Mario e Vinícius, que fizeram seus projetos de graduação ou participaram como bolsistas, pelas extensas horas de trabalho, disparando armas, alimentando o sistema, realizando análises. Sem eles este trabalho não teria acontecido.

Aos meus colegas de trabalho Eduardo Makoto Sato e Marcelo Jost que foram meus mestres na criminalística e que sempre apoiaram e incentivaram a prosseguir com este estudo.

A todos que contribuíram para a realização desse trabalho, de forma direta ou indireta.

Lehi Sudy dos Santos 
“A evidência física não pode estar errada, não pode cometer perjúrio por si própria, não se pode tornar ausente. Cabe aos humanos, procurá-la, estudá-la e compreendê-la, apenas os humanos podem diminuir o seu valor".

Edmond Locard 


\section{RESUMO}

Armas de fogo são máquinas térmicas que operando em processos cíclicos transformam energia térmica em energia cinética do projétil. Geralmente seus canos e diversas peças são fabricados com aço de elevada dureza, permitindo resistirem às altas pressões geradas durante o disparo e ciclagem. Por mais rigorosos que sejam os processos de fabricação e acabamento destas peças, invariavelmente elas adquirem imperfeições microscópicas. Estas imperfeições marcam estojos e projéteis (elementos de munição) disparados da arma e por meio de um exame comparativo destas marcas é possível estabelecer uma relação unívoca entre um elemento de munição e a arma que o disparou. Esta comparação pode ser feita por meio de microscópio óptico ou por meio de sistemas de comparação automatizada.

Sistemas de comparação automatizada de última geração apresentam muitos avanços em qualidade de captura de imagens e nos processos de comparação automatizada, porém estudos de efetividade destes sistemas têm demonstrado que diversos fatores, como aumento no banco de dados, ou munições provenientes de diferentes fabricantes, podem tornar estes equipamentos muito imprecisos.

Para este estudo foi implementado um banco de dados de imagens balísticas de referência (RBID), obtidas de estojos e projéteis coletados de armas de fogo nos calibres ponto trinta e oito Special (.38SPL) e nove milímetros Luger (9mm Luger), no Sistema de Identificação Balística EVOFINDER ${ }^{\circledR}$, e controlado os seguintes parâmetros que poderiam afetar a efetividade do sistema: tipo de projétil, tipo de estojo, e qualificação do usuário para operar o sistema.

A efetividade do sistema com projéteis ogivais de chumbo (CHOG) no calibre .38SPL foi $0,31( \pm 0,06)$, valor bem inferior a efetividade do sistema com projéteis encamisados, 0,67 $( \pm 0,14)$. Pela análise de dureza Brinell e rugosidade destes projéteis, evidenciou-se uma relação entre a dureza do projétil .38SPL e a efetividade do sistema, apontando uma explicação para a diferença observada.

Os resultados não mostraram diferenças estatisticamente significativas nas efetividades do sistema em relação ao tipo de projétil no calibre $9 \mathrm{~mm}$ Luger, ou ao tipo de estojo nos calibres .38SPL e 9mm Luger.

Em relação as efetividades obtidas por tipo de usuário, com projéteis .38SPL encamisados (excluídos os CHOG) o sistema apresentou uma efetividade de 0,67 $( \pm 0,14)$ com imagens cadastradas e manipuladas com peritos e de $0,53( \pm 0,14)$ com imagens de alunos, diferença que, utilizando análise de variância, mostrou-se estatisticamente relevante. Em relação a todos os demais parâmetros controlados não foram observadas diferenças de performances significativas entre tipo de usuários.

Os resultados obtidos podem ser utilizados para estabelecer quais os parâmetros ótimos de implementação de um banco de dados de armas de fogo nos calibres estudados.

Palavras-chave: Comparação Balística Automatizada; Dureza Brinell de Projéteis;

Rugosidade de Projéteis; Armas de Fogo. 


\begin{abstract}
Firearms are heat engines that operating in cyclical processes convert thermal energy into kinetic energy of the projectile. Usually their barrels and many parts are manufactured from high hardness steel, allowing withstand high pressures generated during shooting and cycling. No matter how precise is the manufacturing processes and finishing of these parts, they invariably acquire microscopic imperfections. These imperfections mark cartridges cases and projectiles (elements of ammunition) fired from the gun and through a comparative analysis of these marks is possible to establish an unambiguous relationship between an element of ammunition and the gun that shot it. This comparison can be made with an optical microscope or by means of automated comparison systems.

State of the art of automated comparison systems have many advances in image capture quality and the automated comparison process, but effectiveness studies of these systems has shown that various factors, such as increase in the database or ammunition from different manufacturers, can make them very inaccurate equipments.

For this study was implemented a reference ballistic image database (RBID), composed of images of cases and projectiles collected from firearms in calibers point thirty-eight Special (.38SPL) and nine millimeters Luger (9mm Luger) on the Ballistic Identification System EVOFINDER $^{\circledR}$, and controlled the following parameters that could affect the effectiveness of the system: type of projectile, type of case, and user training to operate the system.

The effectiveness of the system with lead round nose projectiles (LRN) in caliber .38SPL was $0.31( \pm 0.06)$, very below to the effectiveness of system with jacketed projectiles, $0.67( \pm 0.14)$. The Brinell hardness and rugosity analysis of these projectiles, revealed a relationship between the hardness of .38SPL projectiles and the effectiveness of the system, and provided one reasonable explanation for this observed difference.

The results showed no statistically meaningfully differences in effectiveness system regard the type of projectile caliber 9mm Luger, or the type of case in calibers .38SPL and 9mm Luger.

Regarding the effectiveness obtained by type of user, with jacketed projectiles .38SPL (excluding LRN) the system had an effectiveness of $0.67( \pm 0.14)$ with images registered and manipulated by experts, and $0.53( \pm 0.14)$ with images of students, a difference that using analysis of variance was found statistically relevant. For all others controlled parameters were not observed meaningfully difference in performance between types of users.

The results can be used to establish the optimal parameters to implementing a firearms database in the studied calibers.
\end{abstract}

Keywords: Automated ballistics comparison; Projectiles Brinell hardness; Projectiles roughness; Firearms. 


\section{LISTA DE FIGURAS}

Figura 1 - Taxas de mortalidade (em 100 mil habitantes) por armas de fogo - 22 População Total e Jovem - Brasil - 1980/2010

Figura 2 - Fotografias do interior de dois canos de arma de fogo, mostrando à esquerda cano com raiamento com bordas retangulares e à direita raiamento do tipo poligonal.

Figura 3 - Ilustração de um cartucho de munição com sistema de fogo central, 31 demonstrando os diversos elementos de munição que o constituem.

Figura 4 - Classificação das armas de fogo quanto ao modo e funcionamento.

Figura 5 - Fotografia identificando partes de um revólver.

Figura 6 - Fotografias de um revólver e um estojo de munição (Em detalhes placa de obturação, janela por onde o percussor atua para comprimir a cápsula de espoletamento e aspecto do culote do estojo após percussão e deflagração da munição).

Figura 7 - Fotografia identificando principais partes de uma pistola 36 desmontada.

Figura 8 - Fotografia identificando a face da culatra e janela do pino percussor em uma pistola.

Figura 9 - Microfotografia da mistura iniciadora da cápsula de espoletamento de um cartucho de munição CBC 9mm Gold.

Figura 10 - Microfotografia de grãos de pólvora de uma munição CBC 9mm Gold.

Figura 11 - Fotografia de três projéteis de munição calibre .38SPL, da esquerda para direita, de liga de chumbo, semiencamisado e encamisado.

Figura 12 - Desenho esquemático de medidas em polegadas (em parêntesis em milímetros) para o calibre .38 SPL.

Figura 13 - Desenho esquemático de medidas em polegadas (em parêntesis em milímetros) para o calibre 9x19mm.

Figura 14 - Pressão interna e velocidade do projétil no cano em função da distância percorrida pelo projétil no cano.

Figura 15 - Analogia de preenchimento de caixas com a individualização de estrias combinantes.

Figura 16 - Microscópio comparador marca Leica modelo FSM e ilustração do seu funcionamento óptico.

Figura 17 - Meios de coleta de projéteis padrões.

Figura 18 - Figura representando a melhor posição na lista de resultados para comparações tanto de pino percussor (círculos) quanto de marca de culatra (losango), fornecido por um RBID de tamanho variando entre 50 e 600 armas.

Figura 19 - Gráfico representando a porcentagem cumulativa de acertos na lista de resultados de comparações tanto de pino percussor quanto de marca de 
culatra (até a posição 30) conforme fornecido pelo Evofinder ${ }^{\circledR}$ e pelo IBIS $^{\circledR}$ Heritage $^{\mathrm{TM}}$.

Figura 20 - Padrões de projéteis 9mm Luger; probabilidade de que um acerto seja encontrado além dos $n$ candidatos da lista de resultados.

Figura 21 - Probabilidade cumulativa de acerto até a posição $i$ da lista de resultados.

Figura 22 - Rede completa BIS EVOFINDER ${ }^{\circledR}$.

Figura 23 - Estação de Aquisição de Dados (DAS) Evofinder ${ }^{\circledR}$ composta por computador pessoal, escâner e acessórios de fixação de elementos de munição.

Figura 24 - Princípio de medida de dureza Brinell. F é a força de carregamento, d é o diâmetro da impressão, e $\mathrm{D}$ é o diâmetro do penetrador.

Figura 25 - Exemplo de designação da dureza Brinell.

Figura 26 - Perfil de superfície obtido pela interseção da superfície real do corpo com um plano escolhido.

Figura 27 - Obtenção da textura primária (rugosidade) por meio de filtros que eliminam o desvio de forma e a textura secundária do perfil efetivo.

Figura 28 - Ordenadas $(\mathrm{Z}(\mathrm{x}))$ dos picos $(\mathrm{Zp})$ e vales $(\mathrm{Zv})$ bem como a altura máxima do perfil $(\mathrm{Rz})$ ao longo do comprimento de amostragem $\left(\lambda_{\mathrm{c}}\right)$.

Figura 29 - Esboço de funcionamento de um microscópio confocal.

Figura 30 - Fotografia do conjunto de armas utilizadas nos exames.

Figura 31 - Parâmetros de operação do Scanner Control Center para cada tipo 80 de calibre estudado.

Figura 32 - Ilustração de processo de captura e armazenamento de imagens dos elementos de munição.

Figura 33 - Escaneamento de projétil quadro a quadro com imagem final combinada, já assinalados os traços secundários de raias e traços de cavados.

Figura 34 - Banco de dados de referência utilizado nas comparações automatizadas.

Figura 35 - Confronto balístico positivo de duas imagens de projéteis.

Figura 36 - Resultado de auto identificação de projétil, mostrando lista de semelhança por traço secundário de raia.

Figura 37 - P x n para o teste preliminar de projéteis padrões no calibre .38SPL.

Figura 38 - Parâmetros utilizados na função Solver do Microsoft Office Excel para ajustar a curva da hiperbólica, minimizando a soma dos quadrados das diferenças (\$E\$) em função dos parâmetros $a$ e $b$ (\$E $\$ 10: \$ E \$ 11)$, conforme Equações 2 e 3 (cálculos da Tabela 12).

Figura 39 - P x n para o teste preliminar de estojos padrões no calibre .38SPL.

Figura 40 - P x n em três diferentes configurações do sistema. Mostra-se os 92 valores para os critérios de efetividade por Rahm $\left(\Gamma_{0}\right)$ e os novos critérios de efetividade proposto por este estudo $\left(\Gamma_{1}\right)$. 
Figura 41 - Utilização do durômetro ZHU250 em projétil .38SPL PP1.

Figura 42 - Microscópio confocal a Laser OLIMPUS LEXT OLS 4100.

Figura 43 - Parâmetros de operação do microscópio confocal para medições do

perfil de rugosidade dos projéteis amostrados, e exemplo de resultados com projétil .38SPL PP1.

Figura 44 - P x n para projétil .38SPL configuração I1A.

100

Figura 45 - P x n para estojo .38SPL configuração IV3P.

101

Figura 46 - P x n para projétil 9mm Luger configuração IV2A.

102

Figura 47 - P x n para estojo 9mm Luger configuração I4P.

102

Figura 48 - Médias e desvios padrão dos critérios de efetividade $(\Gamma 1)$ por tipo 104 de projétil padrão .38SPL e por usuário.

Figura 49 - Histograma de frequências das efetividades para confrontos automatizados com projéteis .38SPL mostrando razoável normalidade dos dados.

Figura 50 - Valores dos critérios de efetividade do sistema $\left(\Gamma_{1}\right)$ com padrões PP6 em relação aos tipos de projéteis questionados .38SPL (coluna PP6 linhas perito da Tabela 23).

Figura 51 - Valores dos critérios de efetividade do sistema $\left(\Gamma_{1}\right)$ com padrões PP3 em relação aos tipos de projéteis questionados.38SPL (coluna PP3, linhas perito, da Tabela 23).

Figura 52 - Valores dos critérios de efetividade do sistema $\left(\Gamma_{1}\right)$ com projéteis questionados PQI em relação aos tipos de projéteis padrões .38SPL (PP1 a PP7 - linha I Perito da Tabela 23).

Figura 53 - Comparação das efetividades do sistema $\left(\Gamma_{1}\right)$ no teste preliminar e no teste com todo o banco de dados com projéteis padrões no calibre .38SPL.

Figura 54 - Médias e desvios padrão dos critérios de efetividade $\left(\Gamma_{1}\right)$ por tipo de estojo padrão .38SPL (EP1 a EP7) e por usuário.

Figura 55 - Comparação das efetividades do sistema $\left(\Gamma_{1}\right)$ no teste preliminar e no teste com todo o banco de dados com estojos padrões no calibre .38SPL.

Figura 56 - Médias e desvios padrão dos critérios de efetividade $\left(\Gamma_{1}\right)$ por tipo de projétil padrão 9mm Luger (PP1 a PP4) e por usuário.

Figura 57 - Comparação da efetividade do sistema $\left(\Gamma_{1}\right)$ entre amostras de perito e amostra de aluno para projéteis padrões no calibre 9mm Luger.

Figura 58 - Critérios de efetividade $\left(\Gamma_{1}\right)$ por armas no calibre 9mm Luger (18 a 33) e por usuário.

Figura 59 - Médias e desvios padrão dos critérios de efetividade por tipo de estojo padrão 9mm Luger (EP1 a EP4) e por usuário.

Figura 60 - Médias e desvios padrão das durezas Brinell para projéteis .38SPL. 116

Figura 61 - Comparação das médias dos critérios de efetividade do sistema $(\Gamma 1) \quad 117$ com projéteis .38SPL (PP1 a PP6) com as respectivas durezas Brinell. 
Figura 62 - Comparação de imagens de dois projéteis padrões disparados por 118 uma mesma arma, a de baixo do tipo PP1 e a de cima do tipo PP6.

Figura 63 - Médias e desvios padrão das durezas Brinell para projéteis 9mm 119 Luger.

Figura 64 - Comparação dos critérios de efetividade do sistema $(\Gamma 1)$ com 119 projéteis 9mm Luger (PP1 a PP4) com as respectivas durezas Brinell.

Figura 65 - Imagens de cavados dos projéteis .38SPL analisados no 120 microscópio confocal (escala em vermelho e branco $=400 \mu \mathrm{m}$ ).

Figura 66 - Imagens de cavados dos projéteis 9mm Luger analisados no microscópio confocal (escala em vermelho e branco $=400 \mu \mathrm{m}$ ).

Figura 67 - Comparação dos critérios de efetividade do sistema ( $\Gamma 1)$ com projéteis .38SPL (PP1 a PP6) com os respectivos parâmetros de rugosidade Ra.

Figura 68 - Comparação dos critérios de efetividade do sistema ( $\Gamma 1)$ com 122 projéteis .38SPL (PP1 a PP6) com os respectivos parâmetros de rugosidade Rz.

Figura 69 - Comparação dos critérios de efetividade do sistema $(\Gamma 1)$ com projéteis 9mm Luger (PP1 a PP4) com os respectivos parâmetros de rugosidade Ra.

Figura 70 - Comparação dos critérios de efetividade do sistema ( $\Gamma 1)$ com projéteis 9mm Luger (PP1 a PP4) com os respectivos parâmetros de rugosidade Rz. 


\section{LISTA DE TABELAS}

Tabela 1 - Banco de dados e quantidade de correlações efetuadas por calibre e $\quad 59$ tipo de elemento de munição no estudo de Rahm (2012).

$\begin{array}{ll}\text { Tabela } 2 \text { - Efetividades de correlação de Rahm. } & 61\end{array}$

Tabela 3 - Munições utilizadas na coleta de padrões das armas de calibre 75 38SPL.

Tabela 4 - Munições utilizadas na coleta de padrões das armas de calibre 9mm 77 Luger.

Tabela 5 - Projéteis questionados coletados por arma de calibre .38SPL. $\quad 78$

Tabela 6 - Estojos questionados coletados por arma de calibre .38SPL. $\quad 78$

Tabela 7 - Projéteis questionados coletados por arma de calibre 9mm Luger. $\quad 79$

Tabela 8 - Estojos questionados coletados por arma de calibre 9mm Luger. $\quad 79$

Tabela 9 - Confrontos automatizados realizados por arma. 86

Tabela 10 - Exemplos de utilização da nomenclatura adotada para 86 configurações do sistema.

Tabela 11 - Resultado dos confrontos automatizados no teste preliminar 88 envolvendo projéteis padrões no calibre .38SPL.

Tabela 12 - Ajuste da curva hiperbólica aos resultados de probabilidade acumulativa em função da posição da lista de resultados pelo método dos mínimos quadrados para o teste preliminar de projéteis padrões de calibre .38SPL.

Tabela 13 - Cálculo do critério de efetividade do sistema $\left(\Gamma_{0}\right)$ no teste 90 preliminar de projéteis padrões de calibre .38SPL.

Tabela 14 - Resultado dos confrontos automatizados no teste preliminar 90 envolvendo estojos padrões no calibre .38SPL.

Tabela 15 - Cálculo do critério de efetividade do sistema $\left(\Gamma_{0}\right)$ no teste 91 preliminar de estojos padrões de calibre .38SPL.

Tabela 16 - Efetividades do sistema $\left(\Gamma_{1}\right)$ para confrontos automatizados com 94 projéteis .38SPL.

Tabela 17 - ANOVA, fator duplo com repetição, dos dados da Tabela 16.

Tabela 18 - Parâmetros de operação do durômetro nos testes de dureza Brinell. 96

Tabela 19 - Resultado dos confrontos automatizados no sistema com projéteis 99 .38SPL configuração I1 A.

Tabela 20 - Resultado dos confrontos automatizados no sistema com estojos .38SPL configuração IV3P.

Tabela 21 - Resultado dos confrontos automatizados no sistema com projéteis 101 9mm Luger configuração IV2A.

Tabela 22 - Resultado dos confrontos automatizados no sistema com estojos 102 9mm Luger configuração I4P. 
Tabela 23 - Efetividades do sistema $\left(\Gamma_{1}\right)$ para confrontos automatizados com 103 projéteis .38SPL.

Tabela 24 - ANOVA, fator duplo com repetição, dos dados da Tabela 23.

Tabela 25 - ANOVA fator duplo com repetição (dados das colunas PP2 a PP6 106 da Tabela 23).

Tabela 26 - Diferenças entre o teste preliminar e o teste de todo o banco de 108 dados (BD) com projéteis .38SPL.

Tabela 27 - Efetividades do sistema $\left(\Gamma_{1}\right)$ para confrontos automatizados com estojos .38SPL.

Tabela 28 - Diferenças entre o teste preliminar e o teste de todo o banco de dados (BD) com estojos .38SPL.

Tabela 29 - Efetividades do sistema $\left(\Gamma_{1}\right)$ para confrontos automatizados com projéteis 9mm Luger.

Tabela 30 - Efetividades do sistema $\left(\Gamma_{1}\right)$ por arma no calibre $9 \mathrm{~mm}$ Luger.

Tabela 31 - Efetividades do sistema $\left(\Gamma_{1}\right)$ para confrontos automatizados com estojos 9mm Luger.

Tabela 32 - Médias e desvios padrão dos resultados de dureza Brinell com projéteis disparados e não disparados no calibre .38SPL.

Tabela 33 - Médias e desvios padrão dos resultados de dureza Brinell com projéteis disparados e não disparados no calibre $9 \mathrm{~mm}$ Luger.

109

Tabela 34 - Médias e desvios padrão dos resultados de rugosidade com projéteis disparados no calibre .38SPL.

Tabela 35 - Médias e desvios padrão dos resultados de rugosidade com 122 projéteis disparados no calibre 9mm Luger.

Tabela 36 - Relação de armas de calibre .38 SPL.

Tabela 37 - Relação de armas de calibre 9mm Luger.

Tabela 38 - Resultados dos testes de dureza Brinell em projéteis .38SPL.

Tabela 39 - Resultados dos testes de dureza Brinell em projéteis 9mm Luger.

Tabela 40 - Resultados dos testes de rugosidade em projéteis disparados .38SPL.

Tabela 41 - Resultados dos testes de rugosidade em projéteis disparados 9mm 


\section{LISTA DE SÍMBOLOS}

\section{Símbolos Latinos}

a Parâmetro a ser determinado por ajuste da curva da função

hiperbólica da equação (2.7) aos resultados da probabilidade cumulativa

$b \quad$ Parâmetro a ser determinado por ajuste da curva da função hiperbólica da equação (2.7) aos resultados da probabilidade cumulativa Parâmetro da equação (2.7) a ser determinado pelos parâmetros $a$ e $b$ de acordo com a equação (2.10)

C Elemento químico carbono

d d é o diâmetro da impressão na amostra sob teste de dureza Brinell

D D é o diâmetro do penetrador no teste de dureza Brinell

F $\quad$ Força de carregamento no teste de dureza Brinell

$g \quad$ grama

gr grain

$H \quad$ Elemento químico hidrogênio

$i \quad$ Tamanho do banco de dados para cada calibre de estojo ou calibre e tipo raiamento de projétil

$n \quad$ Melhore posição, de um padrão da mesma arma que o elemento questionado, na lista de resultados dos confrontos automatizados

$N \quad$ Elemento químico nitrogênio

$O \quad$ Elemento químico oxigênio

$\mathrm{Pb} \quad$ Elemento químico chumbo

$\mathrm{P}(n) \quad$ Probabilidade cumulativa de um acerto até a posição $n$ da lista de resultados de um confronto automatizado

$Q \quad$ Energia fornecida ao sistema na deflagração da pólvora

W Trabalho sobre o projétil

I O comprimento de avaliação total no teste de rugosidade

Ra Desvio aritmético médio do perfil avaliado no teste de rugosidade

$\mathrm{Rz} \quad$ Altura máxima do perfil no teste de rugosidade 
$v \quad$ Quantidade de variáveis independentes

$\mathrm{Zp} \quad$ Altura de pico do perfil no teste de rugosidade

$\mathrm{Zv} \quad$ Profundidade de vale no teste de rugosidade

$\mathrm{Z}(\mathrm{x}) \quad$ Valores absolutos das ordenadas no comprimento da amostragem no teste de rugosidade

\section{Símbolos Gregos}

$\Delta U \quad$ Variação de energia interna

$\Gamma_{0} \quad$ Efetividades de correlação de Rahm

$\Gamma_{1} \quad$ Novo critério de efetividade proposto por este estudo

$\lambda_{c} \quad$ O comprimento de amostragem (cut-off) no teste de rugosidade

$\mu \mathrm{m} \quad$ Micrômetro $=10^{-6}$ metros 
Siglas

ABNT

ATF

BF

BIS

BKA

BUL

CBC

${ }^{\circ} \mathrm{C}$

CC

CHOG

CMS

COBIS

DAS

DP

ETOG

E.U.A

EXPO

EWS

FBI

FCC

FP

gl

HBW

IBIS $^{\circledR}$

Kgf

LEA

MD-IBIS

$\mathrm{mm}$

Mpa

MQ

NIBIN
Associação Brasileira de Normas Técnicas

Bureau of Alcohool, Tobacco, Firearms and Explosives

Breech Face (face da culatra)

Ballistic Identification System

Polícia Federal da Alemanha

Bullet (projétil)

Companhia Brasileira de Cartuchos.

Graus Celsius

Cartridge case (estojo)

Ogival de chumbo

Consecutively Matching Striae

Combined Ballistic Identification System

Estação de Aquisição de Dados no BIS Evofinder ${ }^{\circledR}$

Desvio padrão

Encamisado total ogival

Estados Unidos da América

Expansivo ponta oca

Estação de trabalho dos peritos no BIS Evofinder ${ }^{\circledR}$

Federal Bureau of Investigation

Função de Correlação Cruzada

Firing Pin (percutor)

Graus de liberdade

Valor da dureza Brinell

Integrated Bullet Identification System

Quilograma-força

Land engraved area

Maryland-Integrated Ballistics Identification System

Milímetros

Mega Pascal $=10^{6}$ Pascal

Média dos quadrados

National Integrated Ballistic Information Network 
RBID

SAS

SQ

UNB

$.38 \mathrm{SPL}$

9mm Luger
Reference Ballistic Image Database (Banco de dados de imagens balísticas de referência)

Sistema de Análise de Amostras no BIS Evofinder ${ }^{\circledR}$

Soma de quadrados

Universidade de Brasília

Ponto trinta e oito Special

Nove milímetros Luger 


\section{SUMÁRIO}

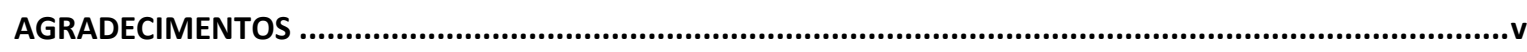

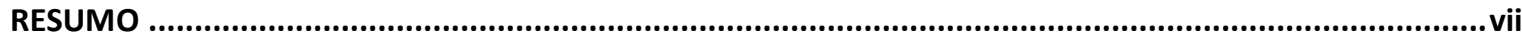

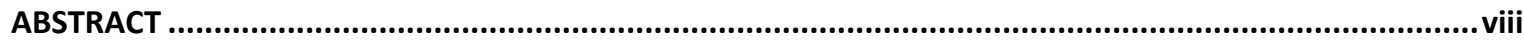

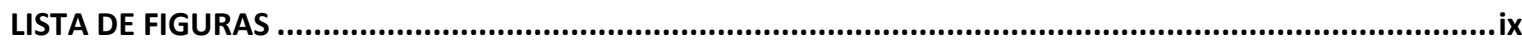

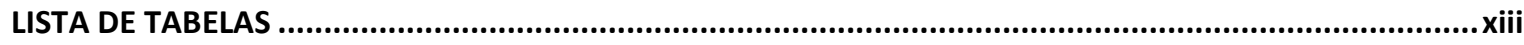

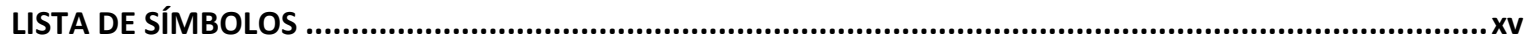

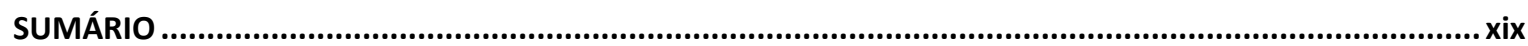

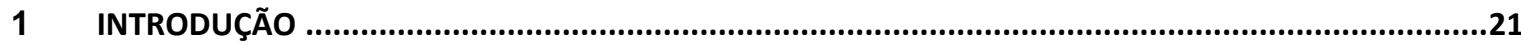

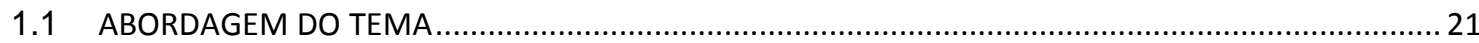

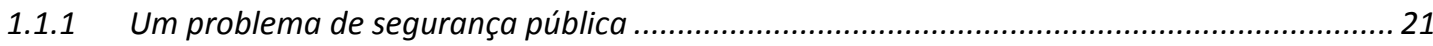

1.1.2 Desafio para Ciências Forense .............................................................................. 23

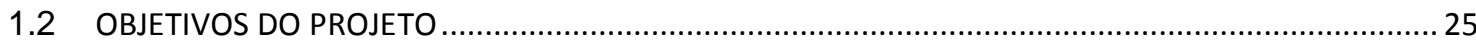

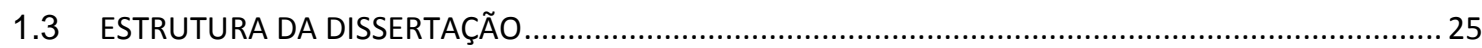

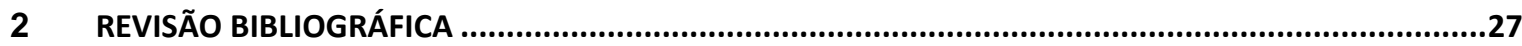

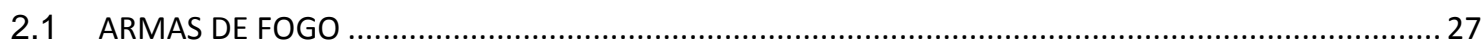

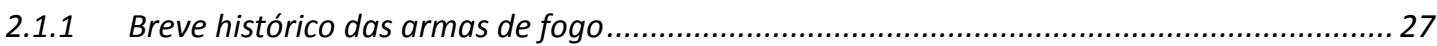

2.1.2 Raiamento dos canos................................................................................................ 28

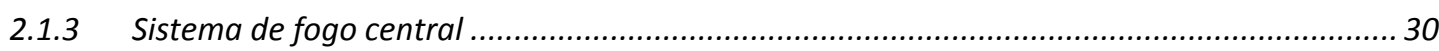

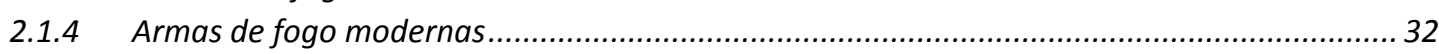

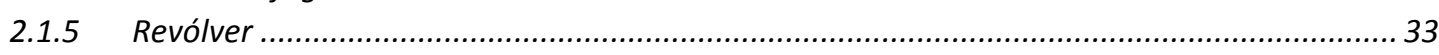

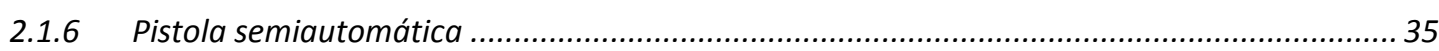

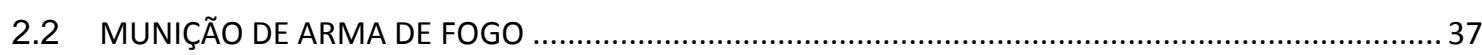

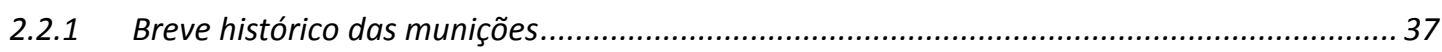

2.2.2 Componentes dos cartuchos de munição ................................................................... 38

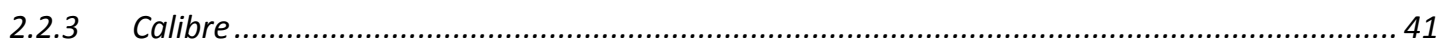

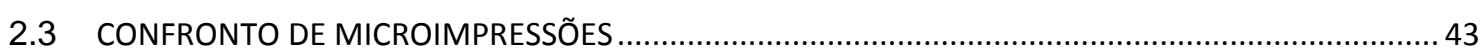

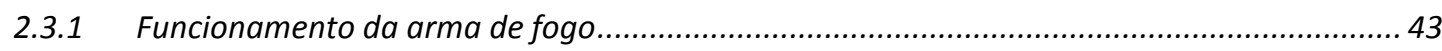

2.3.2 Comparação balística ................................................................................................... 45

2.3.3 Reprodutibilidade e individualização de marcas................................................................ 46

2.3.4 Uso de microscópio comparador ......................................................................................5 50

2.3.5 Coleta de padrões e realização do exame comparativo ..................................................... 51

2.3.6 Limitações da comparação balística ............................................................................. 52

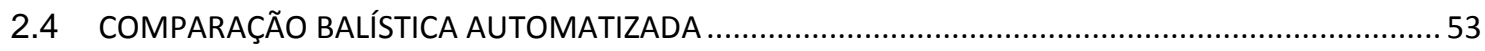

2.4.1 Breve histórico da comparação automatizada .................................................................... 53

2.4.2 Técnicas de captura de imagens e correlação automatizada ............................................. 54

2.4.3 Estudos de efetividade em comparações automatizadas................................................... 55

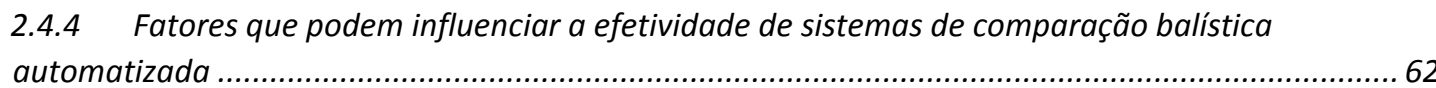

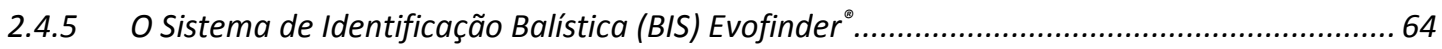

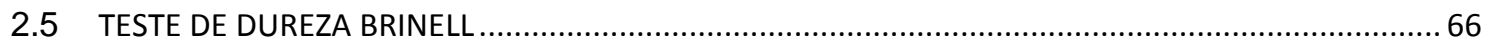

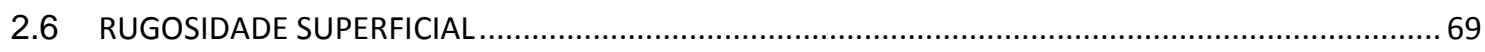

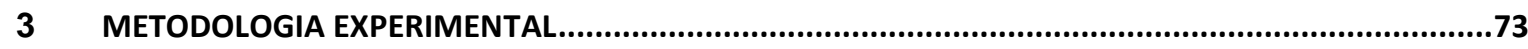

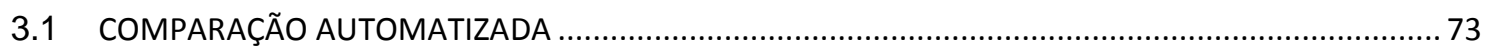

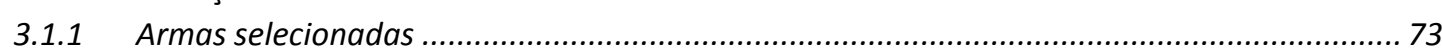

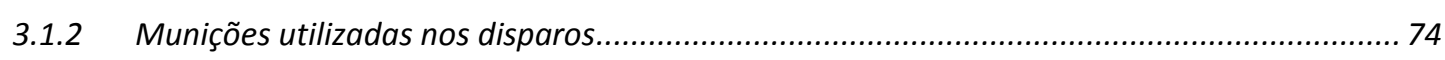

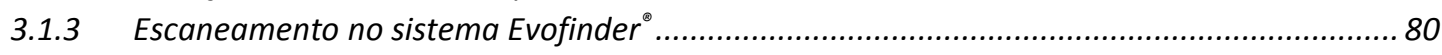

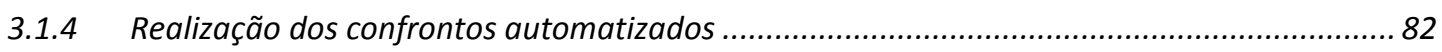


3.1.5 Cálculo da efetividade do sistema ............................................................................ 88

3.1.6 Uso da tabela de Análise de Variância........................................................................ 93

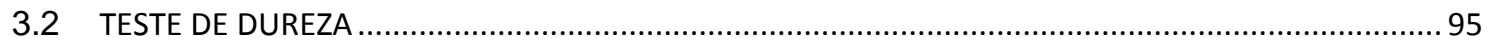

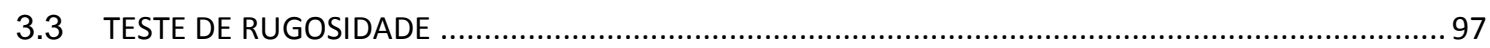

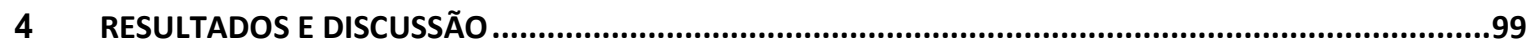

4.1 RESULTADOS E ANÁLISES DOS TESTES DE EFETIVIDADE ENVOLVENDO TODO O BANCO DE

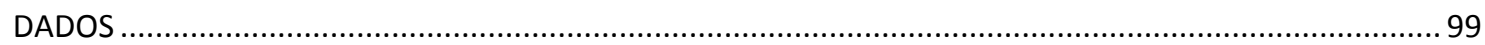

4.1.1 Exemplos de cálculo dos critérios de efetividade ..............................................................99

4.1.2 Influência do tipo de projétil .38SPL na efetividade do sistema.......................................... 103

4.1.3 Influência do tipo de estojo .38SPL na efetividade do sistema ........................................... 109

4.1.4 Influência do tipo de projétil 9mm Luger na efetividade do sistema................................... 111

4.1.5 Influência do tipo de raiamento de arma 9mm Luger na efetividade do sistema ................ 113

4.1.6 Influência do tipo de estojo 9mm Luger na efetividade do sistema.................................... 114

4.2 RESULTADOS E ANÁLISES DOS TESTES DE DUREZA ................................................................. 115

4.2.1 Testes de dureza em projéteis .38SPL ............................................................................. 115

4.2.2 Testes de dureza em projéteis $9 \mathrm{~mm}$ Luger .................................................................... 118

4.3 RESULTADOS E ANÁLISES DOS TESTES DE RUGOSIDADE..................................................... 120

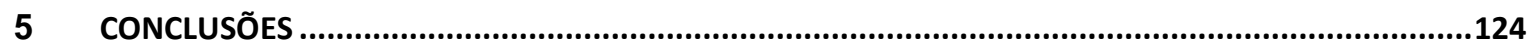

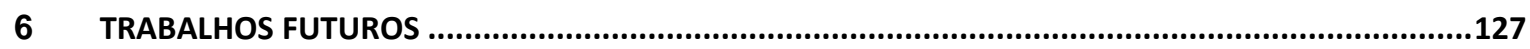

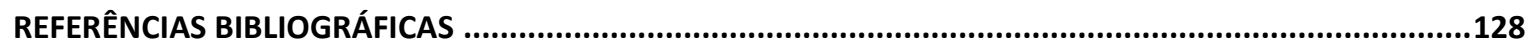

ANEXO I: Fatores de carga para diferentes condições de ensaio nos testes de dureza brinell ................133

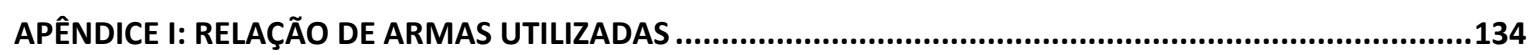

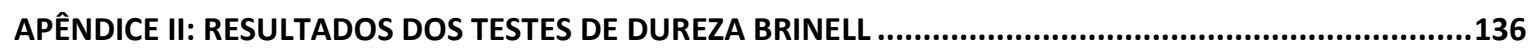

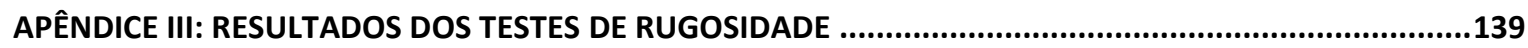




\section{INTRODUÇÃO}

Este capítulo apresenta de forma sucinta a abordagem do tema, contextualizando $e$ definindo o problema, os objetivos do projeto e a estrutura em que foi elaborado esse trabalho.

\subsection{ABORDAGEM DO TEMA}

O problema em estudo tem dois motivadores. Trata-se de um problema de segurança pública relacionado à baixa taxa de solução de crimes envolvendo armas de fogo e também de um desafio técnico científico de automatização de comparações balísticas que grandemente auxiliariam a solucionar estes crimes.

\subsubsection{Um problema de segurança pública}

O Brasil é um país que apresenta grandes índices de homicídios quando comparado com a maioria de todos os países do mundo (MORAES, 2012). Estudos recentes apontaram que dentre as 50 (cinquenta) cidades mais violentas do mundo, 16 (dezesseis) estão no Brasil (CITY MAYORS STAFF, 2014). A grande maioria destes homicídios foram perpetrados com uso de arma de fogo. Dados oficiais apontam que mais de 70\% (setenta por cento) das mortes violentas no país são praticadas por meio de uso de arma de fogo (WAISELFISZ, 2008).

Este é um grave problema enfrentado por nossa sociedade, acarreta custos das mais variadas formas, e impacta de forma negativa a qualidade de vida de todos os brasileiros.

O problema é ainda mais crítico quando se percebe que ele se agrava ano após ano. Dados do Mapa da Violência de 2013 (WAISELFISZ, 2013) mostram a evolução da taxa de mortalidade por 100mil habitantes nas últimas três décadas (ver Figura 1).

Após ampla análise dos dados oficiais, o relatório de Waiselfisz (2013) indicou pelo menos três fatores que devem estar diretamente relacionados a esta realidade alarmante: facilidade de acesso a armas de fogo, cultura da violência e impunidade.

A questão da impunidade é um fator grave. O documento cita estudos que apontam que a taxa de solução de homicídios no país esteja entre 5\% e $8 \%$ (cinco e oito por cento). Taxa que pode chegar a $90 \%$ (noventa por cento) em países desenvolvidos. Quando se pensa em toda tecnologia disponível, em todos os sistemas de monitoramento, em todo aparelhamento do 
estado para solucionar e tornar efetiva a justiça os criminosos, esta taxa de solução dos homicídios no país se torna um problema que precisa ser enfrentado com a maior atenção.

Figura 1 - Taxas de mortalidade (em 100 mil habitantes) por armas de fogo - População Total e Jovem - Brasil - 1980/2010.

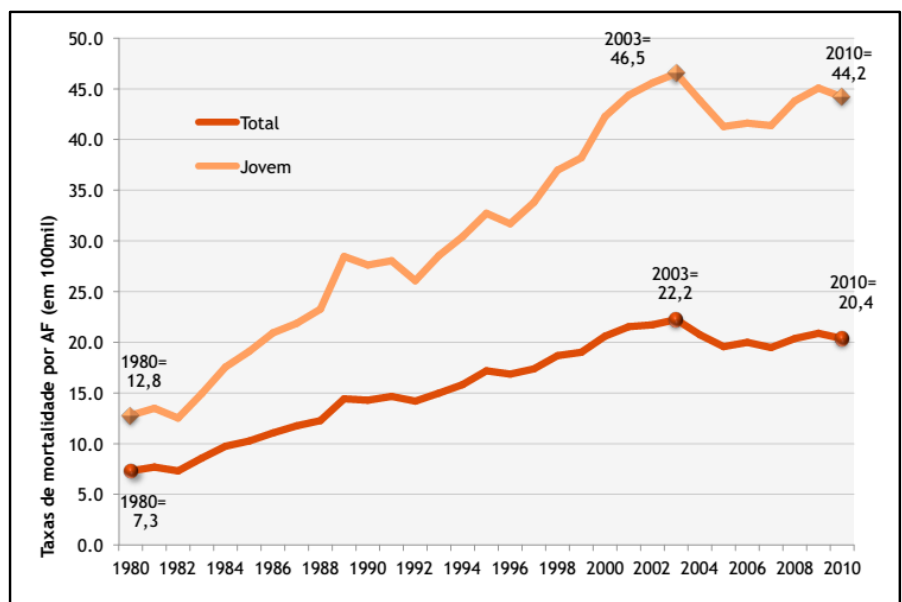

Fonte: SIV/SVS/MS, apud WAISELFISZ, 2013, p. 14.

Para crimes cometidos com uso de arma de fogo, uma das tarefas forenses mais significativas para solução do crime, seria responder se elementos de munição encontrados no local do crime foram provenientes de uma arma de fogo suspeita.

Esta correlação entre arma e elementos de munição é possível, na maioria dos casos, devido a elevada pressão interna gerada durante o disparo. Isso faz com que o estojo se choque violentamente contra partes da arma e receba uma impressão das imperfeições que estas peças apresentem. A pressão também impulsiona o projétil através do cano, o que gera, devido ao seu deslocamento, ao fato do projétil ser mais dúctil que o cano, e à existência de raias e imperfeições no cano, cavados e microestriamentos nas laterais do projétil. A comparação destas marcas impressas nos elementos de munição é realizada no exame denominado comparação balística.

Este tipo de exame é realizado em microscópio óptico comparador, onde são confrontadas marcas de dois elementos de munição para verificar se foram disparados por uma mesma arma de fogo. Embora seja um exame utilizado com sucesso em incontáveis casos criminais, apresenta algumas limitações importantes, como muito tempo gasto nas comparações de dois a dois elementos no microscópio, e a necessidade de haver a arma suspeita para comparação, por não existir um RBID.

Motivados em parte por estas e outras limitações do exame de comparação balística, laboratórios forenses de todo o mundo têm tentado implementar soluções tecnológicas que 
permitam a realização de confrontos automatizados entre diversos elementos de munição e a criação de bancos de dados de padrões de armas de fogo.

As soluções até agora implementadas tem permitido armazenar e tratar casos abertos de uma maneira apropriada, relacionar crimes cometidos com uma mesma arma, e fornecer uma lista de amostra mais semelhantes à questionada, diminuindo a quantidade de comparações quando há muitos elementos a cotejar.

Porém estas soluções, bastante promissoras em teoria, tem encontrado na prática diversos outros desafios tecnológicos, e para se implementar um sistema, bem como um banco de dados confiável, e que verdadeiramente ajude a solucionar crimes, muitas questões tem sido objeto de estudo pela comunidade científica.

Os estudos objeto desta dissertação, foram grandemente motivados por alguns dos desafios tecnológicos que este tema ainda enfrenta e que cada vez mais têm impulsionado pesquisas na área.

\subsubsection{Desafio para Ciências Forense}

Praticamente todos os laboratórios de balística de países desenvolvidos já têm implantado alguma solução comercial para automatizar as comparações balísticas e criar um banco de dados de padrões de armas de fogo ${ }^{1}$.

No entanto, independente da solução adotada, diversos testes nestes equipamentos têm demonstrando que ainda não há uma solução definitiva e completa para o problema (GERULES; BHATIA; JACKSON, 2013).

O laboratório de balística do Instituto Nacional de Criminalística da Polícia Federal em Brasília, por exemplo, examinou diversos equipamentos comerciais disponíveis e decidiu pela compra do Sistema de Identificação Balística EVOFINDER ${ }^{\circledR}$, desenvolvido pela empresa Russa ScannBI Technology.

O aparelho tem sido utilizado com sucesso em diversos casos criminais que foram encaminhados ao laboratório desde 2011, porém assim como os estudos publicados têm apontado (DE KINDER; TULLENERS; THIEBAUT, 2004), com o aumento de amostras no banco de dados aumenta-se a posição em que o a amostra correta é relacionada na lista de resultados, em outras palavras, a efetividade do sistema piora com a aumento do tamanho do

\footnotetext{
${ }^{1}$ Ver por exemplo os países em os sistemas Evofinder ${ }^{\circledR}$ e IBIS ${ }^{\circledR}$ divulgam ter implementado suas soluções para comparação automatizada (EVOFINDER, 2015; IBIS, 2015).
} 
banco de dados, e para encontrar a amostra correta um número maior de candidatos na lista de resultados tem que ser verificada (RAHM, 2012).

Após armazenar imagens dos elementos de munição no equipamento, utiliza-se algoritmos de comparação para automatizar a comparação de uma amostra contra as demais do banco de dados. Os estudos sobre efetividade destes sistemas têm tentado prever as efetividades destes algoritmos de comparação, determinando o grau de probabilidade com que o software lista nas primeiras posições de sua lista de resultados amostras que corretamente são provenientes de uma mesma arma.

Outra questão crítica quando se idealiza a criação de um banco de dados é qual a capacidade de armazenamento de amostras de forma que o algoritmo empregado ainda seja eficiente em apontar semelhanças significativas e descartar as inevitáveis semelhanças aleatórias.

Equipamentos com melhor efetividade tem obviamente ganhado espaço neste mercado e alguns estudos tem apontado o EVOFINDER ${ }^{\circledR}$ como um dos sistemas mais precisos (CEUSTER; DUJARDIN, 2015). Ademais, há outros aspectos técnicos que precisam ser melhor esclarecidos na tentativa de criação de um banco de dados de padrões de armas de fogo.

Uma das premissas para ligar arma a elemento de munição é realizar a comparação em microscópio óptico de amostras que possuam as mesmas características. Ou seja, para que a comparação seja bem-sucedida espera-se que durante os disparos sejam reproduzidas as mesmas condições físicas que levaram à produção das marcas microscópicas. Para que isso seja, a priori, garantido, devem ser comparados elementos de munição mais semelhantes possíveis. E são muitas as fontes de variações entre munições de um mesmo tipo de arma, dentre as quais: fabricante, tipo e quantidade de pólvora no cartucho, composição do estojo, composição e formato do projétil.

O desafio surge quando pretende-se cadastrar uma arma para ligar a um crime, passado ou futuro, que não se sabe absolutamente com qual tipo de munição será ou fora utilizada. Nos estudos de De Kinder, Tulleners e Thiebaut (2004), e de Ceuster e Dujardin (2015), que se limitaram a bancos de dados de estojos, ficou evidente que em confrontos automatizados com munições de diferentes fabricantes as efetividades dos sistemas diminuíram consideravelmente. Porém, o que acontece quando se cadastra e realiza confrontos automatizados com munições de um mesmo fabricante que apresentam quantidade de pólvora variável ou projéteis de composições diferentes? Existe algum tipo de estojo ou projétil recomendado para o cadastro que melhor se relaciona com os demais tipos daquele calibre? 
Por último é importante ressaltar que processos automatizados têm sido implementados na expectativa de minimizar interferência por parte do operador do sistema, mas há ainda partes do processo de cadastro de imagens no sistema que demandam escolhas pelo usuário e podem impactar na efetividade de correlação, a depender do grau de experiência deste usuário, fator indesejado e que estudos precisam revelar se pode ser minimizado. Torna-se, portanto, relevante estudar no sistema em tese, qual o grau de qualificação em confrontos balísticos dos usuários a operá-lo, decidindo como isso poderá afetar o desempenho de um futuro banco de dados criado sobre esta plataforma.

\subsection{OBJETIVOS DO PROJETO}

Objetivo geral: Avaliar como alguns parâmetros dos elementos de munição podem afetar a efetividade do Sistema de Identificação Balística Evofinder ${ }^{\circledR}$ para armas nos calibres .38SPL e 9mm Luger, de forma a identificar os parâmetros ótimos para criação de um banco de dados de imagens de projéteis e estojos nestes calibres.

\section{Objetivos específicos:}

- Avaliar a influência do tipo de propelente, composição, dureza e rugosidade de elementos de munição na efetividade de confrontos automatizados nos calibres .38SPL e 9mm Luger;

- Verificar a influência do grau de experiência do operador do sistema, na efetividade de confrontos automatizados realizados no Evofinder ${ }^{\circledR}$.

\subsection{ESTRUTURA DA DISSERTAÇÃO}

Este trabalho está dividido em 6 capítulos numerados, referências bibliográficas, um anexo e três apêndices.

O capítulo 1 introduz o tema proposto dando uma visão geral do problema na segurança pública e o desafio à Ciência Forense, que deram motivação a realização desse estudo.

O capítulo 2 aborda os principais conceitos envolvidos no contexto deste trabalho, como uma breve explicação sobre o funcionamento das armas de fogo e munições, o processo de formação das marcas geradas durante o disparo e utilizadas nos confrontos de microimpressões, os fatores que influenciam a reprodutibilidade ou alteração destas marcas, os princípios que permitem a identificação da arma que disparou um elemento de munição, as iniciativas, projetos 
e estado da arte dos confrontos automatizados, os estudos de efetividade destes sistemas automatizados, e uma revisão sobre dureza Brinell e rugosidade superficial.

O capítulo 3 descreve a metodologia e os procedimentos empregados nos experimentos: de confrontos automatizados para determinação das efetividades do sistema; e de caracterização dos elementos de munição utilizados, com testes de dureza e rugosidade.

O capítulo 4 apresenta os resultados comentados obtidos nos experimentos, o capítulo 5 as conclusões e o capítulo 6 as sugestões para trabalhos futuros.

Após esses capítulos numerados, são apresentadas as referências bibliográficas utilizadas neste trabalho, e por fim os anexos e apêndices, que incluem os resultados dos testes de dureza e rugosidade. 


\section{REVISÃO BIBLIOGRÁFICA}

Este capítulo engloba uma revisão sobre o funcionamento das armas de fogo e suas munições, o confronto de microimpressões, as iniciativas, projetos e estado da arte dos confrontos automatizados, os estudos de efetividade destes sistemas automatizados, $e$ uma revisão sobre dureza Brinell e rugosidade superficial.

\subsection{ARMAS DE FOGO}

Neste trabalho foram estudados dois tipos de armas de fogo de repetição, revólveres não automáticos no calibre .38SPL e pistolas semiautomáticas no calibre 9mm Luger. Os termos para entender esta nomenclatura bem como outros detalhes de funcionamento destas armas que são de relevância nesta dissertação serão explicados a seguir.

\subsubsection{Breve histórico das armas de fogo}

O primeiro tipo de arma de fogo a ser portada pelo homem, tratava-se de um canhão manual, composto por um pequeno cano de liga de ferro ou bronze, envolto em alguma armação de metal ou couro. Seu carregamento ocorria a partir da própria boca do cano, onde eram introduzidos pólvora, bucha e o projétil. O disparo era feito enfiando um pavio, ou brasa na extremidade posterior do cano, onde se encontrava uma carga de pólvora inicial, a qual gerava uma faísca ou chama, que se comunicava com a carga principal de pólvora, provocando a queima, expansão dos gases e consequente lançamento do projétil (HEARD, 2008).

Precisar a data de início de uso deste tipo de artefato é uma tarefa muito difícil, mas há registros de seu uso nas civilizações ocidentais nos séculos XIII e XIV, pelo menos na forma em que podem ser consideradas como antecessoras dos canhões e morteiros modernos. Por séculos este tipo de arma foi utilizado e os principais avanços ocorreram na forma de gerar a faísca ou chama inicial (RABELLO, 1995).

$\mathrm{O}$ arcabuz, bem como seu sucessor, o mosquete, foram armas manuais muito famosas e difundidas, mas funcionavam como descrito nos canhões manuais acima, canos lisos e sistema de carregamento pela boca do cano. O diferencial deles está na existência de um sistema de ignição, o fecho de mecha, que de certa forma facilitou a geração da chama iniciadora e o manuseio da arma. 
No mosquete por exemplo, a mecha era mantida em um gancho curvo aparafusado ao lado da armação, e seu basculamento levava a mecha queimando a ter contato com a carga de pólvora inicial. Estas armas se tornaram mais sofisticadas e o gancho assumiu uma forma de serpente. Eventualmente, a cauda da serpentina se alongou e esta peça pode ser vista como uma precursora dos gatilhos das armas modernas.

Os registros de uso desta arma são mais precisos, e aparecem em uma mesma época em que se registraram armas com um cano e várias câmaras que giravam em torno de um eixo (do inglês revolving), cada um com seu próprio sistema de mecha e carga iniciadora (HEARD, 2008).

Sistemas mais autônomos foram sendo concebidos e tornaram o uso do fecho de mecha obsoleto. O fecho de roda e o fecho de miquelete, geravam uma faísca de uma pederneira por meio de atrito, e diminuíram consideravelmente o tempo gasto para se produzir um disparo, permitindo os fatores surpresa e emboscada.

O próximo grande avanço nas armas de fogo foi possível ao se revolucionar o modo de deflagração da pólvora, utilizando-se um composto sintetizado em 1800, muito sensível à impacto, que quando detonado gerava uma chama capaz de iniciar a queima da pólvora, o fulminato de mercúrio (BECK et al., 2007). Diversos sistemas foram testados até se colocar o fulminato de mercúrio em uma cápsula, onde tal qual atualmente, recebe o impacto do percussor da arma e gera a faísca inicial que deflagrará a pólvora. Primeiramente estas cápsulas eram externas à arma e separadas da pólvora, e um forma de ignição muito famosa ocorria por meio de um pino lateral. Depois se tornaram parte do cartucho de munição, e constituíram parte fundamental para o estabelecimento do que se tornariam a forma de disparo da maioria das armas modernas, o sistema de fogo central.

O uso destes cartuchos metálicos com todos os elementos da munição, tornou possível também outro avanço, que tornou as armas dispositivos mais precisos, o raiamento do cano. Para a existência e utilidade deste raiamento se tornou necessário abandonar o sistema de carregamento pela boca do cano, uma vez que o projétil teria que apresentar um diâmetro ligeiramente maior que o diâmetro interno do cano, sendo necessário efetuar o carregamento da arma por meio da extremidade posterior do cano.

\subsubsection{Raiamento dos canos}

As primeiras armas de fogo apresentavam cano "de alma lisa"; ou seja, seu interior tratava-se de uma superfície cilíndrica circular lisa. Isso fazia com que o projétil, que em sua 
grande maioria apresentava formato esférico, após deixar o cano da arma não apresentasse nenhuma estabilidade que o levasse a seguir uma trajetória definida, o que tornava a arma um dispositivo com pontaria imprecisa (HEARD, 2008).

Para levar o projétil a seguir uma trajetória alinhada com o cano, e com isso poder escolher o alvo a ser atingido, foi inventado o raiamento dos canos e adotados projéteis com formato cônico ogival. O raiamento, presente em armas a partir do século XV, trata-se de um conjunto de sulcos, produzidos na superfície interna do cano, e que têm a finalidade de dar ao projétil uma estabilidade giroscópica.

Um projétil para ser utilizado neste tipo de cano deve apresentar um diâmetro ligeiramente maior do que o diâmetro interior do cano. Ao passar pelo cano o projétil é forçado pelos sulcos existentes a seguir uma trajetória helicoidal que fornece a ele uma rotação.

Ao sair do cano o projétil fica sujeito a ação da força da gravidade e da resistência do ar, e este momento rotacional que adquiriu se torna fundamental para que ele siga uma trajetória alinhada com o cano e possa atingir o alvo escolhido.

As armas de fogo atuais apresentam raiamento que podem variar de uma simples raia até doze, mas parece que o número de raias tem pouca influência sobre seu efeito estabilizante (HEARD, 2008).

Um fator que influencia na estabilidade do projétil é o passo do raiamento. O passo é a distância, geralmente medida em polegadas, para o raiamento helicoidal completar uma volta completa. Se o passo for muito longo, induzindo no projétil uma baixa rotação, isso tenderá a aumentar a inclinação da ponta do projétil em relação ao eixo de trajetória, levando-o a tombar e completamente se desestabilizar. Se por outro lado o passo levar a uma rotação muito superior a ideal ele desgastará prematuramente o cano e poderá levar o projétil a desintegrar-se sobre ação de forte força centrífuga.

O formato destes sulcos também pode variar muito entre tipos de arma. As mais comuns apresentam bordas retangulares, com sulcos pronunciados. Porém existem armas cujo formato da raia é poligonal, como bordas arredondados.

No processo de fabricação do cano primeiramente ele é furado grosseiramente por meio de uma broca. Em seguida é fresado para suavizar a rugosidade de arranhões espirais adquiridos durante o processo de furo (HEARD, 2008). Finalmente são produzidas as raias, por meio de algum processo, dentre os quais os que geram os raiamentos que podem ser visualizados na Figura 2.

O processo de raiamento dos canos mais comum é conhecido como "raiamento por broca". Neste processo os raiamentos são obtidos com uso de uma série de 20 a 30 discos de 
aço em uma haste, cada disco sendo ligeiramente maior que o antecessor, e são utilizados para cortar progressivamente o interior do cano, sendo utilizada uma broca cortante para dar as dimensões finais a todas as raias de uma vez só, gerando raias com bordas retangulares como pode ser visualizado na fotografia à esquerda da Figura 2 (HEARD, 2008).

Outro método de raiamento, que em geral gera melhor qualidade final, é o "raiamento por estampagem ou martelamento". Neste método o cano é fresado com diâmetro ligeiramente maior que o diâmetro final requerido. Um mandril (feito de aço muito duro) contendo um negativo do que deverá ser o raiamento final, é forçado através do cano enquanto o lado externo do cano é martelado ou hidraulicamente comprimido. Assumindo que o mandril seja de boa qualidade, é produzido cano com qualidade excepcional e raiamento com bordas arredondadas conforme pode ser visualizado na fotografia à direita da Figura 2 (HEARD, 2008).

Figura 2 - Fotografias do interior de dois canos de arma de fogo, mostrando à esquerda cano com raiamento com bordas retangulares e à direita raiamento do tipo poligonal.
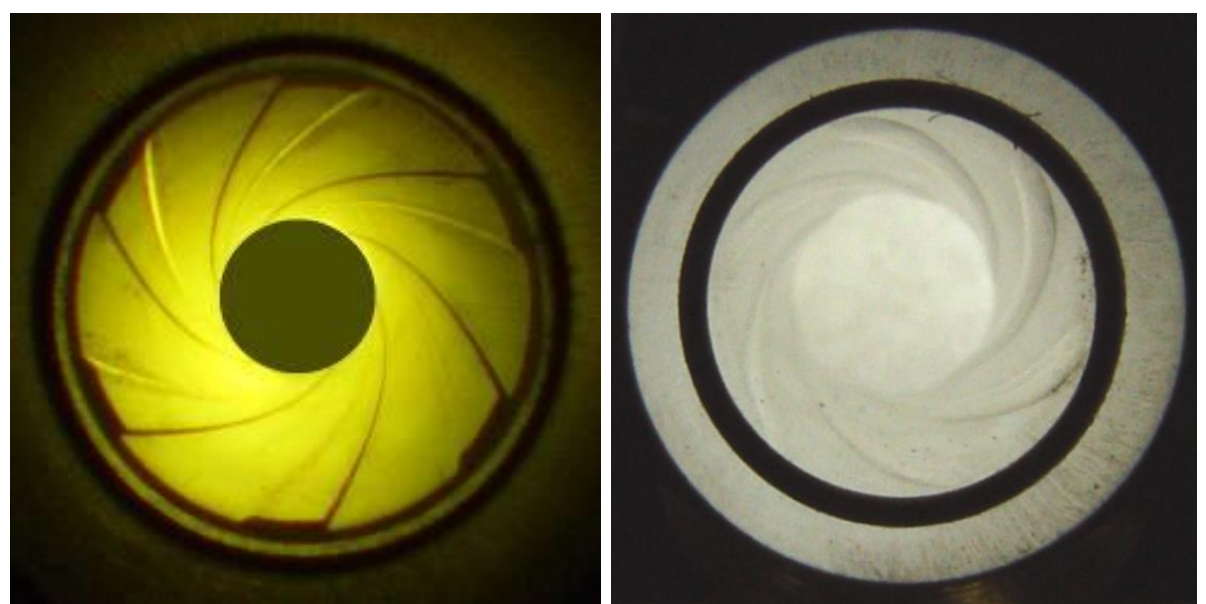

Fonte: Jost, Santos e Sato (2014).

As diferenças de atuação das ferramentas nestes processos de fabricação e acabamento de raiamentos explicam porque os raiamentos poligonais apresentam menos marcas identificadoras do que os com raias com bordas retangulares.

Além da quantidade e do formato, o ângulo de inclinação destas raias, bem como o sentido, se horário ou anti-horário, são fatores que variam de cano para outro.

\subsubsection{Sistema de fogo central}

Como já mencionado, para funcionar em cano raiado, o projétil não poderia mais ser carregado através da boca do cano, por isso passou-se a fabricar cartuchos de munição, nos 
quais um estojo é utilizado para receber a cápsula de espoletamento, a carga de projeção e o projétil, permitindo carregar a munição com todos seus elementos a partir da extremidade posterior do cano. Para o disparo ocorrer o cartucho precisa ser posicionado de forma a permitir que o percussor, ao ser liberado pelo acionamento do gatilho, pressione a cápsula de espoletamento, isso pode ocorrer por meio de percussão lateral, circular, ou pelo sistema mais largamente utilizado, o sistema de fogo central.

Este sistema (ver Figura 3), largamente em uso nas armas de fogo modernas, é considerado por HEARD (2008, p. 11) como "o grande marco no desenvolvimento de armas e munições".

Figura 3 - Ilustração de um cartucho de munição com sistema de fogo central, demonstrando os diversos elementos de munição que o constituem.

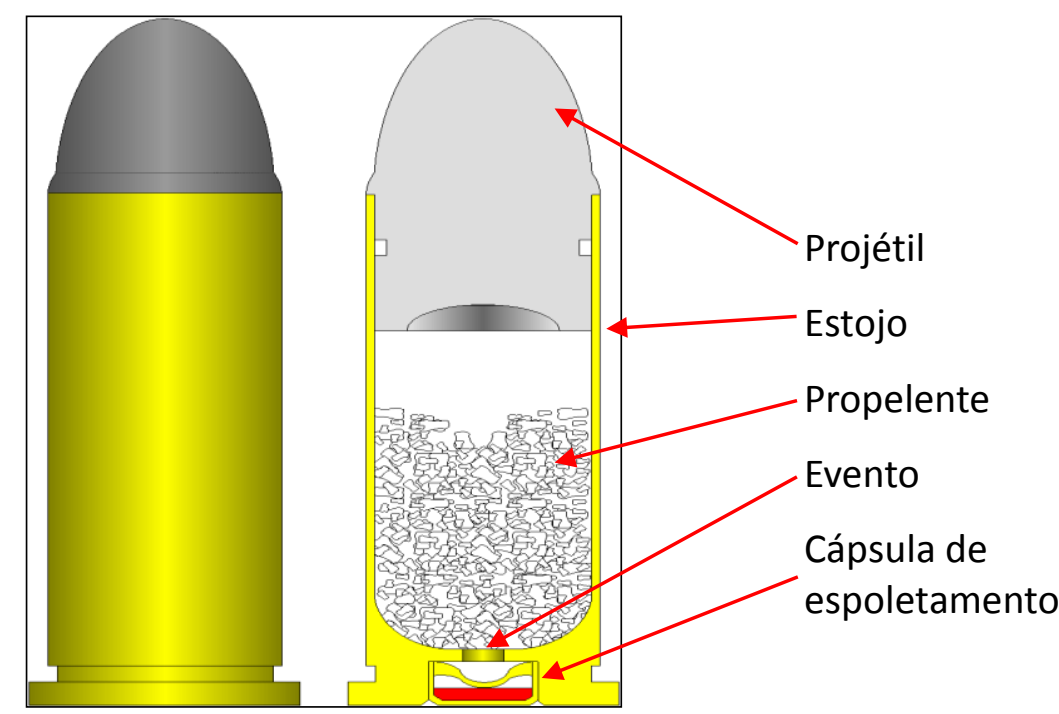

Fonte: Adaptado pelo autor de fonte não identificada.

No centro da base do estojo da Figura 3 observa-se a cápsula de espoletamento. Nela está contida a mistura iniciadora (em vermelho), sendo essa a única parte que necessita ser sensível à pressão, o que tornou este tipo de munição segura e de fácil produção. Já o estojo pode ser feito de material mais resistente, atualmente a maioria em latão, permitindo suportar uma pressão muito maior e possibilitando disparos de projéteis mais pesados com relativa segurança.

O sistema também permite que os estojos sejam reaproveitados, num procedimento padrão conhecido como recarga de munição. Após um disparo o estojo pode ser recondicionado, e colocando-se nova cápsula de espoletamento, nova pólvora e novo projétil pode ser utilizado para outro disparo. 


\subsubsection{Armas de fogo modernas}

As armas de fogo modernas apresentam muitas das características de suas antecessoras (RABELLO, 1995). Dentre a grande variedade de armas modernas são de interesse a este estudo as com cano de alma raiada e que utilizam o sistema de fogo central.

Outra relevante característica de uma arma para este estudo é quanto ao seu modo de funcionamento. O esquema da Figura 4 ilustra como as armas de fogo se classificam em relação ao modo de funcionamento.

Figura 4 - Classificação das armas de fogo quanto ao modo e funcionamento.

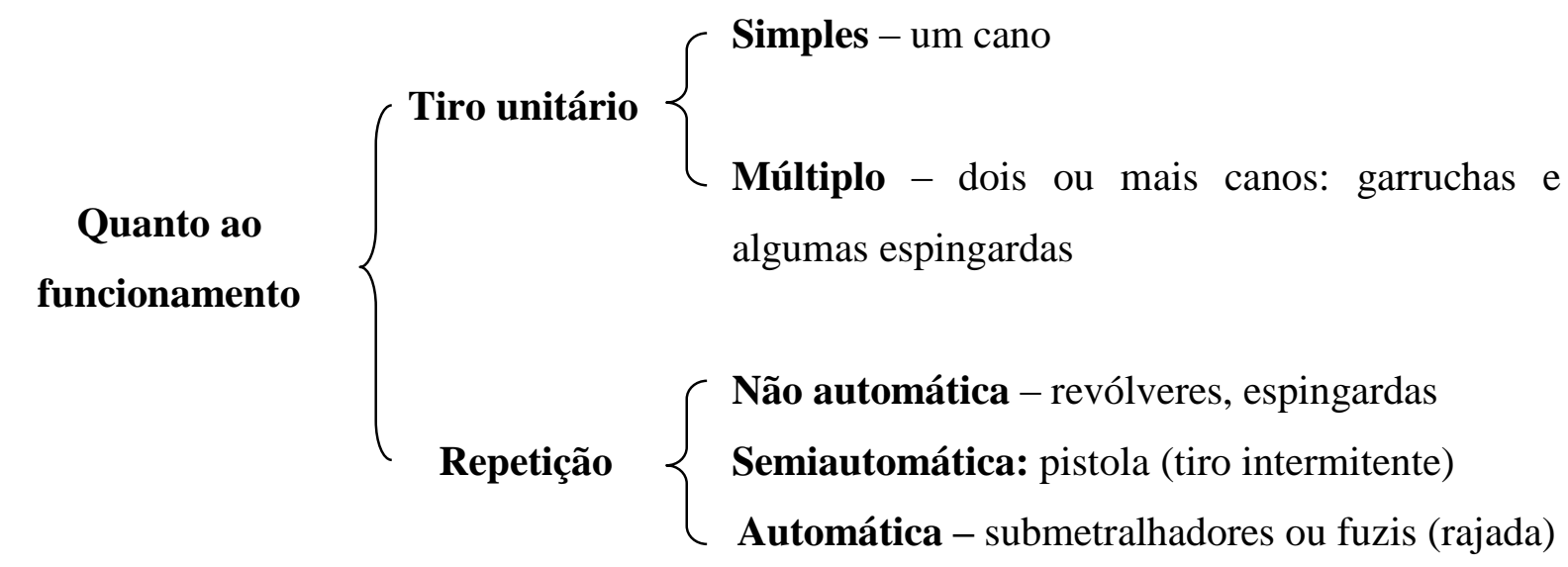

Fonte: Adaptado de Rabello (1995).

Nas armas de tiro unitário há compartimento para apenas um cartucho de munição por cano, sendo necessário extrair o cartucho após o disparo e introduzir outro na arma para efetuar novo disparo.

Já as armas de repetição possuem compartimentos que permitem que sejam alimentadas com dois ou mais cartuchos para disparo. São exemplos destes compartimentos as câmaras do tambor nos revólveres ou os pentes carregadores nas pistolas. Ainda que possuam carga para dois ou mais disparos, existe a necessidade de ou se extrair o estojo de munição da câmara e alimentar com outro cartucho íntegro ou rodar o tambor, para se efetuar um novo disparo. $\mathrm{O}$ modo de extração do estojo e carregamento de um cartucho, conhecido como ciclagem da arma, ou de rodar o tambor, determinará se arma é classificada como não automática, semiautomática ou automática (RABELLO, 1995).

As armas não automáticas são aquelas em que a ciclagem é feita por aproveitamento da energia muscular do atirador, transmitida à arma quando do acionamento do gatilho. É o que 
ocorre com os revólveres não automáticos em que o mecanismo do gatilho é acionado pelo dedo do atirador e faz o tambor girar, apresentando um novo cartucho de munição na posição correta para ser percutido e deflagrado (JOST; SANTOS; SATO, 2014).

As armas semiautomáticas e automáticas utilizam a energia proveniente da expansão dos gases para efetuar a ciclagem da arma, extraindo o estojo da munição deflagrada e carregando um novo cartucho na câmara de combustão. A ciclagem pode ocorrer aproveitandose a conservação de momento linear entre projétil e estojo ou por sistema de recuperação de gases. Nas semiautomáticas, como as pistolas, a cada ciclagem é necessário liberar e acionar novamente o gatilho para efetuar um disparo (tiro intermitente), enquanto que nas automáticas, como os fuzis, enquanto se mantiver acionado o gatilho e houver munição íntegra no carregador, continuará ocorrendo disparos (rajadas).

O estudo desta dissertação foi feito utilizando revólveres não automáticos e pistolas semiautomáticas, todas com sistema de fogo central, e com mecanismo de disparo que pode ser resumidamente descrito em:
a) carregamento da munição na câmara de combustão;
b) acionamento do gatilho com liberação do percussor sobre a cápsula de espoletamento;
c) detonação da espoleta com geração de uma chama que se comunica com a pólvora por meio de eventos dentro do estojo;
d) deflagração da carga de projeção (pólvora) com geração de gases e elevação da pressão no interior do estojo;
e) aceleração do projétil por meio da expansão dos gases através do cano;
f) movimento do estojo em sentido contrário ao projétil devido à conservação de momento linear;
g) nos revólveres o estojo permanece dentro da câmara na qual foi deflagrado, e na pistola é ejetado durante a ciclagem da arma.

\subsubsection{Revólver}

Os revólveres são armas de fogo que apresentam um único cano e um tambor rotativo com diversas câmaras de combustão que se alinham uma por vez com o cano.

Tem sido uma arma muito utilizada devido à sua robustez e confiabilidade. Talvez uma das grandes razões pelo seu uso tão disseminado e sua preferência por muitos, seja que mesmo 
quando sujeita a condições adversas, como sujeira, água ou areia, seu sistema simples de disparo permite que a arma funcione normalmente (JOST; SANTOS; SATO, 2014).

Os revólveres apresentam quatro partes fundamentais: armação, tambor, cano e mecanismo. Na Figura 5 são identificadas estas partes.

Figura 5 - Fotografia identificando partes de um revólver.

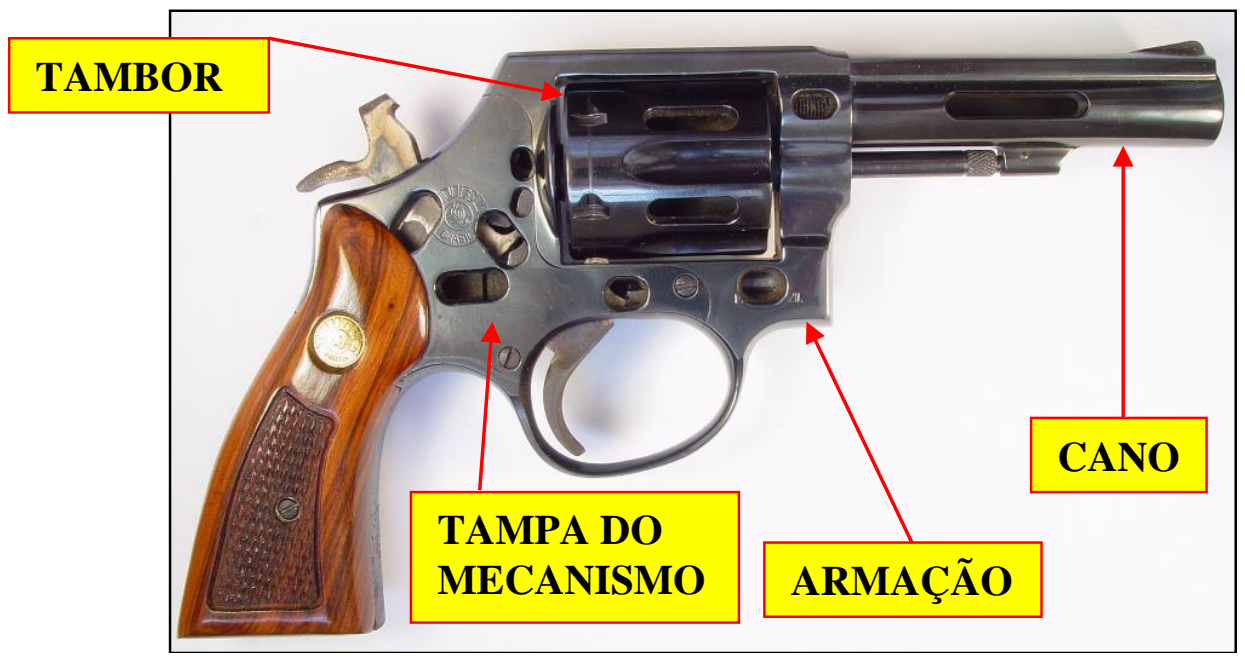

Fonte: Elaborado pelo autor.

A armação constitui a peça sobre a qual são acopladas as demais peças, constituindo o corpo principal da arma. Em geral é a peça da arma que apresenta gravado o número de série e o logotipo do fabricante. Porém, como os exames de identificação de projétil disparado de fato identificam apenas o cano da arma através do qual o projétil foi disparado, peça esta que pode ser trocada na arma, atualmente a legislação pátria exige que gravação do número de série também ocorra no cano ${ }^{2}$.

O cano é peça responsável por receber o projétil após a deflagração da munição e fornecer a ele direção e momento rotacional. Em sua extremidade posterior ele é liso e apresenta um estrangulamento denominado cone de forçamento, destinado a apropriadamente admitir o projétil ao cano. Após o cone de forçamento, a parte interna do cano apresenta o sistema de raias, que conforme já descrito em 2.1.2, serve para fornecer ao projétil uma estabilidade giroscópica necessária para manter-se na trajetória desejada.

O tambor apresenta diversas câmaras que possuem dimensões específicas para receber cartuchos de munição no calibre nominal da arma de fogo (ver explicação sobre calibre em 2.2.3). Ele está apoiado através de um eixo central, e ao acionamento do gatilho gira, alinhando

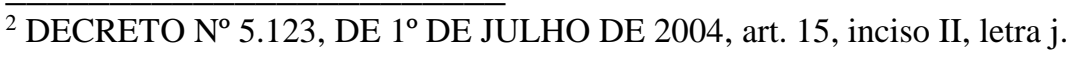


à parte posterior da câmara com o pino percussor e sua anterior com o cano, o que permite o disparo. Ao ocorrer a deflagração da munição o estojo recebe a marca do percussor na cápsula de espoletamento e se choca contra as paredes da câmara e em seu culote (base do estojo) contra a placa de obturação (ver Figura 6).

O mecanismo é um conjunto de peças que permite que o revólver funcione como uma arma de repetição. Esta alojado no interior da armação, protegido pela tampa do mecanismo e apresenta, dentre outros: cão, percussor, peça de articulação, gatilho, impulsor e retém do tambor. Como parte do mecanismo alguns revólveres apresentam dispositivos de segurança, como barra de percussão ou calço de interposição (RABELLO, 1995).

Figura 6 - Fotografias de um revólver e um estojo de munição (Em detalhes placa de obturação, janela por onde o percussor atua para comprimir a cápsula de espoletamento e aspecto do culote do estojo após percussão e deflagração da munição).
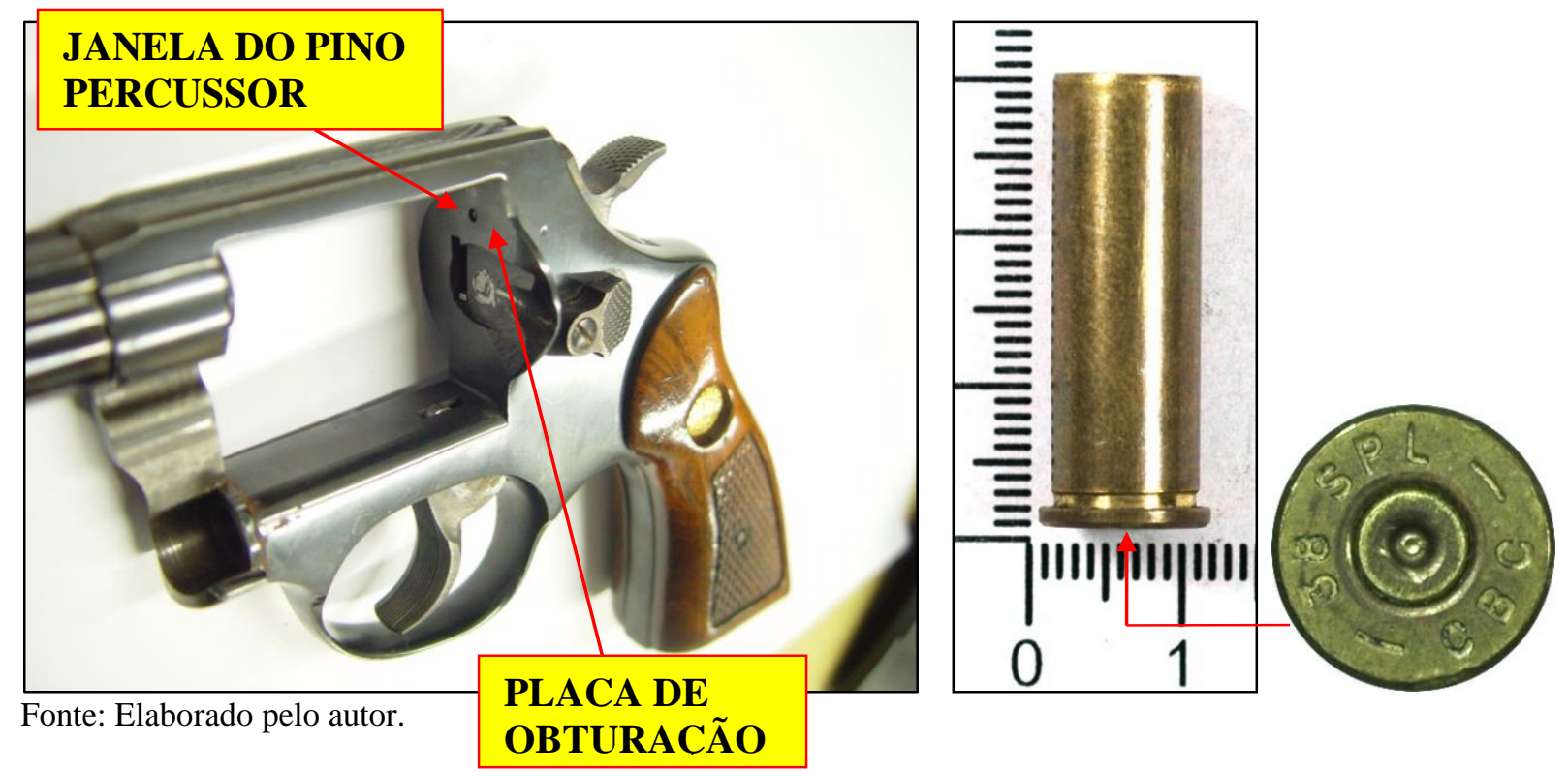

\subsubsection{Pistola semiautomática}

O advento dos cartuchos de munição, nos quais todos os elementos de munição necessários ao disparo foram acoplados, tornou possível o desenvolvimento de armas semiautomáticas e automáticas (HEARD, 2008).

O princípio de funcionamento das pistolas semiautomáticas consiste no aproveitamento da conservação do momento linear do conjunto estojo e projétil, para efetuar a ciclagem da arma. A realização deste ciclo de extração e carregamento após cada disparo, prepara a pistola para um próximo disparo e a caracteriza como arma semiautomática. 
As principais partes da pistola semiautomática são: armação, carregador, cano e ferrolho. Na Figura 7 são identificadas estas partes.

Figura 7 - Fotografia identificando principais partes de uma pistola desmontada.

Fonte: Elaborado pelo autor.

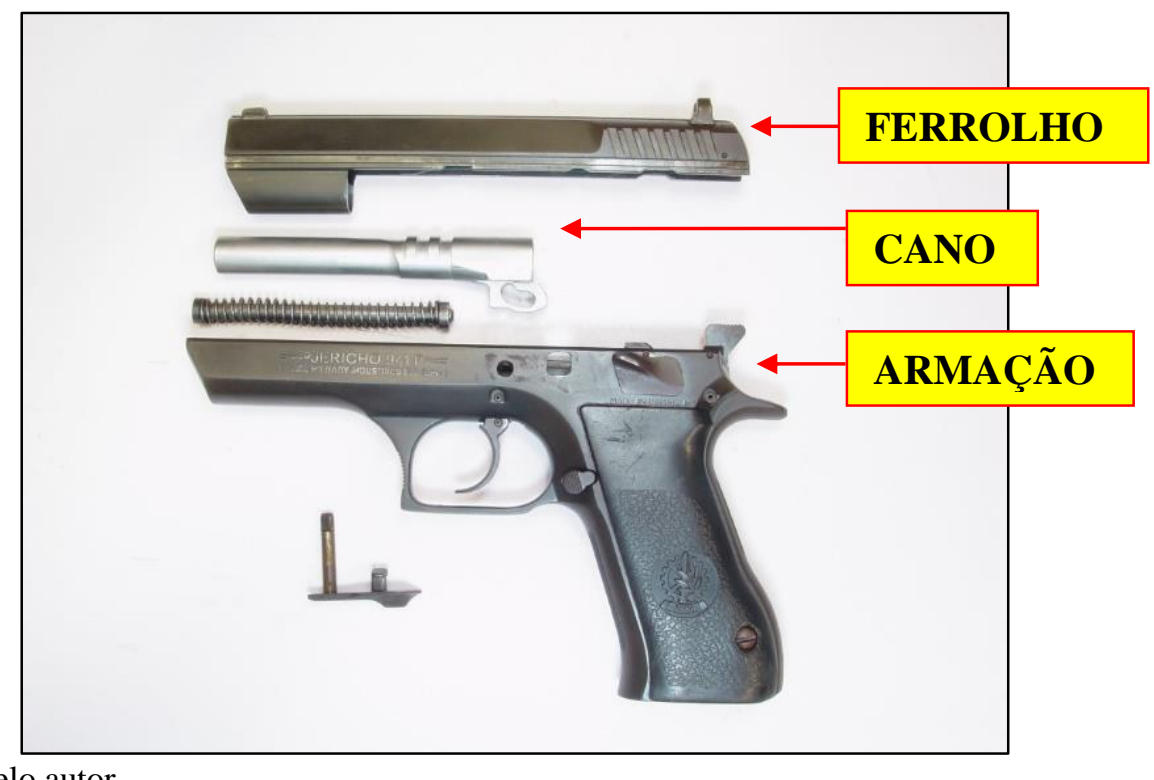

A armação, tal qual no revólver, serve de suporte às demais peças, como cano, ferrolho e carregador. Porém o mecanismo de disparo, na maioria das pistolas, apresenta partes na armação e partes no ferrolho.

O cano apresenta câmara de combustão em sua extremidade posterior e raiamento ao longo do resto do seu comprimento interior.

O pente carregador é geralmente uma peça separada da arma, que serve como receptáculos dos cartuchos de munição íntegros (antes do disparo). Para tanto constitui-se de um tubo oco com as dimensões específicas para armazenar enfileirados os cartuchos de munição que serão apresentados na ciclagem da arma à câmara de combustão.

O ferrolho, é uma peça apoiada sobre trilhos da armação, e que com o disparo move-se sob a ação da força exercida pelo estojo na culatra. É esta força exercida pelo estojo sobre o ferrolho que faz com que este mova-se sobre o trilho, e por meio de pequenas peças efetue a extração do estojo deflagrado e apresentação de novo cartucho, proveniente do carregador, na câmara de combustão. Na face da culatra sob o qual assenta-se o culote do estojo existe a janela do pino percussor por onde o percussor realiza seu curso para pressionar a cápsula de espoletamento (ver Figura 8). 
Figura 8 - Fotografia identificando a face da culatra e janela do pino percussor em uma pistola.

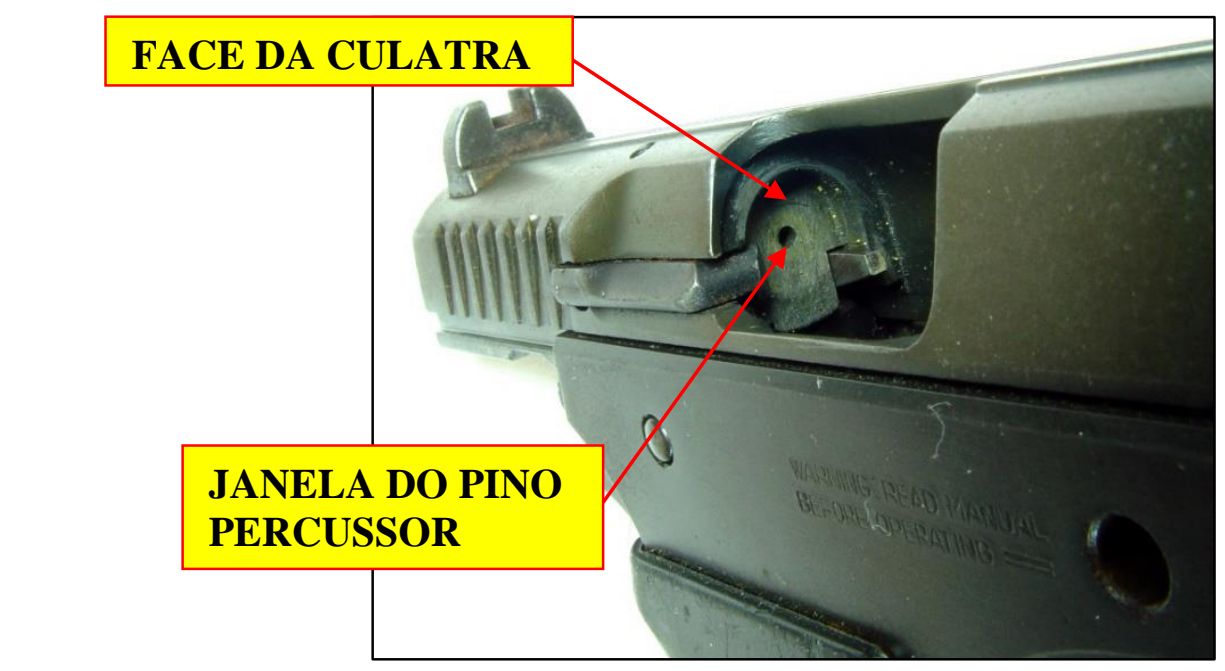

Fonte: Elaborado pelo autor.

\subsection{MUNIÇÃO DE ARMA DE FOGO}

Como relatado em 2.1.1 a evolução das armas está intimamente relacionada à evolução dos cartuchos de munição.

\subsubsection{Breve histórico das munições}

As primeiras formas de munição consistiam em uma pólvora em pó, carregada em um frasco ou chifre, que juntamente com projéteis de formatos irregulares eram introduzidos a partir da boca do cano.

Por volta do século XV a "pólvora negra" (uma mistura de salitre (nitrato de sódio), carvão e enxofre) se tornou o padrão para uso em arma de fogo, com seu carregamento, bem como do projétil, ainda a partir da boca do cano. Mas esta pólvora, além de ineficiente, produzia diversos inconvenientes para o disparo, como muita fumaça, e foi substituída com o tempo pela pólvora sem fumaça (HEARD, 2008).

Na evolução das munições momento especial ocorreu com a invenção dos cartuchos de munição, onde cápsula de espoletamento, projétil e propelente passaram a serem acoplados ao estojo de munição, constituindo uma unidade de munição completa. Isto permitiu o estabelecimento do sistema de fogo central bem como o uso de canos com raiamento. 


\subsubsection{Componentes dos cartuchos de munição}

Como já ilustrado na Figura 3, os principais componentes de um cartucho de munição de fogo central são: estojo, cápsula de espoletamento, propelente e projétil.

\subsubsection{Estojo de Munição}

O estojo é a parte do cartucho sob a qual são montadas as outras partes da munição.

Seu formato e dimensões são determinadas pelo calibre nominal da arma a ser utilizada, possibilitando seu uso na câmara de combustão do tipo de arma para a qual é designado. Para armas de alma raiada o estojo é metálico, geralmente de cobre ou latão, e para armas de alma lisa possui uma base metálica e um corpo de plástico (RABELLO, 1995).

Uma de suas extremidades é aberta, denominada boca do estojo, onde fica engastado o projétil, e outra fechada, denominada culote. Em cartuchos de fogo central é no culote que se aloja a cápsula de espoletamento e é onde estão impressos os caracteres que identificam o calibre e o fabricante, além de outras características da munição (JOST; SANTOS; SATO, 2014).

\subsubsection{Cápsula de Espoletamento}

As cápsulas de espoletamento são pequenos recipientes, às vezes parte do estojo, às vezes neste montado, em que é colocada a mistura iniciadora (ver Figura 9), um explosivo químico, altamente sensível à pressão, que quando detonado, gera uma chama para iniciar o propelente (JOST; SANTOS; SATO, 2014).

Figura 9 - Microfotografia da mistura iniciadora da cápsula de espoletamento de um cartucho de munição CBC 9mm Gold.

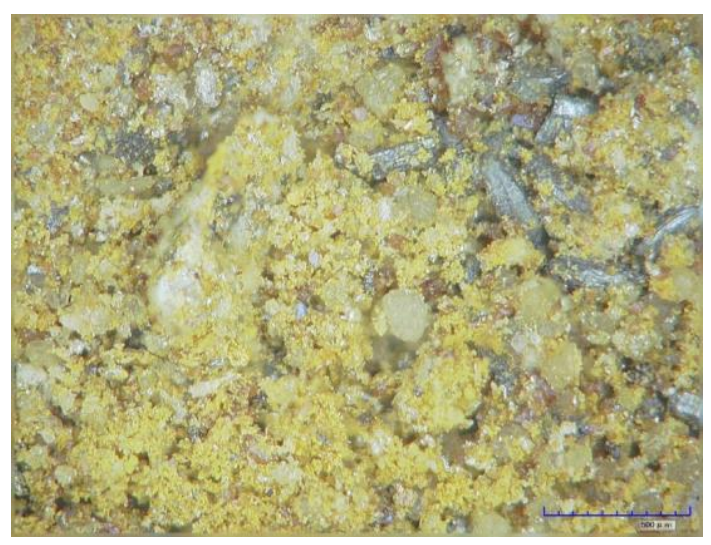


O fato de ser montado no estojo permite que apenas esta cápsula seja de material macio, possibilitando que estojo e projétil sejam feitos de ligas mais duras e, portanto, capazes de suportar maior pressão no disparo, o que por sua vez propicia disparos com velocidades maiores.

A exata composição da mistura iniciadora varia entre fabricantes, mas em geral contém um composto organometálico, como estifnato de chumbo, e outros compostos como nitrato de bário, trissulfeto de antimônio, e alumínio em pó (JOST; SANTOS; SATO, 2014).

\subsubsection{Propelente}

O propelente, ou carga de projeção, trata-se de um combustível sólido, com grãos em formatos variados (ver Figura 10), que se destina a inflamar com grande velocidade, gerando gases que serão responsáveis pelo aumento da pressão, o que por sua vez impulsionará o projétil enquanto percorrer o interior do cano.

Em geral são constituídas de nitrocelulose, recebendo a denominação de base simples, ou de nitrocelulose e nitroglicerina, denominando-se de base dupla (JOST; SANTOS; SATO, 2014).

Sua composição e o formato de seus grãos determina sua taxa de queima, e isso é utilizado a depender do tamanho do cano da arma empregada, escolhendo pólvoras mais lentas para armas com cano longo e pólvoras mais rápidas, ou ditas vivas, para armas de cano curto.

Nos cartuchos de munição CBC é comum o culote do estojo apresentar inscrições "+P” e "+P+", para designar munições que possuam carga de projeção que levará, no disparo, respectivamente a "mais pressão" e "pressão ainda maior" (CBC, 2005, p. 4).

Figura 10 - Microfotografia de grãos de pólvora de uma munição CBC 9mm Gold.

Fonte: Elaborado pelo autor

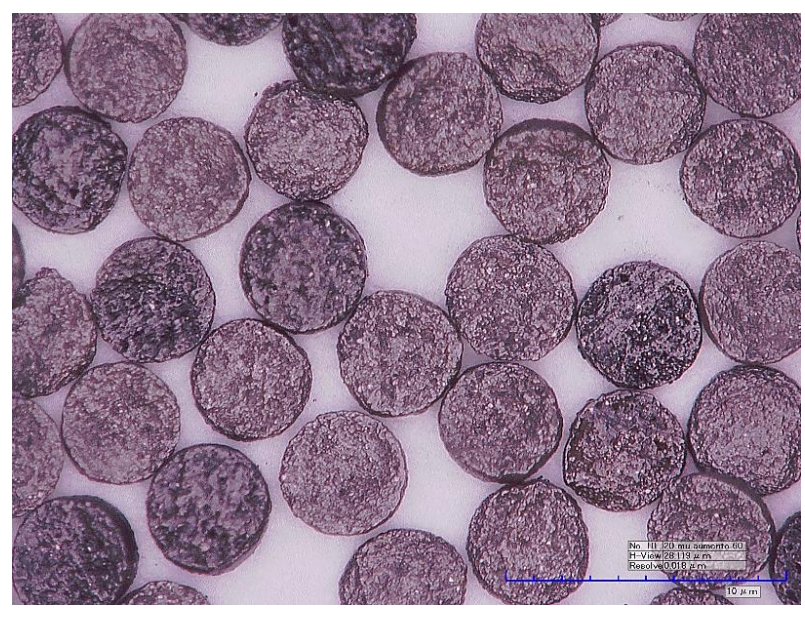




\subsubsection{Projétil}

O projétil é a parte da munição que deverá produzir o efeito principal do disparo no alvo. Inicialmente engastado na boca do estojo, deste se desprende sob a pressão dos gases resultantes da queima da pólvora e é acelerado por estes gases através do cano, numa trajetória helicoidal por conta das raias existentes (RABELLO, 1995).

Nos cartuchos de fogo central para armas de porte geralmente o projétil é único, destacando-se três tipos principais: de liga de chumbo, semiencamisados e encamisados (ver Figura 11).

Os projéteis de liga de chumbo nu podem apresentar diversos formatos, sendo o mais comum deles o formato ogival. Em geral apresentam uma pequena porcentagem de antimônio em sua composição para aumentar sua dureza.

Já os projéteis encamisados (dos quais não se vê o núcleo) ou semiencamisados (dos quais em geral aparece o núcleo apenas na ponta) apresentam núcleo de liga de Chumbo e revestimento de liga de Cobre, alguns deles com Zinco e /ou Níquel. O objetivo principal do encamisamento é impedir o derretimento do projétil quando sujeito a temperaturas e pressões elevados, possibilitando disparos em armas de maior poder de fogo. Além disso o encamisamento diminui a deposição de chumbo no cano, diminuindo seu desgaste e contribuindo para uma melhor manutenção das propriedades de tiro do armamento (JOST; SANTOS; SATO, 2014).

Figura 11 - Fotografia de três projéteis de munição calibre .38SPL, da esquerda para direita, de liga de chumbo, semiencamisado e encamisado.

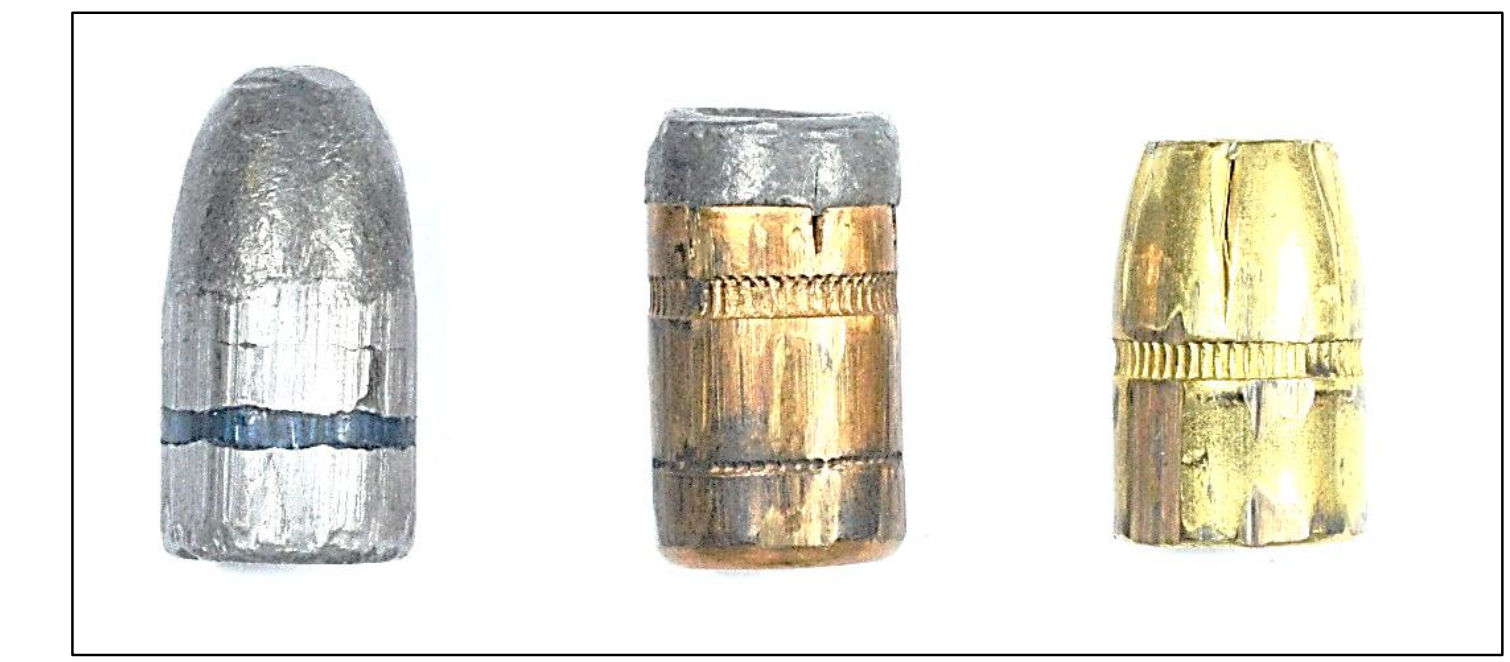

Fonte: Elaborado pelo autor. 


\subsubsection{Calibre}

Uma das variações mais importantes nos tipos de munições e armas existentes diz respeito ao calibre. Para entender as nomenclaturas empregadas e os sistemas de medidas utilizados nas designações de calibres de armas e munições é necessário diferenciar o calibre real do calibre nominal.

O calibre real de uma de fogo é uma medida do menor diâmetro interno do cano. $\mathrm{O}$ calibre real de um projétil é a medida do maior diâmetro ao longo de seu formato. Essas medidas são reais, podem ser feitas com paquímetro, e em geral são expressas em milímetros.

Já o calibre nominal trata-se de uma designação do tipo de munição e tipo de arma, que devem coincidir para que o disparo seja efetuado. Quando se refere ao calibre nominal se referencia não só o diâmetro real do projétil, mas também das dimensões do cartucho de munição íntegro que deverão coincidir com dimensões da câmara de combustão da arma para que percussão, deflagração e disparo possam ocorrer apropriadamente. A seguir dois exemplos de calibre nominal, que representam os calibres trabalhados nesta dissertação.

- calibre nominal .38SPL: os dois primeiros dígitos fazem referência à .38" (trinta e oito centésimos de polegada) e corresponde a um valor aproximado dos diâmetros interno do cano arma e externo do projétil; estes valores são apenas aproximados. Além disso, a designação SPL (Special) permite que arma e cartucho de munição sejam fabricados com dimensões compatíveis de utilização. Na Figura 12 um desenho esquemático da Sporting Arms and Ammunition Manufactures Institute (SAAMI) ${ }^{3}$ com todas as medidas e intervalos de tolerância para produção do cartucho neste calibre nominal.

- calibre nominal 9x19mm: o primeiro dígito faz referência a 9mm (nove milímetros) e corresponde ao valor aproximado dos diâmetros interno da arma e externo do projétil; mais uma vez referindo-se a valores aproximados. A segunda referência, $19 \mathrm{~mm}$ (dezenove milímetros), diz respeito ao tamanho do estojo utilizado nos cartuchos de munição; na Figura 13 um desenho esquemático de padronização da SAAMI com todas as medidas e intervalos de tolerância para este tipo de calibre nominal.

\footnotetext{
${ }^{3}$ Sporting Arms and Ammunition Manufactures Institute (SAAMI) é uma associação dos principais fabricantes americanos de arma de fogo, munições e componentes, criada para padronização, segurança e intercâmbio de elementos relacionados a armas de fogo.
} 
Com a designação acima não se confundiria por exemplo o calibre nominal .38SPL com o calibre nominal .38 Curto, que apresentam calibres reais semelhantes, mas demais medidas não.

Figura 12 - Desenho esquemático de medidas em polegadas (em parêntesis em milímetros) para o calibre .38 SPL.

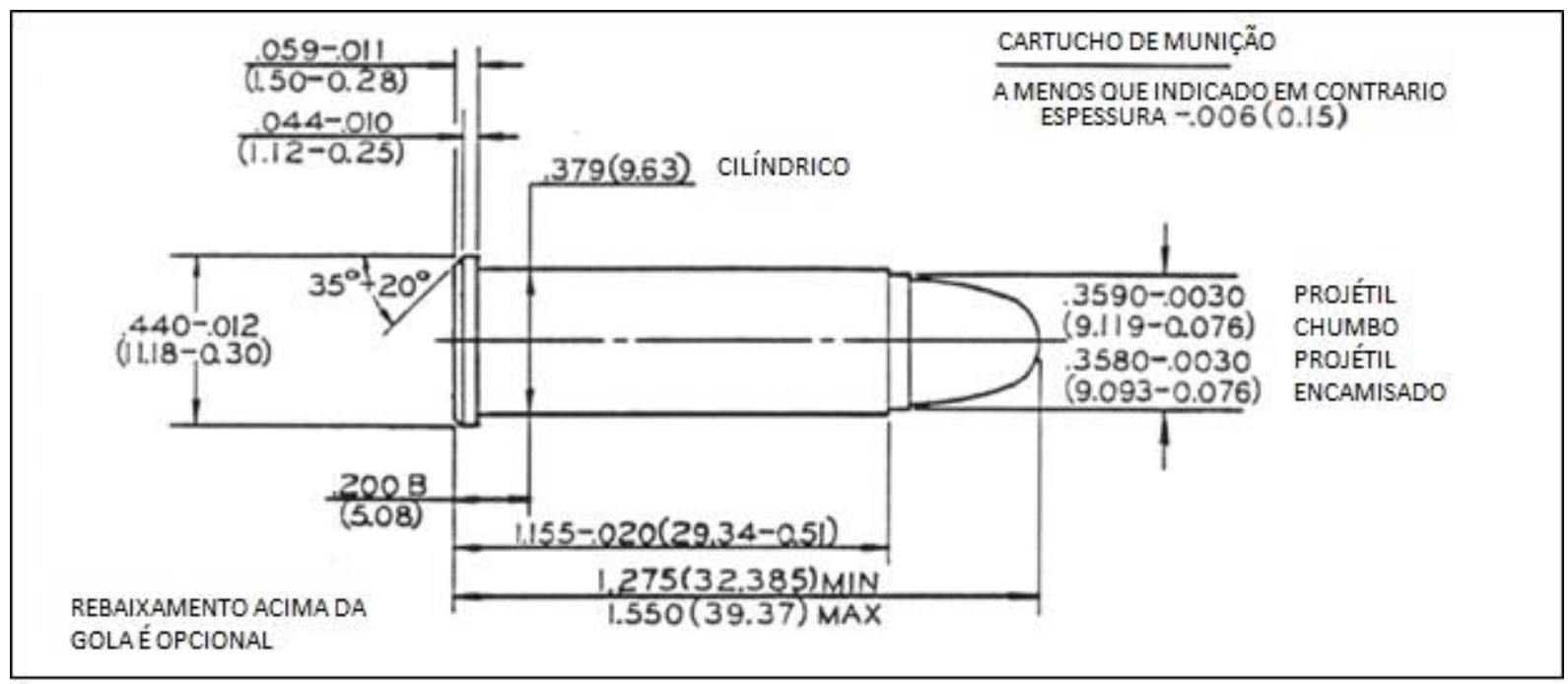

Fonte: Adaptado de SAAMI 2015a.

Figura 13 - Desenho esquemático de medidas em polegadas (em parêntesis em milímetros) para o calibre $9 \times 19 \mathrm{~mm}$.

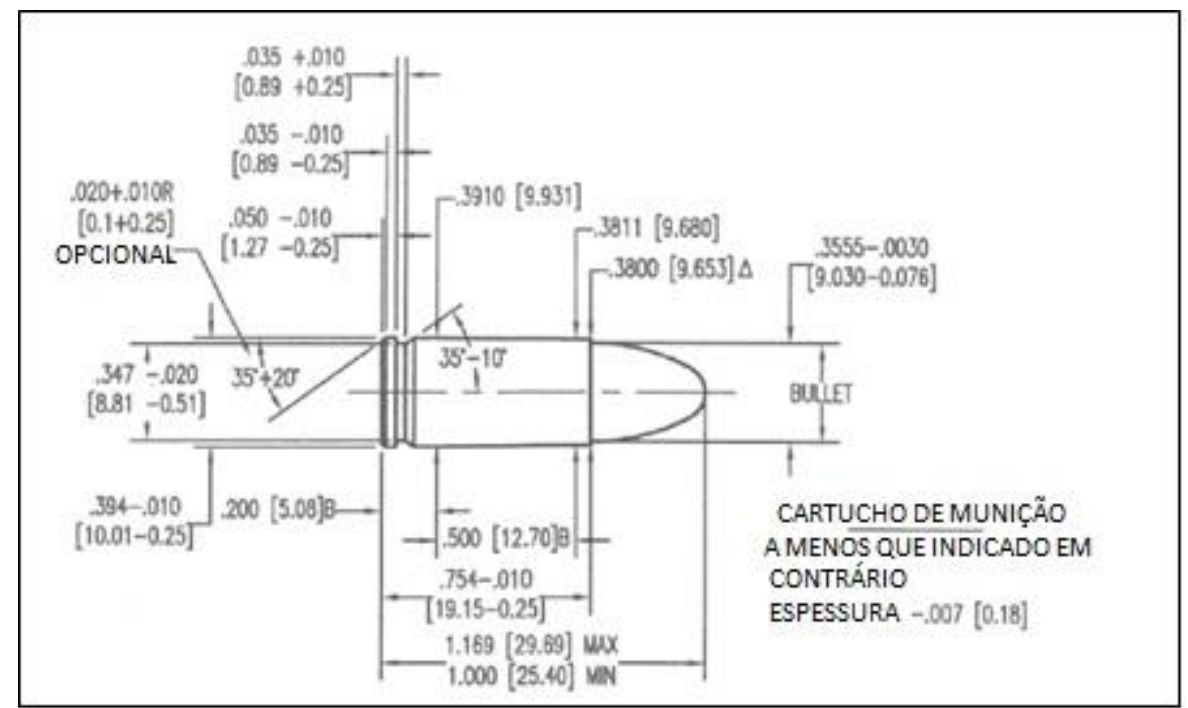

Fonte: Adaptado de SAAMI 2015b.

Em relação a calibre nominal também é importante ressaltar que alguns são ditos equivalentes, ou recebem mais de uma designação a depender do fabricante, o 9mm Luger por exemplo é o mesmo que 9mm Luger, 9mm Luger Parabellum, 9mm Para, ou 9mm Luger Nato. 


\subsection{CONFRONTO DE MICROIMPRESSÕES}

Durante o disparo de uma arma de fogo, devido às elevadas pressões internas geradas pela deflagração da munição, estojo e projétil entram em contato com partes específicas da arma, recebendo destas marcas de imperfeições que contenham. Os processos de fabricação de partes da arma, como os citados em relação ao raiamento do cano (ver 2.1.2), explicam o porquê da existência destas marcas internas, e o entendimento do funcionamento da arma permite uma compreensão de como estas marcas são transferidas para estojos e projéteis, possibilitando o exame de comparação balística.

\subsubsection{Funcionamento da arma de fogo}

Para o disparo um cartucho íntegro tem que ser posicionado corretamente na câmara de combustão da arma. No revólver a inserção é feita manualmente diretamente na câmara e na pistola é feita a partir do pente carregador com o manejo do ferrolho.

Pressionando a tecla do gatilho o mecanismo da arma movimenta o percussor (fixo ou basculante, por meio direto ou indireto) em direção à cápsula de espoletamento, que contém um explosivo primário, como estifnato de chumbo $\left(\mathrm{C}_{6} \mathrm{HN}_{3} \mathrm{O}_{8} \mathrm{~Pb}\right)$, sensível a impacto (TAYLOR; RINKENBACH, 1927).

Nas espoletas da CBC por exemplo, até 1975 era utilizado o fulminato de mercúrio, mas após esta data passou-se a utilizar o estifnato de chumbo como iniciador do processo e nitrato de bário e trissulfeto de antimônio, respectivamente como oxidante e combustível (SCHWOEBLE; EXLINE, 2000), além de outros estabilizantes como alumínio em pó (CUNICO, 2010).

Quando a cápsula é percutida o estifnato de chumbo libera energia através de uma reação exotérmica, cujo valor exato da variação de entalpia dependerá dos constituintes formados, mas geralmente gera-se uma chama a temperatura em torno de $2500^{\circ} \mathrm{C}$ (dois mil e quinhentos graus Celsius). Esta chama se comunica com o propelente através de eventos do estojo e contém energia suficiente para deflagrá-lo (RABELLO, 1995).

O propelente, composto de nitrocelulose $\left(\mathrm{C}_{6} \mathrm{H}_{9}\left(\mathrm{NO}_{2}\right) \mathrm{O}_{5}\right)$ em pólvoras de base simples, é uma substância gelatinosa que pode ser moldado a diferentes formatos e tamanhos. Isso permite um ajuste entre o peso do propelente e área de exposição, o que por sua vez determinará a taxa de queima e consequentemente a pressão dos gases gerados (B-GL-306-006, 1992). 
Na Figura 14 há um gráfico de velocidade do projétil no cano e pressão interna em função da distância percorrida pelo projétil, mostrando o grande pico de pressão ocorrido com a queima do propelente.

Figura 14 - Pressão interna e velocidade do projétil no cano em função da distância percorrida pelo projétil no cano.

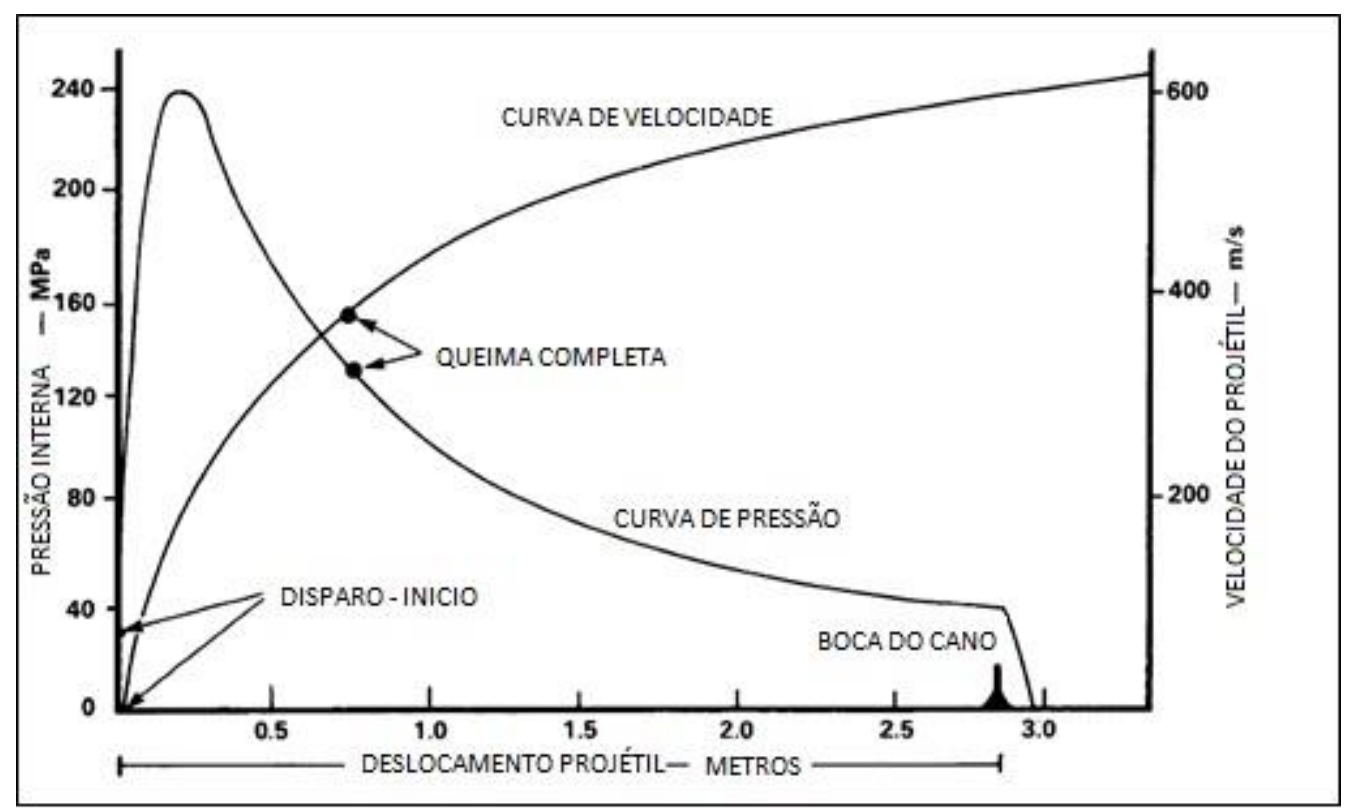

Fonte: Adaptado de B-GL-306-006 (1992).

O manual B-GL-306-006 (1992, p. 29) ressalta ainda que "a avaliação de numerosos diagramas de pressão interna mostra que a curva de pressão interna de diferentes armas e tipos de propelentes são similares em características gerais. Variações no peso do projétil, forma e tamanho do propelente, temperatura do propelente e muitos outros fatores, causarão uma pequena alteração de um disparo a outro na curva de pressão interna”.

Considerando que a deflagração da pólvora fornecerá uma energia Q, e o propelente sofrerá uma variação de energia interna $\Delta \mathrm{U}$, seria realizado um trabalho sobre o projétil $\mathrm{W}$, que obedeceria a segunda lei da termodinâmica (CARLUCCI; JACOBSON, 2007):

$$
Q=\Delta U+W+\text { perdas }
$$

Quando o projétil finalmente deixa o cano da arma ele adquiriu uma energia cinética de aproximadamente $30 \%$ (trinta por cento) da energia total liberada no disparo. O restante de energia foi desperdiçado em forma de calor (B-GL-306-006, 1992). Ou seja, a arma de fogo pode ser condiserada uma máquina térmica com eficiência em torno de $30 \%$ (trinta por cento). 
Com o trabalho realizado o projétil é acelerado pelo cano, seguindo a trajetória helicoidal determinada pelos sulcos do raiamento.

Neste trajeto dentro do cano o projétil recebe marcas das imperfeições que o cano contenha; como o projétil está em movimento estas marcas aparecem na forma de cavados e estrias longitudinais em sua superfície lateral.

A elevada pressão interna também expande o estojo, selando a câmara de combustão e, por conservação de momento linear entre projétil e estojo, impulsiona este último em direção oposta à direção que o projétil se movimenta, provocando o choque do culote do estojo contra a face da culatra da pistola ou contra a placa de obturação do revólver. Desta forma o estojo recebe marcas de contato com a face da culatra (no revólver placa de obturação) e câmara. Nas pistolas, como a ciclagem é semiautomática, também atuam sobre estojo, e nesse deixam marcas, os lábios do carregador, a garra de extração e o ejetor.

\subsubsection{Comparação balística}

Essas marcas deixadas em projétil ou estojo funcionam como um meio de identificar a arma que foi utilizada. A maioria das marcas estriadas deixadas no interior de canos completamente raiados são criadas durante as operações de furo, alargamento, raiamento e acabamento. Rebarbas também são deixadas após a coroação do cano e o corte da câmara e do cone de forçamento (WARLOW, 2005). A análise destas marcas pode evidenciar existência de características de classe, subclasse ou individuais.

Características de classe e subclasse serão comuns a um conjunto de armas. Como por exemplo, o número e sentido das marcas de raiamento é uma característica de classe, o que significa que todas as armas que possuem cano com raiamento 6D marcarão os projéteis com este padrão de cavados. Com boa precisão estas marcas de classe servem para excluir armas suspeitas com características incompatíveis.

Já as mais importantes, as marcas com características individuais, permitem identificar a arma especifica que marcou um elemento de munição. Elas surgem acidentalmente durante o processo de fabricação, ou por uso, dano e corrosão durante o subsequente tempo de utilização da arma. Suas formações aleatórias pelas ferramentas de corte ou acabamento, garantem com que, em termos práticos, sejam únicas para cada arma. A possibilidade de estabelecer uma relação entre elemento de munição e arma surge quando se observa concordância total nas características de classe e suficiente nas características individuais, de tal forma que a 
probabilidade de que outra ferramenta as tenham produzidas é tão remota que possa ser desconsiderada (WARLOW, 2005).

\subsubsection{Reprodutibilidade e individualização de marcas}

A reprodutibilidade e a individualização destas marcas são os elementos chaves para que a correlação unívoca entre elemento de munição e arma utilizada possa ocorrer.

Desde que levado aos tribunais e utilizado na solução de crimes, este exame tem sido alvo de críticas e suspeição, principalmente por operadores do Direito sem conhecimento científico suficiente; não obstante, diversos estudos já demonstraram sua validade e a impossibilidade prática de duas armas produzirem as mesmas marcas microscópicas.

Um dos estudos mais antigos, produzido por Biasotti (1959 apud GRZYBOWSKI et al., 2003, p. 227), comparou a existência de marcas coincidentes entre projéteis de mesma arma e entre projéteis de armas diferentes (os falsos positivos), estabelecendo um primeiro padrão a partir do qual uma combinação de estrias poderia ser com segurança excluída de um falso positivo.

Porém esta combinação era mais qualitativa do que quantitativa, permitindo críticas ao processo de identificação, principalmente em sua aparente subjetividade, na medida que apenas um examinador treinado poderia diferenciar um conjunto de marcas coincidentes aleatórias de outro conjunto que permita afirmar que o elemento de munição proveio daquela arma. Esta abordagem mais qualitativa do que quantitativa é vista por muitos como de difícil descrição ou convencimento do juiz ou júri (CHU et al., 2013).

Dando resposta a este questionamento, mais recentemente Biasotti e Murdock (1997 e 2002 apud GRZYBOWSKI et al., 2003, p. 215), estabeleceram um critério quantitativo para identificação em termos do CONSECUTIVELY MATCHING STRIAE (CMS), ou traduzindo, estrias consecutivas coincidentes, que seriam marcas estriadas que se alinham exatamente umas com às outras em mesmas posições relativas, sem falhas ou acréscimos entre elas (CHU et al., 2013). O critério estabelece que a identificação positiva pode ser determinada por pelo menos:

1 - para marcas tridimensionais: dois grupos de pelo menos 3 estrias consecutivas (em mesma posição relativa) ou um grupo de 6 estrias; 2 - para marcas bidimensionais: dois grupos de pelo menos 5 estrias consecutivas (em mesma posição relativa) ou um grupo de 8 estrias. 
De acordo com este CMS proposto, até então não refutado por nenhum estudo posterior, o critério mínimo estabelecido está acima da máxima combinação já observada entre marcas comparadas de projéteis provenientes de armas diferentes.

Outro estudo levado a cabo em dez anos envolveu 507 participantes, e utilizou 10 armas novas retiradas em sequência da linha de montagem de uma fábrica. Projéteis padrões e "questionados" foram coletados das armas e enviados para laboratórios de balística em 20 países, para reportarem de qual arma cada questionado partira. De 7.605 comparações balísticas efetuadas, houveram 5 (cinco) resultados inconclusivos, 3 (três) projéteis foram considerados em um laboratório como "em não condições para o confronto" e nos demais 7.597 exames houve uma combinação correta entre projéteis questionados e padrões (HAMBY; BRUNDAGE; THORPE, 2009).

Outro interessante estudo lidou com a possibilidade de um examinador ser sugestionado a dizer que um elemento de munição proveio de uma arma com base em informações sobre o caso, muitas vezes repassados por testemunhas ou outros policiais. O estudo mostrou que informações sobre o caso não influenciaram no resultado; de fato, ao final, peritos com menos informação foram menos cuidadosos com suas conclusões, do que aqueles que tinha uma descrição do caso (KERSTHOLT et al., 2010).

Para evitar demasiadas citações de artigos e estudos aceitos pela comunidade científica que validam o exame de comparação balística, recomenda-se consultar o trabalho de Grzybowski et al. (2003) que lista 41 (quarenta e um) artigos de publicações sobre comparações balísticas envolvendo armas de fogo, cartuchos de munição e marcas de ferramentas.

Heard (2008) reconhece a importância e validade destes estudos práticos, porém propõe a seguinte análise estatística para se ter uma ideia de qual seria a probabilidade de diferentes armas apresentarem o mesmo conjunto de estrias.

Para simplificar o assunto foi proposta uma analogia de marcação de estrias nos cavados de projétil com o preenchimento de caixas. Para isso, considere 20 (vinte) caixas enfileiras, 10 (dez) das quais serão aleatoriamente preenchidas conforme ilustração da Figura 15a.

A probabilidade de que dois conjuntos de 20 (vinte) caixas sejam preenchidos da mesma forma pode ser calculada como 1 (uma) em $\mathrm{C}^{\mathrm{m}}{ }_{\mathrm{n}}$ combinações, onde $\mathrm{C}^{\mathrm{m}}{ }_{\mathrm{n}}$ representa o número total de combinações de preenchimento de 10 (dez) das 20 (vinte) caixas, dado pela equação abaixo:

$$
C_{n}^{m}=\frac{m !}{n !(m-n) !}
$$


Onde: $\quad \mathrm{m}=$ número de caixas;

$\mathrm{n}=$ número de caixas preenchidas;

$\mathrm{C}_{\mathrm{n}}^{\mathrm{m}}=$ modos de preenchimento (combinações) de 10 das 20 caixas.

Neste exemplo, $m=20$ e $n=10$, assim:

$$
C_{10}^{20}=\frac{20 !}{10 !(20-10) !}=184.756
$$

Agora acrescente a condição de que as caixas possam ser preenchidas por cinza escuro ou por cinza claro (ver Figura 15b). Assim, como há duas cores possíveis, se for preenchida apenas 1 (uma) caixa, as possibilidades de preenchimento serão 2 (duas); se forem preenchidas 2 (duas) caixas, as combinações com duas cores serão 4 (quatro), ou 22; e assim até o caso de preenchimento de 10 (dez) caixas que apresenta as possíveis combinações:

$$
2 \times 2 \times 2 \times 2 \times 2 \times 2 \times 2 \times 2 \times 2 \times 2=210=1.024
$$

Desta forma, as combinações de preenchimento de 10 caixas de um conjunto de 20 , com duas cores diferentes serão de:

$$
184.756 \times 1.024=189.190 .144 \text {. }
$$

Finalmente admita que cada caixa preenchida possa agora ser marcada com a letra X ou Y (ver Figura 15c), ou seja, novamente as combinações de preenchimento das 10 caixas com uma das letras serão de 1.024 .

Ou seja, as combinações de preenchimento de 10 (dez) caixas de um conjunto de 20 (vinte), com duas cores diferentes e marcação destas 10 (dez) caixa com as letras X ou Y serão de:

$$
1024 \times 189.190 .144=52.860 .000 .000 .
$$

Levando esta analogia para o contexto das estrias em projéteis de armas de fogo, deve-se dividir um simples cavado do projétil em 20 (vinte) seções longitudinais, em 10 (dez) das quais foram marcadas com estrias. A probabilidade de que dois cavados de dois projéteis 
provenientes de armas diferentes tenham as mesmas dez seções longitudinais com estrias será 1 (uma) em 184.756.

Se agora, cada uma destas estrias tiver uma de duas características, por exemplo, um formato de ponta ou uma forma quadrada, a probabilidade de que os dois cavados de projeteis de armas diferentes continuem coincidindo será de 1 (uma) em 189.190.144.

Finalmente, se cada uma destas estrias puder ser classificada como larga ou fina, então a probabilidade de que os dois cavados de projeteis de armas diferentes continuem batendo sob todos estes critérios será de 1 (uma) em 52.860.000.000.

Figura 15 - Analogia de preenchimento de caixas com a individualização de estrias combinantes.
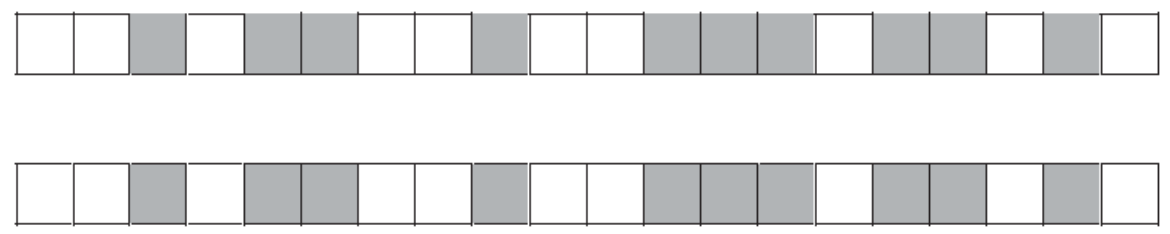

(a) $\mathrm{P}=184.756$ - ver equação (2.3).
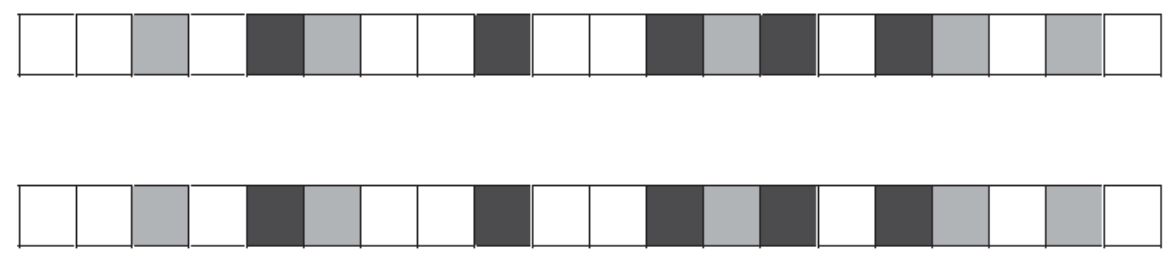

(b) $\mathrm{P}=189.190 .144$ - ver equação (2.5).
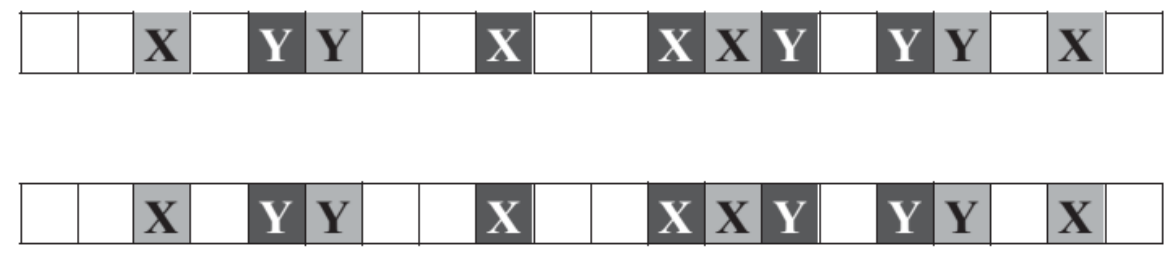

(c) $\mathrm{P}=52.860 .000 .000-$ ver equação (2.6).

Fonte: Adaptado de Heard (2008).

Este é um caso simplificado. Pensando nas centenas de possiblidades de localização das estrias bem como dezenas de formatos possíveis destas estrias, fica claro que a probabilidade de dois projéteis provenientes de armas diferentes apresentarem o mesmo conjunto de estrias, em mesmas posições relativas, atinge valores absolutamente impraticáveis. 


\subsubsection{Uso de microscópio comparador}

Não se sabe ao certo quando inicialmente se observou que estas marcas deixadas pela arma em estojos e projéteis poderiam ser utilizadas para identificar a arma empregada, mas a literatura apresenta alguns exemplos bem antigos de uso desta premissa (HAMBY, 1999).

Em 1835, em uma investigação do assassinato de um morador de Londres, Inglaterra, uma análise cuidadosa dos elementos de munição encontrados na cena de crime, projétil e papel utilizado para separar o projétil da pólvora, permitiu identificar o molde utilizado para dar forma ao projétil, bem como a fonte do papel como sendo provenientes do quarto de um serviçal.

Em 1879 no estado de Minnesota, EUA, a corte solicitou exame em um projétil que causara a morte de uma pessoa e em dois revólveres suspeitos. Como um dos revólveres apresentava cano raiado e outro não, foi possível declarar que o projétil incriminado não poderia ter sido disparado pelo revólver com cano raiado e poderia ter sido disparado pelo outro.

Em 1907, após disparos supostamente efetuados pela infantaria Americana, os responsáveis pela investigação produziram ampliações de fotografias das marcas do pino percussor e puderam identificar as armas utilizadas.

Em 1912 em Paris, o professor V. Balthazard produziu fotografias ampliadas de cavados e cheios de projéteis bem como de diversas partes da arma que interagem com estojos, como percussor, extrator e face da culatra, sendo capaz de identificar a arma utilizada no disparo. Seus estudos e artigos publicados podem ser considerados como os fundamentos para todo o desenvolvimento da ciência de identificação de projéteis e estojos.

Em 1925 foi pela primeira vez mencionado o uso de um microscópio comparador que permite uma visualização ampliada e simultânea de dois projéteis ou dois estojos para efeito de comparação forense.

O uso deste equipamento é considerado por muitos como o grande marco no desenvolvimento da comparação balística, sendo que melhorias posteriores ocorrem apenas quanto ao uso de lentes diferenciadas, processos de gravação e registro de fotografias mais sofisticados, bem como variações nos tipos de iluminação (HEARD, 2008).

O microscópio comparador consiste em uma ponte montada sobre os tubos verticais de dois microscópios, que por meio uma série de prismas internos, dirige as imagens de duas lentes objetivas para uma mesma ocular. A imagem resultante permite a sobreposição das imagens de cada amostra iluminada bem como uma composição de imagens lado a lado, separados por uma linha fina, que facilita grandemente o processo de comparação de estrias e demais marcas individuais. 
Figura 16 - Microscópio comparador marca Leica modelo FSM e ilustração do seu funcionamento óptico.
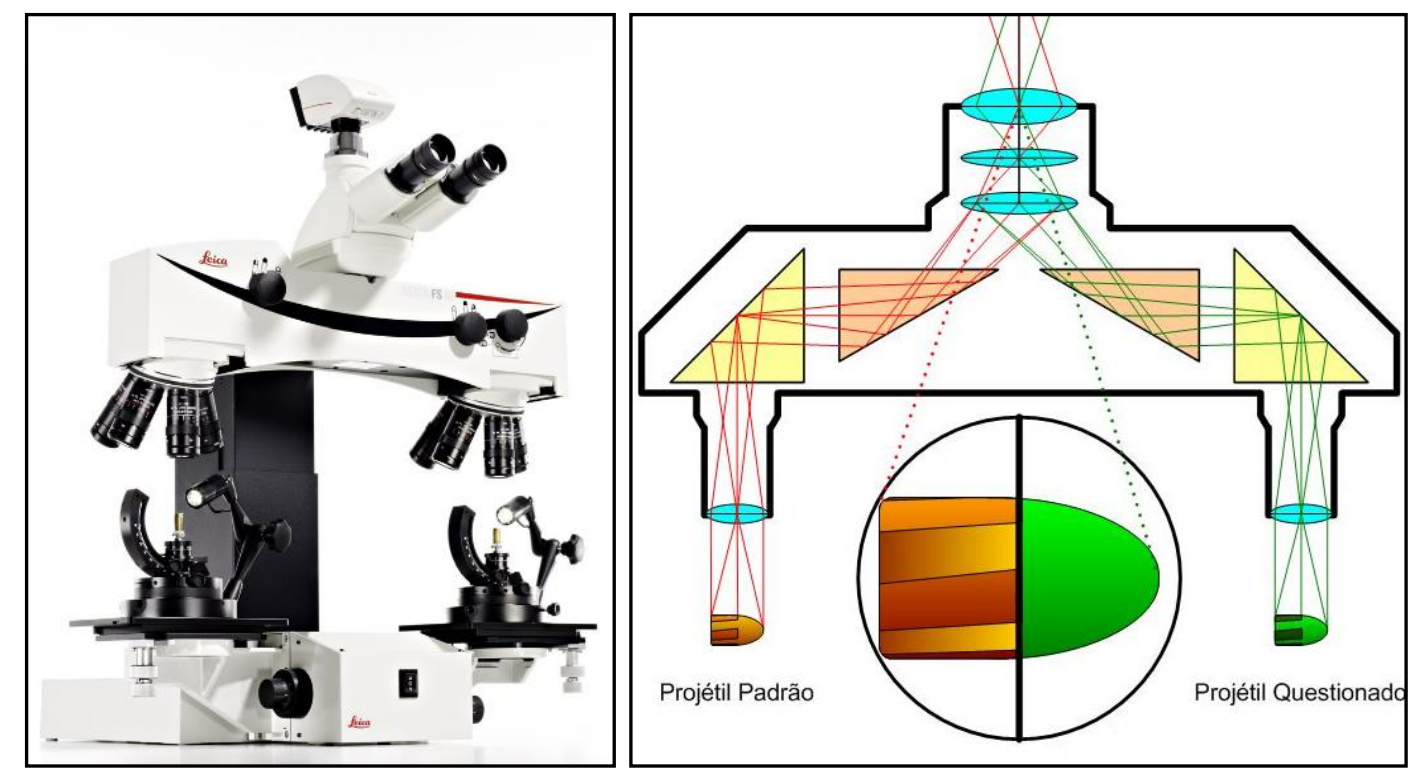

Fonte: Adaptado de Jost, Santos e Sato (2014).

\subsubsection{Coleta de padrões e realização do exame comparativo}

Em termos gerais, o que se dispõe para exames é um projétil ou estojo questionado (relacionado a um local de crime) e uma arma suspeita. Para se utilizar o microscópio comparador se faz necessário coletar projéteis e estojos da arma suspeita, que são denominados padrões da arma.

O procedimento de coleta de padrões de uma arma consiste em disparar a arma contra um meio que permita a frenagem eficiente do projétil sem, contudo, deformá-lo, bem como coletar os estojos deflagrados.

Há dois meios mais comuns para coleta de padrões de projéteis: água e tubo de coleta com estopa e algodão (ver Figura 17).

Após as coletas os padrões são examinados no microscópio comparador num procedimento preliminar para identificação de possíveis marcas individuais. Em seguida a comparação é feita entre padrões e elementos questionados na busca destas marcas individuais para saber se apresentam uma congruência significativa que permita uma identificação positiva.

A água é um excelente meio de frenagem, porém seu uso está limitado a projéteis do tipo ogival, pois projéteis com ponta oca, bem como projéteis com uma razão elevada entre comprimento e diâmetro, tendem a se deformar quando disparados na água e por isso é mais apropriado a utilização do tubo com estopa ou algodão (RABELLO, 1995). 
Figura 17 - Meios de coleta de projéteis padrões.
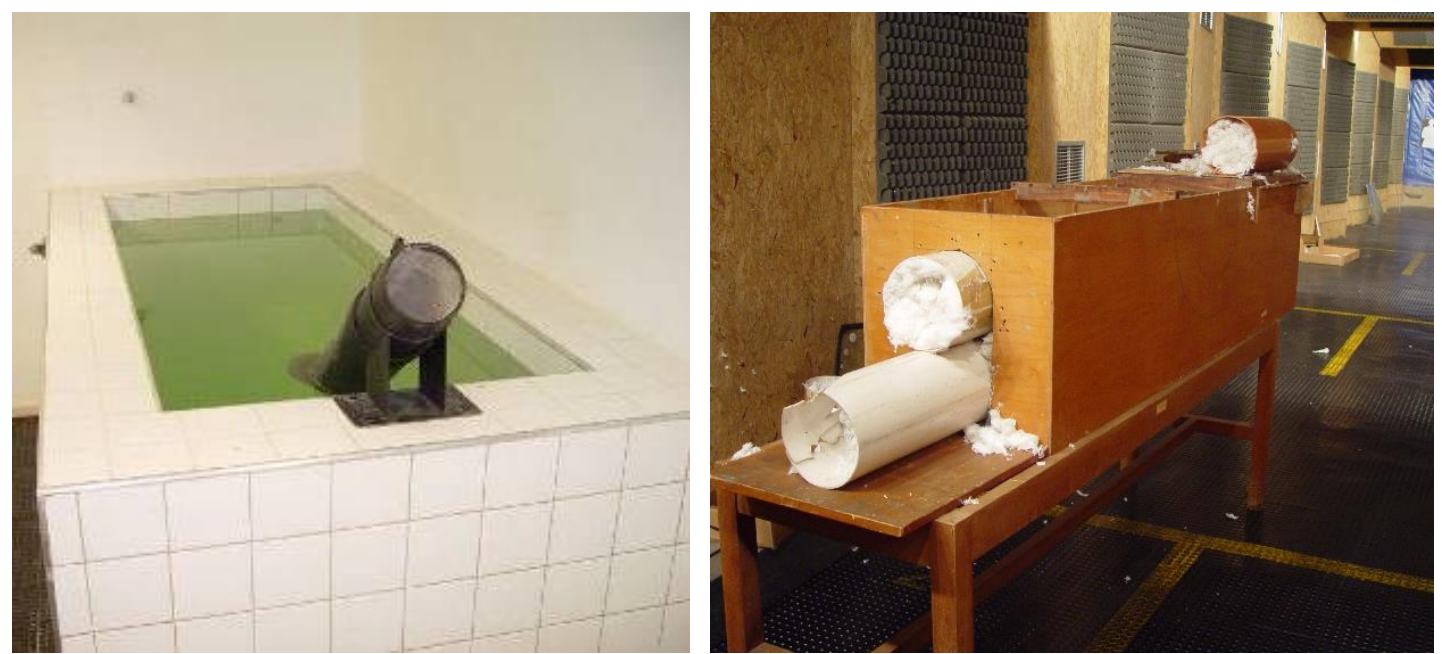

Fonte: Elaborado pelo autor.

\subsubsection{Limitações da comparação balística}

Nos casos práticos nem sempre é possível chegar a uma conclusão se um projétil ou estojo partiram de uma determinada arma. Isso ocorre às vezes devido a uma alta qualidade na fabricação e acabamento da arma, o que implica em poucas ou nenhuma marca com características individuais, levando o exame a um resultado inconclusivo. Porém, na maioria das vezes, exames de comparação balística inconclusivos são devidos a limitações genéricas deste tipo de exame, dentre as quais destacam-se (JOST; SANTOS; SATO, 2014):

a) estado de conservação do projétil: em muitos casos o estado de conversação do elemento de munição impede a visualização das marcas individuais no microscópio comparador; quase sempre, quando isso acontece, se refere a projéteis, que disparados com altíssimas velocidades se danificam ao impactarem superfícies resistentes, como chapas metálicas, paredes de alvenaria ou ossos humanos;

b) tipos de projéteis e estojos: quando se coletam padrões de uma arma, uma característica importante a ser observada é o tipo da munição questionada; como a intenção é reproduzir o mais fielmente possível as condições de disparo, a munição a ser utilizada na coleta de padrões deve possuir o máximo de características coincidentes com o elemento de munição questionado; para projéteis observa-se qual a composição e formato do projétil, para estojos qual a composição do estojo, fabricante e qualquer outra característica da munição informada no culote do estojo;

c) decurso do tempo: como já observado, o uso da arma pode fazer com que algumas características individuais se alterem enquanto outras novas surjam; ainda que se 
espere que algumas marcas estejam presentes na maioria das armas ao longo de toda sua vida útil, processos como limpeza, manutenção ou condições não ideias de conservação podem acelerar o processo de alteração das marcas de uma arma, e por isso, para um confronto eficiente, deve-se buscar contemporaneidade entre os elementos de munição questionados e padrões;

d) ausência de arma suspeita: quando não há uma arma suspeita, pode-se comparar os elementos do local para tentar identificar de quantas armas foram disparados ou quais algumas de suas características, como calibre e número de raias, porém o caso se torna um caso em aberto na espera de alguma arma suspeita para comparação.

Além destes limitantes, em muitos casos práticos, dezenas e às vezes centenas de elementos de munição são coletados de um mesmo local de crime para comparação balística contra armas suspeitas. Como o processo é feito em confronto de dois a dois em microscópio comparador, isso muitas vezes consome muito tempo para solução do caso.

\subsection{COMPARAÇÃO BALÍSTICA AUTOMATIZADA}

Em parte motivados pelas limitações do exame de confronto balístico, ou mesmo buscando otimização de tempo em confrontos com muitos elementos incriminados, sistemas de comparação automatizados têm sido concebidos nas últimas três décadas, e incorporados às rotinas de laboratórios de balística de todo mundo.

\subsubsection{Breve histórico da comparação automatizada}

Em 1989, com a implementação de uma política de combate as drogas na área de Washington D.C, Estados Unidos da América (E.U.A), os laboratórios forenses da região se viram sobrecarregados com uma grande quantidade de armas e munições submetidas (HEARD, 2008).

Para tentar relacionar os casos anteriores com novos casos que chegavam, grandes ampliações de fotografias de projéteis e estojos foram pregadas atrás dos microscópios comparadores na tentativa de permitir ao perito, enquanto analisando um novo caso, o ligasse a algum caso anterior.

Conscientes de que esta tarefa poderia ser melhor executada com tecnologia moderna a Federal Bureau of Investigation (FBI) resolveu patrocinar estudos quanto à digitalização de imagens dando início ao sistema DRUGFIRE. 
Quase na mesma época outra agência americana, a Bureau of Alcohol, Tobacco, Firearms and Explosives (ATF) patrocinou o início de outro sistema, o CEASFIRE, que utilizava uma adaptação de um software de comparação de imagens, rebatizado como Integrated Bullet Identification System (IBIS ${ }^{\circledR}$ ), trabalhando de forma diferente, mas com o mesmo objetivo. Posteriormente estes dois sistemas foram unificados gerando a rede National Integrated Ballistic Information Network (NIBIN), que foi implementada com o sistema IBIS ${ }^{\circledR}$ e ainda está ativa pelos E.U.A e Canadá (COMMITTEE..., 2009).

Em todo mundo diversos países também iniciaram pesquisas e implementações de sistemas automatizados para comparação balística, como por exemplo, ARSENAL Papillon, e CONDOR/EVOFINDER ${ }^{\circledR}$ na Rússia, BALISTIKA na Turquia, CIBLE na França, FIREBALL na Austrália, e LEPUS no Brasil.

No Brasil foram instalados e encontram-se em uso, o sistema IBIS ${ }^{\circledR}$ no Departamento de Polícia Técnica da Bahia, e o sistema Evofinder ${ }^{\circledR}$ nas Polícias Civis do Distrito Federal e de Minas Gerais, na Polícia Técnica de Goiás e na Polícia Federal.

\subsubsection{Técnicas de captura de imagens e correlação automatizada}

Os desafios neste campo são diversos e esclarecem por que não se obteve ainda uma solução definitiva para adoção de um sistema e criação de um banco de dados de todas as armas. Como bem registraram Sakarya, Leloglu e Tunali (2008), identificação automatizada de armas de fogo é um importante e ainda não resolvido problema nas ciências forenses.

O princípio básico de funcionamento de quase todos estes sistemas consiste em capturar imagens de partes do estojo ou projétil, e gerar uma assinatura eletrônica para cada elemento de munição. Desta forma a comparação balística pode ser feita de maneira automatizada tornando a identificação menos dependente da subjetividade e experiência do perito examinador (COMMITTEE..., 2009).

Um desafio na aquisição de imagens de estojos é a mudança radical observada nas marcas impressas e estriadas a depender do ângulo e tipo de iluminação utilizada. Um método proposto para superar esta limitação e possibilitar imagens que não dependam das condições de iluminação foi baseada em estéreo fotometria (SAKARYA; LELOGLU; TUNALI, 2008).

Para os estojos, a estratégia de captura de imagem deve envolver imagens em 3D, pois principalmente a marca de pino percussor tem características relevantes em relação à profundidade. Uma estratégia para comparação seria a segmentação da base do estojo em áreas de interesse e o uso de métodos baseados em modelos para automatização das comparações 
(SAKARYA et al., 2012). A literatura provê ainda estudos de desempenho de diferentes técnicas de comparação de imagens aplicada à comparação de estojos (GERADTS et al., 2001), bem como o uso de momentos geométricos para produzir um conjunto de características numéricas que permitem a identificação da arma a partir da marca de pino percussor (GHAN; LIONG; JEMAIN, 2010).

Para projétil a estratégia é semelhante. Um artigo relata o uso do microscópio confocal para visualizar impressões 3D na lateral de projéteis disparados e realizar uma comparação numérica (BANNO; MASUDA; IKEUCHI, 2004).

Estudos apontam a Função de Correlação Cruzada (FCC) entre dois sinais como uma ferramenta útil para comparação automatizada de amostras balísticas (SILVINO JÚNIOR, 2010), sendo o desempenho de técnica automatizada para comparação de projéteis, utilizando está FCC, apontado como mais eficiente inclusive que sistemas comerciais como IBIS ${ }^{\circledR}$ (LEÓN, 2006).

Um longo estudo de 236 páginas, revisando 123 artigos científicos relacionados a identificação de arma de fogo, analisou técnicas de captura de imagens de elementos de munição em 2D e 3D, bem como os algoritmos propostos e concluiu:

\footnotetext{
Neste artigo, nós consolidamos informação de diferentes fontes de informação sobre processamento de imagem, combinação de imagem e a unicidade de marcas em amostras balísticas. Processamento de imagens para exame de amostras balísticas está claramente em seus estágios iniciais e ainda há dúvidas na literatura na validade do caminho a seguir quando avaliando evidências (GERULES; BHATIA; JACKSON, 2013, p. 248, grifo nosso).
}

Os estudos citados demonstram que os desafios nesta área são em duas frentes, captura da imagem com extração de informações relevantes que possam funcionar como uma assinatura daquele elemento de munição, e subsequente estabelecimento de técnica para comparação de suas assinaturas.

\subsubsection{Estudos de efetividade em comparações automatizadas}

Com o surgimento destes equipamentos automatizados para comparação muitos pensaram que a solução para o problema de crimes cometidos com armas de fogo seria o cadastro de todas as armas em um banco de dados antes de serem colocadas à venda. Pelo menos dois estados estadunidenses investiram bastante recursos financeiros neste intuito, 
Maryland e Nova York, ambos criando bancos de dados de estojos de referência com uso do IBIS $^{\circledR}$, respectivamente Maryland-Integrated Ballistics Identification System (MD-IBIS) e Combined Ballistic Identification System (COBIS) (KOPEL; BURNETT, 2003).

Um relatório da divisão de ciências forenses da Polícia Estadual de Maryland registrou que o MD-IBIS ${ }^{\circledR}$ não ajudou a solucionar ou avançar em nenhuma investigação criminal. Os avaliadores do programa tentaram ainda um teste cego, tendo sido cadastrado no banco de dados uma arma e posteriormente enviado estojos da mesma arma como se fossem de um local de crime, porém mais uma vez o sistema não forneceu ou indicou nenhuma combinação positiva (TOBIN Jr., 2004).

O desempenho do COBIS, programa similar do estado de Nova York, foi idêntico, ou seja, nenhuma combinação positiva foi obtida pelo sistema (KOPEL; BURNETT, 2003).

Resultados desanimadores como estes tem levantado dúvida sobre a capacidade destes sistemas em identificar corretamente a arma que disparou um projétil ou deflagrou um estojo, principalmente quando lidando com bancos de dados cada vez maiores, e por isso alguns estudos foram conduzidos para tentar prever a confiabilidade dos resultados sugeridos em comparações automatizadas.

De Kinder, Tulleners e Thiebaut (2004) coletaram estojos de aproximadamente 600 armas de calibre $9 \mathrm{~mm}$ Luger e utilizaram o sistema IBIS ${ }^{\circledR}$ para avaliarem a efetividade de um RBID. Como resultado, em $72 \%$ (setenta e dois por cento) dos confrontos realizados com estojos de mesmo fabricante obtiveram a amostra correta nas dez primeiras posições da lista de resultados, em contraste a $21 \%$ (vinte e um por cento) quando os confrontos envolveram estojos de diferentes fabricantes.

Eles compararam seus resultados, e encontraram bastante semelhança, com um estudo prévio, realizado com 792 armas de calibre $.40 \mathrm{~S} \& \mathrm{~W}$ (ponto quarenta Smith and Wesson), no qual obtiverem amostras corretas nos dez primeiros resultados em 62\% (sessenta e dois por cento) dos confrontos realizados com estojos de mesmo fabricante, e em confrontos com estojos de diferentes fabricantes 38\% (trinta e oito por cento) (TULLENERS, 2001, apud DE KINDER; TULLENERS; THIEBAUT, 2004, p. 208).

Outro importante resultado no estudo citado acima está representado na Figura 18.

O gráfico abaixo mostra um importante limitante para bancos de dados de armas de fogo, na medida que aumentando o número de amostras no banco de dados aumenta-se a posição em que a amostra correta aparece na lista de resultados. Os pesquisadores concluíram que isso deve ser devido a características de classe similares que estão levando a uma deterioração dos resultados. Diante de seus resultados o grupo ressaltou: "um banco de dados 
de todas as armas novas é atualmente demasiadamente repleto de dificuldades para ser uma ferramenta efetiva" e "muito esforço precisa ser devotado ao problema levantado por este artigo" (DE KINDER; TULLENERS; THIEBAUT, 2004, p. 212).

Figura 18 - Figura representando a melhor posição na lista de resultados para comparações tanto de pino percussor (círculos) quanto de marca de culatra (losango), fornecido por um RBID de tamanho variando entre 50 e 600 armas.

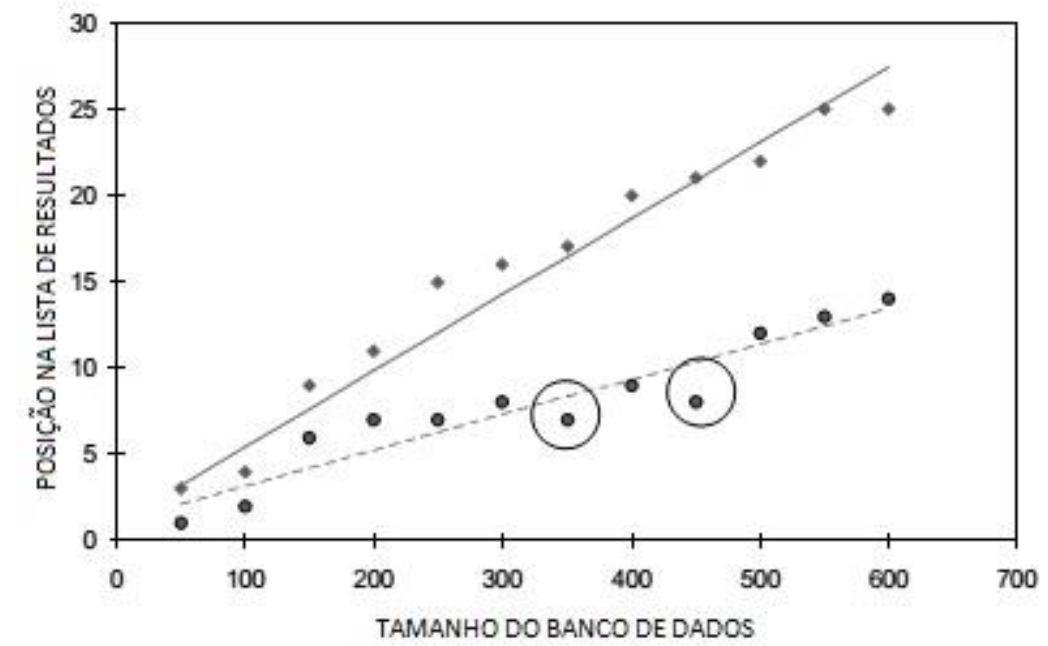

Fonte: Adaptado de De Kinder, Tulleners e Thiebaut (2004).

Dez anos após o estudo citado acima, Ceuster e Dujardin (2015) utilizaram o mesmo RBID para avaliar a efetividade de um novo sistema de comparação automatizado, desenvolvido pela empresa russa ScannBi Technology, denominado Sistema de identificação Balística Evofinder ${ }^{\circledR}$.

De acordo com o artigo, o estado da arte da comparação automatizada, representado por este e outros equipamentos comerciais do mesmo nível, inclui melhorias na resolução das imagens, apresentando resolução de até menos de $5 \mu \mathrm{m}$, captura de informações tridimensionais (topografia) de marcas, seleção semiautomática de áreas relevantes, melhoras na eficiência de correlação, e melhores possibilidades de manipulação das imagens na tela no processo de comparação (CEUSTER; DUJARDIN, 2015). O estudo confirmou a relação linear entre o tamanho do banco de dados e posição da amostra correta na lista de resultados.

Em relação à efetividade do sistema foi observada uma melhora significativa. A Figura 19 mostra o resultado da probabilidade acumulada de acerto em função da posição na lista de resultados, obtido pelo estudo de Ceuster e Dujardin (2015) com Evofinder ${ }^{\circledR}$, em comparação com o estudo anterior de De Kinder, Tulleners e Thiebaut (2004) com IBIS ${ }^{\circledR}$, demonstrando que houve praticamente um dobro na efetividade em posicionar a amostra correta na primeira posição da lista de resultados. 
Figura 19 - Gráfico representando a porcentagem cumulativa de acertos na lista de resultados de comparações tanto de pino percussor quanto de marca de culatra (até a posição 30) conforme fornecido pelo Evofinder ${ }^{\circledR}$ e pelo IBIS ${ }^{\circledR}$ Heritage $^{\mathrm{TM}}$.

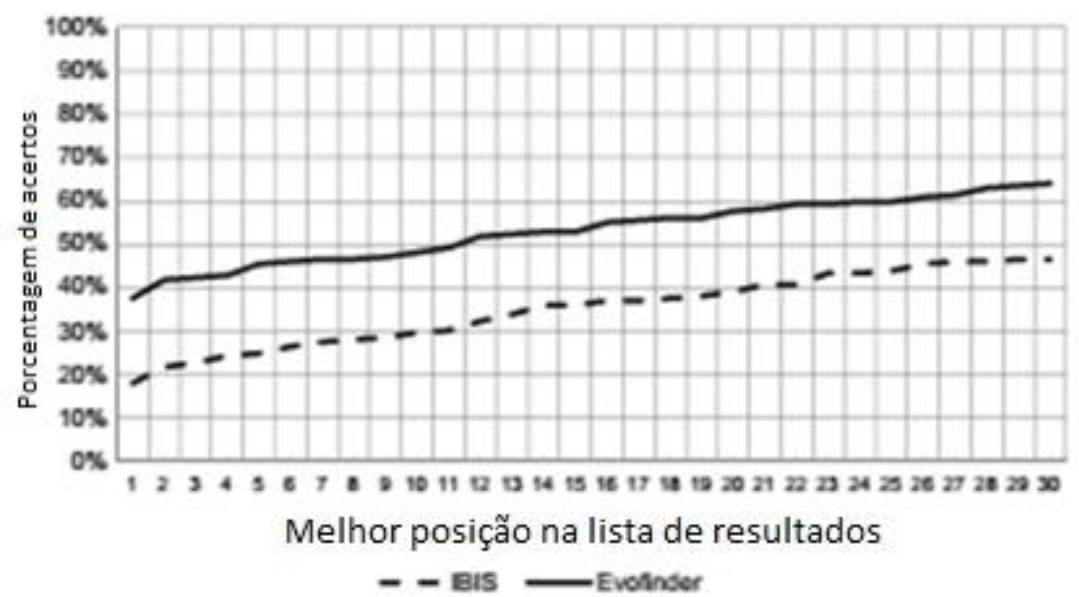

Fonte: Adaptado de Ceuster e Dujardin (2015).

Apesar desta clara melhoria em efetividade do sistema para estas comparações envolvendo o mesmo banco de dados de estojos, o artigo conclui:

O sistema Evofinder ${ }^{\circledR}$ tem demonstrado uma importante melhora em equipamento de imagem balística automática. Sem dúvida isso também é válido para outros equipamentos de ponta disponíveis no mercado atualmente. Não obstante um banco de dados de imagens balística de referência permanece utópica por agora" (CEUSTER; DUJARDIN, 2015, p. 82-83, grifo nosso).

Todos estes estudos resultaram em efetividades dos confrontos automatizados consideradas não ideais, com o problema adicional de que quanto maior o banco de dados mais impreciso os resultados, e as vezes munição de diferentes fabricantes são marcadas diferentes durante o processo de disparo, também influenciando negativamente a efetividade das correlações automatizadas. Os materiais constituintes e as durezas dos estojos, bem como as tolerâncias nos processos de fabricação, são apontados como as bases para estas diferenças (DAVIS, 2010; DE SMET et al., 2008).

Os estudos citados acima foram importantes para avaliação do desempenho destes sistemas quando trabalhando com estojos. Rahm (2012) efetuou outro importante estudo de efetividade do sistema Evofinder ${ }^{\circledR}$ no qual avaliou seu desempenho com estojos e projéteis e propôs ainda um critério quantitativo de efetividade que permite comparar de modo eficiente o desempenho de dois sistemas ou mesmo um sistema operando sob diferentes condições, como 
diferentes calibres, tipos de munição ou qualificações dos operadores. A Tabela 1 especifica o tamanho do banco de dados bem como a quantidade de comparações automatizadas efetuadas.

Para realizar as comparações automatizadas o estudo utilizou as imagens cadastradas em casos da Polícia Federal da Alemanha (BKA). De armas apreendidas eram cadastrados dois estojos e dois projéteis de marcas diferentes. De elementos de munição de locais de crime, três estojos ou três projéteis de uma mesma arma eram registrados no sistema. $\mathrm{O}$ estudo efetuou comparações automatizadas analisando a posição na lista de resultados, respectivamente do segundo ou terceiro elemento de munição.

Tabela 1 - Banco de dados e quantidade de correlações efetuadas por calibre e tipo de elemento de munição no estudo de Rahm (2012).

\begin{tabular}{llcc}
\hline Amostra & Calibre / Raiamento & $\begin{array}{l}\text { Número de } \\
\text { correlações }\end{array}$ & $\begin{array}{l}\text { Média do tamanho } \\
\text { do bando de dados (i) }\end{array}$ \\
\hline CC & 9 mm Luger & 965 & 1075 \\
BUL & 9 mm Luger; 6R, 1.8-2.0 & 329 & 596 \\
CC & 7.65 mm Brown. & 1313 & 804 \\
BUL & 7.65 mm Brown.; 6R, 1.0-1.2 & 233 & 622 \\
CC & 6.35 mm Brown. & 996 & 911 \\
BUL & 6.35 mm Brown.; 6R, 0.8-1.0 & 254 & 317 \\
CC & 9 mm Brown. kurz & 367 & 651 \\
BUL & 9 mm Brown. kurz; 6R, 1.2-1.4 & 63 & 138 \\
BUL & .38, .357; 5R & 119 & 195 \\
CC & 9 mm PA Knall & 977 & 943 \\
CC & 8mm Knall & 326 & 356 \\
\hline
\end{tabular}

$\mathrm{CC}=$ cartridge case $($ estojo); BUL = bullet (projétil)

Fonte: Adaptado de Rahm (2012).

Para análise foram incluídos na lista de resultados a posição da segunda ou terceira amostra da mesma arma até a posição 20 (vinte). Considerando todos os resultados para um mesmo calibre, o número de acertos em dada posição, dividido pelo número de comparações realizadas, estabelece uma probabilidade de encontrar um acerto até a posição $n$. A probabilidade cumulativa, definida como a soma de todas as probabilidades até a posição $n$, foi plotada em função da posição $n$, e o critério de efetividade foi definido usando uma curva hiperbólica que melhor se ajusta aos resultados como mostrado na Figura 20.

A curva proposta pelo estudo para ajustar aos dados é dada pela equação:

$$
\mathrm{P}(\mathrm{n})=\frac{\mathrm{a} \cdot \mathrm{n}}{\mathrm{n}+\mathrm{b}}+\mathrm{c} \cdot \mathrm{n}, \quad \text { a e c } \in[0,1] \text {, and } \mathrm{n} \in[0, i] \text {. }
$$


Onde:

$i$ é o tamanho do banco de dados (ver Tabela 1); e

$\mathrm{P}$ (n) é a probabilidade cumulativa de um acerto até a posição $n$.

As condições de contorno são:

$$
\begin{aligned}
& \mathrm{P}(i)=1, \\
& \mathrm{P}(0)=0 .
\end{aligned}
$$

Da condição de contorno $\mathrm{P}(i)=1$ segue que:

$$
\mathrm{c}=\frac{i \cdot(1-\mathrm{a})+\mathrm{b}}{i \cdot(\mathrm{b}+\mathrm{a})}
$$

Ou seja, apenas $a$ e $b$ são parâmetros a serem determinados para ajustar a curva aos resultados.

Figura 20 - Padrões de projéteis 9mm Luger; probabilidade de que um acerto seja encontrado além dos $n$ candidatos da lista de resultados.

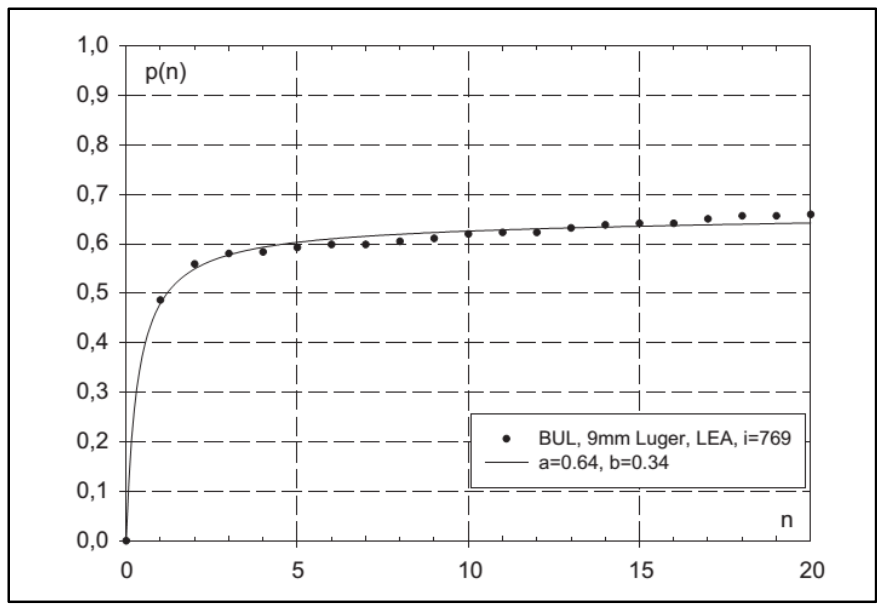

LEA = land engraved area (área marcada dos cheios)

Fonte: Rahm (2012).

Para determinação de um critério de efetividade foi proposto a divisão do gráfico em duas áreas, conforme Figura 21.

Considerando a probabilidade de um acerto em função da posição da lista de resultados (P x $n$ ) da Figura 21 o critério de efetividade $\left(\Gamma_{0}\right)$ foi definido como: 


$$
\begin{gathered}
\Gamma_{0}=\frac{A 2}{A 1+A 2}, \\
\Gamma_{0}=\frac{\int_{0}^{i} P(n) d n}{1 \cdot i}, \\
\Gamma_{0}=a+\frac{c}{2} \cdot i+\frac{k}{i}, \\
\text { com } \quad k=a \cdot b \cdot(\ln b-\ln (i+b)) .
\end{gathered}
$$

Figura 21 - Probabilidade cumulativa de acerto até a posição $i$ da lista de resultados.

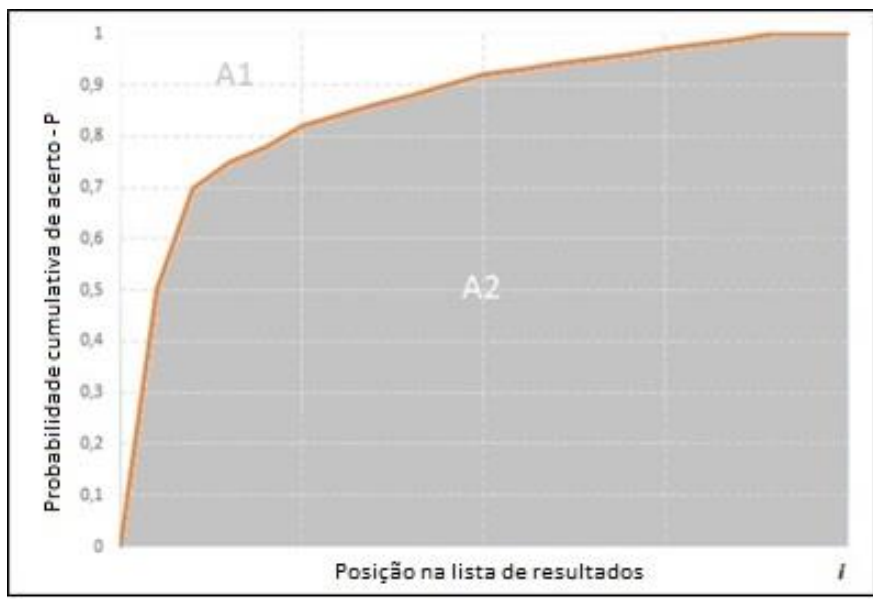

Fonte: Elaborado pelo autor.

Tabela 2 - Efetividades de correlação de Rahm.

\begin{tabular}{lll}
\hline ESTOJO/PROJETIL & \multicolumn{1}{c}{ Calibre / Raiamento } & $\Gamma_{O}$ \\
\hline CC & 9 mm Luger & 0.96 \\
BUL & 9 mm Luger; 6R, 1.8-2.0 & 0.82 \\
CC & 7.65 mm Brown; & 0.95 \\
BUL & 7.65 mm Brown.; 6R, 1.0-1.2 & 0.81 \\
CC & 6.35 mm Brown. & 0.94 \\
BUL & 6.35 mm Brown.; 6R, 0.8-1.0 & 0.87 \\
CC & 9 mm Brown. kurz & 0.90 \\
BUL & 9 mm Brown. kurz; 6R, 1.2-1.4 & 0.92 \\
BUL & .38,.357; 5R & 0.83 \\
CC & 9 mm PA Knall & 0.94 \\
CC & $8 \mathrm{~mm}$ Knall & 0.98 \\
\hline
\end{tabular}

Fonte: Adaptado de Rahm (2012). 
Em resumo, para obter o critério de efetividade foi plotada a probabilidade cumulativa de obter um acerto até a posição $n$ em função da posição $n$, e ajustada a curva hiperbólica descrita pela equação (2.7) em função dos parâmetros $a, b$ e $c$, com $c$ obtido pela equação (2.10). Finalmente o critério de efetividade foi calculado pela equação (2.13).

Rahm (2012) efetuou um passo a mais nas equações (2.7) e (2.10) e considerou o caso especial em que $|a|,|b| \leq 1$ and $i \gg 1$. Os resultados de efetividades calculadas neste estudo em função dos calibres e tipos de elementos de munição estão lançados na Tabela 2.

\subsubsection{Fatores que podem influenciar a efetividade de sistemas de comparação balística automatizada}

Quando se planeja a implementação de um banco de dados de balística deve-se levar em consideração que "a eficiência deste banco dependerá da qualidade e quantidade de dados que contenham" (DE KINDER, 2002, p. 198-199).

Em relação ao tamanho do banco, estudos já citados demonstraram que um aumento no banco de dados prejudica a capacidade do sistema em colocar o elemento de munição da mesma arma nas primeiras posições da lista de resultados apresentados (DE KINDER, TULLENERS E THIEBAUT, 2004; e CEUSTER; DUJARDIN, 2015).

Outro problema relacionado à efetividade destes sistemas diz respeito a qualidade destes elementos de munição inseridos, uma vez que alguns outros fatores podem dificultar a efetividade de correlação dos sistemas automatizados.

Os mesmos estudos de De Kinder, Tulleners e Thiebaut (2004), e de Ceuster e Dujardin (2015), demonstraram que as efetividades dos sistemas diminuem consideravelmente quando comparando estojos de diferentes fabricantes em relação aos estojos de mesmo fabricante.

Com projéteis o problema surge na escolha do tipo a ser selecionado para coleta de padrões, pois projéteis feitos de diferentes materiais podem apresentar um conjunto de estrias diferentes para identificação (BACHRACH, 2000, apud GERULES; BHATIA; JACKSON, 2013, p. 247). Estudo no IBIS ${ }^{\circledR}$ concluiu que a efetividade com projéteis encamisados de cobre foi significativamente melhor que com projéteis de chumbo (BRINCK, 2008, apud GERULES; BHATIA; JACKSON, 2013, p. 248).

Os projéteis também tentem a impactar com grande velocidade os alvos que atingem, ocasionando deformações, diminuindo áreas com marcas com características individuais e também dificultando o processo de aquisição de imagens digitalizada. Torna-se um verdadeiro 
desafio aos equipamentos comerciais disponíveis, escanear projéteis deformados (SJASTAD; SIMONSEN; ANDERSEN, 2014).

Além disso, certas armas não apresentam marcas com características individuais em quantidade ou qualidade suficientes para uma identificação por meio de confronto balístico, algo intrinsicamente relacionado a qualidade de fabricação do cano (BACHRACH, 2006, apud GERULES; BHATIA; JACKSON, 2013, p. 238). Mas este, assim como a questão de projéteis deformados é uma limitação inclusive para exames tradicionais realizados no microscópio óptico comparador.

O uso da arma pode afetar as marcas com características individuais e por isso comparações de elementos de munição coletados com a arma com muito tempo de diferença entre eles podem diminuir significativamente a chance de identificação correta da arma (KOPEL; BURNETT, 2003; e GERULES; BHATIA; JACKSON, 2013).

Esta alteração das marcas com seu uso é um dos fatores que tornam a identificação de arma de fogo diferente das identificações de pessoas por meio de impressões digitais e exame de DNA, que são marcas perenes (KOPEL; BURNETT, 2003).

Ou seja, ainda que a comparação automatizada tenha sido introduzida como um avanço em relação às limitações do confronto balístico tradicional (ver 2.3.6), outros problemas surgiram como apontaram Thomas e Leary (2010), dentre os quais, os algoritmos de correlação tem que operar entre dados com muito ruído e por isso até o momento nota-se baixa efetividade nas correlações automatizadas, o processo de aquisição não se encontra apropriadamente padronizado, e há falta de interoperabilidade entre as diferentes tecnologias.

A questão da padronização é um fator importante pois o planejamento de bancos de dados de balística deve levar em conta a possibilidade de amostrar coletadas e cadastradas em um laboratório poderem serem comparadas com amostras de outro. De Kinder (2002) sugere que para se estabelecer um banco de dados em balística devam ser padronizados: número de padrões, dados a serem armazenados, tipo de armas a serem cadastradas, e rotina de inserção e comparação.

Para isso, ou se adota equipamentos de mesmo fabricante e gera-se um procedimento de calibração ou deve-se buscar uma interconectividade ainda não existente entre aparelhos de diferentes fabricantes.

Para a calibração de aparelhos de uma mesmo fabricante há um exemplo de uso do microscópio confocal com captura de imagens em 3D de projéteis e estojos pelo National Institute of Standards and Technology (NIST) junto com a Alcohol, Tobacco, Firearms, and Explosives (ATF), visando estabelecer uma cadeia de calibrações nos aparelhos de comparação 
automatizada integrantes da rede NIBIN. O trabalho propôs o uso de dois parâmetros para calibração, o valor máximo da função de correlação cruzada (FCC) e a rugosidade superficial, permitindo avaliar as incertezas admissíveis tanto para medidas da topografia dos elementos de munição como para a correlação automatizadas das imagens destes elementos (SONG, et al. 2009).

Quanto à falta de comunicação entre sistemas de diferentes sistemas, na Europa há vários sistemas em uso, que não se comunicam entre si. Neste sentido existe um projeto para implementar uma plataforma, denominada Odyssey, que pretende disponibilizar às organizações policiais dados balísticos de outras agências através da Europa. Quando implementado permitiria aos investigadores relacionarem elementos de munição não apenas a armas locais cadastradas em seu banco de dados próprios, mas a armas cadastradas em qualquer outro banco de dados em toda a Europa, independente do sistema que utilizem (WILSON et al., 2010).

\subsubsection{O Sistema de Identificação Balística (BIS) Evofinder ${ }^{\circledR}$}

O BIS EVOFINDER ${ }^{\circledR}$ é um sistema concebido para captura de imagens em alta qualidade da superfície de projéteis disparados e estojos deflagrados, e que permite armazenamento destas imagens para comparações balísticas manuais ou automatizadas. Suas principais características incluem ${ }^{4}$ :

- receber, tratar e armazenar imagens digitais de alta qualidade em 2D e 3D da superfície de revolução total de projéteis, inclusive fortemente deformados, bem como estojos com qualquer tipo de base ou superfície lateral;

- criar banco de dados regionais de imagens de projéteis disparados ou estojos deflagrados e uni-los em uma única rede de informação; os dados são indexados por campos numéricos e textuais, organizados de acordo com o tipo de arma de fogo com as suas principais características (calibre, número de cheios, largura dos cheios, ângulo e direção do raiamento);

- realizar uma identificação automática de uma imagem de um elemento de munição contra as demais imagens no banco de dados, fornecendo uma lista de imagens mais semelhantes;

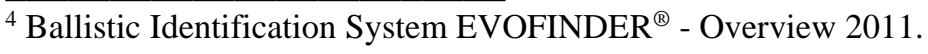


- visualizar em tempo real a superfície de um elemento de munição na tela do monitor, realizando focagem manual ou automática, ou mudando a direção de iluminação;

- carregar até duas imagens anteriormente salvas e movê-las nas janelas de forma independente ou alinhadas, desta forma possibilitando a identificação por comparação manual;

- imprimir imagens e relatórios para ser apresentado no tribunal.

Figura 22 - Rede completa BIS EVOFINDER ${ }^{\circledR}$.

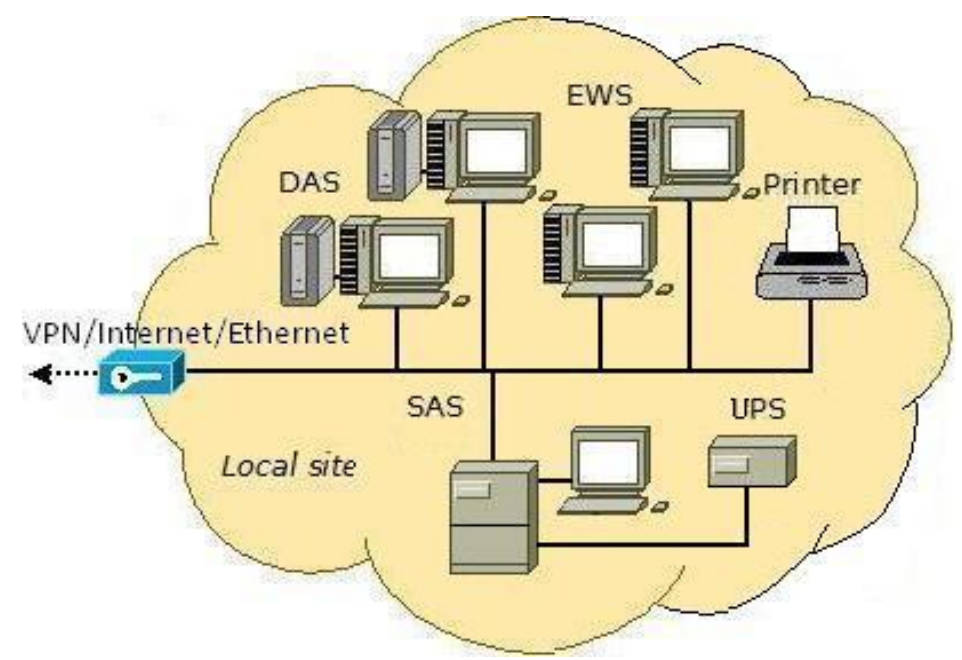

Fonte: Ballistic Identification System EVOFINDER ${ }^{\circledR}$ - Overview 2011, p. 3.

BIS EVOFINDER ${ }^{\circledR}$ inclui três partes principais: Sistema de Análise de Amostras (SAS), Estação de Aquisição de Dados (DAS) e Estação de trabalho dos peritos (EWS) unidos em uma rede única tal qual Figura 22. A quantidade de DAS e EWS pode variar de acordo com as necessidades do cliente.

O DAS é a unidade para escaneamento do elemento de munição e registro no banco de dados, e é composta por acessórios para fixação de estojos e projéteis e um escâner, conectado a um computador pessoal por cabo USB e operado pelo software Scanner Control Center (ver Figura 23).

O modo de funcionamento deste equipamento, a semelhança da grande maioria dos equipamentos do gênero, consiste em capturar imagens da superfície lateral do projétil ou da base do estojo. Tendo armazenado as imagens são utilizados algoritmos de comparação para automatizar a comparação de uma amostra contra as demais do banco de dados, fornecendo como resultado uma lista de amostras mais semelhantes para que o perito examinador possa abrir as imagens e verificar se aquela semelhança apontada determina ou não uma identificação 
positiva, ou seja, se há elementos congruentes significativos para poder se afirmar que são provenientes de uma mesma arma de fogo.

Figura 23 - Estação de Aquisição de Dados (DAS) Evofinder ${ }^{\circledR}$ composta por computador pessoal, escâner e acessórios de fixação de elementos de munição.

Fonte: Elaborado pelo autor.

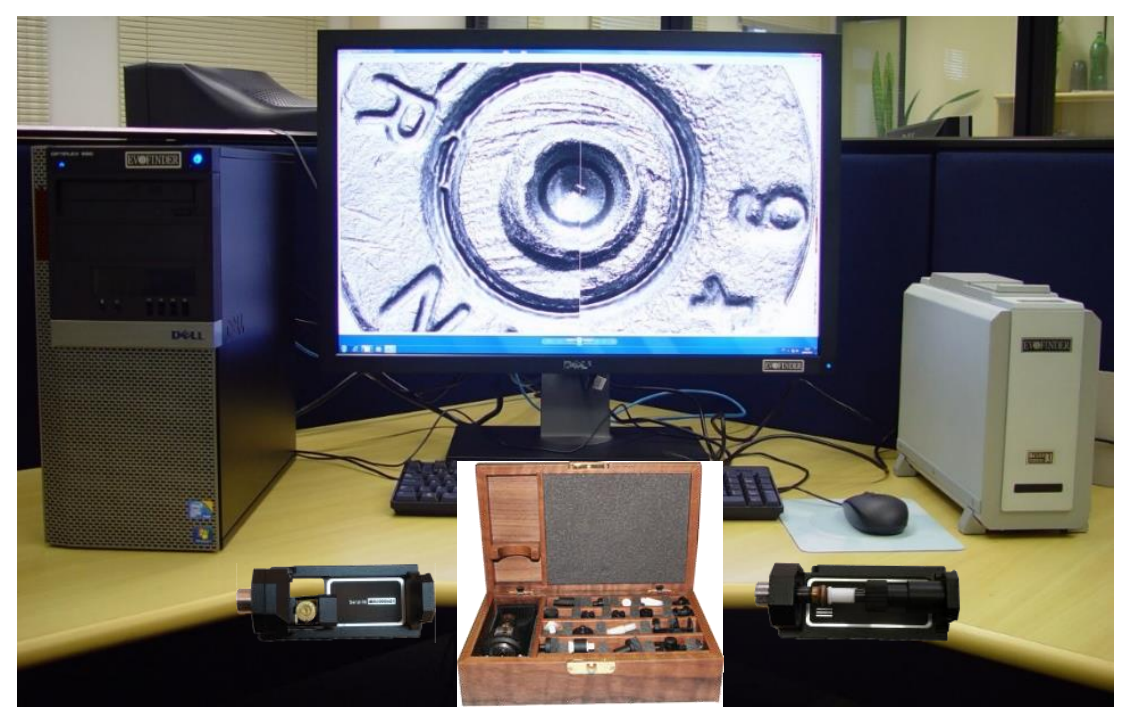

\subsection{TESTE DE DUREZA BRINELL}

Em 1901, J. A. Brinell propôs uma maneira simples e eficaz para medir a dureza de materiais. O teste consiste em aplicar uma força conhecida para pressionar uma esfera de alta rigidez sobre uma superfície sólida, e medir o diâmetro da esfera impressa no material.

Após sua proposição o teste passou a ser muito utilizado e estudos empíricos posteriores relacionaram a dureza medida a propriedades uniaxiais do material (BIWA; STORÅKERS, 1995). Estudo publicado em 2008, por exemplo, descobriu que "a relação entre tensão de resistência à tração e o valor da dureza Brinell é muito intensa" (TIEN, 2008, apud LEYI et al., 2011, p. 2129).

Hill, Storakers e Zdunek (1989) ressaltaram que a popularidade deste teste se deve a: o penetrador esférico ser um instrumento preciso, ainda que robusto e barato; poder ser utilizado diretamente no material sem danificá-lo; haver um procedimento codificado, e totalmente objetivo; e o valor obtido ser indicativo de propriedades básicas do material como resistência à tração e capacidade de endurecimento.

Leyi et al. (2011) propuseram a Figura 24 para explicar o teste Brinell. 
Figura 24 - Princípio de medida de dureza Brinell. F é a força de carregamento, d é o diâmetro da impressão, e D é o diâmetro do penetrador.

Fonte: LEYI et al. (2011).

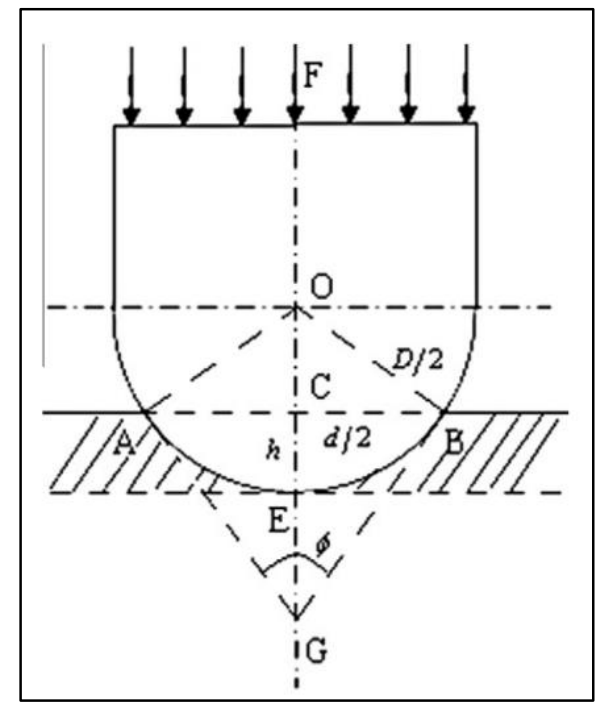

A figura ilustra um penetrador de ponta esférica de diâmetro D sobre o qual atua uma carga F. A ação lenta deste penetrador sobre o material gera a cavidade permanente com altura h e diâmetro d. O valor da dureza Brinell obtida com ponta de carboneto de tungstênio (HBW) é calculada por:

$$
\mathrm{HBW}=\frac{0.102 \times F}{\pi \cdot D^{2}\left(1-\sqrt{1-\frac{d^{2}}{D^{2}}}\right)}
$$

O teste é padronizado para materiais metálicos até o limite de $650 \mathrm{HBW}$ pela norma da Associação Brasileira de Normas Técnicas (ABNT) NBR NM ISO 6506-1:2010.

Para realização do teste, a norma especifica alguns cuidados importantes:

a) A espessura do corpo de prova deve ser de no mínimo oito vezes a profundidade de impressão;

b) Para que seja ensaiada a maior área representativa do corpo-de-prova, deve ser escolhido o maior diâmetro possível da esfera de ensaio;

c) A distância entre a borda do corpo de prova e o centro de cada impressão deve ser de no mínimo duas vezes e meia o diâmetro de impressão médio;

d) A distância entre os centros de duas impressões adjacentes deve ser de no mínimo três vezes o diâmetro de impressão médio; 
e) Deve-se medir o diâmetro de cada impressão em duas direções perpendiculares entre si. A média aritmética das duas leituras deve ser considerada no cálculo da dureza Brinell.

O teste de dureza Brinell é bem indicado para materiais heterogêneos. Para evitar erros de leitura do diâmetro da impressão o raio de curvada de amostra deve ser de no mínimo cinco vezes o diâmetro da esfera penetradora.

O ensaio padronizado por Brinell sugeria a utilização de uma esfera de $10 \mathrm{~mm}$ (dez milímetros) com carga de 3000Kgf (quilograma-força), porém é possível chegar aos mesmos valores de dureza desde que a escolha da carga (F), e diâmetro do penetrador (D), gere uma impressão de diâmetro (d), em que (NBR NM ISO 6506-1:2010):

$$
\text { 0,24. D }<d<0,6 \text {. D. }
$$

Para obter o diâmetro de impressão dentro dos valores especificados deve-se manter constante a relação entre $\mathrm{F}$ e o quadrado do diâmetro, denominado de fator de carga (FC):

$$
\mathrm{FC}=\frac{F}{D^{2}}
$$

O ANEXO I, retirado da NBR NM ISO 6506-1:2010, especifica fatores de carga para diferentes valores de força nominal e diâmetro da esfera penetradora.

Figura 25 - Exemplo de designação da dureza Brinell.

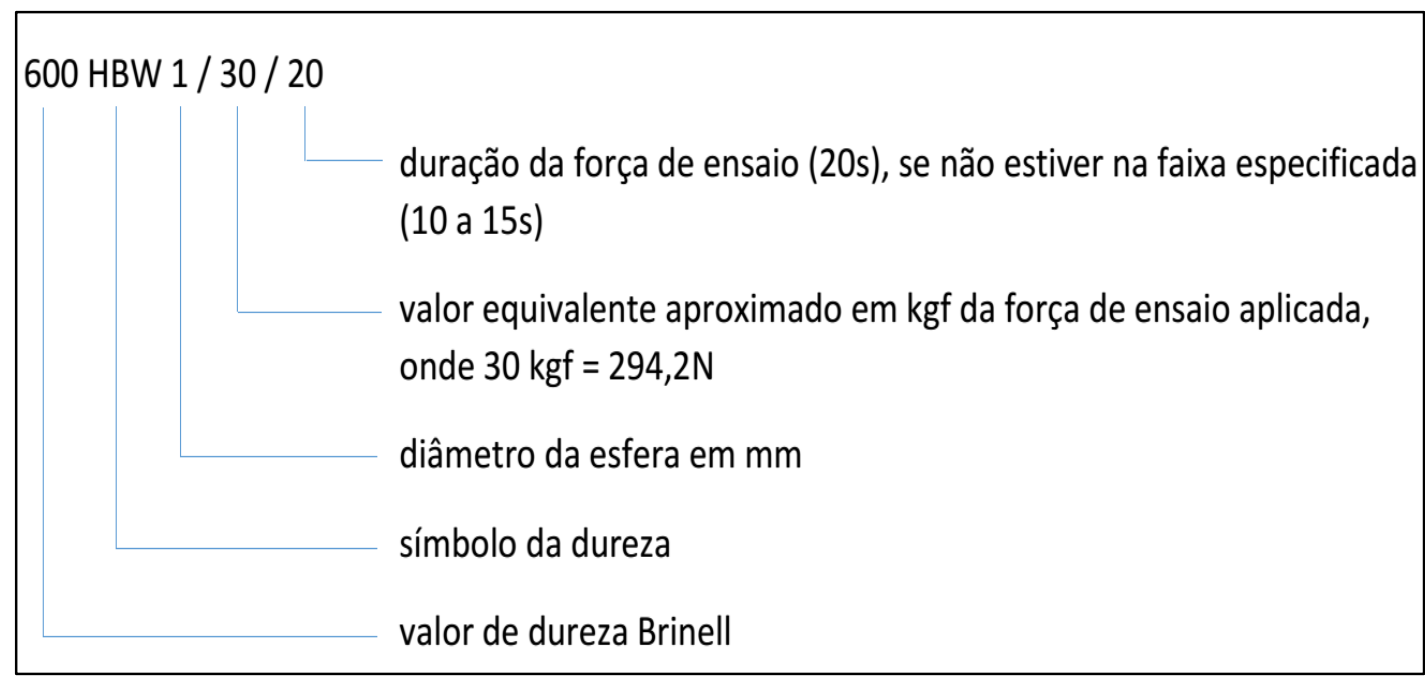

Fonte: NBR NM ISO 6506-1:2010, p. 3. 
As fontes que afetam a incerteza da medida de dureza Brinell incluem erro na medida no diâmetro da impressão, erro na força aplicada, erro no diâmetro do penetrador, falha na estabilidade da máquina ou amostra na medida, e qualidade da superfície da amostra (LEYI et al., 2011).

A Figura 25 contém um exemplo da norma NBR NM ISO 6506-1:2010 de como deve ser a designação da dureza Brinell.

\subsection{RUGOSIDADE SUPERFICIAL}

O acabamento superficial de uma peça pode influenciar seu desempenho, e por isso em muitas aplicações é necessário quantificar a rugosidade da superfície, sendo esta rugosidade entendida como o conjunto de reentrâncias e saliências que a superfície apresenta (PIRATELLI FILHO, 2011).

A norma da ABNT NBR ISO 4287:2002 especifica os termos, definições e parâmetros para a determinação do estado de uma superfície (rugosidade, ondulação e perfil primário) pelo método de levantamento de perfil.

Para determinar a rugosidade de uma superfície inicialmente deve-se considerar que todo corpo apresenta uma superfície real que limita o corpo e o separa do meio ambiente. Escolhendo um plano em uma direção apropriada para mediação que se deseja realizar obtêmse um perfil da superfície, caracterizado pela interseção da superfície real com este plano (ver Figura 26) (PIRATELLI FILHO, 2011).

Figura 26 - Perfil de superfície obtido pela interseção da superfície real do corpo com um plano escolhido.

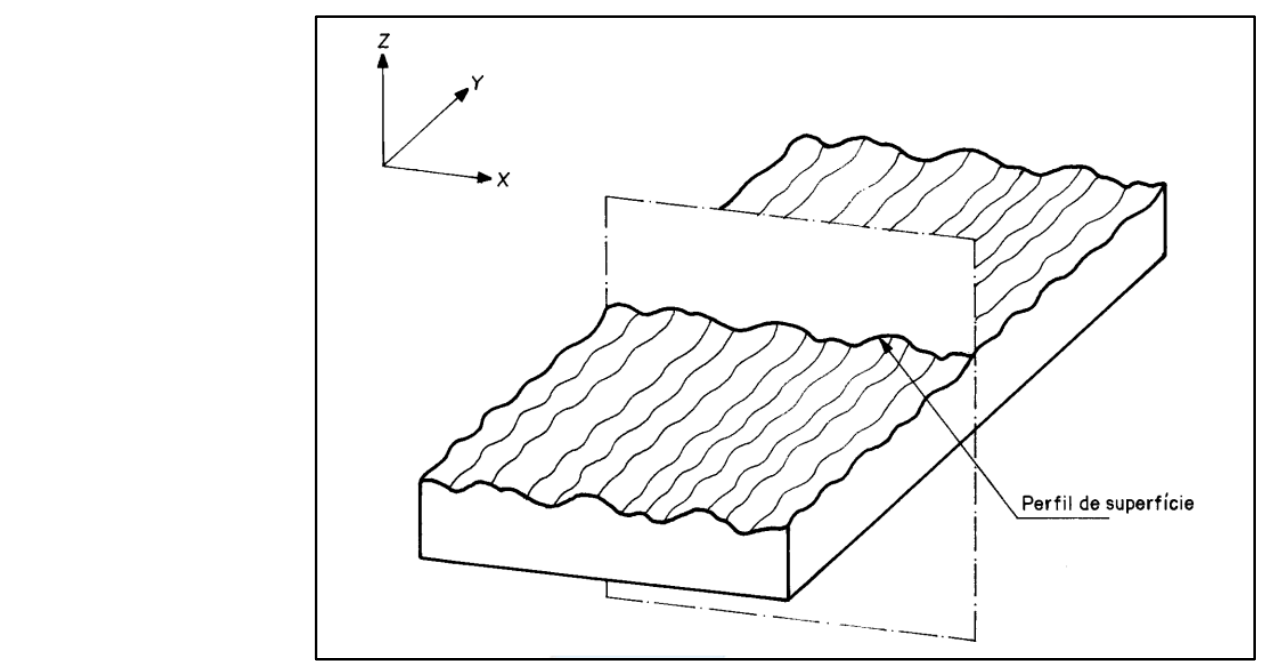

Fonte: NBR ISO 4287:2002, p. 3. 
Por meio de filtros apropriados obtêm-se a rugosidade da superfície (ou textura primária) eliminando-se a textura secundária e o desvio de forma que o perfil efetivo eventualmente apresente (ver Figura 27).

Figura 27 - Obtenção da textura primária (rugosidade) por meio de filtros que eliminam o desvio de forma e a textura secundária do perfil efetivo.

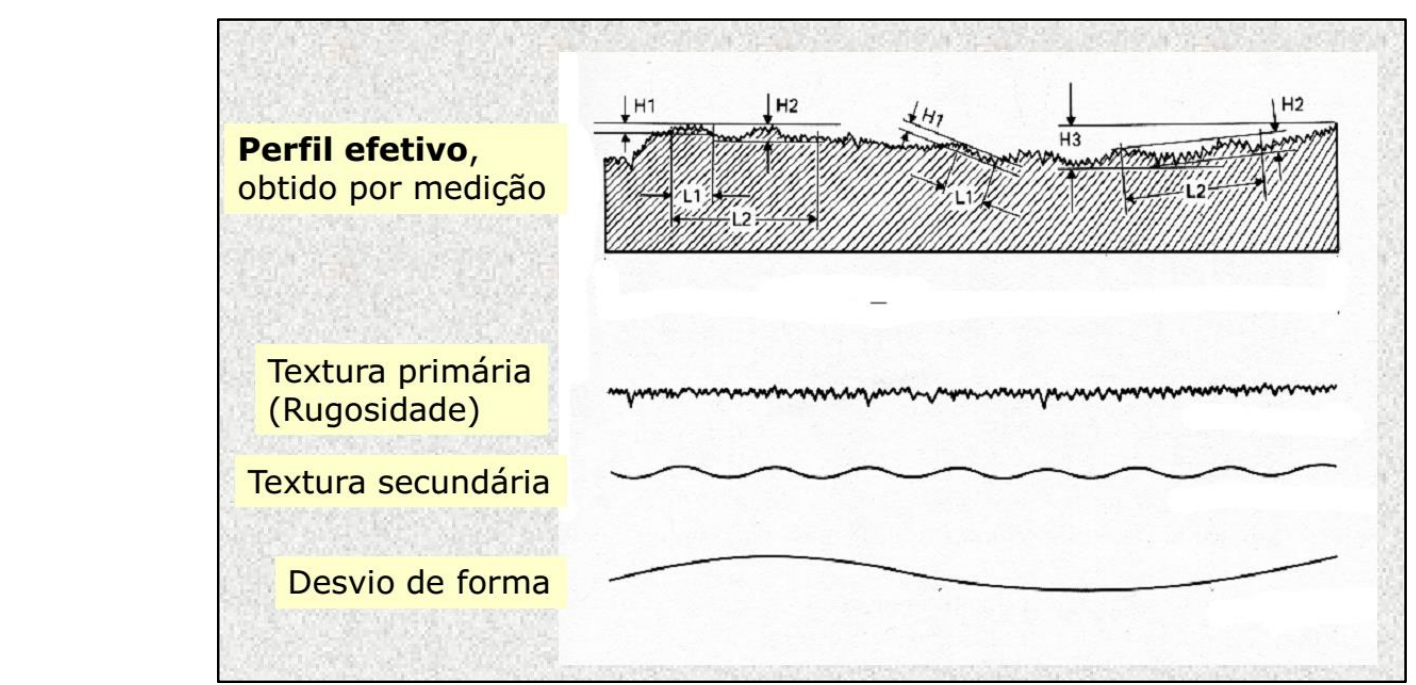

Fonte: PIRATELLI FILHO (2011).

Para minimizar os efeitos de desvio da forma na avaliação da rugosidade estabelece-se o comprimento de amostragem (cut-off $-\lambda_{\mathrm{c}}$ ) para medição. O comprimento de avaliação total (1) será determinado por quantos $\lambda_{c}$ foram especificados para medição (PIRATELLI FILHO, 2011).

Diversos são os parâmetros utilizados para quantificar a rugosidade. A norma convenciona a letra $\mathrm{R}$ para os parâmetros derivados do perfil de rugosidade, e estabelece o sistema de linha média para medições utilizadas na determinação destes parâmetros.

Na Figura 28 há algumas definições para entendimento dos seguintes parâmetros:

- $\mathbf{R a}=$ desvio aritmético médio do perfil avaliado: obtido pela média aritmética dos valores absolutos das ordenadas $\mathrm{Z}(\mathrm{x})$ no comprimento da amostragem.

$$
\mathrm{Ra}=\frac{1}{l} \int_{0}^{l}|Z(x)| d x
$$


- $\mathbf{R z}=$ altura máxima do perfil: Soma da altura máxima dos picos do perfil (Zp) com a maior das profundidades dos vales do perfil (Zv), no comprimento de amostragem.

Figura 28 - Ordenadas $(\mathrm{Z}(\mathrm{x}))$ dos picos $(\mathrm{Zp})$ e vales $(\mathrm{Zv})$ bem como a altura máxima do perfil $(\mathrm{Rz})$ ao longo do comprimento de amostragem $\left(\lambda_{\mathrm{c}}\right)$.

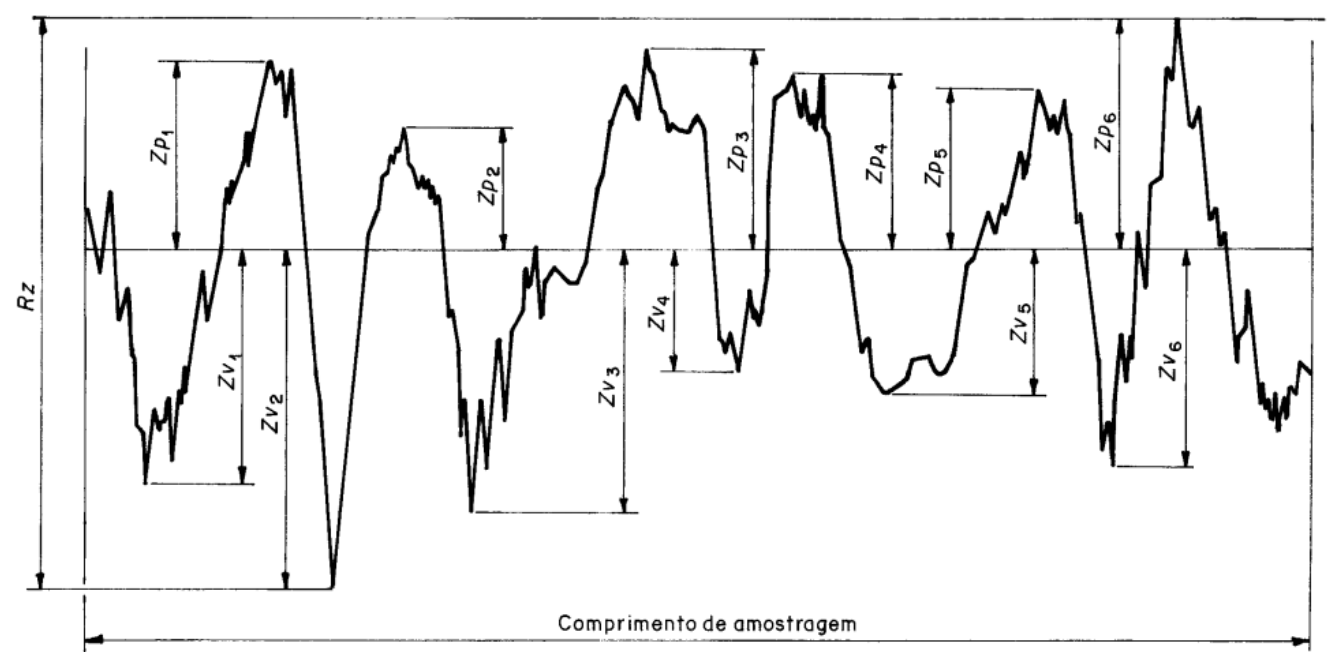

Fonte: NBR ISO 4287:2002, p. 9.

Diversos outros parâmetros são especificados pela norma, mas suas utilidades práticas estão relacionadas à intenção de uso da superfície avaliada.

Para obtenção do perfil efetivo, podem ser utilizados diversos tipos de aparelhos, tais como rugosímetros, que obtêm perfil por contato de uma ponta de diamante, perfilômetros ópticos, baseados em técnicas interferométricas e confocais, e até sondas de varredura microscópica.

Dentre os perfilômetros ópticos, o uso de software para determinação de rugosidade a partir de imagens obtidas em microscópio confocal tem sido muito difundido. Um esboço do funcionamento de um microscópio confocal pode ser visualizado na Figura 29.

No esboço da Figura 29 pode-se visualizar um laser e um orifício de iluminação que produzem um “feixe de luz pontual”. O feixe de luz é 50\% (cinquenta por cento) refletido pelo divisor de feixe para as lentes objetivas, que focam a luz em uma pequena região iluminada no plano focal. A resolução do microscópio é determinada pelas dimensões da região iluminada. A luz refletida pelo objeto é então transmitida pelo divisor de feixe (novamente 50\%) ao orifício de detecção. É essencial para o microscópio confocal que as distâncias entre as lentes objetivas e os orifícios de iluminação e detecção sejam as mesmas, permitindo que a luz refletida do plano em foco passe pelo orifício de detecção enquanto que as refletidas pelos planos acima ou 
abaixo do plano em foco sejam bloqueadas pelo orifício. Desta forma a informação em foco é separada de informação fora de foco. Para formação da imagem se faz necessário ainda escanear o ponto iluminado e armazenar a intensidade da luz refletida em foco no fotodetector. Assim é formada uma imagem confocal $2 \mathrm{D}$ do ponto iluminado. Transladando o objeto após cada imagem 2D registrada obtêm-se uma imagem 3D (BONFANTI; GHAUHARALI, 2000).

Operando acoplados a microscópios confocais diversos software provêm um perfil efetivo da superfície, aplicam filtros e determinam a rugosidade (textura primária) e utilizam as informações de plano focal registradas para calcular diversos parâmetros de rugosidade.

Figura 29 - Esboço de funcionamento de um microscópio confocal.

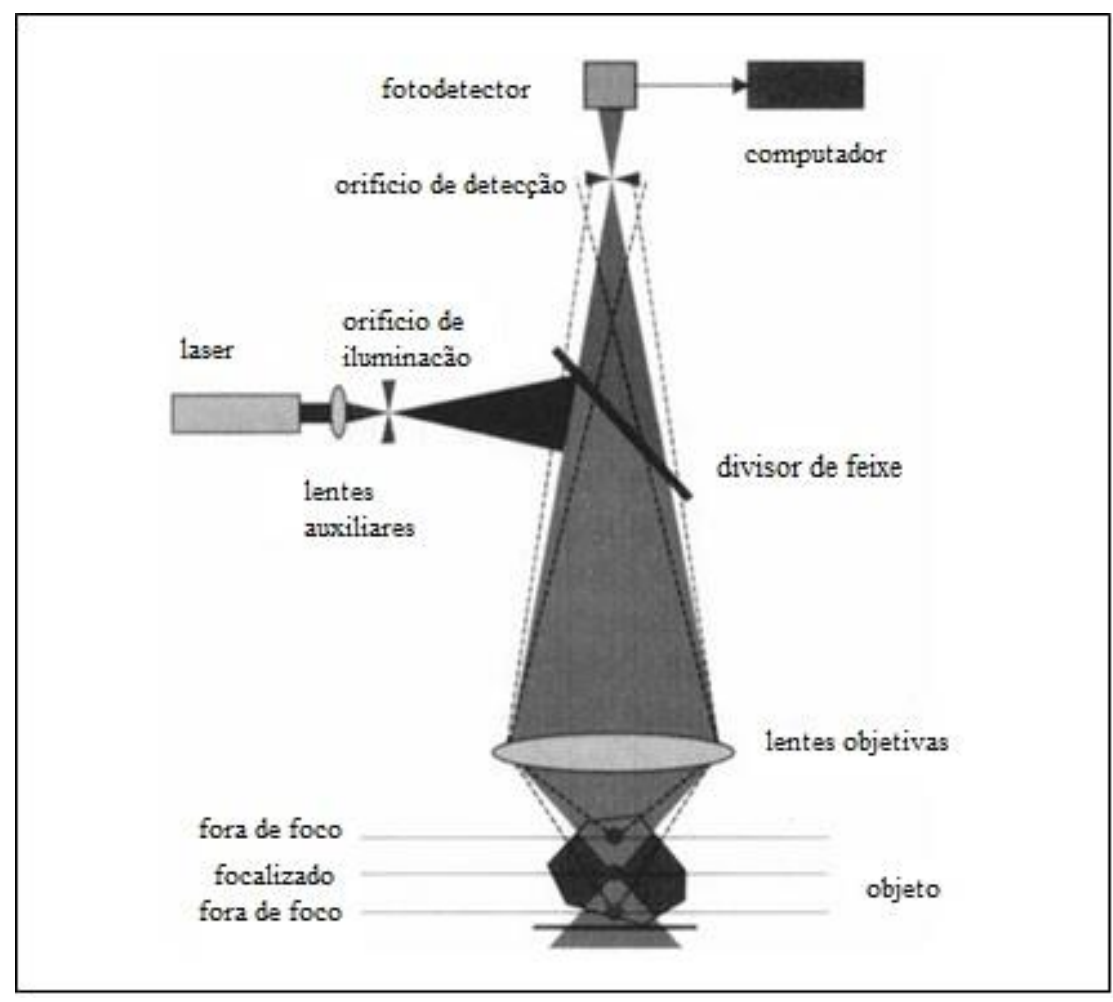

Fonte: Adaptado de Bonfanti e Ghauharali (2000). 
3 METODOLOGIA EXPERIMENTAL Neste capítulo serão apresentadas as metodologias experimentais adotadas nos confrontos automatizados para determinação das efetividades do sistema com diferentes projéteis ou estojos, e de caracterização dos elementos de munição utilizados, com testes de dureza e rugosidade.

\subsection{COMPARAÇÃO AUTOMATIZADA}

Para realização dos confrontos automatizados foram seguidos os seguintes passos:

- $\quad$ seleção de 16 (dezesseis) armas do tipo revólver no calibre .38SPL e 16 (dezesseis) armas do tipo pistola semiautomática no calibre 9mm Luger;

- coleta de padrões destas armas, utilizando 7 (sete) conjuntos de munição no calibre .38SPL e 4 (quatro) no calibre 9mm Luger;

- coleta de projéteis e estojos questionados das armas, utilizando 5 (cinco) conjuntos de munição no calibre .38SPL e 4 (quatro) no calibre 9mm Luger;

- $\quad$ escaneamento dos projéteis e estojos no sistema Evofinder ${ }^{\circledR}$;

- realização dos confrontos automatizados utilizando banco de dados composto por projéteis e estojos, padrões e questionados, das armas selecionadas, e imagens já cadastrados e disponíveis no sistema Evofinder ${ }^{\circledR}$.

Estes passos são detalhados a seguir.

\subsubsection{Armas selecionadas}

Para o estudo foram selecionadas 16 (dezesseis) armas do tipo revólver no calibre .38SPL, sendo 11 (onze) de marca Taurus, com canos de comprimentos variados, e 5 (cinco) de marca Rossi. Uma análise com estereoscópio nos canos revelou que os raiamentos destas armas são caracterizados por bordas retangulares (ver 2.1.2 e Figura 2), 9 (nove) armas possuindo cano com raiamento do tipo 6D (seis raias dextrogiras) e 7 (sete) com raiamento 5D (cinco raias dextrogiras).

Também foram selecionadas 16 (dezesseis) armas do tipo pistola semiautomática no calibre 9mm Luger, sendo 11 (onze) de marca Taurus, 02 (duas) de marca Jerico, 01 (uma) de marca FN (Frabiqué Nationale), 01 (uma) de marca Nurico e 01 (uma) de marca Smith \& 
Wesson. Quanto ao tipo de raiamento, as duas armas de marca Jerico apresentam raiamento do tipo 6D poligonal, enquanto que as demais armas raiamento 6D com bordas retangulares (ver 2.1.2 e Figura 2).

No Apêndice I há uma relação das armas utilizadas com os respectivos números de série e demais características relevantes, e na Figura 30 fotografia destas armas, todas apresentando estado de conversação e limpeza semelhantes entre si.

Figura 30 - Fotografia do conjunto de armas utilizadas nos exames.

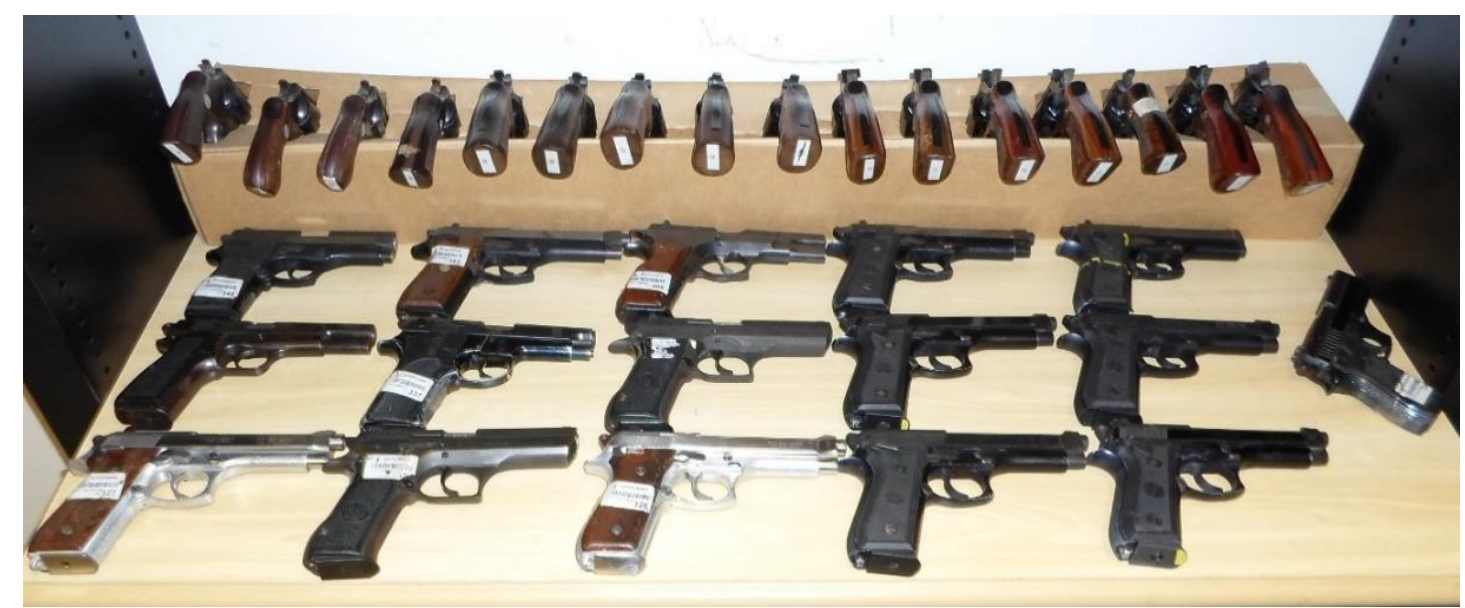

Fonte: Elaborado pelo autor.

\subsubsection{Munições utilizadas nos disparos}

Para este estudo foram utilizados cartuchos de munição de fogo central da fabricante Companhia Brasileira de Cartuchos $(\mathrm{CBC})^{5}$. Os disparos com as armas foram realizados contra tubo de coleta com estopa e algodão (ver Figura 17) e foram utilizadas munições apresentadas na Tabela 3 e na Tabela 4.

Na Tabela 3 deve-se notar que os projéteis .38SPL PP1 e PP7 são do mesmo tipo, mas foram coletados para verificar se após os disparos haveria mudanças nas marcas apresentadas em PP7, que seria o último padrão a ser coletado, em relação à PP1, que seria o primeiro.

Ainda no calibre .38SPL, os projéteis PP2 e PP3 também são do mesmo tipo, a diferença entre eles está no estojo e carga, sendo PP2 acondicionado em estojo de latão e PP3 em estojo niquelado com carga de propelente $+\mathrm{P}$.

A massa dos projéteis é dada em grain (gr), unidade comumente utilizada por fabricantes de munição, sendo sua relação com o grama (g) dada por: 1 gr = 0,06479891 g.

\footnotetext{
${ }^{5} \mathrm{O}$ grupo $\mathrm{CBC}$ Ammo consiste de quarto marcas internacionalmente reconhecidas: Magtech, CBC, Sellier \& Bellot and MEN) (HGA, 2015).
} 
Tabela 3 - Munições utilizadas na coleta de padrões das armas de calibre .38SPL.

\begin{tabular}{|c|c|c|c|}
\hline $\begin{array}{c}\text { Cartucho } \\
\text { íntegro }\end{array}$ & $\begin{array}{c}\text { Elementos de munição } \\
\text { deflagrada }\end{array}$ & Descrição & $\begin{array}{l}\text { Nomenclatura } \\
\text { na dissertação }\end{array}$ \\
\hline & & Projétil $\mathrm{CHOG}^{\mathrm{a}}$ 158gr & PP1 \\
\hline & & Estojo de latão .38SPL & EP1 \\
\hline & & Projétil EXPO ${ }^{\mathrm{b}} 158 \mathrm{gr}$ & PP2 \\
\hline & & Estojo de latão .38SPL & EP2 \\
\hline & & Projétil EXPO 158gr & PP3 \\
\hline & & Estojo niquelado $.38 \mathrm{SPL}+\mathrm{P}$ & EP3 \\
\hline & & $\begin{array}{l}\text { Projétil ETOG }{ }^{\mathrm{c}} \text { Silver Point } \\
125 \mathrm{gr}\end{array}$ & PP4 \\
\hline & $7 \pi$ & Estojo niquelado .38SPL+P & EP4 \\
\hline
\end{tabular}




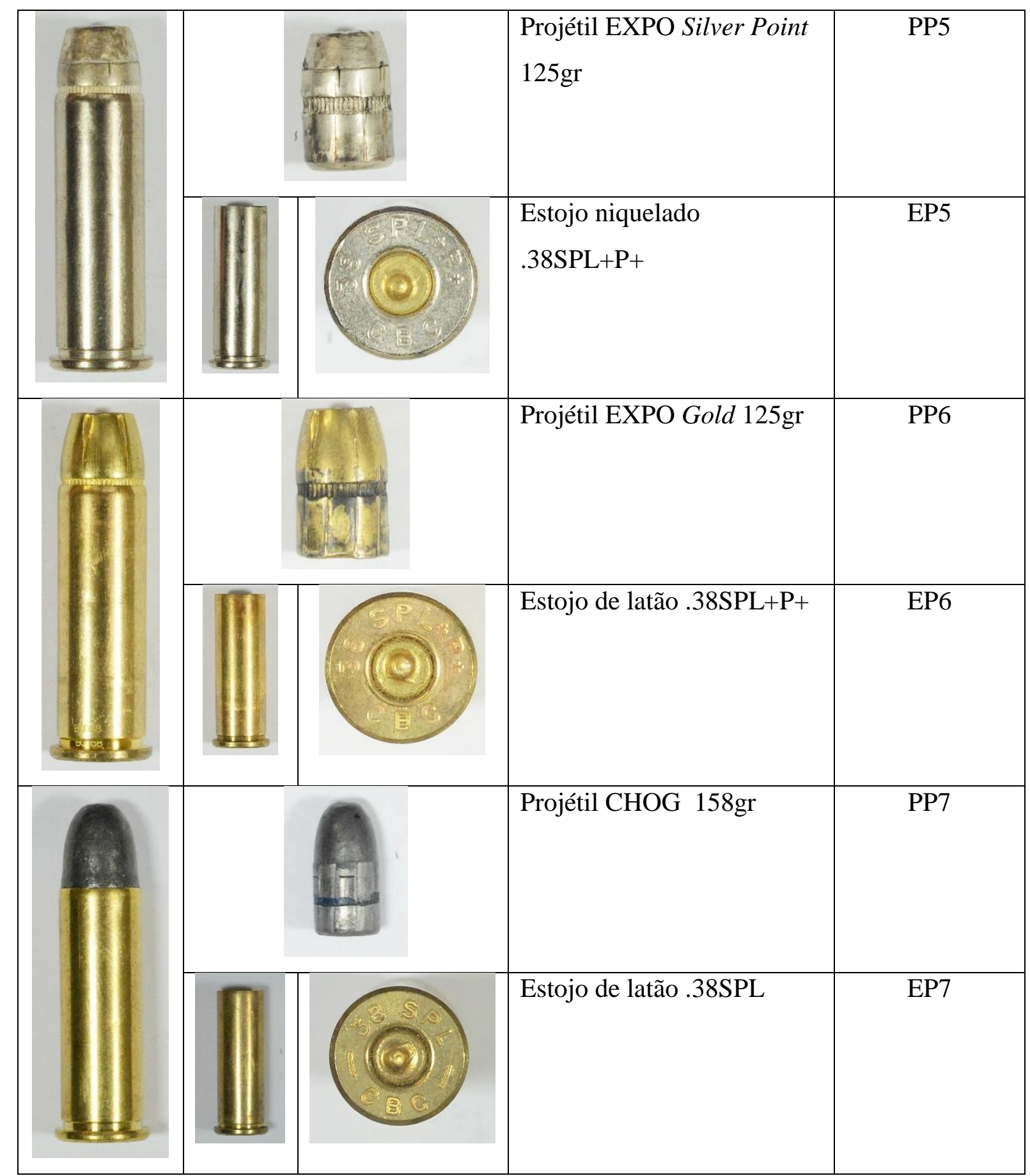

$\mathrm{a}-\mathrm{CHOG}=$ ogival de chumbo; $\mathrm{b}-\mathrm{EXPO}=$ expansivo ponta oca;

$\mathrm{c}-\mathrm{ETOG}=$ encamisado total ogival.

Foram efetuados dois disparos com cada tipo de munição por arma, na ordem apresentada na tabela acima, totalizando 14 (quatorze) projéteis padrões e 14 (quatorze) estojos padrões por arma no calibre .38SPL.

No calibre 9mm Luger também foram efetuados dois disparos por cada tipo de munição por arma, totalizando 8 (oito) projéteis padrões e 8 (oito) estojos padrões por arma no calibre 9mm Luger, conforme tabela a seguir. 
Tabela 4 - Munições utilizadas na coleta de padrões das armas de calibre 9mm Luger.

\begin{tabular}{|c|c|c|c|}
\hline $\begin{array}{c}\text { Cartucho } \\
\text { íntegro }\end{array}$ & $\begin{array}{c}\text { Elementos de munição } \\
\text { deflagrada }\end{array}$ & Descrição & $\begin{array}{l}\text { Nomenclatura } \\
\text { na dissertação }\end{array}$ \\
\hline & & Projétil ETOG 124gr & PP1 \\
\hline & & Estojo de latão $9 \mathrm{~mm}$ & EP1 \\
\hline & & Projétil EXPO 115gr & PP2 \\
\hline & & Estojo de latão 9mm Luger & EP2 \\
\hline & & Projétil EXPO Gold 115gr & PP3 \\
\hline & & Estojo de latão $9 \mathrm{~mm}+\mathrm{P}+$ & EP3 \\
\hline & & $\begin{array}{l}\text { Projétil EXPO COPPER } \\
92,6 \mathrm{gr}\end{array}$ & PP4 \\
\hline & & $\begin{array}{l}\text { Estojo niquelado } 9 \mathrm{~mm} \\
\text { Luger }\end{array}$ & EP4 \\
\hline
\end{tabular}


Para coleta de elementos de munição tratados como questionados no calibre .38SPL, foi observado que dentre as munições utilizadas havia 5 (cinco) tipos diferentes de projéteis e 4 (quatro) tipos diferentes de estojos, portanto, foram realizados mais cinco disparos com cada arma e selecionados os projéteis e estojos questionados conforme Tabela 5 e Tabela 6.

Tabela 5 - Projéteis questionados coletados por arma de calibre .38SPL.

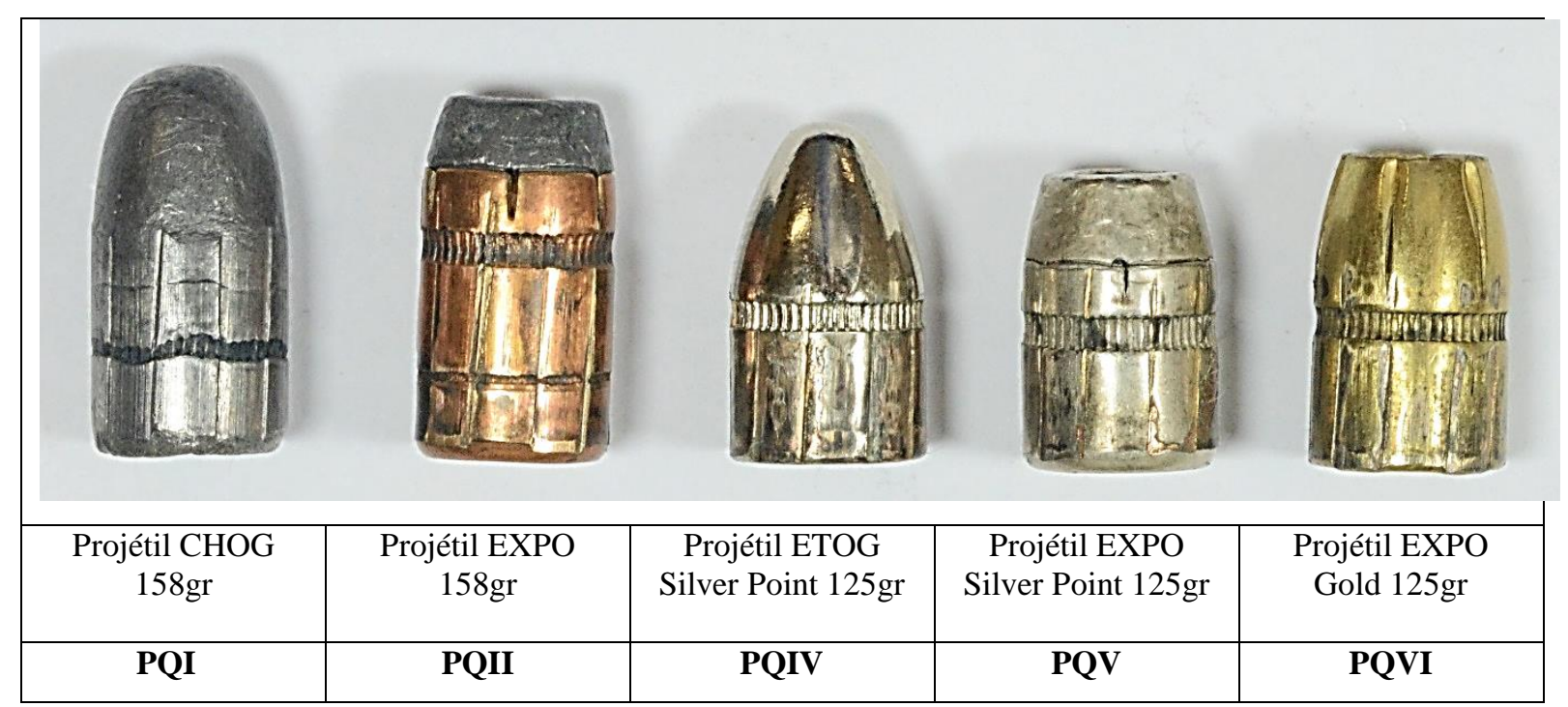

Tabela 6 - Estojos questionados coletados por arma de calibre .38SPL.

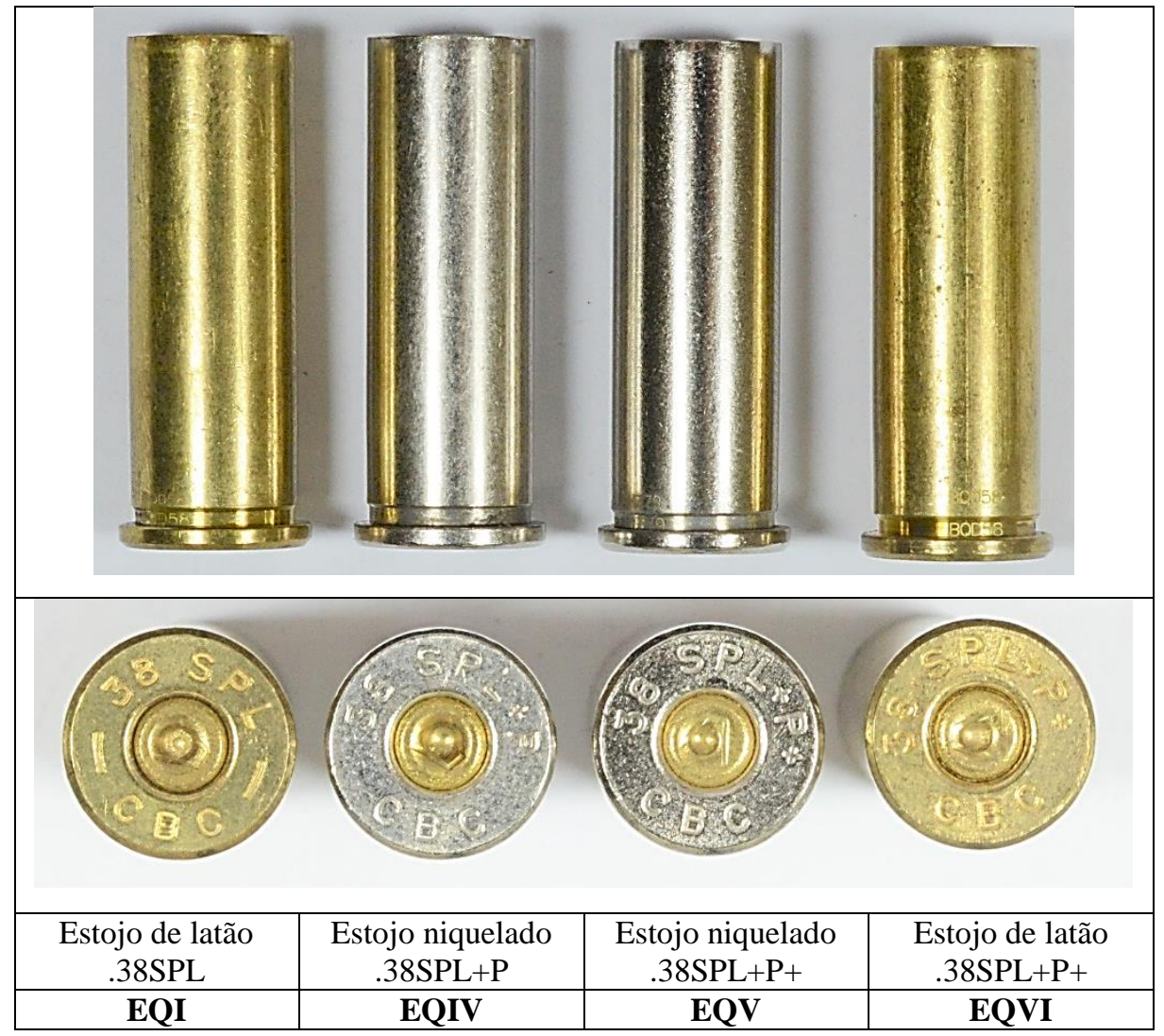


Para o calibre 9mm Luger foram realizados mais 4 (quatro) disparos por arma, e coletados os projéteis e estojos questionados conforme Tabela 7 e Tabela 8.

Tabela 7 - Projéteis questionados coletados por arma de calibre 9mm Luger.

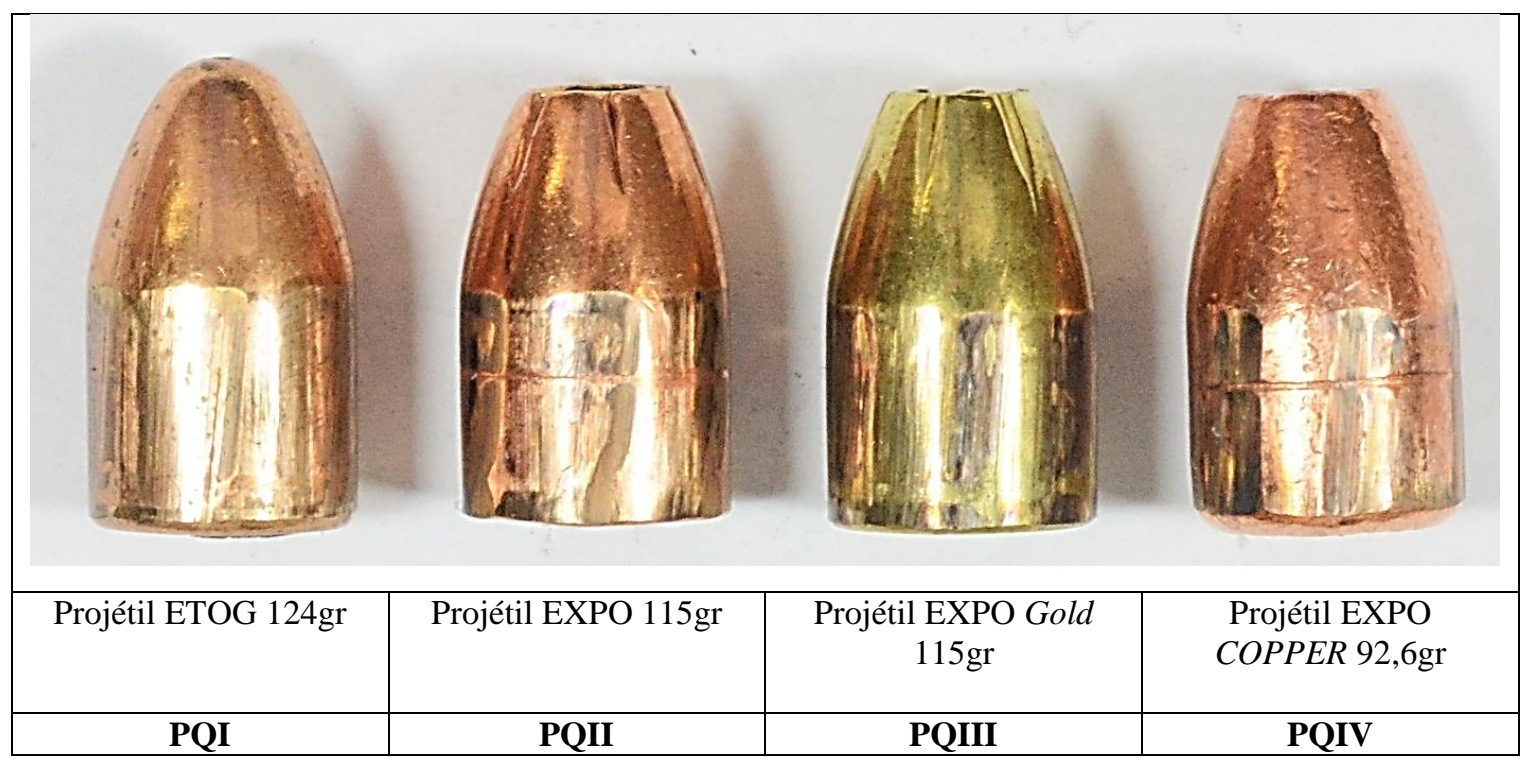

Tabela 8 - Estojos questionados coletados por arma de calibre 9mm Luger.

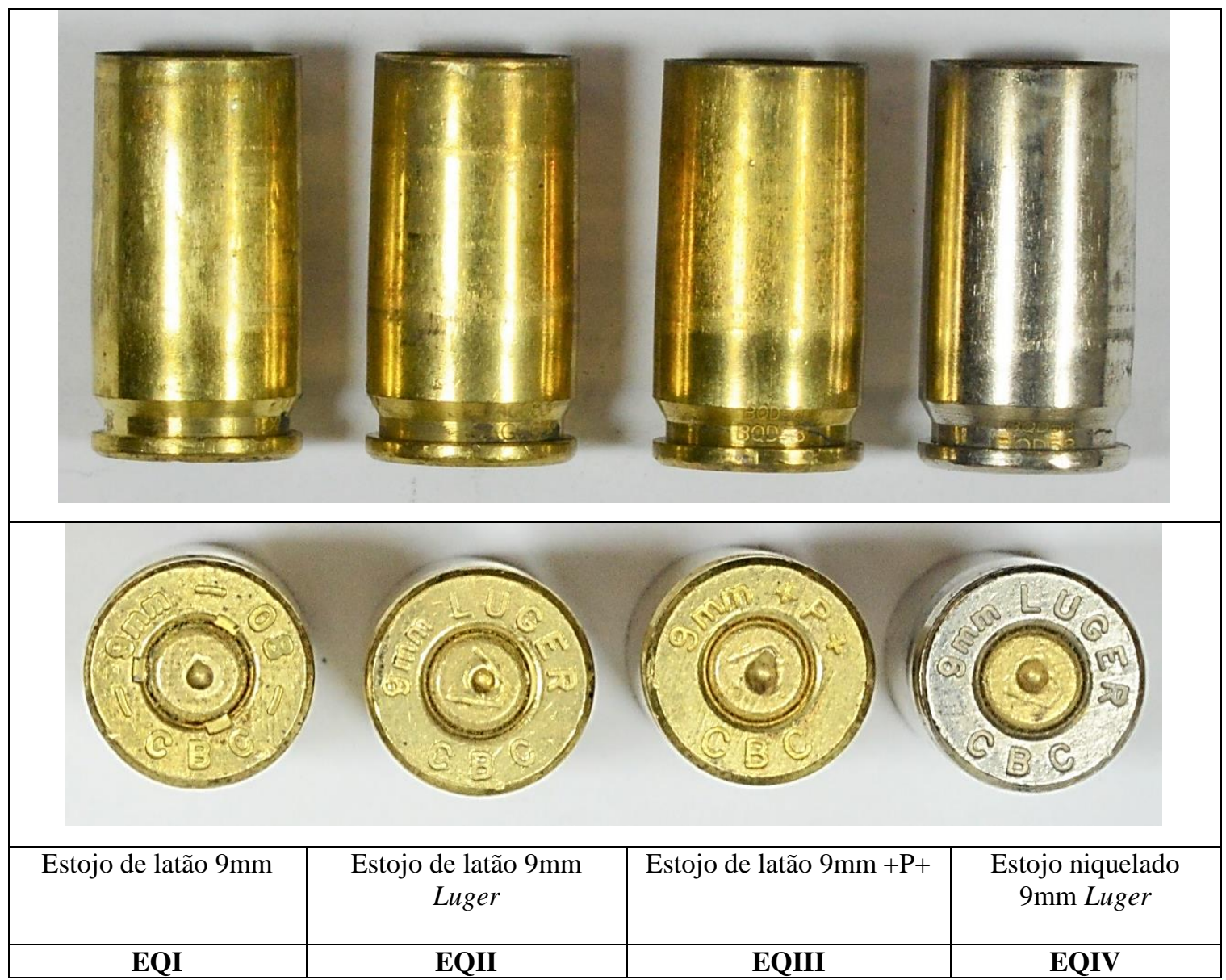




\subsubsection{Escaneamento no sistema Evofinder ${ }^{\circledR}$}

Os projéteis e estojos obtidos foram escaneados no sistema Evofinder ${ }^{\circledR}$.

Para o escaneamento a superfície do projétil é dividida em camadas, e cada camada em quadros, sendo construído um perfil por meio do giro do projétil através de seu eixo longitudinal, e focagem automática ou manual de cada quadro. O processo para escaneamento da base do estojo é semelhante, só que operando sem seu giro, mas com o posicionamento de cada quadro por deslocamento horizontal ou vertical. Isso permite a captura de imagens quadro a quadro, com posterior processamento e união de imagens.

Os parâmetros de operação do aplicativo de controle do escanear (Scanner Control Center) para cada tipo de calibre (.38SPL/9mm Luger) são mostrados na Figura 31.

Figura 31 - Parâmetros de operação do Scanner Control Center para cada tipo de calibre estudado.
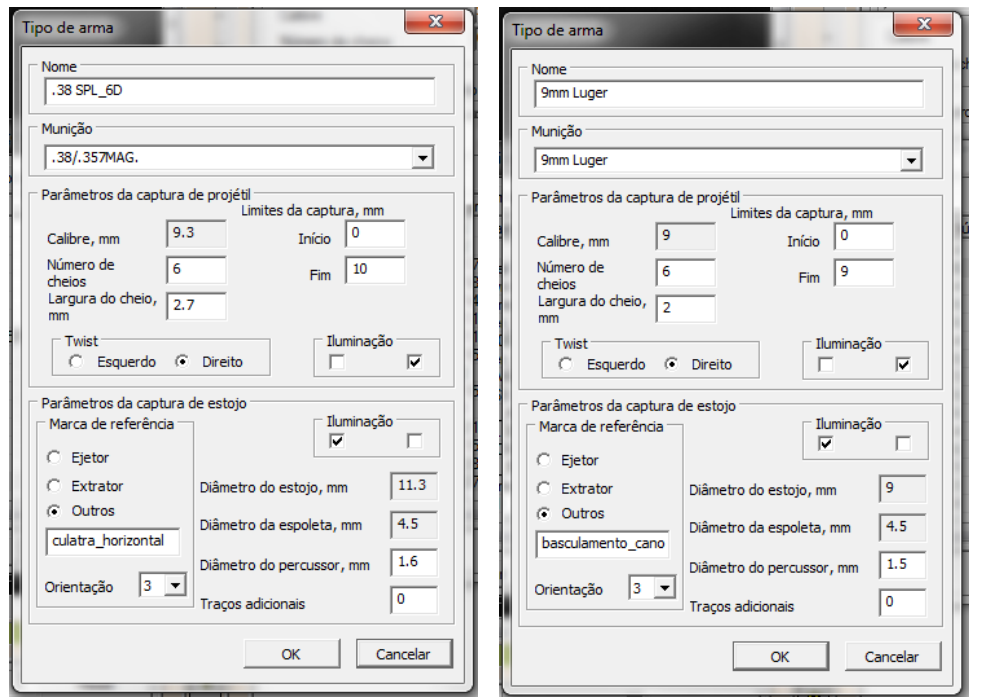

Fonte: Elaborado pelo autor.

A Figura 32 ilustra as etapas dos cadastros dos 976 (novecentos e setenta e seis) elementos de munição coletados.

Após a imagem do projétil ser capturada e salva é necessário realizar a marcação das áreas para comparação automatizada. Em cada cavado do projétil é marcado um retângulo que contenham um conjunto de estrias julgadas relevantes para identificação, denominadas no sistema como "traços secundários de raias". Em cheios do projétil são marcadas regiões que também contenham marcas com características individuais, denominadas pelo sistema como “traços de cavados” por serem produzidas por cavados do cano da arma (ver Figura 33). 
Figura 32 - Ilustração de processo de captura e armazenamento de imagens dos elementos de munição.

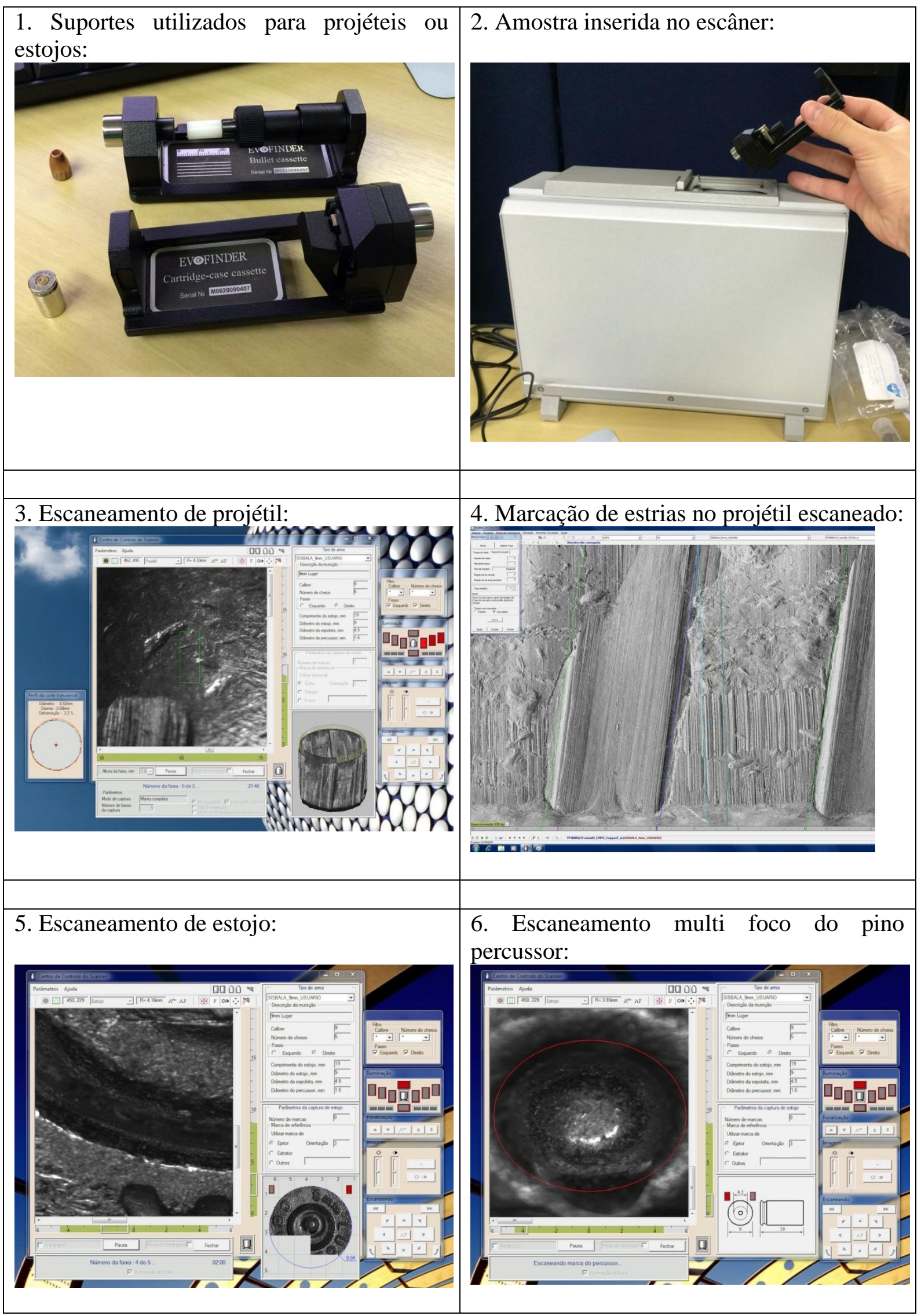


Figura 33 - Escaneamento de projétil quadro a quadro com imagem final combinada, já assinalados os traços secundários de raias e traços de cavados.
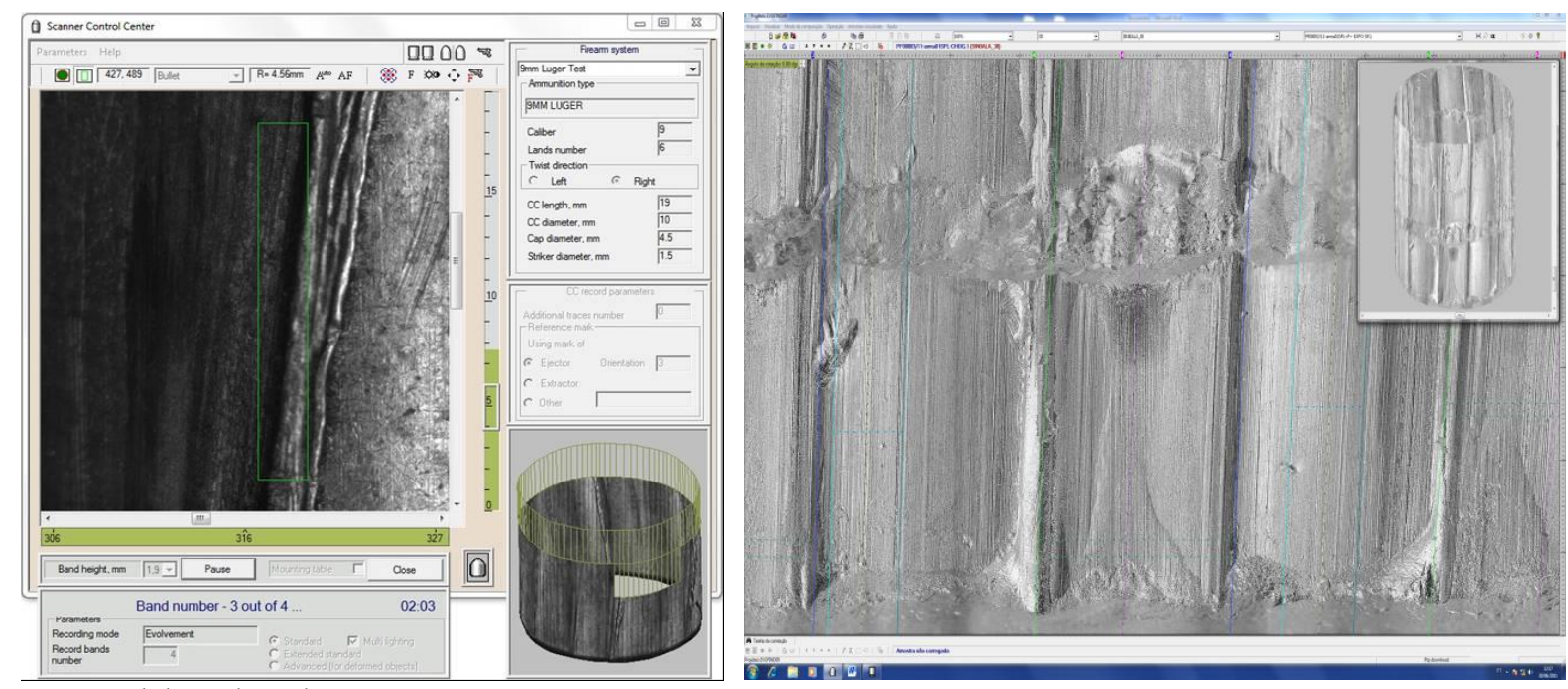

Fonte: Elaborado pelo autor.

Durante a fase final de captura de imagem do estojo é necessário delimitar a posição, formato e borda da marca de pino percussor, sobre a qual o sistema realiza um escaneamento com variação de foco, capturando assim as características relevantes na profundidade da marca.

Como um dos objetivos do estudo é verificar a influência do grau de experiência do operador do sistema nos resultados, os escaneamentos e marcações nos elementos de munição foram realizados em duplicata, de maneira independente, por peritos com experiência em comparação balística e por alunos da Universidade de Brasília sem esta experiência. Posteriormente os confrontos automatizados foram realizados em duplicada utilizando os elementos de munição cadastrados por estes dois grupos.

A Figura 34 ilustra o banco de dados implementado e especifica a quantidade de imagens constante em cada pasta de armazenamento.

\subsubsection{Realização dos confrontos automatizados}

Para o gerenciamento do banco de dados os projéteis são manipulados pela aplicação Bullets EVOFINDER e os estojos pela Cartridge-Cases EVOFINDER. A comparação automatizada é realizada abrindo a amostra no aplicativo apropriado e pressionando o botão de auto identificação, que fornece opções de escolhas quanto ao tipo de comparação e pastas de imagens a comparar. Projéteis podem ser comparados por traços secundários de raias ou por traços de cavados, e estojos por marcas de ferrolho ou marcas de percussor.

Figura 34 - Banco de dados de referência utilizado nas comparações automatizadas. 

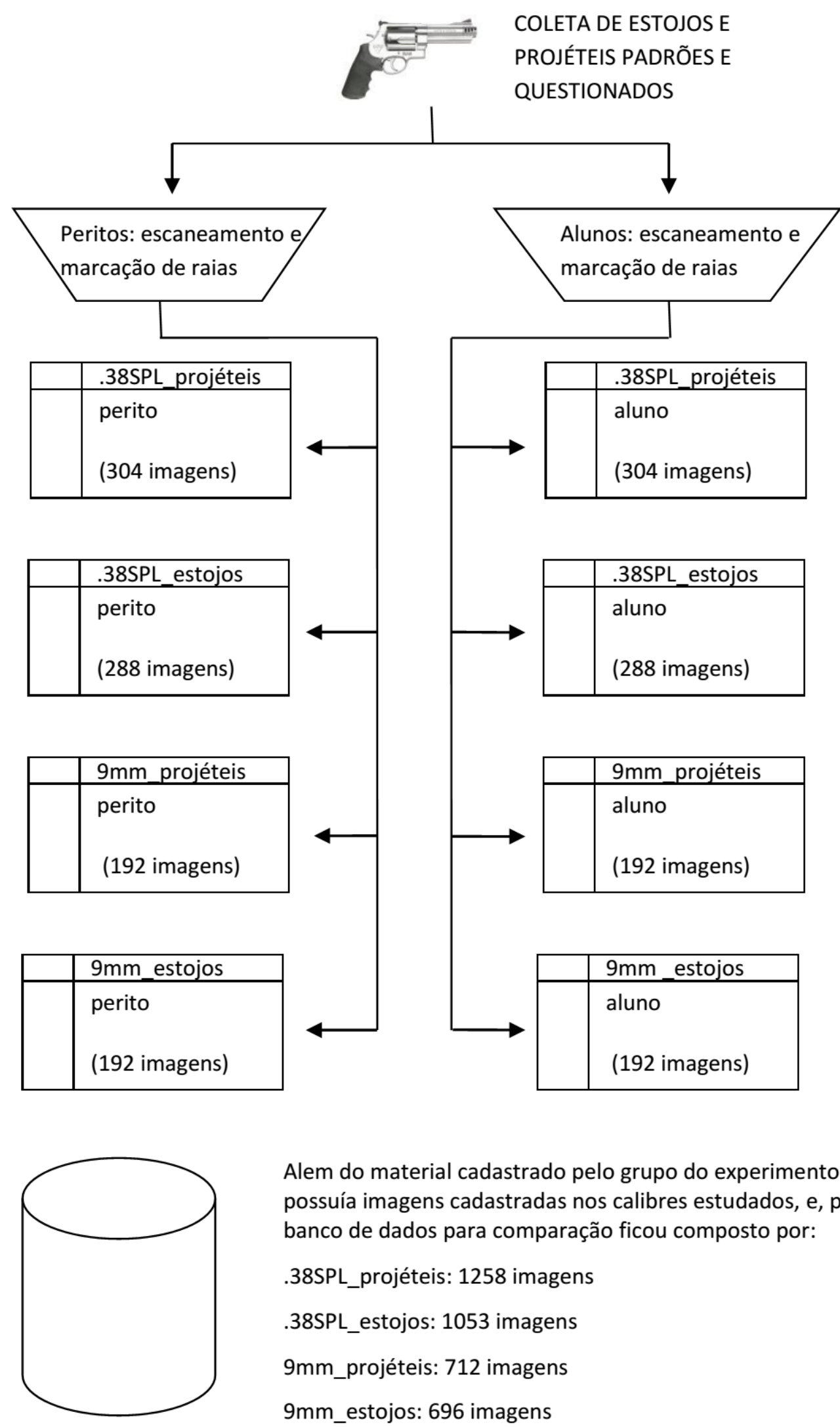

Alem do material cadastrado pelo grupo do experimento o sistema já possuía imagens cadastradas nos calibres estudados, e, portanto, o banco de dados para comparação ficou composto por:

.38SPL_projéteis: 1258 imagens

.38SPL_estojos: 1053 imagens

9mm_projéteis: 712 imagens

9mm_estojos: 696 imagens

Fonte: Elaborado pelo autor. 
O sistema indica as pastas que contenham imagens de arma com características compatíveis com o calibre e cavados da imagem a ser comparada, mas cabe ao usuário selecionar ou não uma pasta, determinando quais imagens devam ser incluídas na comparação automatizada.

Os resultados de uma comparação automatizada compreendem listas em ordem decrescente de similaridade, de acordo com o tipo de comparação que foi escolhida (secundário/cavados; ferrolho/percussor), entre a amostra de referência e as demais amostras constantes nas pastas selecionadas para comparação (ver Figura 36).

Figura 35 - Confronto balístico positivo de duas imagens de projéteis.

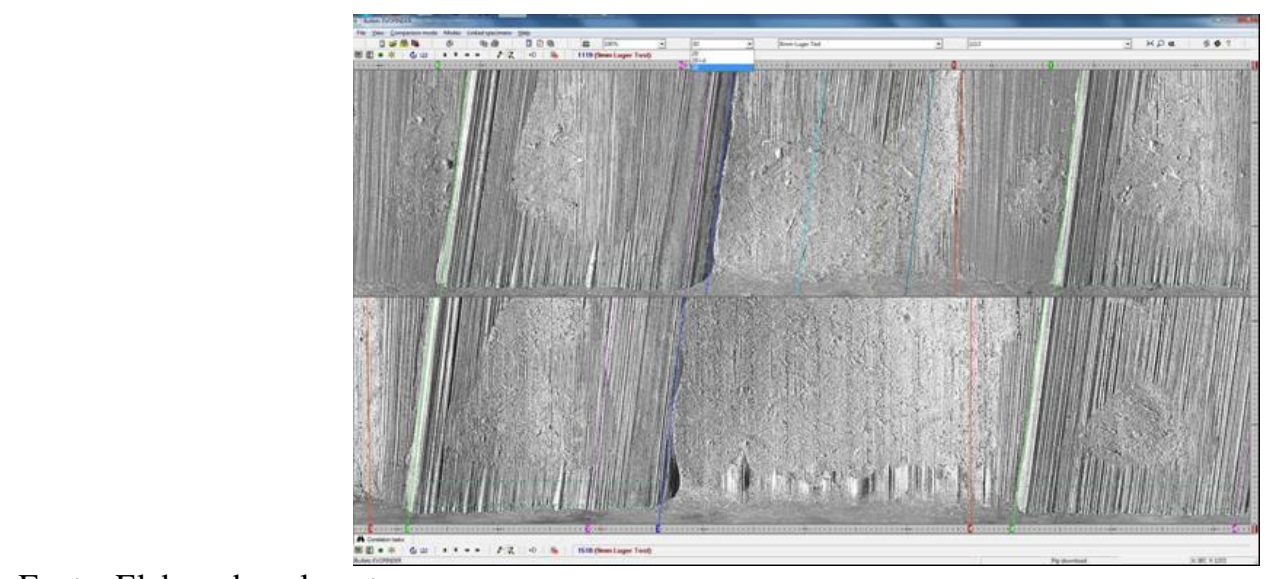

Fonte: Elaborado pelo autor.

Figura 36 - Resultado de auto identificação de projétil, mostrando lista de semelhança por traço secundário de raia.



Fonte: Elaborado pelo autor. 


\subsubsection{Teste preliminar envolvendo projéteis no calibre .38SPL}

Primeiramente foi proposto e executado um teste para avaliar a capacidade do sistema em correlacionar padrões da mesma arma, comparando apenas os projéteis e estojos padrões cadastrados para as 16 (dezesseis) armas de calibre .38SPL entre si.

Para realização destas comparações automatizadas, uma imagem de projétil padrão de arma era carregada e efetuada comparação automatizada por "traço secundário de raia" e por "traço de cavado" contra os demais 223 (duzentos e vinte três) padrões cadastrados, dentre as quais 13 (treze) imagens eram de projéteis padrões da mesma da mesma arma que o padrão carregado. O procedimento para comparações automatizadas de estojos foi o mesmo, efetuando as comparações por "marca de ferrolho" e por "marca de percutor".

O processo se repetiu realizando os confrontos de 7 (sete) tipos de padrões de projéteis/estojos de cada uma das 16 (dezesseis) armas, totalizando 112 (cento e doze) comparações automatizadas de projéteis e 112 (cento e doze) comparações automatizadas de estojos.

\subsubsection{Comparações automatizadas envolvendo todo o banco de dados}

Para verificar da efetividade do sistema em diferentes configurações, variando tipo de projétil ou estojos, questionado ou padrão, bem como tipo de usuário, perito ou aluno, foram efetuadas comparações automatizadas envolvendo todo o banco de dados disponível.

O planejamento escolhido para o experimento foi $\mathrm{o}$ fatorial, no qual, foi selecionada uma quantidade de níveis (ou versões) para cada um dos fatores (variáveis) e realizado o experimento em todas as possíveis combinações (BOX; HUNTER; HUNTER, 2005).

A Tabela 9 especifica por calibre e tipo de elemento de munição a quantidade de variáveis independentes e os níveis ou versões para cada tipo de fator, sendo determinado o número de confrontos automatizados realizados.

Para o confronto automatizado era carregado um elemento de munição questionado, e colocadas na pasta temporária, dois padrões da mesma arma que a do elemento questionado. Além disso na pasta temporária eram acrescentadas todas as imagens disponíveis que fossem compatíveis para comparação, porém provenientes das demais armas utilizadas neste experimento ou do banco de imagens do Evofinder ${ }^{\circledR}$. Desta forma em cada uma das comparações realizadas uma imagem de elemento questionado foi confrontada contras demais 
constantes na pasta temporária, dentre as quais apenas duas eram de padrões da mesma arma que o elemento questionado. A posição destes dois padrões na lista de resultados foi registrada e o padrão colocado em melhor posição, em qualquer uma das listas de resultados geradas para projétil ou estojos, foi considerada.

Tabela 9 - Confrontos automatizados realizados por arma.

\begin{tabular}{|l|c|c|c|c|}
\hline $\begin{array}{c}\text { Elemento de } \\
\text { munição }\end{array}$ & $\begin{array}{c}\text { Tipos de } \\
\text { questionados }^{\mathbf{d}}\end{array}$ & $\begin{array}{c}\text { Tipos de } \\
\text { padrões }^{\mathbf{e}}\end{array}$ & $\begin{array}{c}\text { Tipo de } \\
\text { usuário }^{\mathbf{f}}\end{array}$ & RESULTADOg $^{\mathbf{2}}$ \\
\hline Projétil .38SPL & 5 & 7 & 2 & 70 \\
\hline Estojo .38SPL & 4 & 7 & 2 & 56 \\
\hline Projétil 9mm Luger & 4 & 4 & 2 & 32 \\
\hline Estojo 9mm Luger & 4 & 4 & 2 & 32 \\
\hline
\end{tabular}

$\mathrm{d}-$ ver Tabelas 3 e 4

e - ver Tabelas 5, 6, 7 e 8 ;

$\mathrm{f}$ - aluno ou perito;

$\mathrm{g}$ - representa a quantidade de confrontos automatizados realizados para cada tipo de elemento de munição por arma.

Conforme visto em 3.1.2 os elementos questionados foram designados com algarismos romanos e os padrões com algarismos arábicos. Para designar o tipo de usuário que foi responsável pelo cadastro e marcação da amostra utilizou-se a letra "a" para "aluno" e a letra “p” para perito. A Tabela 10 apresenta exemplos de uso desta nomenclatura.

Tabela 10 - Exemplos de utilização da nomenclatura adotada para configurações do sistema.

Exemplo 1: projétil .38SPL configuração I1A.

A imagem do questionado PQI da arma 1 de calibre .38SPL, armazenada na pasta .38SPL_projéteis_aluno, foi carregada para comparação automatizada. Na pasta temporária foram colocadas as duas imagens PP1 da arma 1, retiradas da pasta .38SPL_projéteis_aluno, e todas as demais imagens de projéteis no calibre .38SPL 6D que não fossem da arma $1 . \mathrm{O}$ confronto foi realizado por marca de traço secundário de raia e por traço de cavado e a melhor posição dos dois padrões da arma 1 nas listas de resultados foi considerada. Caso a melhor posição fosse acima da $20^{\text {a }}$ (vigésima) o valor registrado era 21.

A configuração foi repetida para todas as armas neste calibre e a efetividade do sistema para projétil .38SPL nesta configuração I1A foi calculada (ver 4.1.2). 
Exemplo 2: estojo .38SPL configuração IV3P.

A imagem do questionado EQIV da arma 1 de calibre .38SPL, armazenada na pasta .38SPL_estojos_perito, foi carregada para comparação automatizada. Na pasta temporária foram colocadas as duas imagens de EP3 da arma 1, retiradas da pasta .38SPL_estojos_perito, e todas as demais imagens de estojos no calibre .38SPL que não fossem da arma $1 . \mathrm{O}$ confronto foi realizado por marca de ferrolho e por marca de percussor e a melhor posição dos dois padrões da arma 1 na lista de resultados foi considerada.

A configuração foi repetida para todas as armas neste calibre e a efetividade do sistema para estojo .38SPL nesta configuração IV3P foi calculada (ver 4.1.3).

Exemplo 3: projétil 9mm Luger configuração IV2A.

A imagem do questionado PQIV da arma 18 de calibre 9mm Luger, armazenada na pasta 9mm_projéteis_aluno, foi carregada para comparação automatizada. Na pasta temporária foram colocadas as duas imagens PP2 da arma 18, retiradas da pasta 9mm_projéteis_aluno, e todas as demais imagens de projéteis no calibre 9mm Luger 6D que não fossem da arma 18. Foi considerada a melhor posição dos dois padrões da arma 18 nas listas de resultados do confronto automatizado.

A configuração foi repetida para todas as armas neste calibre e a efetividade do sistema para projétil 9mm Luger nesta configuração IV2A foi calculada (ver 4.1.4).

\section{Exemplo 4: estojo 9mm Luger configuração I4P.}

A imagem do questionado EQI da arma 18 de calibre 9mm Luger, armazenada na pasta 9mm_estojos_perito, foi carregada para comparação automatizada. Na pasta temporária foram colocadas as duas imagens EP4 da arma 18, retirada da pasta 9mm_estojos_perito, e todas as demais imagens de estojos no calibre 9mm Luger que não fossem da arma 18. Foi considerada a melhor posição dos dois padrões da arma 18 nas listas de resultados do confronto automatizado.

A configuração foi repetida para todas as armas neste calibre e a efetividade do sistema para estojo 9mm Luger nesta configuração I4P calculada (ver 4.1.6).

Para armas no calibre .38SPL foram realizados 126 (cento e vinte e seis) comparações automatizas por arma e para armas no calibre 9mm Luger, 64 (sessenta e quatro) comparações por arma, totalizando 3040 (três mil e quarenta) comparações automatizadas. Os resultados 
destas comparações permitiram analisar as efetividades do sistema em relação aos parâmetros controlados, ou seja, tipo de projétil ou estojo e qualificação do usuário (ver 4.1).

\subsubsection{Cálculo da efetividade do sistema}

Após serem realizados os confrontos automatizados e tabelados os resultados, as efetividades do sistema foram calculadas.

\subsubsection{Cálculo de efetividade conforme proposto por Rahm (2012)}

A Tabela 11 foi usada, neste caso com dados do teste preliminar de projéteis, para registrar quantas vezes a posição $n$ foi a menor posição em que um padrão da mesma arma que o projétil comparado foi encontrado na lista de resultados, e para calcular a probabilidade de acerto e a probabilidade cumulativa correspondente a cada posição $n$.

Tabela 11 - Resultado dos confrontos automatizados no teste preliminar envolvendo projéteis padrões no calibre .38SPL.

\begin{tabular}{|c|c|c|c|c|c|c|c|c|c|c|c|}
\hline $\begin{array}{l}\text { Posição na lista de } \\
\text { resultados }-n\end{array}$ & 0 & 1 & 2 & 3 & 4 & 5 & 6 & 7 & 8 & 9 & 10 \\
\hline Resultado $^{h}$ & 0 & 103 & 5 & 1 & 1 & 1 & 0 & 0 & 0 & 0 & 0 \\
\hline $\begin{array}{l}\text { Probabilidade de } \\
\text { acerto }^{i}\end{array}$ & 0 & 0,920 & 0,045 & 0,009 & 0,009 & 0,009 & 0,000 & 0,000 & 0,000 & 0,000 & 0,000 \\
\hline $\begin{array}{l}\text { Probabilidade } \\
\text { cumulativa - P }\end{array}$ & 0 & 0,920 & 0,964 & 0,973 & 0,982 & 0,991 & 0,991 & 0,991 & 0,991 & 0,991 & 0,991 \\
\hline $\begin{array}{l}\text { Posição na lista de } \\
\text { resultados }-n\end{array}$ & 11 & 12 & 13 & 14 & 15 & 16 & 17 & 18 & 19 & 20 & \\
\hline Resultado & 0 & 0 & 1 & 0 & 0 & 0 & 0 & 0 & 0 & 0 & \\
\hline $\begin{array}{l}\text { Probabilidade de } \\
\text { acerto }\end{array}$ & 0,000 & 0,000 & 0,009 & 0,000 & 0,000 & 0,000 & 0,000 & 0,000 & 0,000 & 0,000 & \\
\hline $\begin{array}{l}\text { Probabilidade } \\
\text { cumulativa - P }\end{array}$ & 0,991 & 0,991 & 1,000 & 1,000 & 1,000 & 1,000 & 1,000 & 1,000 & 1,000 & 1,000 & \\
\hline
\end{tabular}

$\mathrm{h}$ - quantas vezes nos confrontos esta foi a menor posição encontrado um padrão correto; i - resultado / 112 .

Em seguida foram lançadas em um gráfico as probabilidades cumulativas de acerto $(\mathrm{P})$ em função da posição na lista de resultados $(n)$, no caso da Figura 37, os pontos em azul correspondem aos dados obtidos no teste preliminar de projéteis no calibre .38SPL.

Para os pontos em azul da Figura 37 o estudo de Rahm (2012; ver p. 59 em 2.4.3) propõe utilizar uma curva hiperbólica para ajustar aos dados, com parâmetros $a, b$ e $c$ da equação (2.7).

Para ajustar a curva hiperbólica descrita pela equação (2.7) em função dos parâmetros $a, b$ e $c$, utilizou-se o método dos mínimos quadrados. Para isso, foram dados valores iniciais 
de $a$ e $b$ e calculados os quadrados das diferenças entre as linhas 2 e 3 da Tabela 12. Para minimizar a soma dos quadrados das diferenças (SQ Residual) foi utilizada a função SOLVER do editor de planilhas Microsoft Office Excel, conforme parâmetros mostrados na Figura 38.

Desta forma foram obtidos os parâmetros $a, b$ e $c$, e em seguida calculado o critério de efetividade de Rahm (2012; ver p. 61 em 2.4.3), conforme resultados da Tabela 13 e utilizando a equação (2.13).

Figura $37-\mathrm{P}$ x n para o teste preliminar de projéteis padrões no calibre .38 SPL.

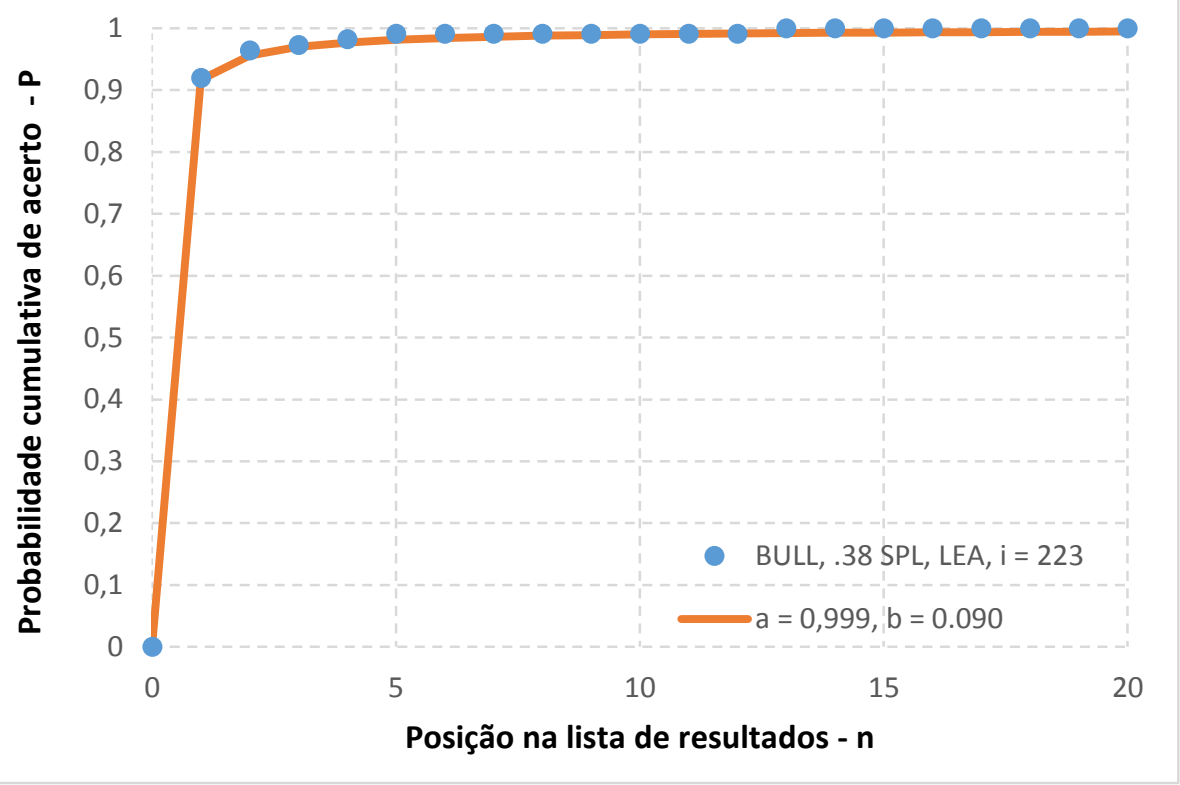

Tabela 12 - Ajuste da curva hiperbólica aos resultados de probabilidade acumulativa em função da posição da lista de resultados pelo método dos mínimos quadrados para o teste preliminar de projéteis padrões de calibre .38SPL.

\begin{tabular}{|c|c|c|c|c|c|c|c|c|c|c|c|}
\hline $\begin{array}{l}\text { Posição na lista de } \\
\text { resultados }-n\end{array}$ & 0 & 1 & 2 & 3 & 4 & 5 & 6 & 7 & 8 & 9 & 10 \\
\hline $\begin{array}{l}\text { Probabilidade } \\
\text { cumulativa }\end{array}$ & 0 & 0,920 & 0,964 & 0,973 & 0,982 & 0,991 & 0,991 & 0,991 & 0,991 & 0,991 & 0,991 \\
\hline $\begin{array}{l}P(n)= \\
a \cdot n /(n+b)+c . n\end{array}$ & 0 & 0,917 & 0,956 & 0,970 & 0,977 & 0,981 & 0,984 & 0,986 & 0,988 & 0,989 & 0,990 \\
\hline $\begin{array}{l}\text { Quadrado da } \\
\text { diferença }\end{array}$ & 0 & $\begin{array}{c}9,764 \\
E-06\end{array}$ & \begin{tabular}{|c|}
6,869 \\
$E-05$
\end{tabular} & $\begin{array}{c}1,082 \\
\mathrm{E}-05\end{array}$ & $\begin{array}{c}2,599 \\
E-05\end{array}$ & \begin{tabular}{|c|}
9,413 \\
$E-05$
\end{tabular} & \begin{tabular}{|c|}
4,618 \\
$E-05$
\end{tabular} & $\begin{array}{c}2,216 \\
\mathrm{E}-05\end{array}$ & $\begin{array}{c}9,822 \\
\mathrm{E}-06\end{array}$ & \begin{tabular}{|c|}
3,630 \\
$E-06$
\end{tabular} & $\begin{array}{c}8,442 \\
\mathrm{E}-07 \\
\end{array}$ \\
\hline $\begin{array}{l}\text { Posição na lista de } \\
\text { resultados }-n\end{array}$ & 11 & 12 & 13 & 14 & 15 & 16 & 17 & 18 & 19 & 20 & \\
\hline $\begin{array}{l}\text { Probabilidade } \\
\text { cumulativa }\end{array}$ & 0,991 & 0,991 & 1,000 & 1,000 & 1,000 & 1,000 & 1,000 & 1,000 & 1,000 & 1,000 & \\
\hline $\begin{array}{l}P(n)= \\
a . n /(n+b)+c . n\end{array}$ & 0,991 & 0,992 & 0,992 & 0,993 & 0,993 & 0,994 & 0,994 & 0,994 & 0,994 & 0,995 & \\
\hline $\begin{array}{l}\text { Quadrado da } \\
\text { diferença }\end{array}$ & \begin{tabular}{|c|}
1,191 \\
$E-08$
\end{tabular} & \begin{tabular}{|c|}
3,222 \\
$E-07$
\end{tabular} & \begin{tabular}{|c|}
6,063 \\
$E-05$
\end{tabular} & $\begin{array}{c}5,318 \\
E-05\end{array}$ & $\begin{array}{c}4,711 \\
E-05\end{array}$ & \begin{tabular}{|c|}
4,208 \\
$E-05$
\end{tabular} & \begin{tabular}{|c|}
3,787 \\
$E-05$
\end{tabular} & $\begin{array}{c}3,430 \\
E-05\end{array}$ & $\begin{array}{c}3,125 \\
E-05\end{array}$ & $\begin{array}{c}2,862 \\
E-05\end{array}$ & \\
\hline
\end{tabular}


Figura 38 - Parâmetros utilizados na função Solver do Microsoft Office Excel para ajustar a curva da hiperbólica, minimizando a soma dos quadrados das diferenças (\$E\$9) em função dos parâmetros $a$ e $b$ (\$E\$10:\$E\$11), conforme Equações 2 e 3 (cálculos da Tabela 12).

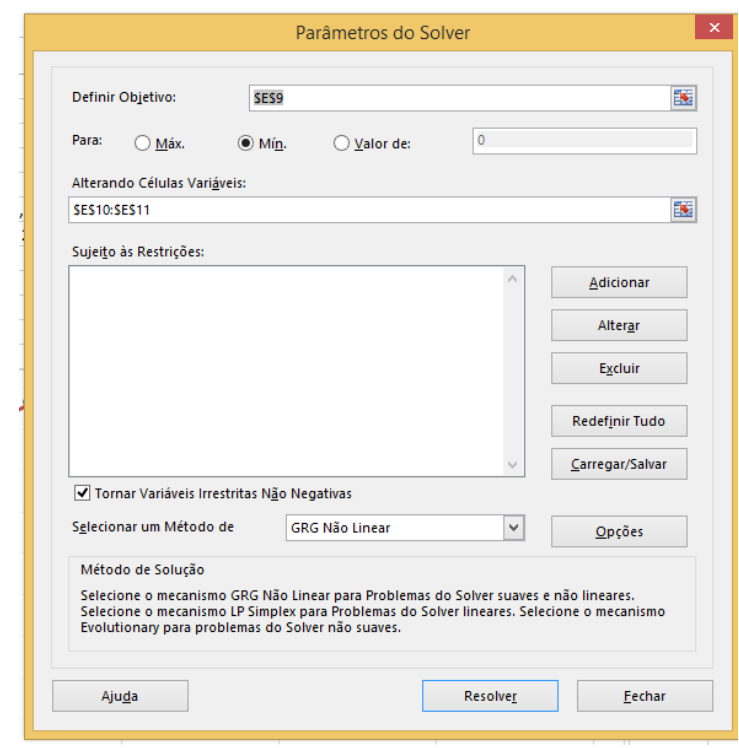

Tabela 13 - Cálculo do critério de efetividade do sistema $\left(\Gamma_{0}\right)$ no teste preliminar de projéteis padrões de calibre .38SPL.

\begin{tabular}{|c|c|c|c|c|}
\hline SQ Residual & $\boldsymbol{a}$ & $\boldsymbol{b}$ & $\boldsymbol{c}$ & $\Gamma_{0}$ \\
\hline 0,001 & 0,999 & 0,090 & 0,0000063 & $\mathbf{1 , 0 0}$ \\
\hline
\end{tabular}

Os mesmos procedimentos foram seguidos para realização de um teste preliminar de efetividade do sistema com estojos padrões de calibre .38SPL. Os resultados dos confrontos automatizados foram lançados na Tabela 14, e o gráfico de probabilidades cumulativas e resultado da efetividade calculada, respectivamente na Figura 39 e Tabela 15.

Tabela 14 - Resultado dos confrontos automatizados no teste preliminar envolvendo estojos padrões no calibre .38SPL.

\begin{tabular}{|c|c|c|c|c|c|c|c|c|c|c|c|}
\hline $\begin{array}{l}\text { Posição na lista de } \\
\text { resultados }-n\end{array}$ & 0 & 1 & 2 & 3 & 4 & 5 & 6 & 7 & 8 & 9 & 10 \\
\hline Resultado' & 0 & 64 & 34 & 4 & 6 & 1 & 1 & 0 & 0 & 0 & 1 \\
\hline $\begin{array}{l}\text { Probabilidade } \\
\text { cumulativa - P }\end{array}$ & 0 & 0,571 & 0,875 & 0,911 & 0,964 & 0,973 & 0,982 & 0,982 & 0,982 & 0,982 & 0,991 \\
\hline $\begin{array}{l}\text { Posição na lista de } \\
\text { resultados }-n\end{array}$ & 11 & 12 & 13 & 14 & 15 & 16 & 17 & 18 & 19 & 20 & \\
\hline Resultado & 0 & 0 & 0 & 0 & 0 & 0 & 0 & 0 & 0 & 0 & \\
\hline $\begin{array}{l}\text { Probabilidade } \\
\text { cumulativa - P }\end{array}$ & 0,991 & 0,991 & 0,991 & 0,991 & 0,991 & 0,991 & 0,991 & 0,991 & 0,991 & 0,991 & \\
\hline
\end{tabular}

$\mathrm{j}$ - quantas vezes nos confrontos o melhor padrão foi colocado nesta posição na lista de resultados 
Figura 39 - P x n para o teste preliminar de estojos padrões no calibre .38SPL.

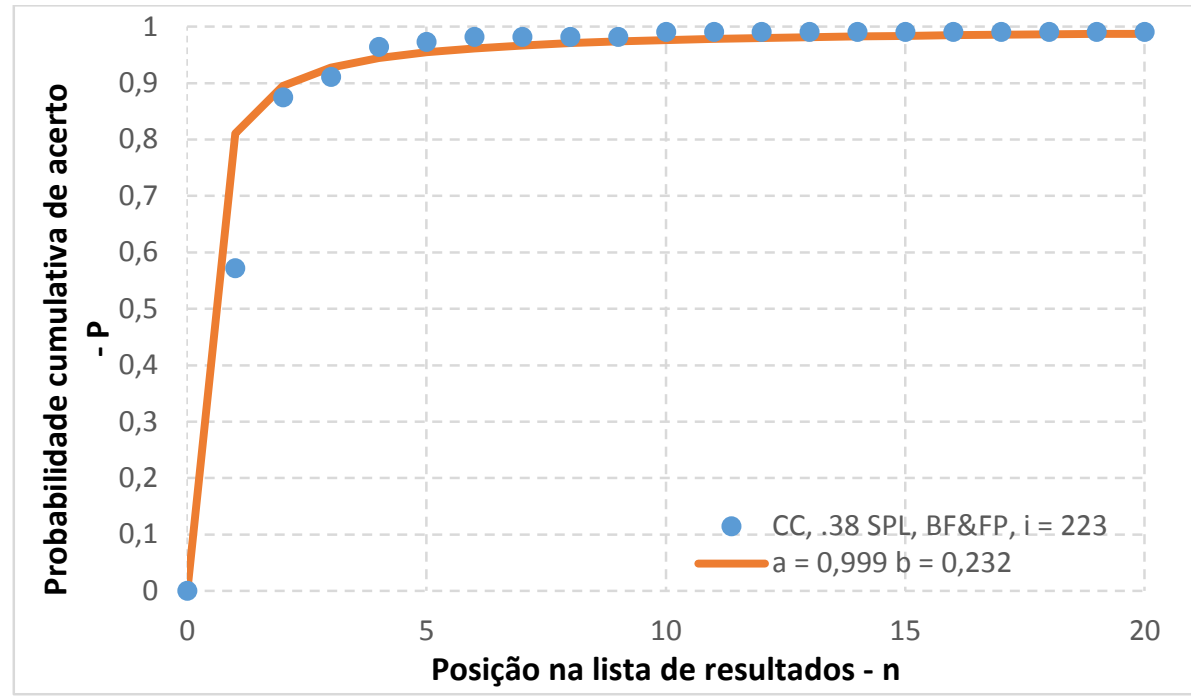

$\mathrm{BF}=$ breech face (face da culatra); $\mathrm{FP}=$ firing pin (percutor).

Tabela 15 - Cálculo do critério de efetividade do sistema $\left(\Gamma_{0}\right)$ no teste preliminar de estojos padrões de calibre .38SPL.

\begin{tabular}{|c|c|c|c|c|}
\hline SQ Residual & $\boldsymbol{a}$ & $\boldsymbol{b}$ & $\boldsymbol{c}$ & $\Gamma_{0}$ \\
\hline 0,060 & 0,999 & 0,232 & 0,0000091 & $\mathbf{0 , 9 9}$ \\
\hline
\end{tabular}

Os resultados deste teste preliminar com estojos e projéteis no calibre .38SPL, demonstraram uma boa capacidade do sistema em identificar padrões da arma correta, porém deve ser enfatizado que estas comparações representaram a busca de 13 (treze) padrões de uma arma num universo de 224 (duzentos e vinte e quatro) imagens confrontadas.

Os critérios de efetividade calculados conforme proposto por Rahm (2012), valores 1,00 e 0,99 , respectivamente para projéteis e estojos, representam a boa efetividade observada nestes testes, mas numa primeira análise, pareceram superestimar a efetividade do equipamento.

As outras efetividades calculadas nos testes com todo o banco de dados apresentaram valores menores e ficou evidente que o modelo proposto por Rahm estava superestimando a efetividade do sistema e apresentando algumas inconsistências, o que levou a proposição de um novo critério de efetividade.

\subsubsection{Novo critério de efetividade proposto.}

Especialmente em casos em que a efetividade nos testes foi muito baixa, foi observado que o critério de efetividade da equação (2.13) superestima a efetividade do sistema. Os resultados da Figura 40 representam dados reais obtidos em três diferentes configurações de 
confrontos com projéteis $9 \mathrm{~mm}$ Luger. Usando equação (2.13) os critérios de efetividade de $\operatorname{Rahm}\left(\Gamma_{0}\right)$ para estes dados são: linha azul 0,89; linha amarela 0,73 ; e linha verde 0,79 .

A razão pela qual a equação (2.13) superestima a efetividade do sistema, para os dados ajustados pela linha azul em particular, é porque esta linha apresenta um grande aclive no final do gráfico $(15<n<20)$. Portanto, a integração da qual surge a equação $(2.13)$, feita de 0 a $i$ na equação (2.12), se torna muito dependente deste comportamento final da linha e não é uma boa representação da melhor efetividade que pode ser visualizada principalmente nos dados ajustados pela linha verde.

Figura 40 - P x n em três diferentes configurações do sistema. Mostra-se os valores para os critérios de efetividade por Rahm $\left(\Gamma_{0}\right)$ e os novos critérios de efetividade proposto por este estudo $\left(\Gamma_{1}\right)$.

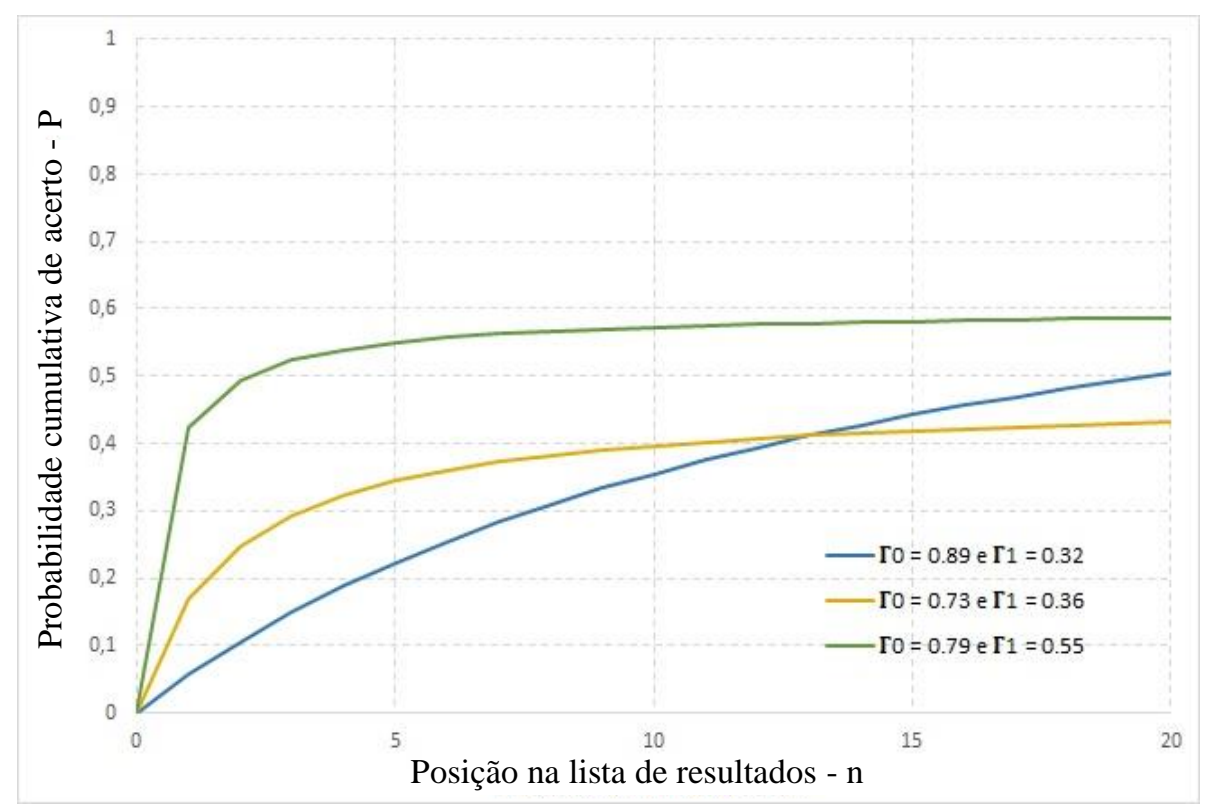

Para corrigir esta inconsistência foi proposto neste estudo uma pequena alteração no cálculo da efetividade para medir os desempenhos do sistema. Uma vez que a lista de resultados sempre foi verificada até apenas a posição 20 (vinte), é mais razoável calcular o critério de efetividade integrando $\mathrm{P}(n)$ de 0 a 20 , ao invés de 0 a $i$. Este novo critério de efetividade $\left(\Gamma_{1}\right)$ foi, portanto, definido como:

$$
\Gamma_{1}=\frac{\int_{0}^{20} P(n) d n}{1.20}
$$




$$
\begin{gathered}
\Gamma_{1}=a+10 c+\frac{k}{20}, \\
\text { com } \quad k=a \cdot b \cdot(\ln b-\ln (20+b)) .
\end{gathered}
$$

Utilizando a equação (3.20) os novos critérios de efetividade $\left(\Gamma_{1}\right)$ para os dados da Figura 40 são: linha azul 0,32; linha amarela 0,36; e linha verde 0,55. Estes novos valores representam mais apropriadamente as diferenças de desempenho do sistema nestas três configurações.

Utilizando este novo critério de efetividade, os dados da Figura 37 (teste preliminar com projéteis .38SPL) levaram a um critério de efetividade de 0,97 (ao invés do anterior 1,00) e os da Figura 39 (teste preliminar com estojos .38SPL) a um critério de efetividade de 0,95 (ao invés do anterior 0,99). Este novo critério de efetividade foi utilizado em todas análises seguintes deste estudo.

\subsubsection{Uso da tabela de Análise de Variância}

Sendo obtidas as efetividades do sistema em relação aos parâmetros estudados utilizou-se um dispositivo proposto por Fisher (BOX; HUNTER; HUNTER, 2005), denominado tabela de Análise de Variância (ANOVA), para avaliar se as diferenças observadas nas efetividades médias, por cada tipo de projétil, ou de estojo, ou de usuário, se tratavam de diferenças aleatórias em torno da média ou diferenças estatisticamente significativas. A Tabela 16 apresenta resultados de efetividades obtidas para três tipos de projeteis .38SPL.

A análise das efetividades médias por tipo de projétil padrão evidencia diferenças de efetividade do sistema em relação ao tipo projétil padrão (PP1, PP2 ou PP3), e entre tipo de usuário (perito ou aluno), mas é necessário verificar se estas diferenças são variações estatisticamente significativas ou variações aleatórias esperadas.

A análise dos resultados da 16, foi lançada na Tabela 17. Nessa, e em todas as outras ANOVAS, foi testada previamente a normalidade dos dados e constância da variância, garantida a independência dos dados e realizados testes com grau de significância de $95 \%$ (noventa e cinco por cento). Os dados foram obtidas por meio da função ANOVA: FATOR DUPLO COM REPETIÇÃO, ou ANOVA: FATOR DUPLO SEM REPETIÇÃO, disponíveis na ferramenta Análise de dados do Microsoft Office Excel. 
Tabela 16 - Efetividades do sistema $\left(\Gamma_{1}\right)$ para confrontos automatizados com projéteis .38SPL.

\begin{tabular}{|c|c|c|c|c|c|c|c|c|}
\hline$P Q$ & USUÁRIO & PP1 & PP3 & PP6 & USUÁRIO & PP1 & PP3 & PP6 \\
\hline 1 & Perito & 0,32 & 0,22 & 0,20 & Aluno & 0,48 & 0,35 & 0,15 \\
\hline II & Perito & 0,40 & 0,91 & 0,72 & Aluno & 0,27 & 0,54 & 0,74 \\
\hline IV & Perito & 0,34 & 0,74 & 0,80 & Aluno & 0,40 & 0,65 & 0,50 \\
\hline V & Perito & 0,25 & 0,65 & 0,70 & Aluno & 0,17 & 0,38 & 0,44 \\
\hline $\mathrm{VI}$ & Perito & 0,25 & 0,70 & 0,86 & Aluno & 0,44 & 0,53 & 0,79 \\
\hline & Média & 0,31 & 0,64 & 0,66 & Média & 0,35 & 0,49 & 0.52 \\
\hline & \multicolumn{2}{|c|}{ Média geral perito } & 0,54 & & \multicolumn{2}{|c|}{ Média geral aluno } & 0,46 & \\
\hline
\end{tabular}

Tabela 17 - ANOVA, fator duplo com repetição, dos dados da Tabela 16.

\begin{tabular}{|c|c|c|c|c|c|c|}
\hline RESUMO & PP1 & PP3 & PP6 & Total & & \\
\hline \multicolumn{7}{|l|}{ Perito } \\
\hline Contagem & 5 & 5 & 5 & 15 & & \\
\hline Soma & 1,56 & 3,22 & 3,28 & 8,06 & & \\
\hline Média & 0,31 & 0,64 & 0,66 & 0,54 & & \\
\hline Variância & 0,00 & 0,07 & 0,07 & 0,07 & & \\
\hline \multicolumn{7}{|l|}{ Aluno } \\
\hline Contagem & 5 & 5 & 5 & 15 & & \\
\hline Soma & 1,76 & 2,45 & 2,62 & 6,83 & & \\
\hline Média & 0,35 & 0,49 & 0,52 & 0,46 & & \\
\hline Variância & 0,02 & 0,02 & 0,07 & 0,03 & & \\
\hline \multicolumn{7}{|l|}{ Total } \\
\hline Contagem & 10 & 10 & 10 & & & \\
\hline Soma & 3,32 & 5,67 & 5,90 & & & \\
\hline Média & 0,33 & 0,57 & 0,59 & & & \\
\hline Variância & 0,01 & 0,04 & 0,06 & & & \\
\hline \multicolumn{7}{|l|}{ ANOVA } \\
\hline $\begin{array}{l}\text { Fonte da } \\
\text { variação }\end{array}$ & $S Q$ & $g l$ & $M Q$ & F-Fisher & valor- $P$ & F crítico \\
\hline $\begin{array}{l}\text { USUÁRIO } \\
\text { PROJÉTEIS }\end{array}$ & 0,050 & 1 & 0,050 & 1,28 & 0,27 & 4,26 \\
\hline PADRÕES & 0,408 & 2 & 0,204 & 5,16 & 0,01 & 3,40 \\
\hline Interações & 0,056 & 2 & 0,028 & 0,71 & 0,50 & 3,40 \\
\hline Dentro & 0,948 & 24 & 0,040 & & & \\
\hline Total & 1,462 & 29 & & & & \\
\hline
\end{tabular}

Para se entender os cálculos de entrada da ANOVA, deve-se notar que em relação a projéteis padrões há dois graus de liberdade $(\mathrm{gl})$ e em relação a usuários há um grau de liberdade, sendo obtidas as entradas de cada linha da ANOVA pela soma dos quadrados (SQ) das diferenças de cada média por tipo de projétil ou usuário em relação à média geral. A média 
dos quadrados (MQ) é obtida pela razão de SQ por gl e o F-Fisher pela razão MQ (variável) por MQ (Dentro), medindo desta forma como a variação dos dados daquela variável se comporta em relação a variação de todos dados do experimento (BOX; HUNTER; HUNTER, 2005).

O correspondente F-Fisher calculado testa a hipótese inicial Ho, de que as médias observadas são variações aleatórias em torno da média, em contrapartida a hipótese H1, de que pelo menos umas das médias é estatisticamente diferente das demais. Dependendo do grau de significância do teste escolhido obtêm-se um F crítico para comparação com F-Fisher.

No caso da tabela acima, a linha USUÁRIO mostra um F-Fisher calculado $(1,28)$ inferior ao F-crítico $(4,26)$, e por isso não pode ser rejeitada a hipótese de igualdade de efetividades do sistema entre usuários, ainda que a média de peritos tenha sido 0,54 e de alunos 0,46 .

Entre os tipos de projéteis padrões, a linha PROJETÉIS PADRÕES mostra um F-Fisher significativo $(5,16)$ em relação ao F-crítico $(2,27)$, o que permite rejeitar a hipótese de igualdade entre tipos de padrões e demonstra que pelo menos uma média dos tipos de projéteis padrões é estatisticamente diferente em relação as demais médias. Análises de variâncias sucessivas devem ser realizadas, retirando os tipos de maior ou menor médias para se evidenciar o tipo de projétil que esta significativamente afetando a efetividade do sistema.

A capacidade do uso da ANOVA para analisar apropriadamente os dados deste estudo não pode ser subestimada pois "A ANOVA é bastante robusta (insensível) à moderada não normalidade e à moderada não igualdade das variâncias dos grupos" (BOX; HUNTER; HUNTER, 2005, p. 140).

\subsection{TESTE DE DUREZA}

Dado as características dos projéteis, como formato cônico e superfície heterogênea nos encamisados, foi escolhido o teste de dureza Brinell para avaliar as durezas dos projéteis.

Para a medição da dureza, foram selecionadas aleatoriamente dois projéteis disparados e dois projéteis não disparados de seis dos sete tipos de projéteis trabalhados no calibre .38SPL (ver Tabela 3 e notar que PP7 é do mesmo tipo que PP1) e de cada um dos quatro tipos de projéteis 9mm Luger (ver Tabela 4).

Os ensaios foram realizados com uso de um durômetro, marca ZWICK/ROELL, modelo ZHU250. Foram utilizados penetradores esféricos de carboneto de tungstênio de diâmetro variável (ver Tabela 18), que atuaram sobre as amostras por 20s (vinte segundos) com carga 
que variou a depender da amostra e diâmetro do penetrador, mas que manteve constante o fator de carga conforme equação (2.17). Com auxílio de uma câmera ajustada ao durômetro foi possível fazer as medições do diâmetro das impressões em duas direções perpendiculares (ver Figura 41).

Para cada projétil analisado, foram realizadas sete impressões em regiões diversas, obedecendo distância da borda e de outras penetrações conforme norma ABNT NBR NM ISO 6507-1:2008.

Tabela 18 - Parâmetros de operação do durômetro nos testes de dureza Brinell.

\begin{tabular}{|c|c|c|c|c|}
\hline \multirow{7}{*}{$\begin{array}{l}\vec{a} \\
\tilde{n} \\
\stackrel{\infty}{n}\end{array}$} & Projétil & Ponta (mm) & Carga (kgf) & $F / D^{2}$ \\
\hline & PP1 & 1 & 2,5 & 2,5 \\
\hline & PP2 & 2,5 & 15,625 & 2,5 \\
\hline & PP3 & 2,5 & 15,625 & 2,5 \\
\hline & PP4 & 2,5 & 15,625 & 2,5 \\
\hline & PP5 & 2,5 & 15,625 & 2,5 \\
\hline & PP6 & 2,5 & 15,625 & 2,5 \\
\hline
\end{tabular}

\begin{tabular}{|c|c|c|c|c|}
\hline \multirow{5}{*}{ 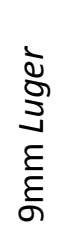 } & Projétil & Ponta $(\mathrm{mm})$ & Carga (kgf) & $F / D^{2}$ \\
\hline & PP1 & 1 & 10 & 10 \\
\hline & PP2 & 1 & 10 & 10 \\
\hline & PP3 & 1 & 10 & 10 \\
\hline & PP4 & 1 & 10 & 10 \\
\hline
\end{tabular}

Figura 41 - Utilização do durômetro ZHU250 em projétil .38SPL PP1.
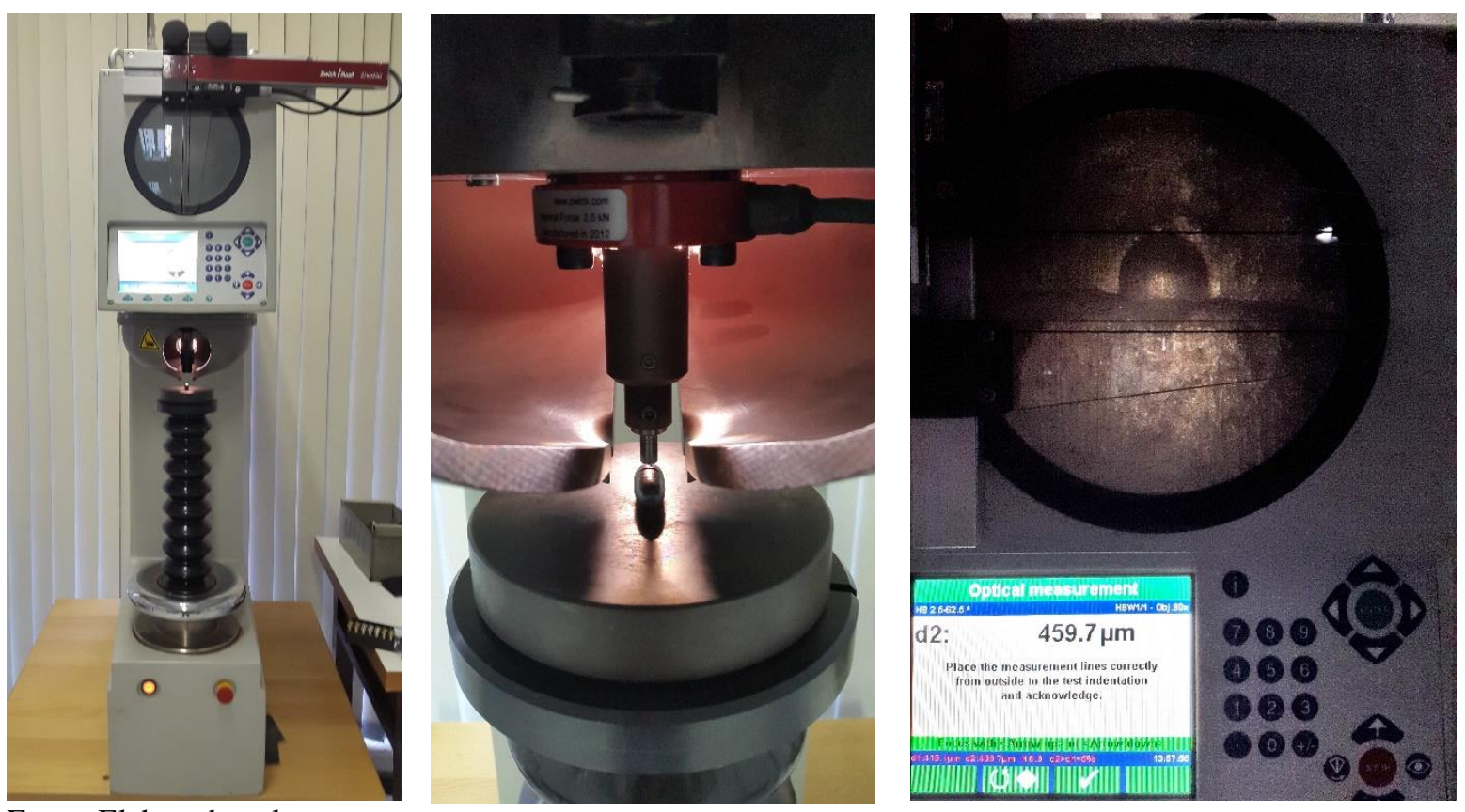

Fonte: Elaborado pelo autor. 


\subsection{TESTE DE RUGOSIDADE}

A fim de investigar a rugosidade das superfícies laterais dos projéteis foram selecionados dois projéteis disparados de seis dos sete tipos de projéteis padrões no calibre .38SPL (ver Tabela 3 e notar que PP7 é do mesmo tipo que PP1) e de cada um dos quatro tipos de projéteis 9mm Luger (ver Tabela 4).

O aparelho utilizado foi um Microscópio Confocal a Laser, da marca OLIMPUS LEXT OLS 4100 (ver Figura 42) para geração de imagens 3D e medições micro geométricas, que opera por seleção da imagem em foco e fora de foco conforme explicado em 2.6 e Figura 29.

Figura 42 - Microscópio confocal a Laser OLIMPUS LEXT OLS 4100.

Fonte: Elaborado pelo autor.

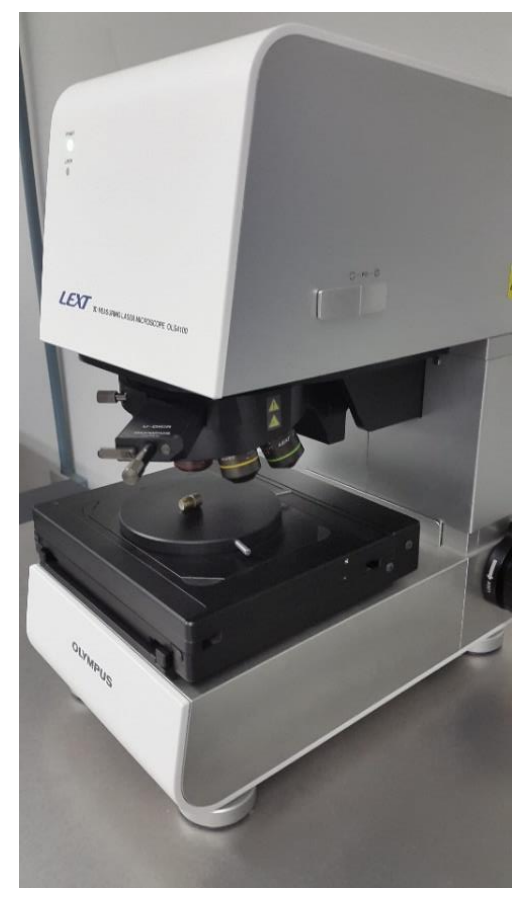

As imagens de cavados dos projéteis analisados no microscópio confocal, foram capturadas com lente de aumento de 5x, Zoom 1x, o que considerando a diagonal da tela de análise, gerou um aumento de $5 \times 1 \times 21,6=108$ vezes (cento e oito vezes).

Para cada projétil analisado foram realizadas três medições de rugosidade, em direção perpendicular ao eixo longitudinal do projétil, sendo especificado um cut-off $\left(\lambda_{c}\right)$ de $80 \mu \mathrm{m}$ (oitenta micrômetros), resultando num comprimento de avaliação total (l) de 2,5mm (dois milímetros e meio) e utilizando os parâmetros de operação do Microscópio confocal conforme Figura 43. 
Figura 43 - Parâmetros de operação do microscópio confocal para medições do perfil de rugosidade dos projéteis amostrados, e exemplo de resultados com projétil .38SPL PP1.

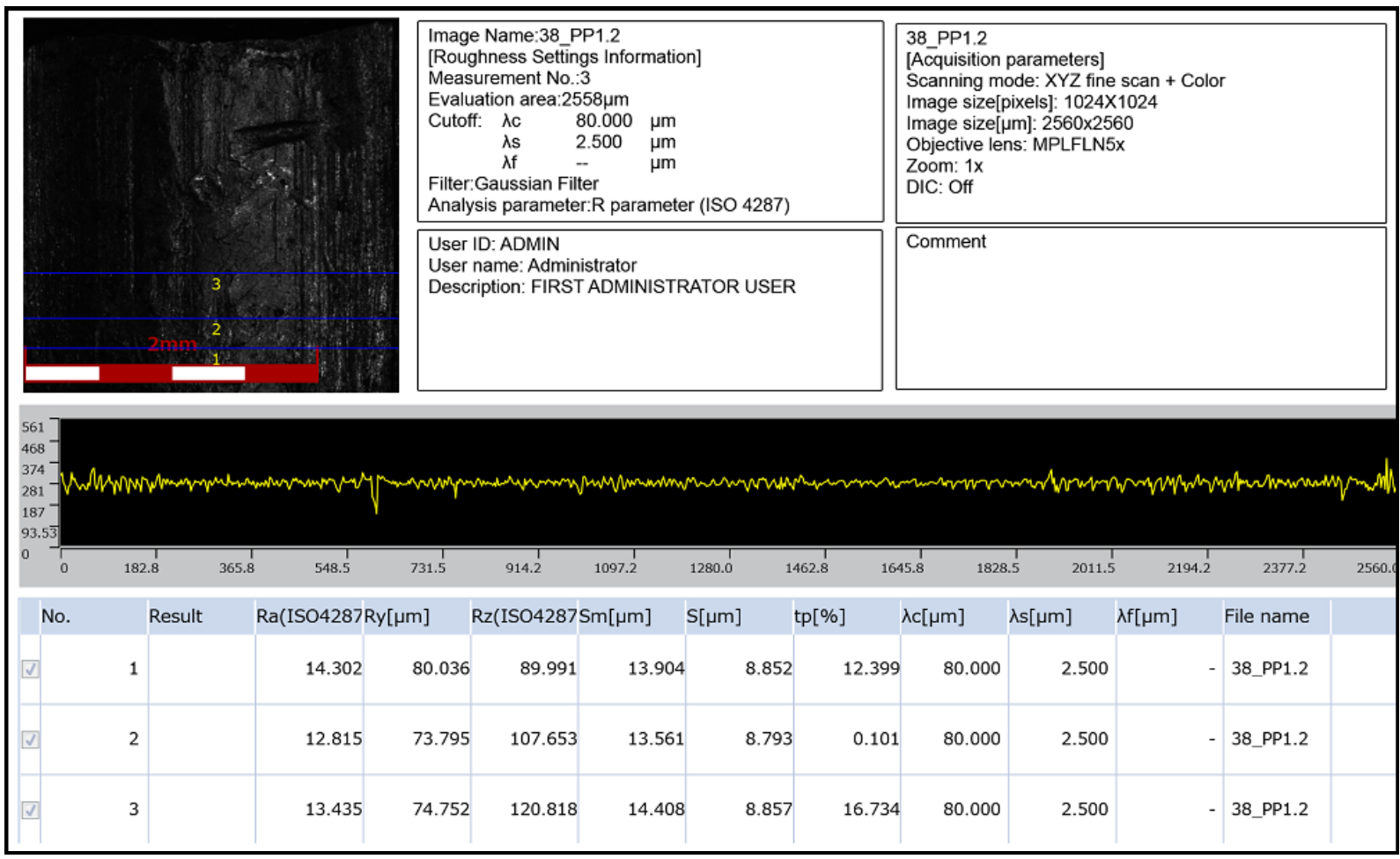

Fonte: Elaborado pelo autor. 


\section{RESULTADOS E DISCUSSÃO}

Este capítulo apresenta os resultados obtidos e as analisados efetuadas, correlacionando os critérios de efetividade com os parâmetros obtidos nos testes nos materiais utilizados.

\subsection{RESULTADOS E ANÁLISES DOS TESTES DE EFETIVIDADE ENVOLVENDO TODO O BANCO DE DADOS}

Conforme explicado em 3.1.4.2, foi utilizado todo o banco de dados disponível para testar as efetividades do sistema sob diferentes configurações. Foram controladas três variáveis independentes, projétil/estojo questionado, projétil/estojo padrão e tipo de usuário, com as instâncias em cada uma delas registradas na Tabela 9. Para cada configuração do sistema foram realizados os confrontos automatizados para todas as armas, e em seguida gerado o gráfico de efetividade, ajustada a curva hiperbólica e obtido o novo critério de efetividade, calculado pela equação (3.20).

\subsubsection{Exemplos de cálculo dos critérios de efetividade}

Seguem exemplos de resultados obtidos em quatro configurações do sistema e procedimentos para cálculo da efetividade.

\subsubsection{Confrontos automatizados com projéteis .38SPL configuração IIA}

Os resultados dos confrontos automatizados com projéteis nesta configuração, repetida para cada arma no calibre .38SPL, foram tabelados e a probabilidade cumulativa de acerto foi lançada na Tabela 19 e na Figura 44.

Tabela 19 - Resultado dos confrontos automatizados no sistema com projéteis .38SPL configuração I1 A.

\begin{tabular}{|l|r|r|r|r|r|r|r|r|r|r|r|}
\hline $\begin{array}{l}\text { Posição na lista de } \\
\text { resultados - } n\end{array}$ & 0 & 1 & 2 & 3 & 4 & 5 & 6 & 7 & 8 & 9 & 10 \\
\hline $\begin{array}{l}\text { Probabilidade } \\
\text { cumulativa - } \mathbf{P}\end{array}$ & 0 & 0,250 & 0,313 & 0,313 & 0,313 & 0,438 & 0,438 & 0,438 & 0,438 & 0,438 & 0,438 \\
\hline $\begin{array}{l}\text { Posição na lista de } \\
\text { resultados - } \boldsymbol{n}\end{array}$ & 11 & 12 & 13 & 14 & 15 & 16 & 17 & 18 & 19 & 20 & \\
\hline $\begin{array}{l}\text { Probabilidade } \\
\text { cumulativa - } \mathbf{P}\end{array}$ & 0,438 & 0,500 & 0,500 & 0,625 & 0,688 & 0,688 & 0,688 & 0,688 & 0,688 & 0,688 & \\
\hline
\end{tabular}


Figura 44 - P x n para projétil .38SPL configuração I1A.

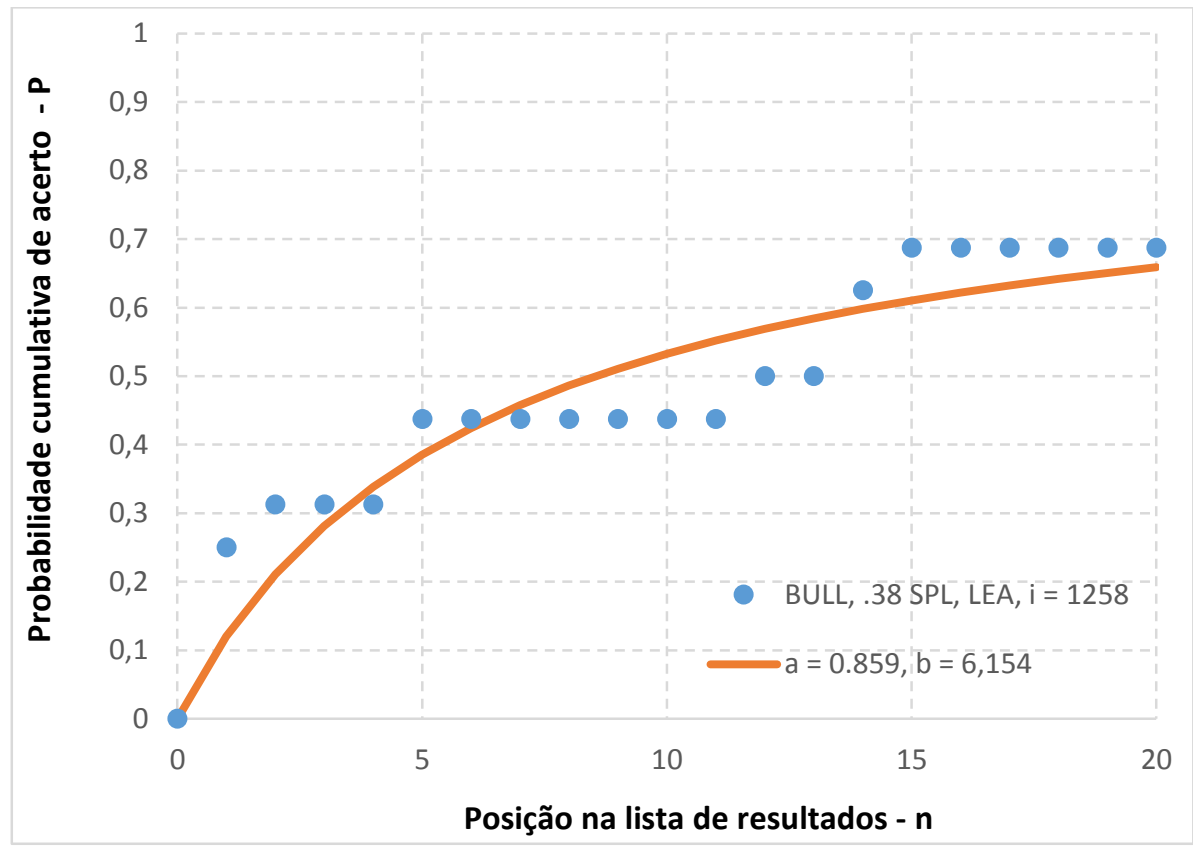

Para ajustar a curva aos dados obtidos e determinar o valor dos parâmetros $a$ e $b$ foram utilizados o método de mínimos quadrados e a função SOLVER do Microsoft Office Excel. Com os valores de $a$ e $b$, foi determinada a efetividade do sistema $\left(\Gamma_{1}\right)$ com projéteis nesta configuração I1A, por meio das equações (3.20) e (3.21), obtendo-se o valor de 0,48.

\subsubsection{Confrontos automatizados com estojos .38SPL configuração IV3P}

Os resultados dos confrontos automatizados com estojos nesta configuração, repetida para cada arma no calibre .38SPL, foram tabelados, e a probabilidade cumulativa de acerto foi lançada na Tabela 20 e Figura 45 . O critério de efetividade do sistema $\left(\Gamma_{1}\right)$ com estojos nesta configuração IV3P foi calculado em 0,70 .

Tabela 20 - Resultado dos confrontos automatizados no sistema com estojos .38SPL configuração IV3P.

\begin{tabular}{|c|c|c|c|c|c|c|c|c|c|c|c|}
\hline $\begin{array}{l}\text { Posição na lista de } \\
\text { resultados }-n\end{array}$ & 0 & 1 & 2 & 3 & 4 & 5 & 6 & 7 & 8 & 9 & 10 \\
\hline $\begin{array}{l}\text { Probabilidade } \\
\text { cumulativa - P }\end{array}$ & 0 & 0,688 & 0,688 & 0,688 & 0,688 & 0,688 & 0,688 & 0,688 & 0,688 & 0,688 & 0,688 \\
\hline $\begin{array}{l}\text { Posição na lista de } \\
\text { resultados }-n\end{array}$ & 11 & 12 & 13 & 14 & 15 & 16 & 17 & 18 & 19 & 20 & \\
\hline $\begin{array}{l}\text { Probabilidade } \\
\text { cumulativa - } \mathbf{P}\end{array}$ & 0,688 & 0,688 & 0,688 & 0,750 & 0,750 & 0,750 & 0,750 & 0,750 & 0,750 & 0,750 & \\
\hline
\end{tabular}


Figura 45 - P x n para estojo .38SPL configuração IV3P.

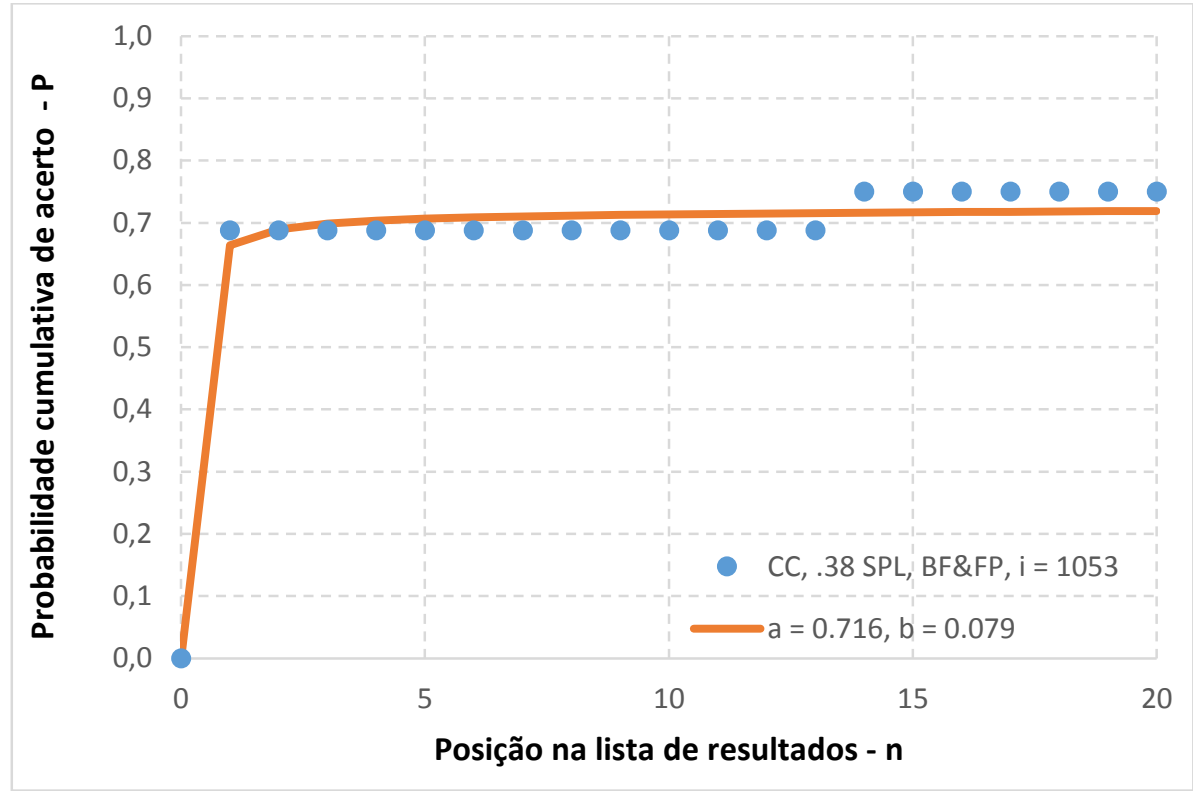

\subsubsection{Confrontos automatizados com projéteisl 9mm Luger configuração IV2A}

Os resultados dos confrontos automatizados com projéteis nesta configuração, repetida para cada arma no calibre $9 \mathrm{~mm}$ Luger, foram tabelados, e a probabilidade cumulativa de acerto foi lançada na Tabela 21 e Figura 46 . O critério de efetividade do sistema $\left(\Gamma_{1}\right)$ com projéteis nesta configuração IV2A foi calculado em 0,59.

Tabela 21 - Resultado dos confrontos automatizados no sistema com projéteis $9 \mathrm{~mm}$ Luger configuração IV2A.

\begin{tabular}{|c|c|c|c|c|c|c|c|c|c|c|c|}
\hline $\begin{array}{l}\text { Posição na lista de } \\
\text { resultados }-n\end{array}$ & 0 & 1 & 2 & 3 & 4 & 5 & 6 & 7 & 8 & 9 & 10 \\
\hline $\begin{array}{l}\text { Probabilidade } \\
\text { cumulativa - P }\end{array}$ & 0 & 0,563 & 0,563 & 0,563 & 0,563 & 0,563 & 0,563 & 0,563 & 0,563 & 0,625 & 0,625 \\
\hline $\begin{array}{l}\text { Posição na lista de } \\
\text { resultados }-n\end{array}$ & 11 & 12 & 13 & 14 & 15 & 16 & 17 & 18 & 19 & 20 & \\
\hline $\begin{array}{l}\text { Probabilidade } \\
\text { cumulativa - P }\end{array}$ & 0,625 & 0,625 & 0,625 & 0,625 & 0,625 & 0,625 & 0,625 & 0,625 & 0,625 & 0,625 & \\
\hline
\end{tabular}

\subsubsection{Confrontos automatizados com estojos 9mm Luger configuração I4P}

Os resultados dos confrontos automatizados com estojos nesta configuração, repetida para cada arma no calibre 9mm Luger, foram tabelados, e a probabilidade cumulativa de acerto foi lançada na Tabela 22 e Figura 47. O critério de efetividade do sistema $\left(\Gamma_{1}\right)$ com estojos nesta configuração I4P foi calculado em 0,74 . 
Figura 46 - P x n para projétil 9mm Luger configuração IV2A.

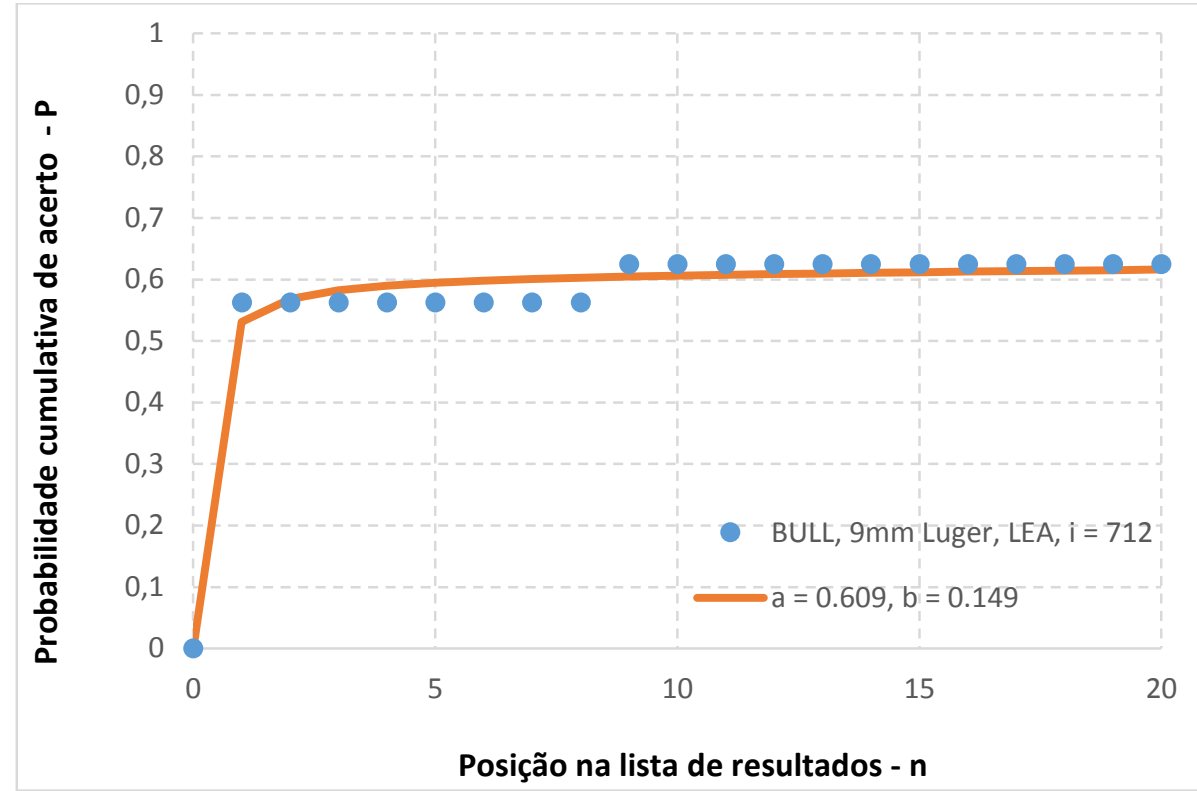

Tabela 22 - Resultado dos confrontos automatizados no sistema com estojos 9mm Luger configuração I4P.

\begin{tabular}{|l|r|r|r|r|r|r|r|r|r|r|r|}
\hline $\begin{array}{l}\text { Posição na lista de } \\
\text { resultados- } \boldsymbol{n}\end{array}$ & 0 & 1 & 2 & 3 & 4 & 5 & 6 & 7 & 8 & 9 & 10 \\
\hline $\begin{array}{l}\text { Probabilidade } \\
\text { cumulativa - } \mathbf{P}\end{array}$ & 0 & 0,813 & 0,813 & 0,813 & 0,813 & 0,813 & 0,813 & 0,813 & 0,813 & 0,813 & 0,813 \\
\hline $\begin{array}{l}\text { Posição na lista de } \\
\text { resultados - } \boldsymbol{n}\end{array}$ & 11 & 12 & 13 & 14 & 15 & 16 & 17 & 18 & 19 & 20 \\
\hline $\begin{array}{l}\text { Probabilidade } \\
\text { cumulativa - } \mathbf{P}\end{array}$ & 0,813 & 0,813 & 0,813 & 0,813 & 0,813 & 0,813 & 0,813 & 0,813 & 0,813 & 0,813 & \\
\hline
\end{tabular}

Figura 47 - P x n para estojo 9mm Luger configuração I4P.

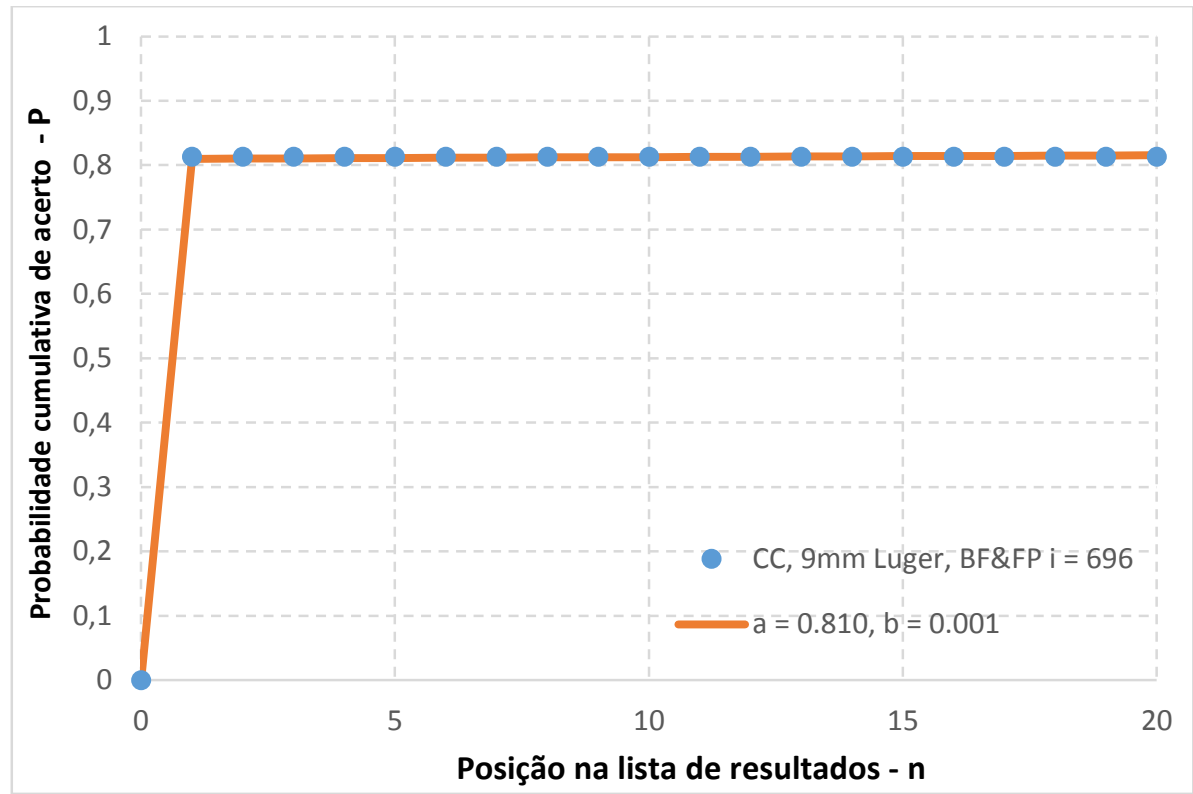


Procedendo da mesma forma que nos quatro exemplos acima, para todas as configurações do sistema, conforme as variáveis independentes da Tabela 9, foram obtidos os critérios de efetividades analisados nas próximas cinco seções.

\subsubsection{Influência do tipo de projétil .38SPL na efetividade do sistema}

No exemplo 4.1.1.1 foi obtida uma efetividade de 0,48, para configuração I1A, este valor foi lançado na linha I Aluno, coluna PP1, da Tabela 23 (ver valor em vermelho). Todas as demais efetividades do sistema $\left(\Gamma_{1}\right)$ para confrontos automatizados com projéteis .38SPL, foram calculadas da mesma forma e lançadas na tabela a seguir.

Tabela 23 - Efetividades do sistema $\left(\Gamma_{1}\right)$ para confrontos automatizados com projéteis .38SPL.

\begin{tabular}{|l|l|r|r|r|r|r|r|r|}
\hline PQ & USUÁRIO & \multicolumn{1}{c|}{ PP1 } & \multicolumn{1}{c|}{ PP2 } & \multicolumn{1}{c|}{ PP3 } & \multicolumn{1}{c|}{ PP4 } & \multicolumn{1}{c|}{ PP5 } & \multicolumn{1}{c|}{ PP6 } & \multicolumn{1}{c|}{ PP7 } \\
\hline I & Perito & 0,32 & 0,30 & 0,22 & 0,27 & 0,16 & 0,20 & 0,35 \\
\hline II & Perito & 0,40 & 0,61 & 0,91 & 0,63 & 0,51 & 0,72 & 0,36 \\
\hline IV & Perito & 0,34 & 0,71 & 0,74 & 0,90 & 0,54 & 0,80 & 0,48 \\
\hline V & Perito & 0,25 & 0,44 & 0,65 & 0,54 & 0,56 & 0,70 & 0,32 \\
\hline VI & Perito & 0,25 & 0,69 & 0,70 & 0,68 & 0,50 & 0,86 & 0,33 \\
\hline I & Aluno & 0,48 & 0,27 & 0,35 & 0,15 & 0,07 & 0,15 & 0,45 \\
\hline II & Aluno & 0,27 & 0,54 & 0,54 & 0,46 & 0,58 & 0,74 & 0,30 \\
\hline IV & Aluno & 0,40 & 0,65 & 0,51 & 0,72 & 0,35 & 0,50 & 0,39 \\
\hline V & Aluno & 0,17 & 0,38 & 0,50 & 0,36 & 0,41 & 0,44 & 0,30 \\
\hline VI & Aluno & 0,44 & 0,53 & 0,65 & 0,54 & 0,47 & 0,79 & 0,47 \\
\hline
\end{tabular}

A Figura 48 mostra as médias e desvios padrão dos critérios de efetividade para cada tipo de projétil padrão (PP1 a PP7) e por usuários perito e aluno. É interessante notar que os padrões PP1 e PP7, ambos do tipo CHOG, apresentaram baixas efetividades quando comparadas às demais efetividades obtidas, e exceto com este dois padrões, as efetividades do sistema com amostras de peritos foram maiores do que as efetividades com amostras de alunos.

Um histograma de frequências por faixa de efetividades dos dados da Tabela 23 (ver Figura 49) permitiu verificar que as efetividades obtidas apresentam uma distribuição com razoável normalidade, e por isso foi utilizado a ANOVA para verificar se há fatores determinantes para a variação observada ou se são variações aleatórias em torno da média. A análise dos dados da Tabela 23 foi lançado na Tabela 24. 
Figura 48 - Médias e desvios padrão dos critérios de efetividade $\left(\Gamma_{1}\right)$ por tipo de projétil padrão .38SPL e por usuário.

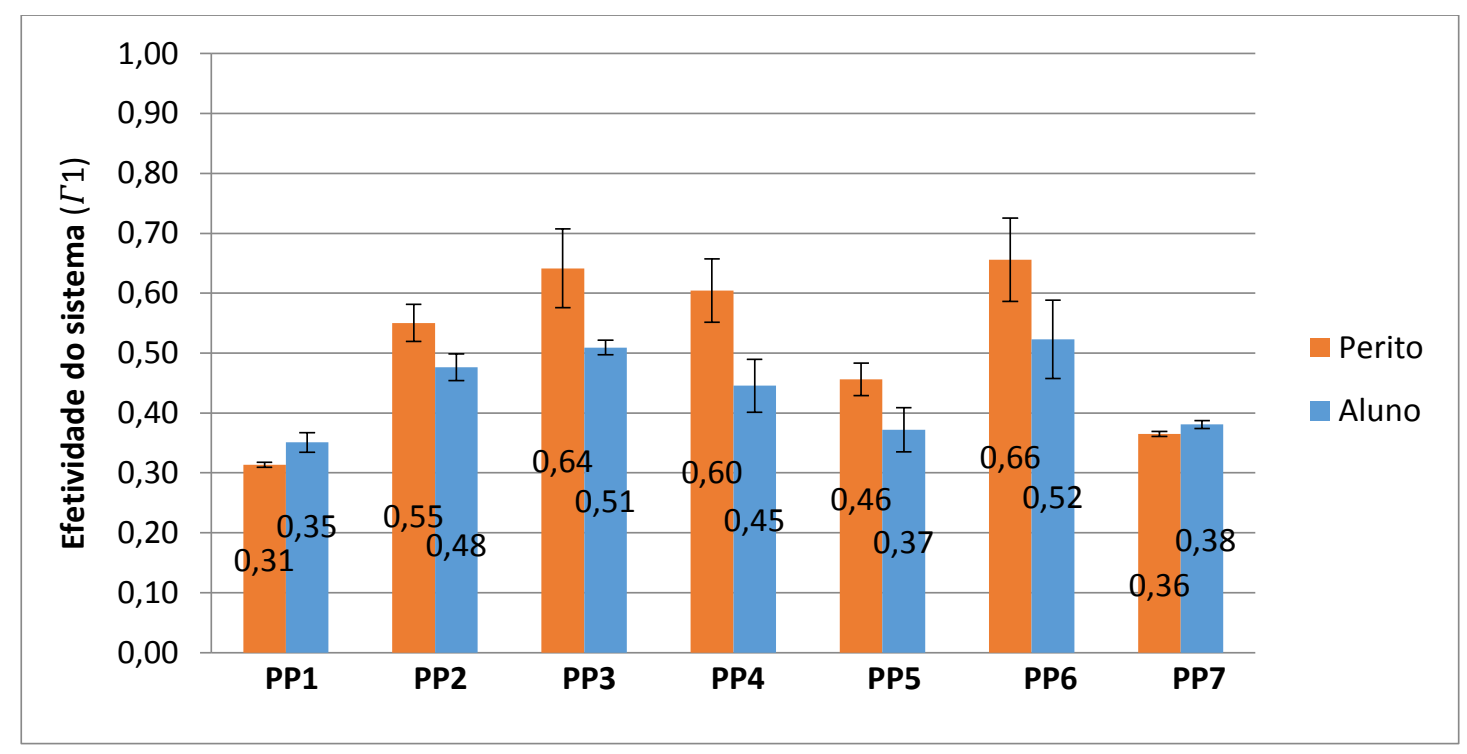

Figura 49 - Histograma de frequências das efetividades para confrontos automatizados com projéteis .38SPL mostrando razoável normalidade dos dados.

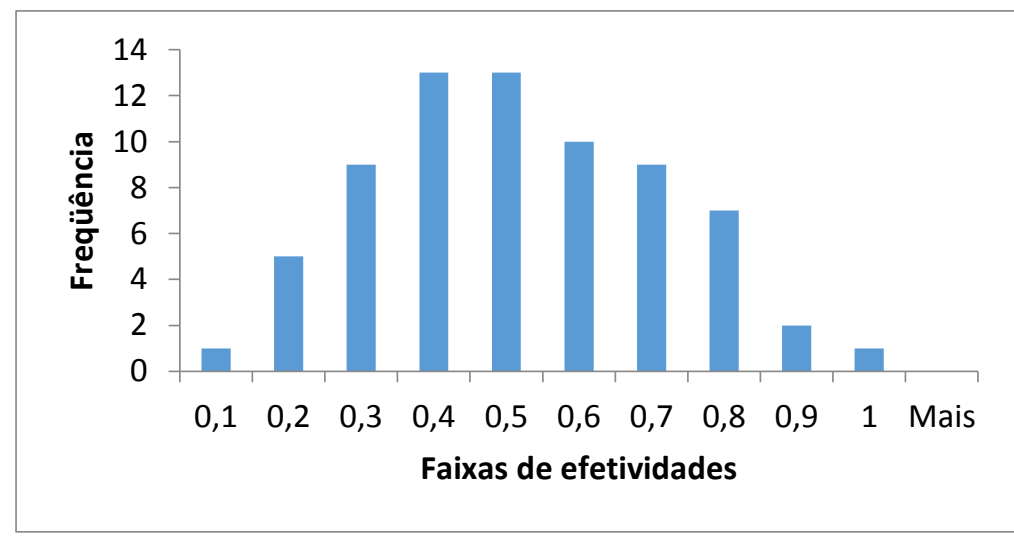

Tabela 24 - ANOVA, fator duplo com repetição, dos dados da Tabela 23.

\begin{tabular}{|c|c|c|c|c|c|c|c|c|}
\hline RESUMO & PP1 & PP2 & PP3 & PP4 & PP5 & PP6 & PP7 & Total \\
\hline \multicolumn{9}{|l|}{ Perito } \\
\hline Contagem & 5 & 5 & 5 & 5 & 5 & 5 & 5,00 & 35 \\
\hline Soma & 1,57 & 2,75 & 3,21 & 3,02 & 2,28 & 3,28 & 1,82 & 17,93 \\
\hline Média & 0,31 & 0,55 & 0,64 & 0,60 & 0,46 & 0,66 & 0,36 & 0,51 \\
\hline Variância & 0,004 & 0,03 & 0,07 & 0,05 & 0,03 & 0,07 & 0,004 & 0,05 \\
\hline \multicolumn{9}{|l|}{ Aluno } \\
\hline Contagem & 5 & 5 & 5 & 5 & 5 & 5 & 5,00 & 35 \\
\hline Soma & 1,75 & 2,38 & 2,55 & 2,23 & 1,86 & 2,62 & 1,90 & 15,29 \\
\hline Média & 0,35 & 0,48 & 0,51 & 0,45 & 0,37 & 0,52 & 0,38 & 0,44 \\
\hline Variância & 0,02 & 0,02 & 0,01 & 0,04 & 0,04 & 0,07 & 0,01 & 0,03 \\
\hline
\end{tabular}




\begin{tabular}{|c|c|c|c|c|c|c|}
\hline Fonte da variação & SO & al & MO & F-Fisher & valor- $P$ & F-crítico \\
\hline USUÁRIO & 0,099 & 1 & 0,099 & 3,04 & 0,09 & 4,01 \\
\hline PROJÉTEIS PADRÃO & 0,617 & 6 & 0,103 & 3,14 & 0,01 & 2,27 \\
\hline INTERAÇÕES & 0,087 & 6 & 0,014 & 0,44 & 0,85 & 2,27 \\
\hline DENTRO & 1,833 & 56 & 0,033 & & & \\
\hline Total & 2,636 & 69 & & & & \\
\hline
\end{tabular}

As médias das efetividades ficaram em $0,51( \pm 0,22)$ para perito e em $0,44( \pm 0,18)$ para aluno, porém a linha USUÁRIO da ANOVA acima mostra um F-Fisher calculado $(3,04)$ inferior ao F-crítico $(4,01)$, e por isso não pode ser rejeitada a hipótese de igualdade de efetividades do sistema entre usuários.

Entre os tipos de projéteis padrões, a linha PROJETÉIS PADRÃO mostra um F-Fisher significativo $(3,14)$ em relação ao F-crítico $(2,27)$, o que permite rejeitar a hipótese de igualdade entre tipos de padrões e demonstra a influência do tipo de projétil padrão na efetividade do sistema.

Sendo verificado que os padrões PP1 e PP7, apresentaram pior efetividade, foi realizada uma nova ANOVA dos dados da Tabela 23, desta vez excluindo da análise as colunas PP1 e PP7, sendo esta nova ANOVA lançada na Tabela 25.

As médias das efetividades ficaram em $0,67( \pm 0,13)$ para perito e em $0,53( \pm 0,13)$ para aluno, e ademais a linha USUÁRIO da ANOVA acima mostra um F-Fisher calculado $(13,84)$ muito acima do F-crítico $(4,17)$, e por isso pôde ser rejeitada a hipótese de igualdade de efetividades do sistema entre usuários. Desta forma, retirando os padrões PP1 e PP7, com os quais o sistema apresentou baixa efetividade, ficou evidenciado um melhor desempenho do sistema quando os confrontos automatizados foram realizados com amostras de peritos do que com amostras de alunos de projéteis .38SPL.

Como o sistema apresentou esta melhor efetividade com amostras do grupo perito, as próximas análises relativas a projéteis .38SPL foram todas feitas com os dados das linhas perito da Tabela 23.

Ainda da análise do gráfico da Figura 48 e dos dados da ANOVA da Tabela 25, verificou-se os padrões PP6 e PP3 apresentaram maiores efetividades médias. Isso levou a investigar se estes projéteis padrões seriam os mais indicados para se coletar padrões no calibre .38SPL, ou seja, se utilizando estes projéteis padrões o sistema teria melhor efetividade em encontrar todos os tipos de projéteis questionados. 
O desempenho do sistema com estes dois tipos de projéteis padrões em relação ao tipo de projétil questionado foi estudado pelos gráficos da Figura 50 e da Figura 51.

Tabela 25 - ANOVA fator duplo com repetição (dados das colunas PP2 a PP6 da Tabela 23).

\begin{tabular}{|c|c|c|c|c|c|c|}
\hline RESUMO & PP2 & PP3 & PP4 & PP5 & PP6 & Total \\
\hline \multicolumn{7}{|l|}{ Perito } \\
\hline Contagem & 4 & 4 & 4 & 4 & 4 & 20 \\
\hline Soma & 2,45 & 2,99 & 2,75 & 2,12 & 3,08 & 13,40 \\
\hline Média & 0,61 & 0,75 & 0,69 & 0,53 & 0,77 & 0,67 \\
\hline Variância & 0,01 & 0,01 & 0,02 & 0,00 & 0,01 & 0,02 \\
\hline \multicolumn{7}{|c|}{ Aluno } \\
\hline Contagem & 4 & 4 & 4 & 4 & 4 & 20 \\
\hline Soma & 2,11 & 2,20 & 2,07 & 1,80 & 2,46 & 10,64 \\
\hline Média & 0,53 & 0,55 & 0,52 & 0,45 & 0,62 & 0,53 \\
\hline Variância & 0,01 & 0,00 & 0,02 & 0,01 & 0,03 & 0,02 \\
\hline \multicolumn{7}{|l|}{ ANOVA } \\
\hline Fonte da variação & $S Q$ & $g l$ & $M Q$ & F-Fisher & valor-P & F-crítico \\
\hline USUÁRIO & 0,189 & 1 & 0,189 & 13,84 & 0,001 & 4,17 \\
\hline PROJÉTEIS PADRÃO & 0,194 & 4 & 0,049 & 3,54 & 0,02 & 2,69 \\
\hline INTERAÇÕES & 0,022 & 4 & 0,005 & 0,39 & 0,81 & 2,69 \\
\hline DENTRO & 0,411 & 30 & 0,014 & & & \\
\hline Total & 0,816 & 39 & & & & \\
\hline
\end{tabular}

Figura 50 - Valores dos critérios de efetividade do sistema $\left(\Gamma_{1}\right)$ com padrões PP6 em relação aos tipos de projéteis questionados .38SPL (coluna PP6 linhas perito da Tabela 23).

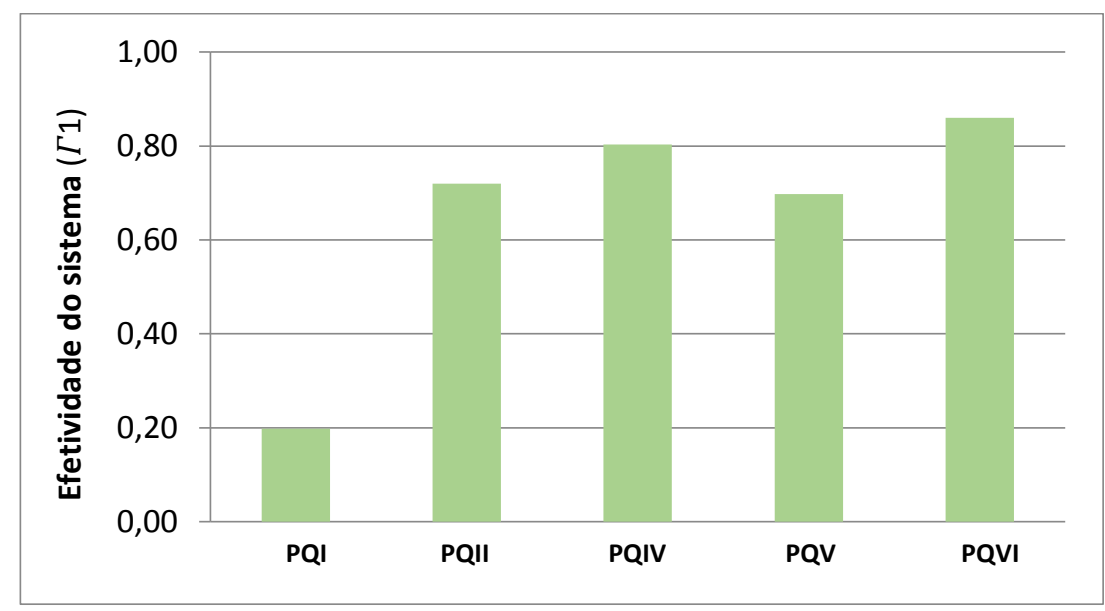


Figura 51 - Valores dos critérios de efetividade do sistema $\left(\Gamma_{1}\right)$ com padrões PP3 em relação aos tipos de projéteis questionados.38SPL (coluna PP3, linhas perito, da Tabela 23).

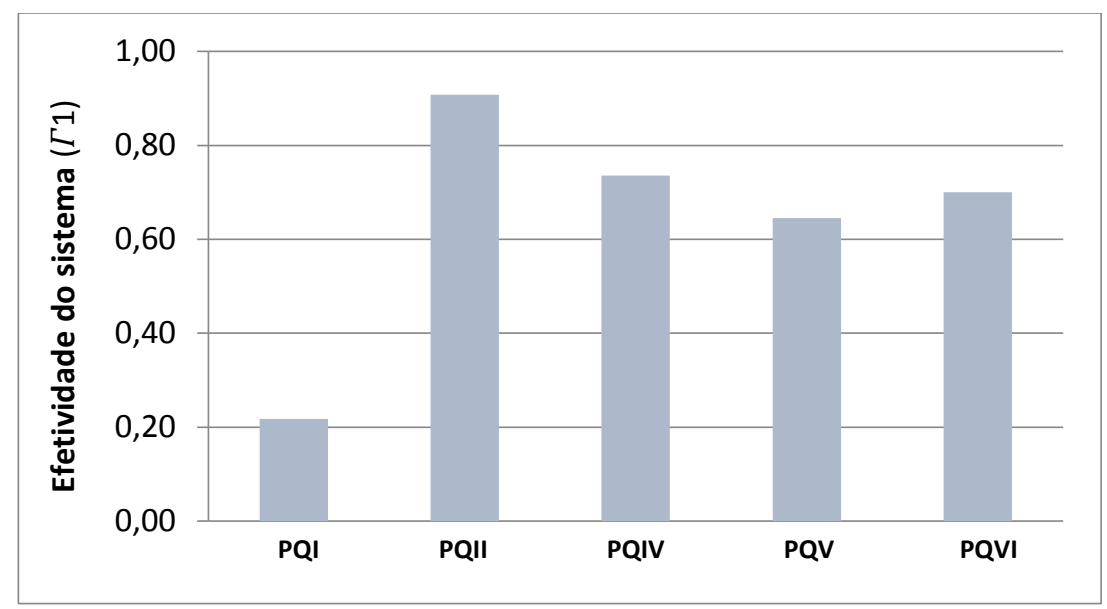

Os gráficos das Figuras 50 e 51 mostram que com padrões PP6 ou PP3 o sistema apresentou bons critérios de efetividade para relacionar a arma correta aos projéteis questionados PQII, PQIV, PQV e PQVI. Porém a baixa efetividade com estes padrões para comparações automatizadas envolvendo os projéteis questionados PQI, também ficou evidenciada.

Para os projéteis questionados PQI as efetividades em relação aos projéteis padrões foram lançadas na Figura 52.

Figura 52 - Valores dos critérios de efetividade do sistema $\left(\Gamma_{1}\right)$ com projéteis questionados PQI em relação aos tipos de projéteis padrões .38SPL (PP1 a PP7 - linha I Perito da Tabela 23).

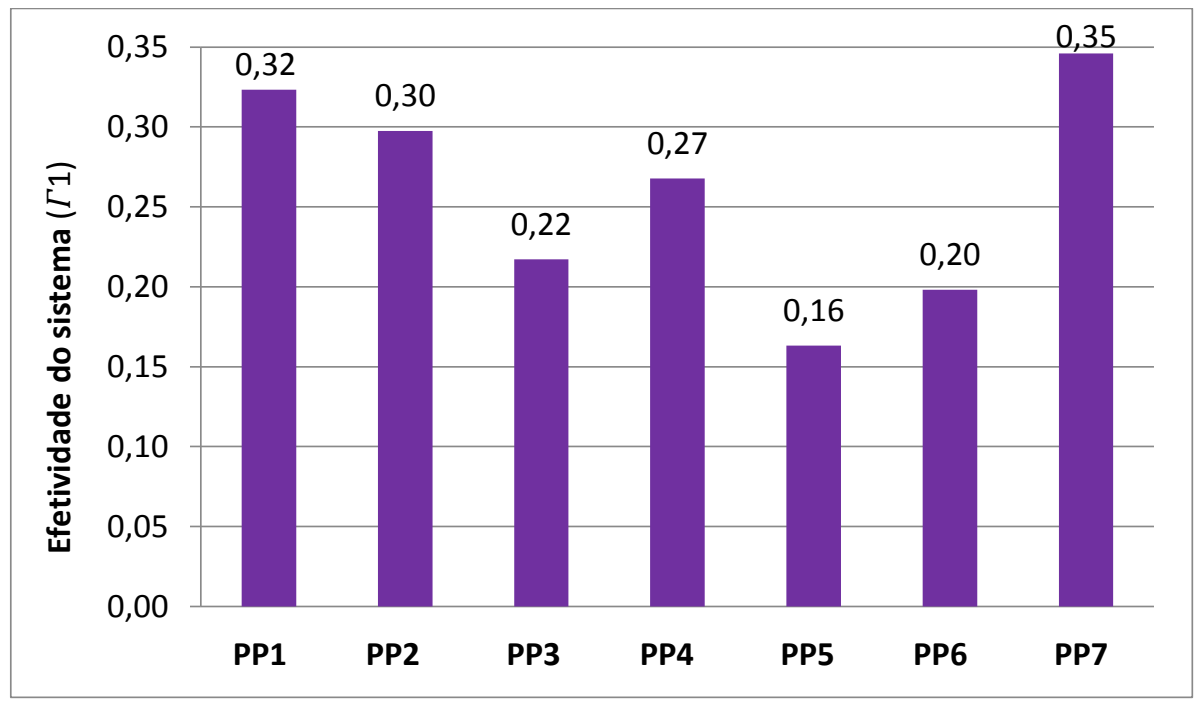


Para encontrar projéteis questionados PQI padrões do tipo PP1 e PP7 tiveram melhor efetividade, portanto, embora PP6 ou PP3 sejam boas escolhas para coletar padrões de armas .38SPL, suas baixas efetividades para encontrar projétil questionado PQI, sugerem a validade de também coletar padrões PP1 para o caso do questionado ser do tipo PQI.

Finalmente, através da Figura 53, foi comparada a efetividade geral deste teste envolvendo todo banco de dados de projéteis no calibre .38SPL, com o teste preliminar analisado pela Figura 37.

Figura 53 - Comparação das efetividades do sistema $\left(\Gamma_{1}\right)$ no teste preliminar e no teste com todo o banco de dados com projéteis padrões no calibre .38SPL.

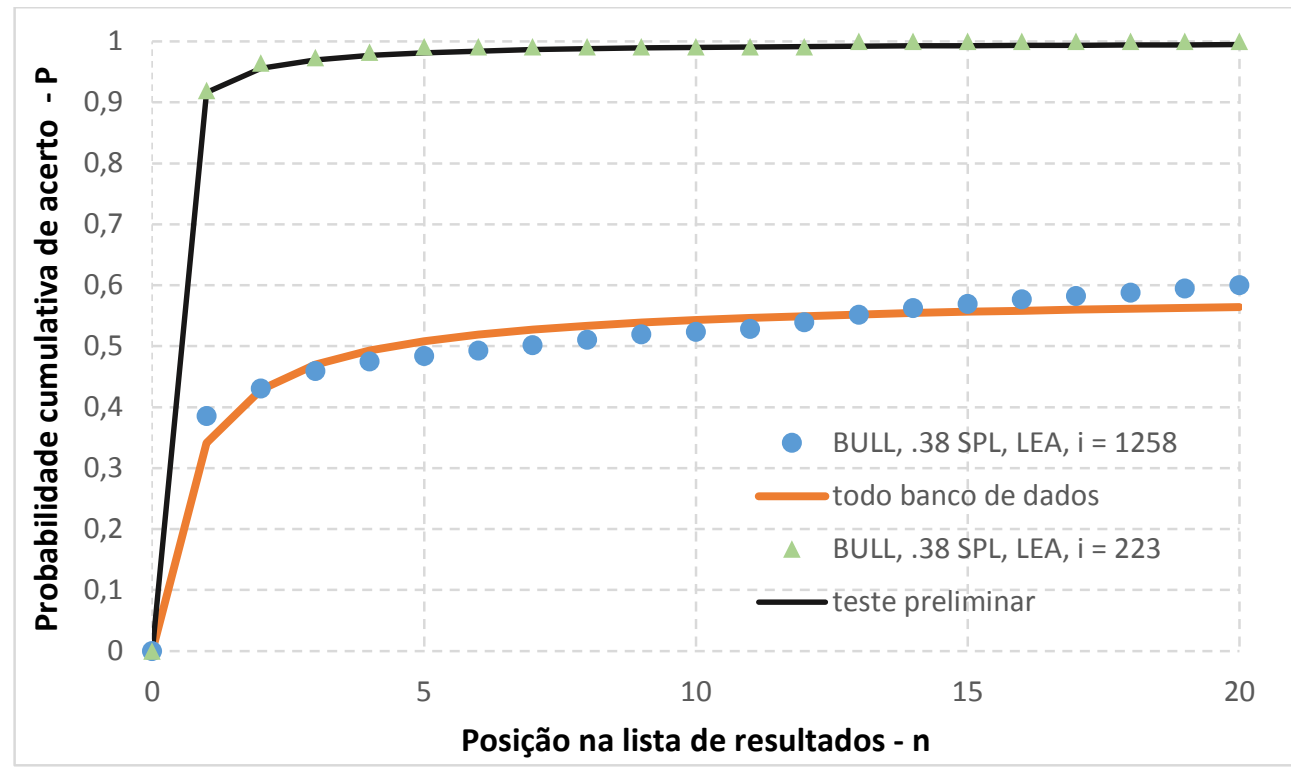

Tabela 26 - Diferenças entre o teste preliminar e o teste de todo o banco de dados (BD) com projéteis .38SPL.

\begin{tabular}{|l|c|c|c|}
\hline \multicolumn{1}{|c|}{ TESTE } & Banco de dados $^{\mathbf{k}}$ & PADRÕES $^{\mathbf{l}}$ & $\begin{array}{c}\text { EFETIVIDADE } \\
\text { DO SISTEMA }\end{array}$ \\
\hline PRELIMINAR & 223 & 13 & 0,97 \\
\hline TODO $B D$ & 1258 & 2 & 0,51 \\
\hline
\end{tabular}

$\mathrm{k}$ - Quantidade de imagens envolvidas no confronto automatizado;

1 - Quantidade de padrões da mesma arma que a do projétil questionado entre as imagens confrontadas.

O critério de efetividade $\left(\Gamma_{1}\right)$ calculado no teste preliminar com projéteis .38SPL ficou em 0,97 enquanto que no teste com todo o banco de dados em 0,51. Isso representa uma grande queda na efetividade do sistema. As grandes diferenças entre estes testes, que podem explicar esta diminuição, estão na quantidade de padrões, em número bem maior nas comparações automatizadas do teste preliminar, e na quantidade de imagens de outras armas envolvidas na 
comparação, em número bem maior no teste de todo o banco de dados, conforme pode ser verificado na Tabela 26.

A clara diminuição da efetividade do sistema observada entre estes dois testes com projéteis .38SPL mostrou-se de acordo com estudos anteriores citados em 2.4.4 (DE KINDER; TULLENERS; THIEBAUT, 2004; e CEUSTER; DUJARDIN, 2015).

\subsubsection{Influência do tipo de estojo .38SPL na efetividade do sistema}

No exemplo 4.1.1.2 foi obtida uma efetividade de 0,70, para configuração IV3P, e este valor foi lançado na linha IV Perito, coluna EP3, da Tabela 27 (ver valor em vermelho). Todas as demais efetividades do sistema $\left(\Gamma_{1}\right)$ para confrontos automatizados com estojos .38SPL, foram calculadas da mesma forma e lançadas na tabela abaixo.

Tabela 27 - Efetividades do sistema $\left(\Gamma_{1}\right)$ para confrontos automatizados com estojos .38SPL.

\begin{tabular}{|l|l|l|l|l|l|l|l|l|}
\hline \multicolumn{1}{|c|}{ EQ } & USUÁRIO & EP1 & EP2 & EP3 & EP4 & EP05 & EP06 & EP07 \\
\hline I & Perito & 0,46 & 0,25 & 0,45 & 0,38 & 0,37 & 0,30 & 0,43 \\
\hline IV & Perito & 0,56 & 0,56 & 0,70 & 0,63 & 0,64 & 0,50 & 0,46 \\
\hline $\mathrm{V}$ & Perito & 0,41 & 0,44 & 0,54 & 0,49 & 0,38 & 0,38 & 0,31 \\
\hline $\mathrm{VI}$ & Perito & 0,34 & 0,23 & 0,33 & 0,52 & 0,40 & 0,36 & 0,26 \\
\hline $\mathrm{I}$ & Aluno & 0,49 & 0,29 & 0,51 & 0,47 & 0,47 & 0,21 & 0,62 \\
\hline $\mathrm{IV}$ & Aluno & 0,44 & 0,29 & 0,77 & 0,58 & 0,65 & 0,35 & 0,43 \\
\hline $\mathrm{V}$ & Aluno & 0,42 & 0,30 & 0,55 & 0,60 & 0,41 & 0,43 & 0,34 \\
\hline $\mathrm{VI}$ & Aluno & 0,51 & 0,35 & 0,33 & 0,34 & 0,46 & 0,32 & 0,42 \\
\hline
\end{tabular}

As médias das efetividades ficaram em $0,43( \pm 0,12)$ para perito e em $0,44( \pm 0,13)$ para aluno, e por isso não pode ser rejeitada a hipótese de igualdade de efetividades do sistema entre usuários com estojos .38SPL.

Para analisar estas efetividades do sistema em relação ao tipo de estojo padrão .38SPL, foram lançadas as médias e desvios padrão de efetividade por tipo de estojo padrão e por usuário na Figura 54.

O gráfico da Figura 54 evidencia, pelas médias e pelos desvios padrão dos critérios de efetividade por tipo de estojo, que embora seja notado uma pequena diferença de desempenho em relação ao tipo de estojo padrão, o desvião padrão de cada média é muito significativo e por isso não pode ser rejeitada a hipótese de igualdade de efetividades do sistema em relação ao tipo de estojo padrão .38SPL. 
Figura 54 - Médias e desvios padrão dos critérios de efetividade $\left(\Gamma_{1}\right)$ por tipo de estojo padrão .38SPL (EP1 a EP7) e por usuário.

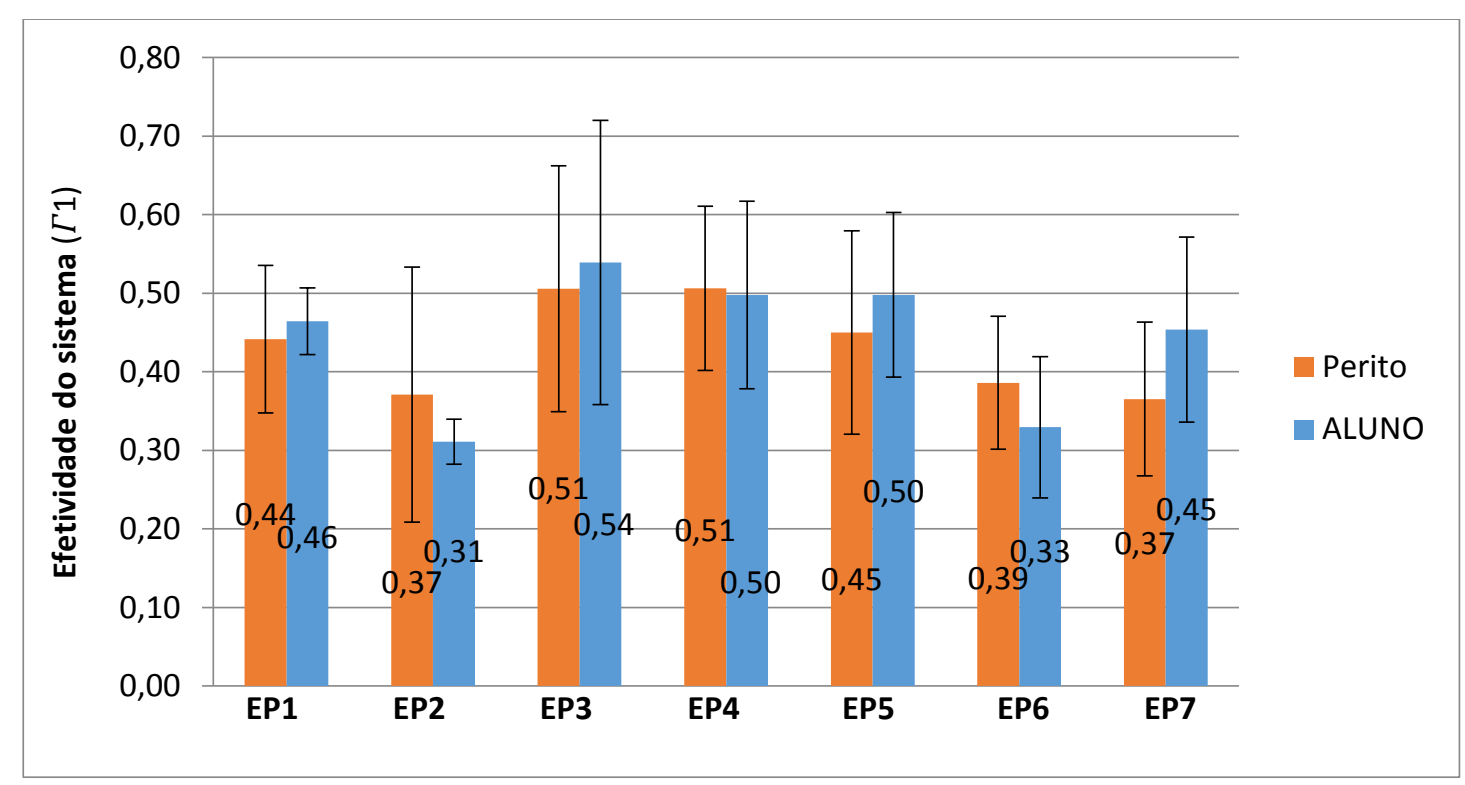

Finalmente, através da Figura 55, foi comparada a efetividade geral deste teste envolvendo todo o banco de dados de projéteis no calibre $38 \mathrm{SPL}$, com o teste preliminar analisado pela Figura 39. As diferenças entre o teste preliminar e o teste com todo o banco de dados forma lançadas na Tabela 28, e mostram porque houve esta diminuição tão grande na efetividade do sistema entre os dois testes.

Figura 55 - Comparação das efetividades do sistema $\left(\Gamma_{1}\right)$ no teste preliminar e no teste com todo o banco de dados com estojos padrões no calibre .38SPL.

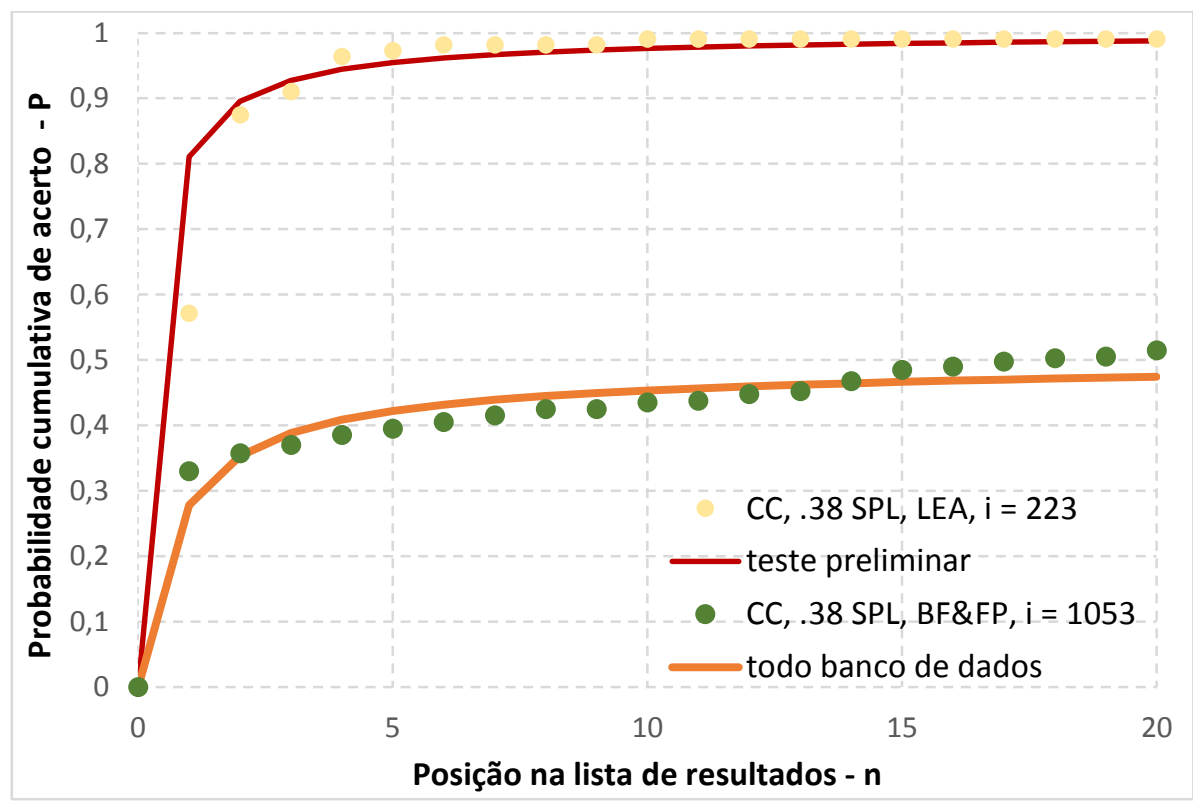


Tabela 28 - Diferenças entre o teste preliminar e o teste de todo o banco de dados (BD) com estojos .38SPL.

\begin{tabular}{|l|c|c|c|}
\hline \multicolumn{1}{|c|}{ TESTE } & Banco de dados $^{\mathbf{m}}$ & PADRÕES $^{\mathbf{n}}$ & $\begin{array}{c}\text { EFETIVIDADE } \\
\text { DO SISTEMA }\end{array}$ \\
\hline PRELIMINAR & 223 & 13 & 0,95 \\
\hline TODO BD & 1053 & 2 & 0,43 \\
\hline
\end{tabular}

$\mathrm{m}$ - Quantidade de imagens do banco confrontado;

$\mathrm{n}$ - Quantidade de padrões da mesma arma que a do projétil questionado entre as imagens confrontadas.

Mais uma vez a diminuição da efetividade do sistema, causada pelo aumento no banco de dados para comparação, mostrou-se qualitativamente de acordo com estudos anteriores citados em 2.4.4 (DE KINDER; TULLENERS; THIEBAUT, 2004; e CEUSTER; DUJARDIN, 2015).

\subsubsection{Influência do tipo de projétil 9mm Luger na efetividade do sistema}

No exemplo 4.1.1.3 foi obtida uma efetividade de 0,59, para configuração IV2A, este valor foi lançado na linha IV Aluno, coluna PP2, da Tabela 29 (ver valor em vermelho). Todas as demais efetividades do sistema $\left(\Gamma_{1}\right)$ para confrontos automatizados com projéteis $9 \mathrm{~mm}$ Luger, foram calculadas da mesma forma e lançadas na tabela abaixo.

Tabela 29 - Efetividades do sistema $\left(\Gamma_{1}\right)$ para confrontos automatizados com projéteis $9 \mathrm{~mm}$ Luger.

\begin{tabular}{|l|l|r|r|r|r|}
\hline \multicolumn{1}{|c|}{ PQ } & USUÁRIO & \multicolumn{1}{c|}{ PP1 } & \multicolumn{1}{c|}{ PP2 } & \multicolumn{1}{c|}{ PP3 } & \multicolumn{1}{c|}{ PP4 } \\
\hline I & Perito & 0,94 & 0,94 & 0,71 & 0,71 \\
\hline II & Perito & 0,81 & 0,97 & 0,79 & 0,71 \\
\hline III & Perito & 0,58 & 0,62 & 0,92 & 0,53 \\
\hline IV & Perito & 0,55 & 0,68 & 0,55 & 0,93 \\
\hline I & Aluno & 0,96 & 0,93 & 0,73 & 0,61 \\
\hline II & Aluno & 0,70 & 0,88 & 0,75 & 0,55 \\
\hline III & Aluno & 0,72 & 0,66 & 0,74 & 0,57 \\
\hline IV & Aluno & 0,73 & $\mathbf{0 , 5 9}$ & 0,55 & 0,82 \\
\hline
\end{tabular}

As médias das efetividades ficaram em $0,75( \pm 0,16)$ para perito e em $0,72( \pm 0,13)$ para aluno, e por isso não pode ser rejeitada a hipótese de igualdade de efetividades do sistema entre usuários com projéteis $9 \mathrm{~mm}$ Luger. 
Para verificar a influência de tipo de projétil nas efetividades do sistema, foram lançadas as médias e desvios padrão das efetividades do sistema com com projétil padrão 9mm Luger na Figura 56, demonstrando visualmente que não foram observadas diferenças estatisticamente relevantes nas efetividades do sistema em relação ao tipo de projétil padrão 9mm Luger e em relação ao usuário.

Os gráficos da Figura 57 mostram as efetividades gerais por perito e por aluno confirmando que não houve diferença de desempenho do sistema em relação ao tipo de usuário que marcou os projéteis para confrontos com projéteis 9mm Luger.

Figura 56 - Médias e desvios padrão dos critérios de efetividade $\left(\Gamma_{1}\right)$ por tipo de projétil padrão 9mm Luger (PP1 a PP4) e por usuário.

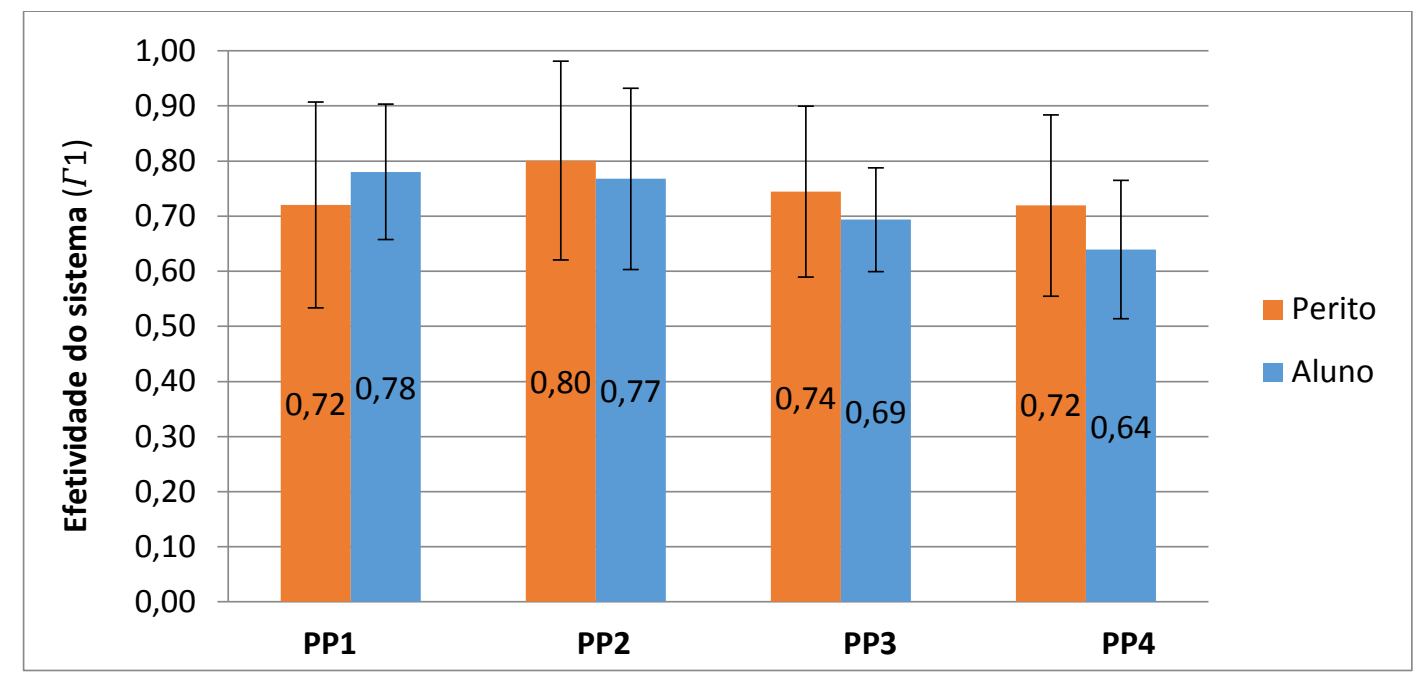

Figura 57 - Comparação da efetividade do sistema $\left(\Gamma_{1}\right)$ entre amostras de perito e amostra de aluno para projéteis padrões no calibre $9 \mathrm{~mm}$ Luger.

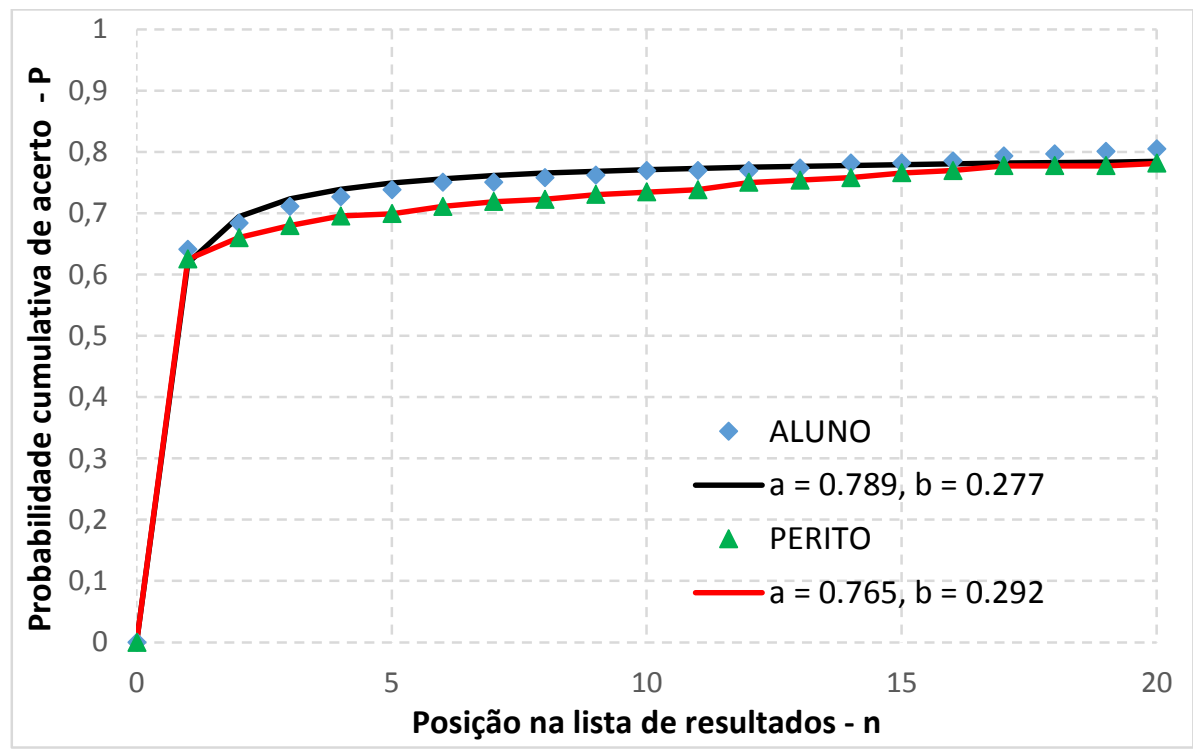




\subsubsection{Influência do tipo de raiamento de arma $9 \mathrm{~mm}$ Luger na efetividade do sistema}

Uma análise da lista de armas do APENDICE I revela que 2 (duas) das 16 (dezesseis) armas no calibre 9mm Luger apresentavam raiamento do tipo poligonal, diferente dos raiamentos das demais armas que eram retangulares. Para estudar a possível influência desta característica da arma na efetividade do sistema foram calculados os critérios de efetividade por arma no calibre 9mm Luger, com os valores lançados na Tabela 30.

Tabela 30 - Efetividades do sistema $\left(\Gamma_{1}\right)$ por arma no calibre $9 \mathrm{~mm}$ Luger.

\begin{tabular}{|l|c|c|c|c|c|c|c|c|}
\hline ARMA & 18 & 19 & 20 & 21 & 22 & 23 & 24 & 25 \\
\hline PERITO & 0,88 & 0,99 & 0,97 & 0,91 & 0,94 & 0,42 & 0,68 & 0,43 \\
\hline ALUNO & 0,88 & 0,98 & 0,94 & 1,00 & 0,70 & 0,26 & 0,68 & 0,65 \\
\hline ARMA & 26 & 27 & 28 & 29 & 30 & 31 & 32 & 33 \\
\hline PERITO & 0,92 & 0,73 & 0,39 & 0,91 & 1,00 & 0,31 & 0,47 & 1,00 \\
\hline ALUNO & 0,93 & 0,86 & 0,44 & 0,58 & 1,00 & 0,24 & 0,43 & 1,00 \\
\hline
\end{tabular}

Figura 58 - Critérios de efetividade $\left(\Gamma_{1}\right)$ por armas no calibre 9mm Luger (18 a 33) e por usuário.

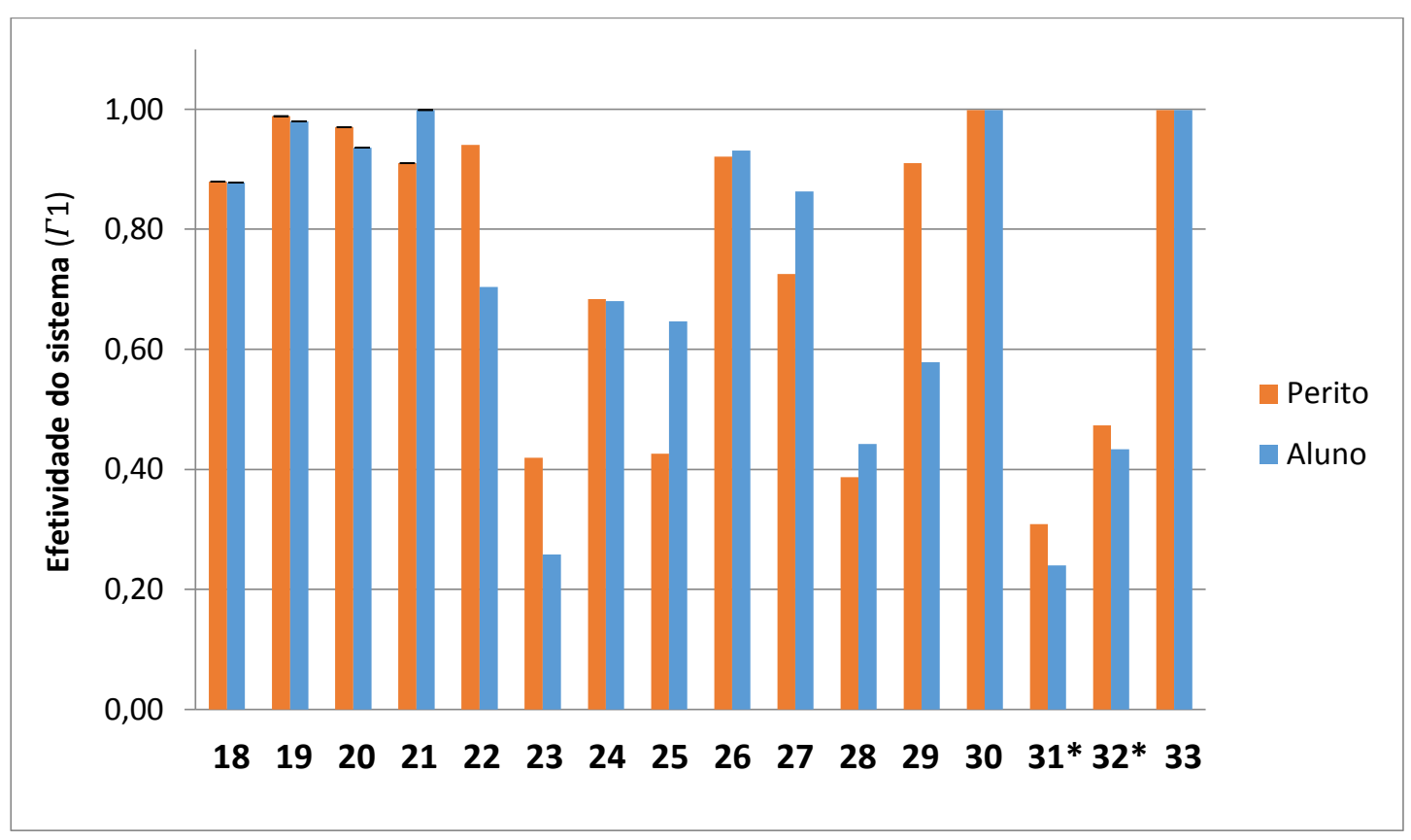

O gráfico da Figura 58 mostra os critérios de efetividade para cada arma no calibre $9 \mathrm{~mm}$ Luger, por usuários perito e aluno, e demonstram diferenças estatisticamente significativa em relação às armas no calibre $9 \mathrm{~mm}$ Luger. 
As armas marcadas com asterisco (31 e 32) apresentavam cano com raiamento do tipo poligonal e com elas o sistema apresentou efetividade média de $0,36( \pm 0,11)$, valor bem inferior à média de efetividade do sistema com as demais quatorze armas, que foi de $0,77( \pm 0,24)$. Isto pode ser um indício de que o sistema apresentou dimuinação nas efetividades das comparações automatizadas com raiamento poligonal.

Porém, deve ser observado que haviam apenas duas armas com raiamento poligonal no conjunto de armas estudadas, e que pelo menos duas armas com raiamento do tipo retangular também apresentaram baixa efetividade (23 e 28), levando à conclusão que apenas um estudo com mais armas com raiamento poligonal poderia confirmar se esta característica da arma diminui a efetividade do sistema.

\subsubsection{Influência do tipo de estojo $9 \mathrm{~mm}$ Luger na efetividade do sistema}

No exemplo 4.1.1.4 foi obtida uma efetividade de 0,74, para configuração I4P, e este valor foi lançado na linha I Perito, coluna EP4, da Tabela 31 (ver valor em vermelho). Todas as demais efetividades do sistema $\left(\Gamma_{1}\right)$ para confrontos automatizados com estojos 9mm Luger foram calculadas da mesma forma e lançadas na Tabela 31.

Tabela 31 - Efetividades do sistema $\left(\Gamma_{1}\right)$ para confrontos automatizados com estojos $9 \mathrm{~mm}$ Luger.

\begin{tabular}{|l|l|r|r|r|r|}
\hline \multicolumn{1}{|c|}{ EQ } & USUÁRIO & \multicolumn{1}{c|}{ EP1 } & \multicolumn{1}{c|}{ EP2 } & \multicolumn{1}{c|}{ EP3 } & \multicolumn{1}{c|}{ EP4 } \\
\hline I & Perito & 0,93 & 0,93 & 0,81 & 0,74 \\
\hline II & Perito & 0,88 & 0,82 & 0,87 & 0,88 \\
\hline III & Perito & 0,88 & 0,94 & 0,77 & 0,80 \\
\hline IV & Perito & 0,81 & 0,85 & 0,65 & 0,69 \\
\hline I & Aluno & 0,91 & 0,94 & 0,80 & 0,73 \\
\hline II & Aluno & 0,89 & 0,84 & 0,88 & 0,90 \\
\hline III & Aluno & 0,90 & 0,92 & 0,79 & 0,78 \\
\hline IV & Aluno & 0,79 & 0,84 & 0,63 & 0,67 \\
\hline
\end{tabular}

O gráfico da Figura 59 mostra as médias dos critérios de efetividade para cada tipo de estojo padrão (EP1 a EP4) por usuários perito e aluno, e a análise visual mostra que não houve diferenças estatisticamente significativas em relação a usuários ou a tipo de estojos padrões quando efetuando comparações automatizadas com estojo 9mm Luger. 
Figura 59 - Médias e desvios padrão dos critérios de efetividade por tipo de estojo padrão 9mm Luger (EP1 a EP4) e por usuário.

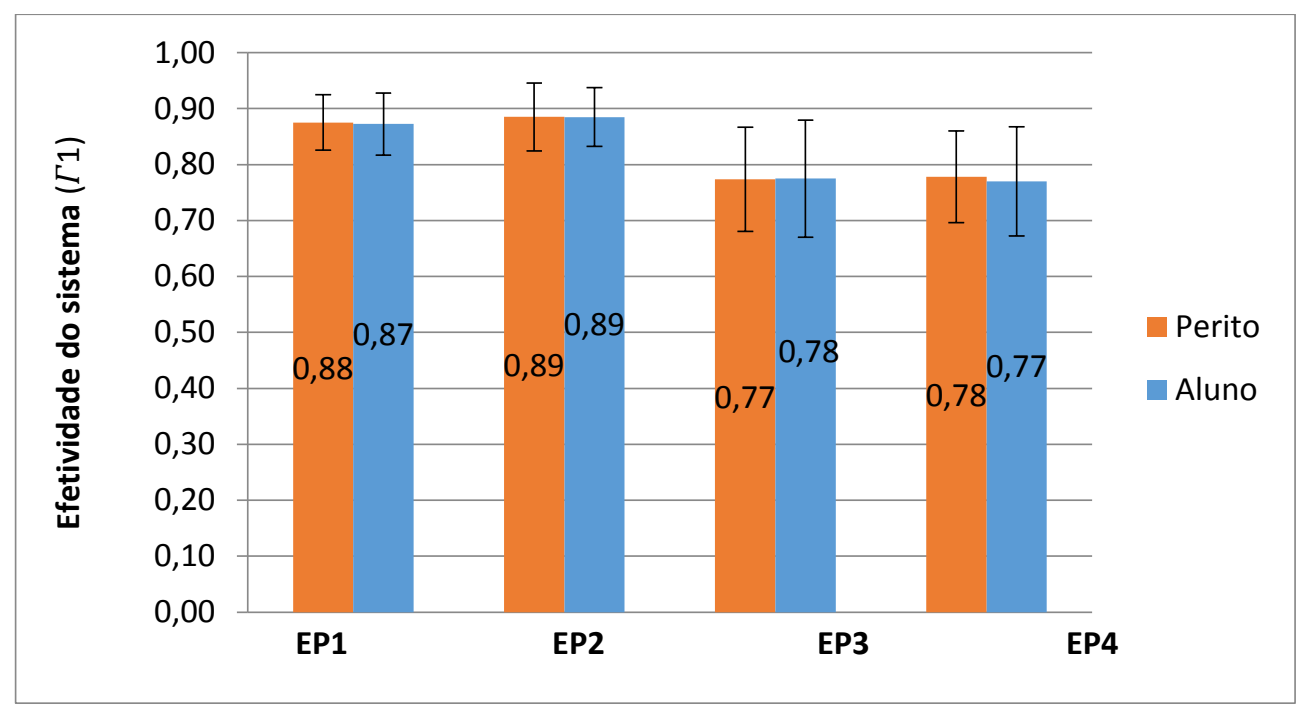

\subsection{RESULTADOS E ANÁLISES DOS TESTES DE DUREZA}

Os resultados dos confrontos automatizados, tanto no calibre .38SPL como no calibre 9mm Luger, não apresentaram diferenças estatisticamente significativas nos critérios de efetividade por estojos, e por isso os testes de dureza foram realizados apenas em projéteis.

Os resultados dos testes de dureza Brinell nos projéteis .38SPL e 9mm Luger, efetuados conforme descrito em 3.2, foram lançados no APÊNDICE II, e analisados nas próximas duas seções.

\subsubsection{Testes de dureza em projéteis .38SPL}

As médias e os desvios padrão (DP) dos resultados de dureza Brinell em projéteis disparados e não disparados no calibre .38SPL foram lançados na Tabela 32 e Figura 60.

Foram realizados ensaios em projéteis antes e após serem disparados para verificar se o projétil teria sofrido encruamento devido à deformação plástica ao passar sob pressão pelo cano, mas não foram observadas diferenças significativas nas médias das durezas entre projéteis não disparados e disparados e, portanto, este encruamento não foi constatado.

Entre os tipos de projéteis padrões ficou evidente as diferenças nas médias de dureza Brinell, uma vez que o projétil PP1 apresentou média de dureza muito inferior aos demais. 
Tabela 32 - Médias e desvios padrão dos resultados de dureza Brinell com projéteis disparados e não disparados no calibre .38SPL.

\begin{tabular}{|c|c|c|c|c|}
\hline \multirow{2}{*}{$\begin{array}{c}\text { Projétil } \\
\text { Padrão }\end{array}$} & \multicolumn{2}{|c|}{ PROJÉTEIS DISPARADOS } & \multicolumn{2}{c|}{ PROJÉTEIS NÃO DISPARADOS } \\
\cline { 2 - 5 } & Média & DP & Média & DP \\
\hline PP1 & 5,0 & 0,3 & 5,9 & 0,4 \\
\hline PP2 & 90,8 & 4,7 & 89,1 & 4,4 \\
\hline PP3 & 103,1 & 6,3 & 97,5 & 5,8 \\
\hline PP4 & 95,2 & 9,9 & 92,8 & 11,0 \\
\hline PP5 & 116,2 & 7,1 & 114,4 & 6,9 \\
\hline PP6 & 108,5 & 5,1 & 107,7 & 6,7 \\
\hline
\end{tabular}

Figura 60 - Médias e desvios padrão das durezas Brinell para projéteis .38SPL.

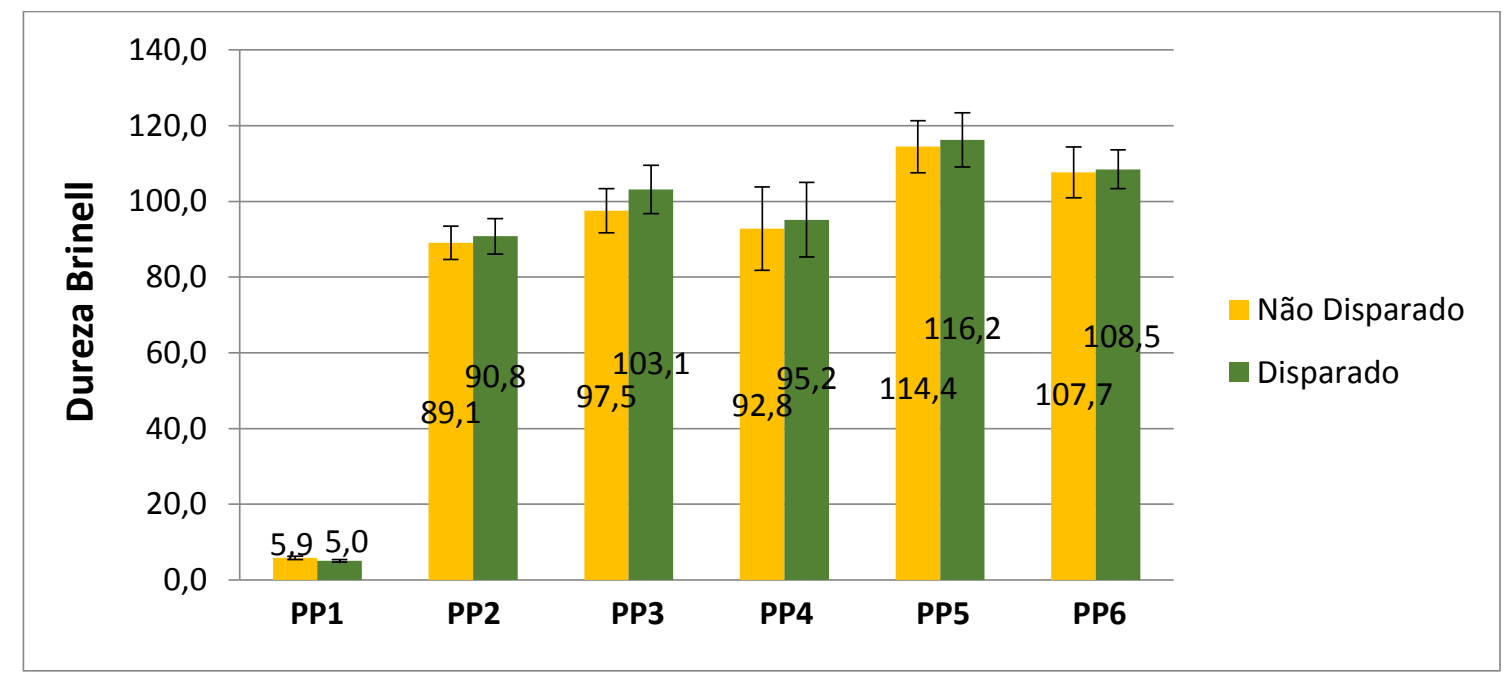

Uma comparação entre as médias de dureza Brinell para cada tipo de projétil .38SPL e as respectivas efetividades do sistema para estes projéteis evidenciou uma importante relação entre dureza do projétil e efetividade do sistema, conforme pode ser visualizado na Figura 61.

A média total de dureza Brinell de projéteis padrões PP1 ficou em 5,4 $( \pm 0,6) \mathrm{HWB}$, valor muito inferior à média de dureza Brinell de todos os demais projéteis padrões, que resultou em $101,5( \pm 10,3)$ HWB, e isso pode servir como explicação para o sistema ter apresentado efetividade tão baixa com este tipo de projétil quando comparada às efetividades com os demais projéteis padrões.

Foi registrado em 4.1.2 que ao operar com projéteis .38SPL PP1 e PP7 o sistema apresentou médias das efetividades iguais a $0,31( \pm 0,06)$ e $0,36( \pm 0,06)$. Isto demonstrou não haver diferença significativa nas efetividades do sistema entre projéteis CHOG coletados no 
início e no final dos disparos. Mas, comparando estes desempenhos com os desempenhos do sistema com os demais tipos de projéteis, fica evidente a dificuldade em fazer correlações corretas quando os padrões cadastrados no banco de dados são do tipo CHOG.

Figura 61 - Comparação das médias dos critérios de efetividade do sistema $(\Gamma 1)$ com projéteis .38SPL (PP1 a PP6) com as respectivas durezas Brinell.

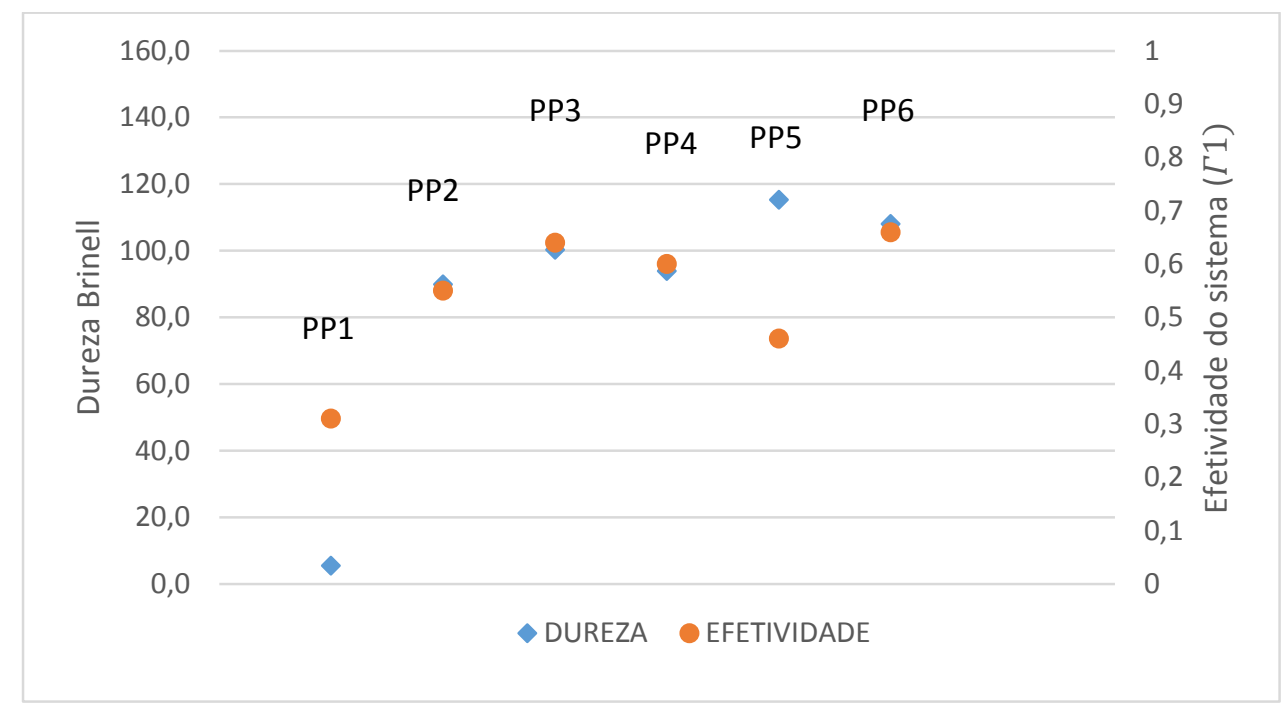

Com projéteis .38SPL questionados do tipo CHOG, a efetividade média do sistema ficou em apenas 0,26 $( \pm 0,07)$, confirmando a dificuldade do sistema em corretamente correlacionar projéteis deste material.

A Figura 62 mostra uma comparação de imagens de mesmos cavados e cheios de dois projéteis disparados por uma mesma arma. A imagem inferior corresponde a um projétil do tipo PP1, com menor dureza que a do projéil de cima, do tipo PP6. Foi notado nessa, e em diversas outras comparações, que projéteis do tipo CHOG, após disparados, apresentam um número muito maior de estrias do que todos os demais tipos de projéteis .38SPL.

Como consequiência da baixa dureza dos projéteis $\mathrm{CHOG}$, o número de marcas estriadas neles geradas quando passam através do cano da arma é muito maior do que para projéteis mais duros. Embora em maior número, nem todas estrias representam características individuais do cano, pois algumas são provenientes de detritos deixados no cano por disparos anteriores, enquanto que outras, ainda que representem características individuais do cano, são muito pequenas e não conseguem marcar projéteis mais duros. Além disso, mesmo pequenas diferenças de pressão na câmara de combustão durante o disparo podem gerar diferenças significativas nas marcas impressas nos projéteis de chumbo, adicionando ruído ao processo de comparação automatizada e resultando em baixa efetividade do sistema. 
Figura 62 - Comparação de imagens de dois projéteis padrões disparados por uma mesma arma, a de baixo do tipo PP1 e a de cima do tipo PP6.

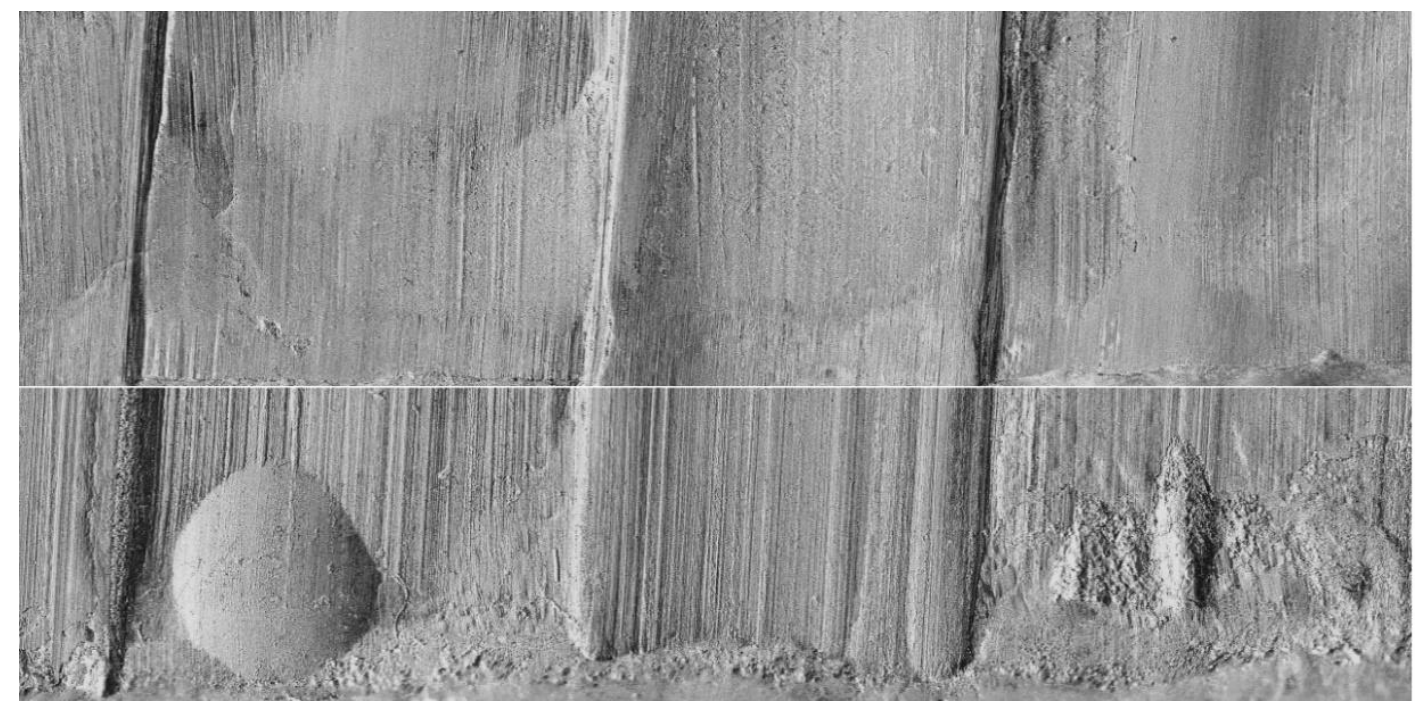

\subsubsection{Testes de dureza em projéteis $9 \mathrm{~mm}$ Luger}

As médias e os desvios padrão dos resultados de dureza Brinell, em projéteis disparados e não disparados, no calibre 9mm Luger, foram lançadas na Tabela 33 e Figura 63.

Tabela 33 - Médias e desvios padrão dos resultados de dureza Brinell com projéteis disparados e não disparados no calibre $9 \mathrm{~mm}$ Luger.

\begin{tabular}{|c|c|c|c|c|}
\hline \multirow{2}{*}{$\begin{array}{c}\text { Projétil } \\
\text { Padrão }\end{array}$} & \multicolumn{2}{|c|}{ PROJÉTEIS DISPARADOS } & \multicolumn{2}{c|}{ PROJÉTEIS NÃO DISPARADOS } \\
\cline { 2 - 5 } & Média & DP & Média & DP \\
\hline PP1 & 138,6 & 11,3 & 136,3 & 7,9 \\
\hline PP2 & 143,7 & 9,1 & 133,1 & 4,5 \\
\hline PP3 & 140,2 & 6,8 & 134,7 & 5,0 \\
\hline PP4 & 70,9 & 3,4 & 70,7 & 3,3 \\
\hline
\end{tabular}

Não foram observadas diferenças significativas nas médias das durezas entre projéteis não disparados e disparados, mas entre os tipos de projéteis padrões ficou evidente as diferenças nas médias, uma vez que o tipo de projétil PP4 apresentou dureza Brinell média de 70,8 $( \pm 3,3)$ HWB e os demais dureza Brinell média de 137,8 $( \pm 8,4)$ HWB.

Para investigar se a efetividade do sistema com estes projéteis estaria relacionada às diferenças em dureza Brinell observadas, tal como ficou evidente para projéteis .38SPL, foi elaborado o gráfico comparativo da Figura 64, comparando as médias totais dos resultados dos 
testes de dureza Brinell com os respectivos critérios de efetividade do sistema com estes projéteis $9 \mathrm{~mm}$ Luger.

Figura 63 - Médias e desvios padrão das durezas Brinell para projéteis 9mm Luger.

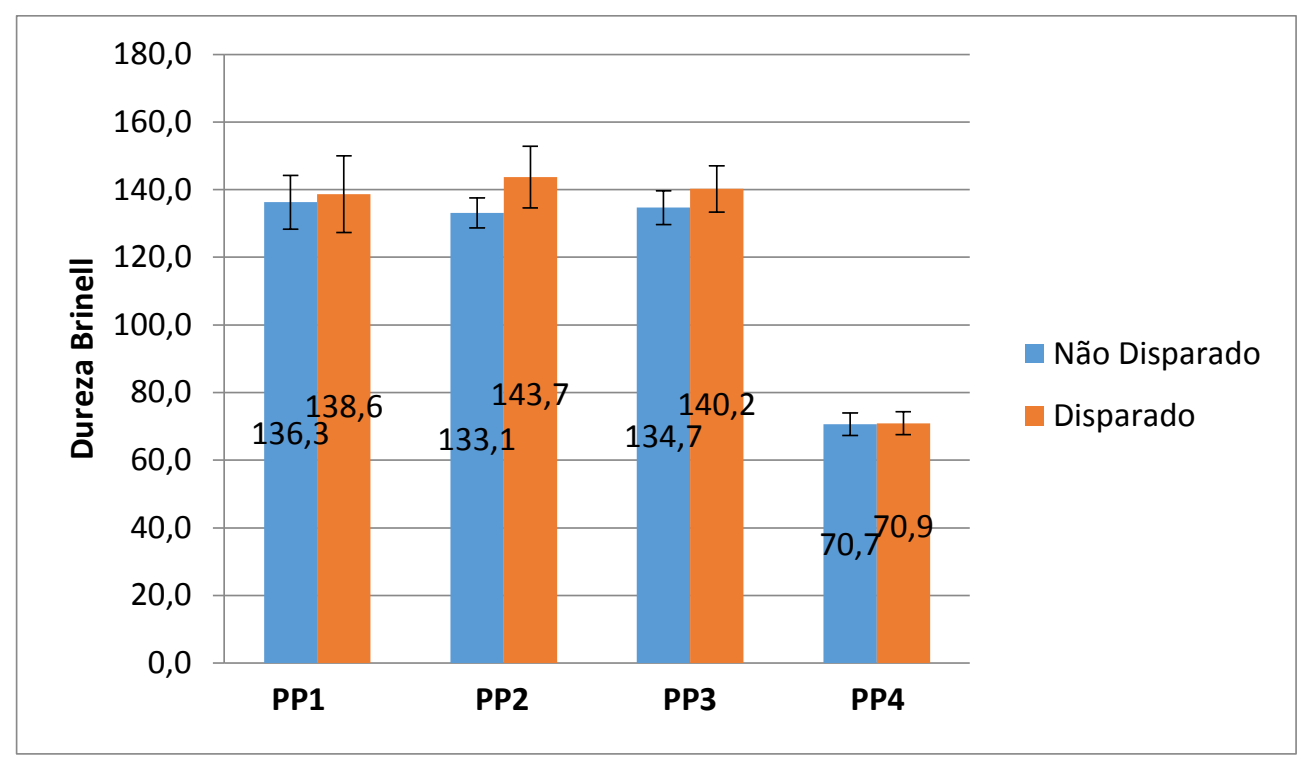

Figura 64 - Comparação dos critérios de efetividade do sistema $(\Gamma 1)$ com projéteis $9 \mathrm{~mm}$ Luger (PP1 a PP4) com as respectivas durezas Brinell.

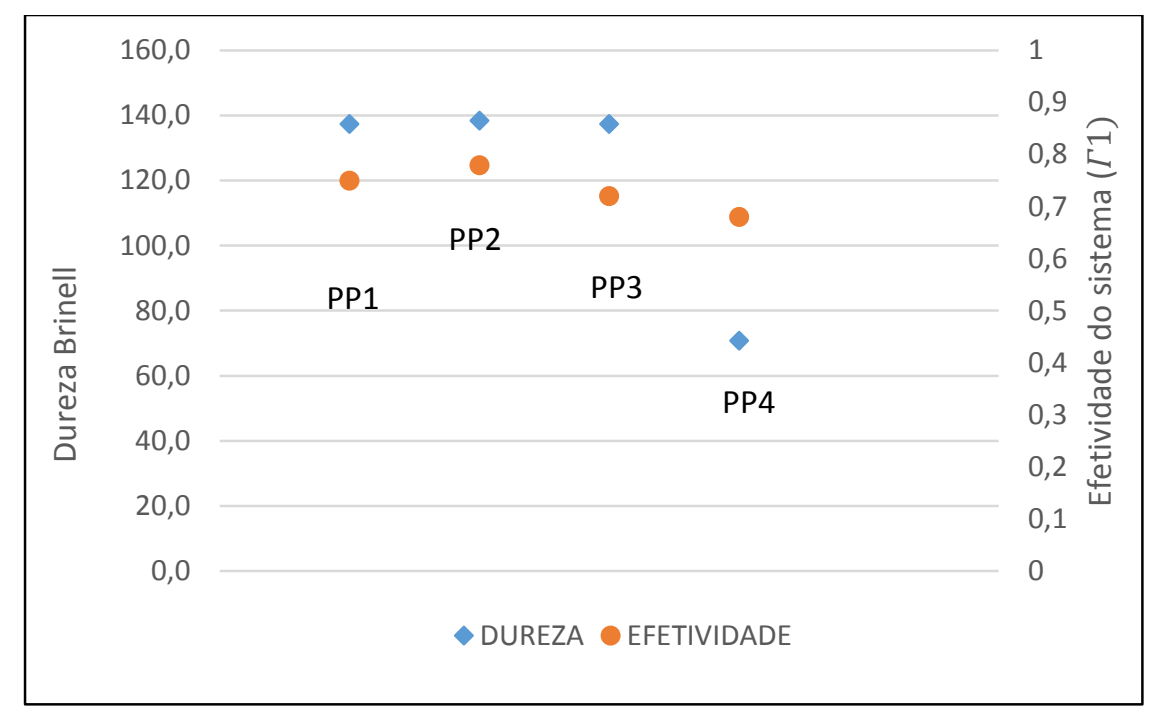

A análise da Figura 64 evidencia a diminuição da efetividade devido a dimunição da dureza do projétil PP4, embora de maneira não tão acentuada como ocorreu com os resultados de projétil .38SPL. Esta diminuição de efetividade mais moderado deve ser devida a uma diferença de dureza também não tão acentuada de PP4 em relação aos demais. 


\subsection{RESULTADOS E ANÁLISES DOS TESTES DE RUGOSIDADE}

Os resultados dos testes de rugosidade com projéteis disparados, de calibres .38SPL e 9mm Luger, efetuados conforme descrito em 3.3, foram lançados no Apêndice III, e analisados nesta seção.

As imagens de cavados dos projéteis analisados no microscópio confocal foram capturadas com lente de aumento de 5x, Zoom 1x, o que, considerando a diagonal da tela de análise, gerou um aumento de 5x1x21,6 = 108 vezes (ver imagens nas Figura 65 e Figura 66).

As médias e os desvios padrão dos parâmetros $\mathrm{Ra}$ e $\mathrm{Rz}$ da rugosidade de projéteis disparados no calibre .38SPL e 9mm Luger foram lançados respectivamente na Tabelas 34 e 35.

Figura 65 - Imagens de cavados dos projéteis .38SPL analisados no microscópio confocal (escala em vermelho e branco $=400 \mu \mathrm{m})$.

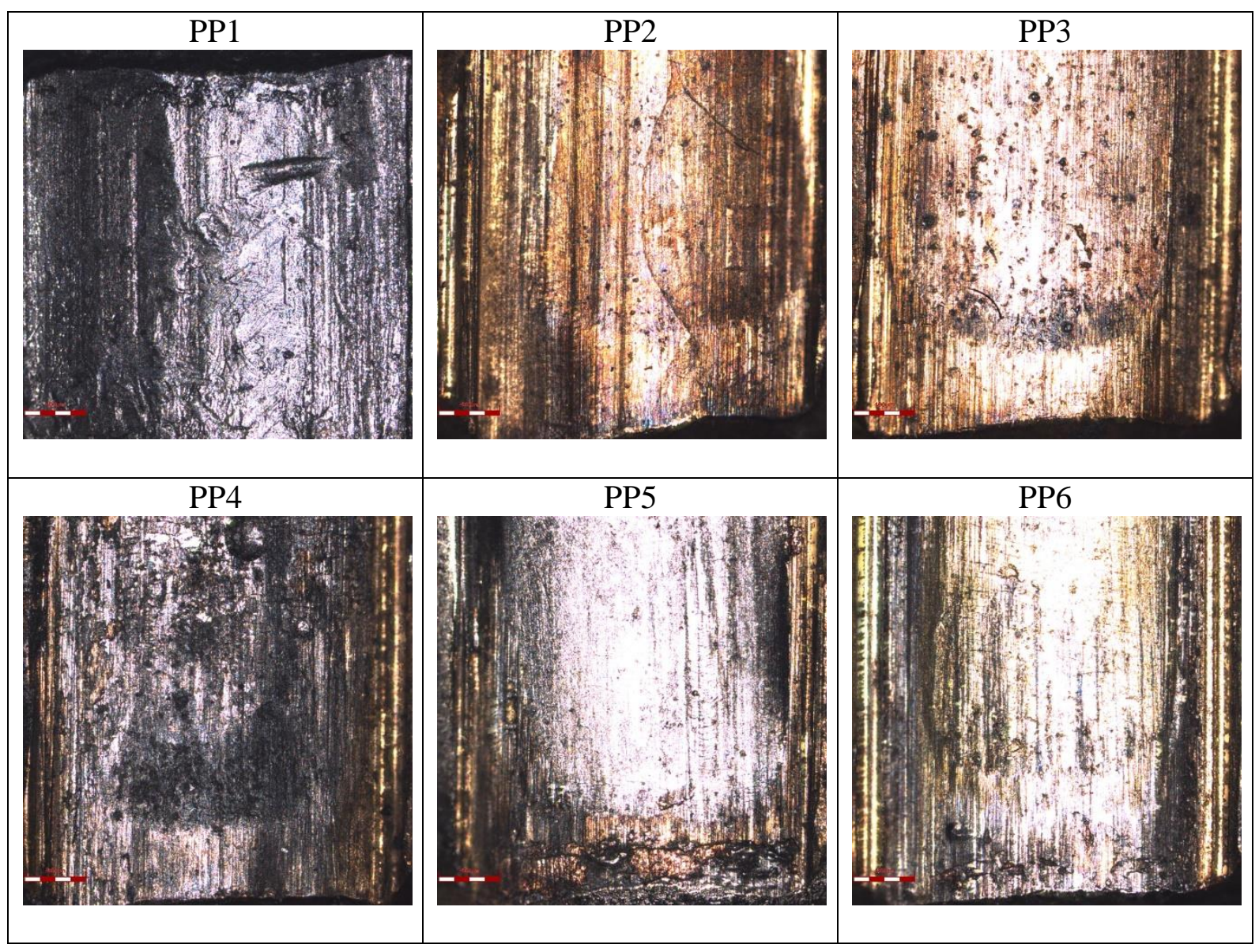


Figura 66 - Imagens de cavados dos projéteis 9mm Luger analisados no microscópio confocal (escala em vermelho e branco $=400 \mu \mathrm{m})$.

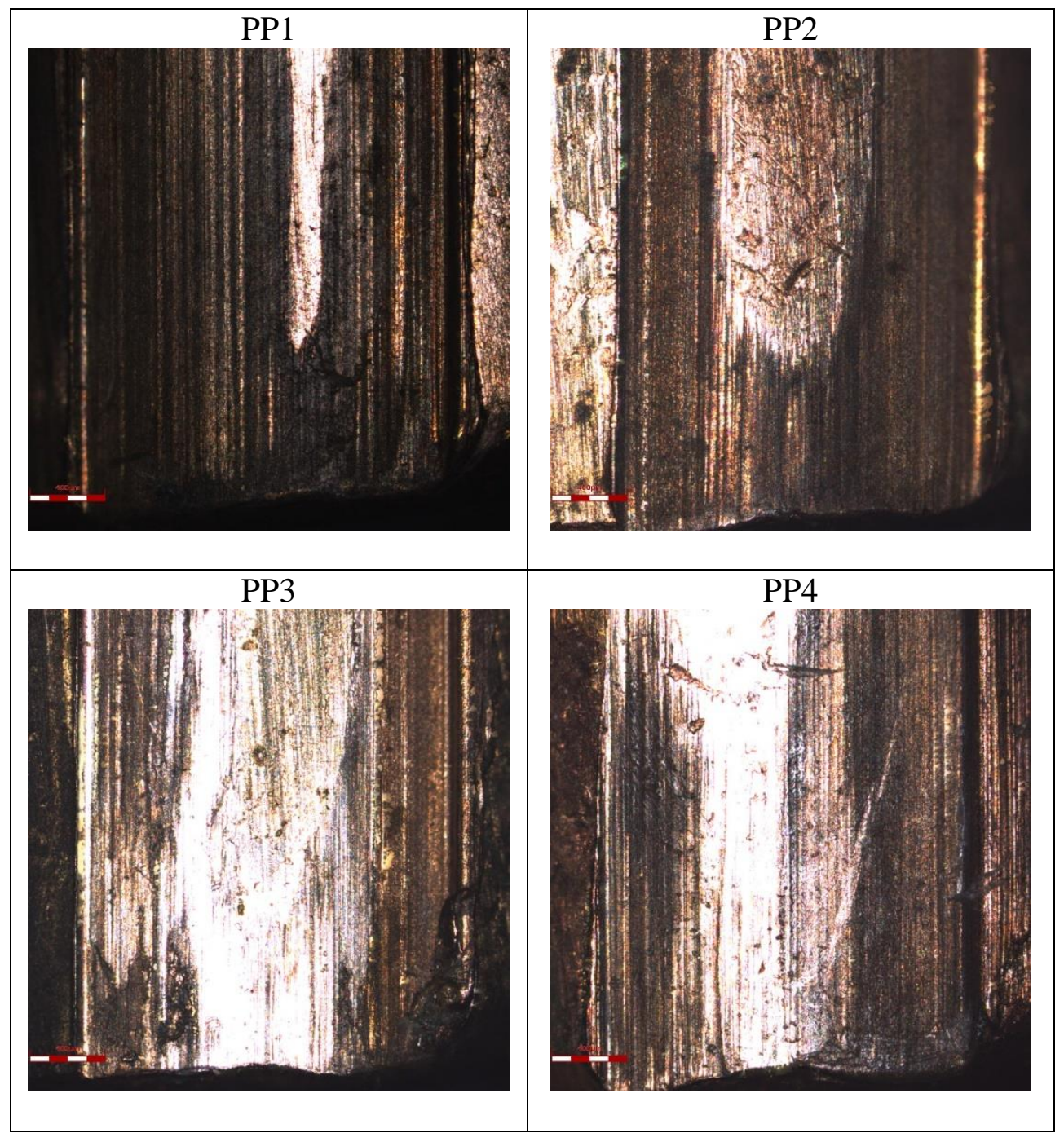

Tabela 34 - Médias e desvios padrão dos resultados de rugosidade com projéteis disparados no calibre .38SPL.

\begin{tabular}{|c|rrrrrr|}
\hline Projétil & \multicolumn{1}{|c}{ PP1 } & \multicolumn{1}{c}{ PP2 } & PP3 & PP4 & PP5 & \multicolumn{1}{c|}{ PP6 } \\
\hline Média Ra & 13,5 & 13,8 & 15,0 & 13,5 & 13,7 & 13,2 \\
DP (Ra) & 0,8 & 0,8 & 0,7 & 0,2 & 0,9 & 1,2 \\
\cline { 2 - 7 } Média Rz & 90,7 & 146,9 & 163,4 & 131,3 & 139,4 & 121,7 \\
DP (Rz) & 16,5 & 22,8 & 38,0 & 20,3 & 37,6 & 5,1 \\
\hline
\end{tabular}

As médias dos parâmetros Ra e Rz obtidos nos testes de rugosidade com projéteis disparados foram comparadas com as respectivas efetividades do sistema com estes projéteis através dos gráficos da Figura 67 à Figura 70. 
Tabela 35 - Médias e desvios padrão dos resultados de rugosidade com projéteis disparados no calibre 9mm Luger.

\begin{tabular}{|c|rrrr|}
\hline Projétil & \multicolumn{1}{|c}{ PP1 } & \multicolumn{1}{c}{ PP2 } & \multicolumn{1}{c|}{ PP3 } & \multicolumn{1}{c|}{ PP4 } \\
\hline Média Ra & 13,1 & 12,3 & 13,4 & 15,5 \\
DP (Ra) & 0,2 & 1,0 & 0,8 & 1,1 \\
\cline { 2 - 5 } Média Rz & 124,9 & 110,7 & 151,2 & 190,7 \\
DP (Rz) & 69,0 & 22,2 & 30,8 & 58,5 \\
\hline
\end{tabular}

Figura 67 - Comparação dos critérios de efetividade do sistema $(\Gamma 1)$ com projéteis .38SPL (PP1 a PP6) com os respectivos parâmetros de rugosidade Ra.

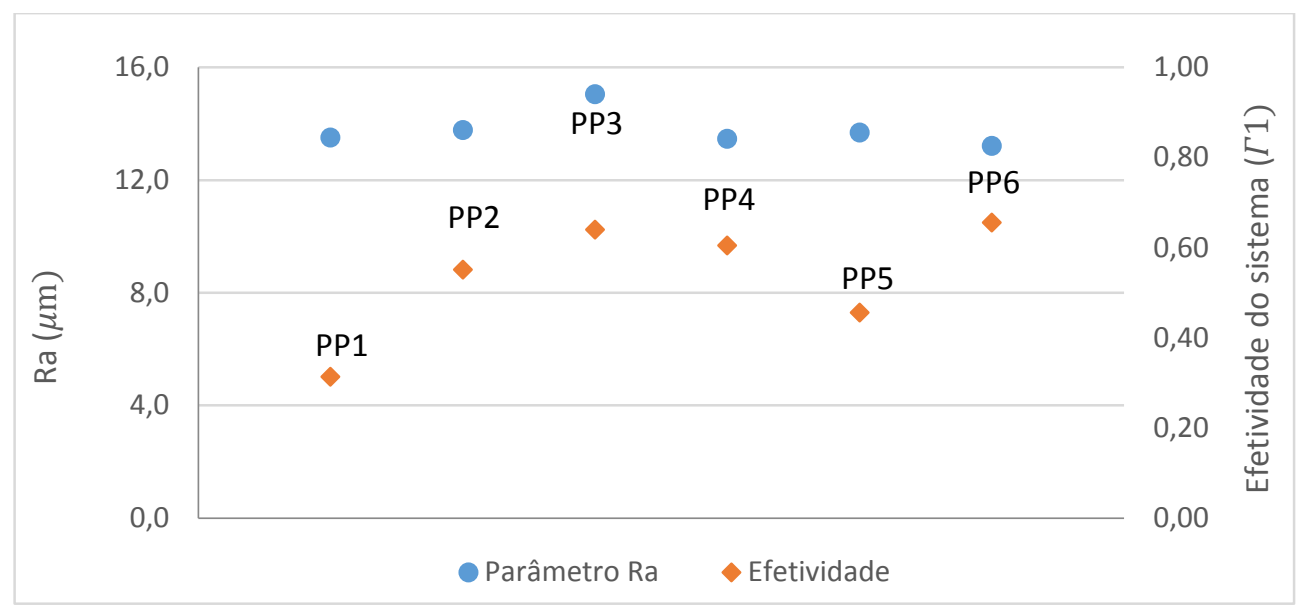

Figura 68 - Comparação dos critérios de efetividade do sistema $(\Gamma 1)$ com projéteis .38SPL (PP1 a PP6) com os respectivos parâmetros de rugosidade Rz.

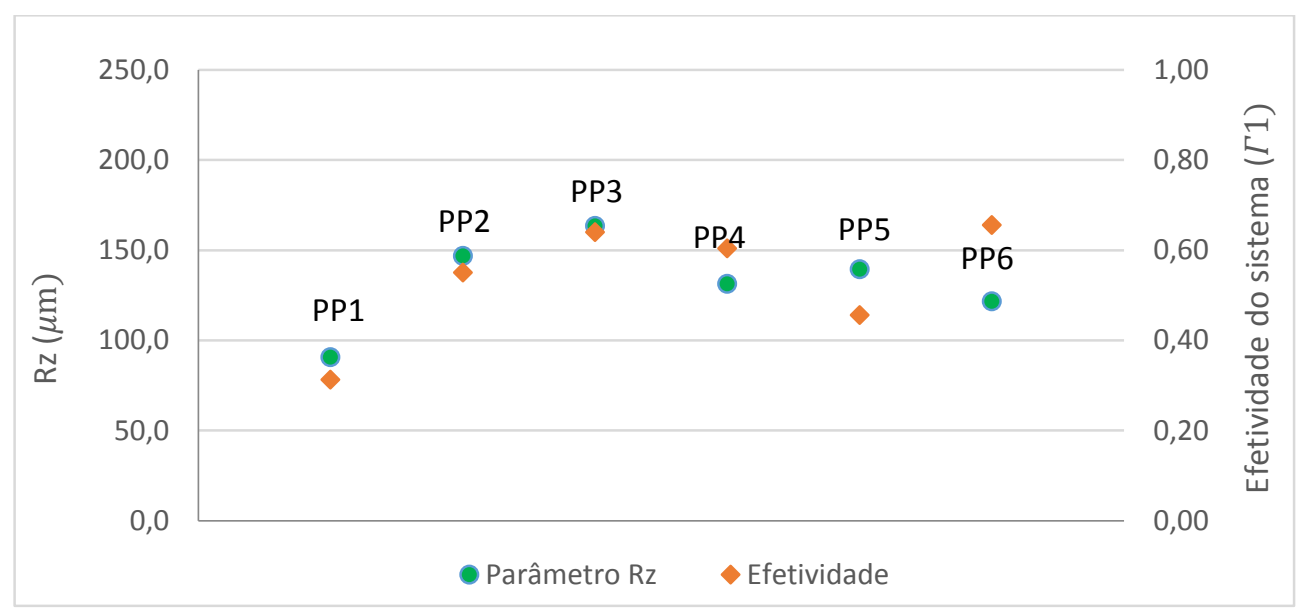

Nos exames realizados não foram detectadas relações entre estes parâmetros obtidos nos testes de rugosidade e as efetividades do sistema com os respectivos projéteis disparados nos calibres .38SPL e 9mm Luger. 
Figura 69 - Comparação dos critérios de efetividade do sistema $(\Gamma 1)$ com projéteis $9 \mathrm{~mm}$ Luger (PP1 a PP4) com os respectivos parâmetros de rugosidade Ra.

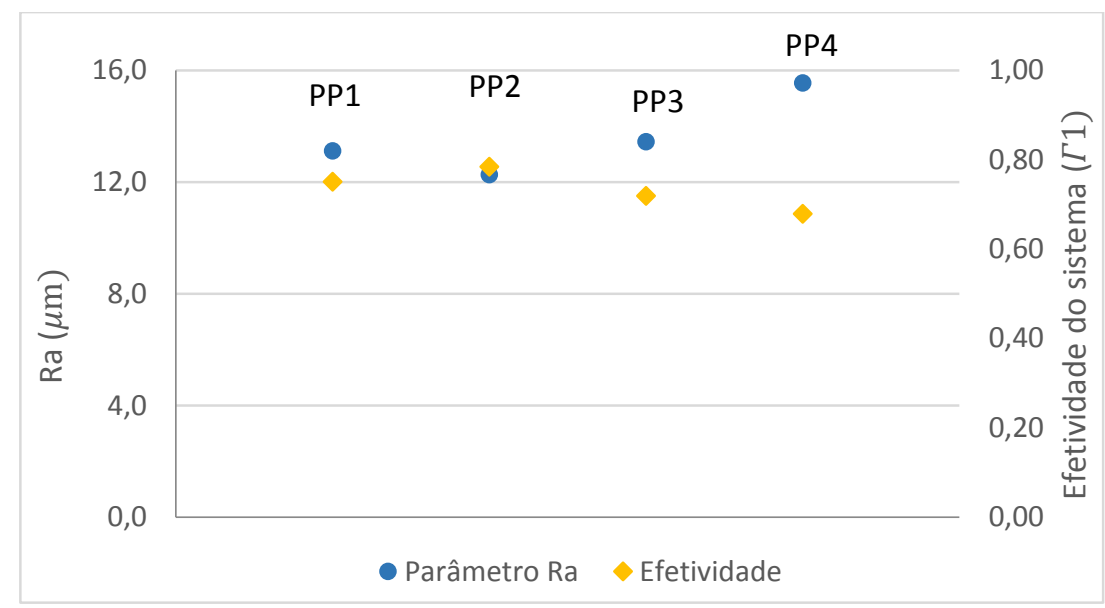

Figura 70 - Comparação dos critérios de efetividade do sistema ( $\Gamma 1)$ com projéteis $9 \mathrm{~mm}$ Luger (PP1 a PP4) com os respectivos parâmetros de rugosidade Rz.

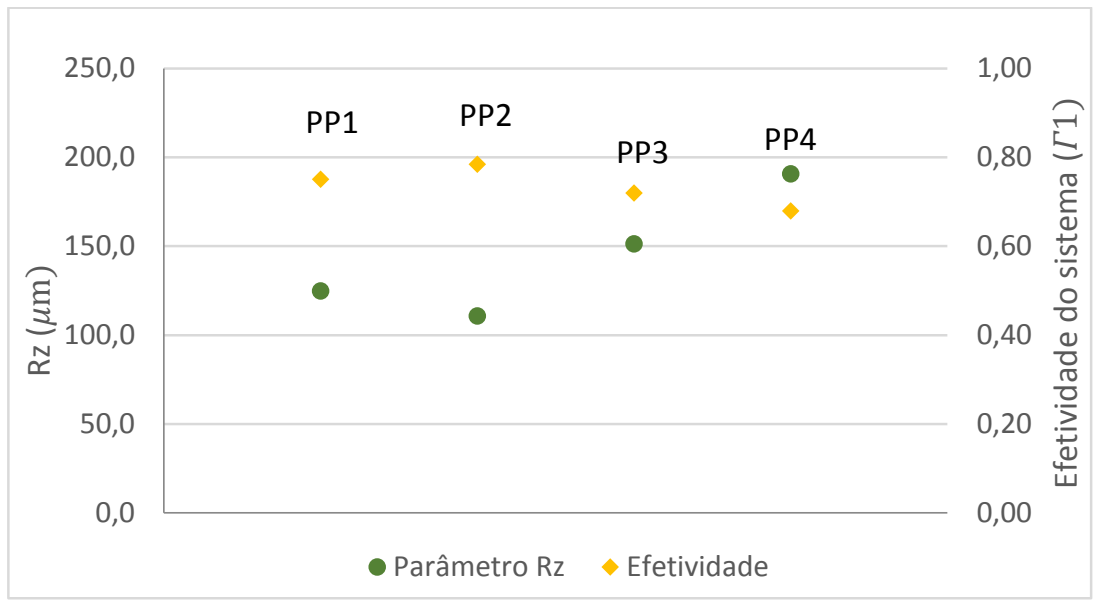




\section{CONCLUSÕES}

Comparação automatizada de elementos de munição proveniente de armas de fogo apresenta importantes desafios às ciências forense. Para verificar parâmetros que podem afetar a efetividade de um sistema de identificação balística foram coletados projéteis e estojos, com diferentes tipos de munição nos calibres .38SPL e 9mm Luger, e realizados confrontos automatizados no sistema de identificação balística Evofinder ${ }^{\circledR}$.

Uma pequena variação do critério de efetividade para comparações automatizadas proposto por Rahm (2012) foi sugerida e utilizada para analisar milhares de comparações automatizadas controladas, demonstrando como o sistema é sensível às propriedades de estojos e projéteis utilizados na coleta de padrões ou às qualificações de usuário operador do sistema.

Para projéteis no calibre .38SPL foram cadastrados sete tipos de projéteis padrões com formatos e composições diferentes. Os exames demonstraram a influência do tipo de projétil e da qualificação do usuário. Com projéteis semiencamisados ponta oca e expansivo ponta oca Gold (tipos PP3 e PP6 da Tabela 3) o sistema apresentou os melhores desempenhos, com efetividades médias em respectivamente $0,64( \pm 0,26)$ e $0,66( \pm 0,26)$, sugerindo que na coleta de padrões de armas no calibre .38SPL, estes tipos de projéteis são os mais recomendados. Com projéteis ogivais de chumbo (tipos PP1 e PP7 da Tabela 3) o sistema apresentou os piores resultados, com efetividades médias em respectivamente $0,31( \pm 0,06)$ e $0,36( \pm 0,06)$. Não obstante, ficou evidente também a validade de cadastrar padrões deste tipo, pois são os mais eficientes em encontrar questionados do mesmo tipo, ou seja, CHOG.

Os testes de dureza nos projéteis e as análises das imagens demostraram que a baixíssima dureza Brinell dos projéteis do tipo $\mathrm{CHOG}$ deve ser o fator para a baixa efetividade do sistema com eles. Como consequiência da baixa dureza destes projéteis, o número de marcas estriadas neles geradas quando passam através do cano da arma é muito maior do que para projéteis mais duros. Embora em maior número, nem todas estrias representam características individuais do cano, pois algumas são provenientes de detritos deixados no cano por disparos anteriores, enquanto que outras, ainda que representem características individuais do cano, são muito pequenas e não conseguem marcar projéteis mais duros. Além disso, mesmo pequenas diferenças de pressão na câmara de combustão durante o disparo podem gerar diferenças significativas nas marcas impressas nos projéteis de chumbo, adicionando ruído ao processo de comparação automatizada e resultando nas baixas efetividades do sistema obtidas com estes projéteis. 
Em uma primeira análise com projéteis .38SPL, os bancos de dados operados por alunos e peritos apresentaram efetividades muito semelhantes nas comparações automatizadas. Porém, quando foram retiradas das análises os resultados envolvendo projéteis do tipo CHOG, evidenciou-se uma melhor efetividade do sistema com amostras cadastradas e marcadas por peritos, com efetividade média de 0,67 $( \pm 0,14)$, em comparação com a efetividade média de $0,53( \pm 0,14)$ com amostras operadas por alunos. Já com projéteis no calibre $9 \mathrm{~mm}$ Luger não houve diferença significativa das efetividades entre peritos e alunos, sendo que as médias das efetividades obtidas foram $0,75( \pm 0,16)$ para perito e $0,72( \pm 0,13)$ para aluno. Foi constatado que no início do experimento, com projéteis .38SPL, os alunos cometeram erros nas marcações de estrias nas imagens dos projéteis, como confusão entre o que seria um cheio e o que seria um cavado e marcação de partes sem estrias significativas, o que explica a diferença de efetividades observada neste calibre. Já na marcação dos projéteis 9mm Luger, os alunos não cometeram os erros citados, e por isso o sistema não apresentou diferença estatisticamente significativa nas efetividades por usuário com projéteis neste calibre.

No calibre 9mm Luger foi constatada uma diferença entre as efetividades por tipo de raiamento do cano da arma, sendo que armas com raiamento do tipo poligonal apresentaram efetividade média de $0,36( \pm 0,11)$, valor bem inferior à média das efetividades das armas com raiamento do tipo retangular, $0,77( \pm 0,24)$. Como as armas com raiamento poligonal apresentam melhor acabamento, isso faz com que projéteis disparados por seus canos apresentem menos marcas com características individuais, o que explica o fato do sistema apresentar pior efetividade nas correlações com estas armas. Apesar disso, foi observado que haviam apenas duas armas com raiamento poligonal no conjunto de armas estudadas, e que pelo menos duas armas com raiamento do tipo retangular também apresentaram baixa efetividade, levando à conclusão de que apenas um estudo com mais armas com raiamento poligonal poderia confirmar se esta característica da arma diminui a efetividade do sistema.

Em relação aos estojos tanto no calibre .38SPL como 9mm Luger não foram observadas diferenças significativas de efetividades entre tipos de estojos e entre tipos de usuários, o que é um importante dado para planejamento de um banco de dados nestes calibres.

As efetividades obtidas neste estudo, por tipo de elemento de munição e calibre, mostram-se de acordo com trabalhos anteriores publicados (DE KINDER; TULLENERS; THIEBAUT, 2004; RAHM, 2012; e CEUSTER; DUJARDIN, 2015) e acrescentam importantes dados à literatura, uma vez que os ensaios foram efetuados com munição de fabricação nacional, e obteve-se efetividades por tipos de projéteis, tipos de estojos e qualificações de usuários. 
Um teste preliminar no calibre .38SPL, comparando apenas os padrões cadastrados, resultou em efetividade de 0,97 com projéteis e de 0,95 com estojos. Já as efetividades dos testes com todo o banco de dados disponível no calibre .38SPL, ficou em 0,51 com projéteis e de 0,43 com estojos. Estas diminuições nas efetividades do sistema confirmaram estudos publicados (DE KINDER; TULLENERS; THIEBAUT, 2004; e CEUSTER; DUJARDIN, 2015) que concluíram que o aumento no banco de dados leva a uma piora significativa de efetividade do sistema, sugerindo que um banco de dados de imagens de todas as armas ainda é fortemente não recomendado, necessitando de maior desenvolvimento e estudos nos sistemas disponíveis. 


\section{TRABALHOS FUTUROS}

Tendo em vista que a grande diminuição na dureza Brinell em projéteis .38SPL levou a uma clara diminuição da efetividade do sistema, e uma pequena diminuição desta dureza em projéteis $9 \mathrm{~mm}$ Luger levou a uma pequena diminuição da efetividade, seria interessante utilizar projéteis 9mm Luger de dureza significativamente menores em relação aos aqui estudados para verificar a influência deste fator em comparações automatizadas com projéteis 9mm Luger.

Ainda em relação a projéteis $9 \mathrm{~mm}$ Luger foi observada uma diminuição na efetividade da arma por tipo de raiamento, o que poderia ser melhor estabelecido aumentando a amostra de armas com raiamento poligonal para uma conclusão mais fundamentada.

Um outro fator não abordado por este estudo, mas de extrema importância no planejamento de um futuro banco de imagens balísticas, seria o exame do desgaste do cano da arma, verificando como este desgaste, provocado pelo uso repetitivo da arma, afetaria a efetividade das comparações automatizadas. 


\section{REFERÊNCIAS BIBLIOGRÁFICAS}

ASSOCIAÇÃO BRASILEIRA DE NORMAS TÉCNICAS. NBR ISO 4287: Especificações geométricas do produto (GPS) - Rugosidade: Método do perfil - Termos, definições e parâmetros da rugosidade. Rio de Janeiro, 2002. 18p.

ASSOCIAÇÃO BRASILEIRA DE NORMAS TÉCNICAS. NBR NM ISO 6506-1: Materiais metálicos - Ensaio de Dureza Brinell Parte 1: Método de ensaio. Rio de Janeiro, 2010. 18p.

BANNO, A.; MASUDA, T.; IKEUCHI, K. Three dimensional visualization and comparison of impressions on fired bullets. Forensic science international, Elsevier, vol. 140, p. 233-240, 2004.

BECK, Wolfgang; EVERS, Jürgen; GÖBEL, Michael; OEHLINGER, Gilbert; KLAPÖTKE, Thomas M. The Crystal and Molecular Structure of Mercury Fulminate. Journal of Inorganic and General Chemistry, Vol. 633, pp. 1417-1422, 2007.

BIWA, S.; STOR ̊̊KERS, B. An analysis of fully plastic Brinell indentation. Journal of the Mechanics and Physics of Solids, Vol. 43, p. 1303-1333, 1995.

BONFANTI, MS; GHAUHARALI, RI. Visualization by confocal microscopy of traces on bullets and cartridge cases. Science \& Justice, Vol. 40, p. 241-256, 2000.

BOX, George E. P.; HUNTER, J. Stuart; HUNTER, William G. Statistics for

Experimenters: Design, Innovation, and Discovery. New Jersey: John Wiley \& Sons, 2005, $655 \mathrm{p}$.

B-GL-306-006/FP-001, Field Artillery, Volume 6, Ballistics and Ammunition, Canada: 1992.

CARLUCCI, Donald E.; JACOBSON, Sidney S. BALLISTICS: Theory and Design of Guns and Ammunition. New York: CRC Press, 2007, 502p.

CEUSTER, Jan De; DUJARDIN, Sylvain. The reference ballistic imaging database revisited. Forensic Science International, Vol. 248, p. 82-87, 2015.

CHU, W.; THOMPSON, R. M.; SONG, J. \& VORBURGER, T. V. Automatic identification of bullet signatures based on consecutive matching striae (CMS) criteria. Forensic Science International, Vol. 231, p. 137-141, 2013.

CITY MAYORS STAFF. Latin American cities are the most dangerous in the world. City Mayors, 12 nov. 2014. Disponível em <http://www.citymayors.com/security/latin-americanmurder-cities.html>. Acesso em: 26 jan. 2015.

COMMITTEE ON IDENTIFYING THE NEEDS OF THE FORENSIC SCIENCES COMMUNITY, NATIONAL RESEARCH COUNCIL. Strengthening Forensic Science in the United States: A Path Forward. Washington D.C: The National Academy Press, 2009. 
COMPANHIA BRASILEIRA DE CARTUCHOS. Informativo Técnico no $\mathbf{4 3}$. Emitido em junho de 2005.

CUNICO, Edimar. Perícia em locais de morte violenta: criminalística e medicina legal. Curitiba: 2010.

DAVIS, J.J. Primer cup properties \& how the affect identification, AFTE Journal, Vol. 42, p. 3-22, 2010.

DE KINDER. Ballistic fingerprinting databases. Science \& Justice, Vol. 42, p. 197-2003, 2002.

DE KINDER, Jan; TULLENERS, Frederic; THIEBAUT, Hugues. Reference ballistic imaging database performance. Forensic Science International, Vol. 40, pp. 207-2015, 2004.

DE SMET, P.; HERMSEN, R; LEUVEN, B. van; DE KINDER, J. ; HOFFMANN, K. Experimental evaluation of the impact of seating depth variations on observed marks on primers. Forensic Science International, Vol. 179, p. 163-171, 2008.

EVOFINDER $^{\circledR}, 2015$. Events. Disponível em <http://evofinder.com/events/>. Acesso em: 22 mai. 2015.

GHANI, Nor Azura MD; LIONG, Choong-Yeun; JEMAIN, Abdul Aziz. Analysis of geometric moments as features for firearm identification. Forensic Science International, Vol. 198, p. 143-149, 2010.

GERADTS, Zeno j.; BIJHOLD, Jurrien; HERMSEN, Rob; MURTAGH, Fionn. Image matching algorithms for breech face marks and firing pins in a database of spent cartridge cases of firearms. Forensic Science International, Vol. 119, p. 97-106, 2001.

GERULES, G.; BHATIA, S. K.; JACKSON, D. E. A survey of image processing techniques and statistics for ballistic specimens in forensic science. Science \& Justice, Vol. 53, p. 236-250, 2013.

GRZYBOWSKI, Richard; MILLER, Jerry; MORAN, Bruce; MURDOCK, John; NICHOLS, Ron; THOMPSON, Robert. Firearm/Toolmark Identification: Passing the Reliability Test under Federal and State Evidentiary Standards. AFTE Journal, vol. 35, 209-241, 2003.

HAMBY, J.E. The history of Firearm and Toolmark identification. AFTE Journal, 30th Anniversary Issue, Vol. 31, Number 3, 1999.

HAMBY, J. E.; BRUNDAGE, D.; THORPE, J. The identification of bullets fired from 10 consecutively rifled 9mm Ruger pistol barrels: A research project involving 507 participants from 20 countries. AFTE Journal, vol. 41, p. 99-110, 2009.

HEARD, Brian J. Handbook of firearms and ballistics: examining and interpreting forensic evidence. $2^{a}$ edição. Chichester: John Wiley \& Sons, 2008. 419p. 
HILL, R.; STORAKERS, B.; ZDUNEK, A. A theoretical study of the Brinell hardness test Proceedings of the Royal Society of London. Mathematical and Physical Sciences, Series A, Vol. 423, p.301-330, 1989.

HGA, 2015. Hand Gun Ammunition. Disponível em <http://www.magtechammunition.com/products/handgun-ammunition/>. Acesso em: 14 mai. 2015.

IBIS, 2015. Solution for a Safety Society. Disponível em <http://www.ultraforensictechnology.com/about\#ibin>. Acesso em: 22 mai. 2015.

JOST, Marcelo; SANTOS, Lehi Sudy dos; SATO, Eduardo Makoto. Balística. Brasília: Academia Nacional de Polícia, 2014. 84p.

KERSTHOLT, J.; EIKELBOOM, A.; DIJKMAN, T.; STOEL, R.; HERMSEN, R. \& VAN LEUVEN, B. Does suggestive information cause a confirmation bias in bullet comparisons? Forensic science international, Elsevier, vol. 198, p. 138-142, 2010.

KOPEL, David B.; BURNETT, H. Sterling. Ballistic Imaging: Not Ready for Prime Time. The National Center for Policy Analysis: POLICY BACKGROUNDER No. 160, 30 abr. 2003.

LEÓN, F. P. Automated Comparison of firearms bullets. Forensic Science International, Vol. 156, p. 40-50, 2006.

LEYI, G.; WEI, Z.; JING, Z.; SONGLING, H. Mechanics analysis and simulation of material Brinell hardness measurement. Measurement, Vol. 44, p. 2129-2137, 2011.

MORAES, Maurício. 2012. Com menos armas, Brasil tem três vezes mais mortes a tiro que os EUA. Disponível em

<http://www.bbc.com/portuguese/noticias/2012/12/121218_armas_brasil_eua_violencia_mm. shtml >. Acesso em: 02 set. 2015.

RABELLO, Eraldo. Balística Forense. 3ª edição. Porto Alegre: Sagra-DC Luzzato, 1995. 488p.

RAHM, Joachim. Evaluation of an electronic comparison system and implementation of a quantitative effectiveness criterion. Forensic Science International, Vol. 214, p. 173-177, 2012.

SAKARYA, Ufuk; LELOGLU, Ugur Murat; TUNALI, Erol. Three-dimensional surface reconstruction for cartridge cases using photometric stereo. Forensic Science International, Vol. 175, p. 209-217, 2008.

SAKARYA, U.; TOPÇU, O.; LELOĞLU, U. M.; SOYSAL, M. \& TUNALI, E. Automated region segmentation on cartridge case base. Forensic science international, Elsevier, vol. 222, p. 277-287, 2012. 
SCHWOEBLE, A. J.; EXLINE, DAVID L. Current methods in forensic gunshot residue analysis. London: CRC Press, 2000. 171p.

SILVINO JÚNIOR, João Bosco. 2010. 121f. Desenvolvimento de um sistema automatizado para captura e comparação de estriamentos de projéteis de armas de fogo. Dissertação (Mestrado em Engenharia Elétrica). Universidade Federal de Minas Gerais, Belo Horizonte, 2010.

SJASTAD, Knut-Endre; SIMONSEN, Siri Lene; ANDERSEN, Tom H. Lead isotope ratios for bullets, a descriptive approach for investigative purposes and a new method for sampling of bullet lead. Forensic Science International, Vol. 244, pp. 7-15, 2014.

SONG, John; VORBURGER, Theodore; BALLOU, Susan; MA, Li; RENEGAR, Thomas; ZHENG, Alan; OLS, Martin. Traceability for ballistics signature measurements in forensic Science. Measurement, vol. 42, p. 1433-1438, 2009.

SPORTING ARMS AND AMMUNITION MANUFACTURES INSTITUTE, 2015a. Maximum Cartridge / Minimum Chamber: .38 SPECIAL - .38 SPECIAL +P. Disponível em <http://www.saami.org/pubresources/cc_drawings/Pistol/38\%20Special_38\%20Special\% 20+P.pdf >. Acesso em: 28 ago. 2015.

SPORTING ARMS AND AMMUNITION MANUFACTURES INSTITUTE, 2015b. Maximum Cartridge / Minimum Chamber: 9mm Luger - 9mm Luger +P. Disponível em <http://www.saami.org/pubresources/cc_drawings/Pistol/9mm\%20Luger\%20\%209mm\%20Luger\%20+P.pdf >. Acesso em: 28 ago. 2015.

PIRATELLI FILHO, Antônio. Rugosidade Superficial. $3^{\circ}$ Seminário de Metrologia, Faculdade de Tecnologia, Departamento de Engenharia Mecânica, Universidade de Brasília, 2011. 41p.

TAYLOR, C.A.; RINKENBACH, WM.H. Sensitivities of detonating compounds to frictional impact, impact, and heat. Journal of the Franklin Institute, Vol. 204, Issue 3, p. 369-376, 1927.

THOMAS, J.; LEARY, R. Improving accuracy and effectiveness of forensic ballistics analysis and technology. Science \& Justice, Vol. 50, Issue 1, p. 30, 2010.

TOBIN Jr., John J. MD-IBIS Progress Report \#2. Maryland State Police: Forensic Science Division: set. 2004.

WAISELFISZ, Julio Jacobo. Mapa da violência dos municípios brasileiros 2008. Brasília: 2008. 114p.

WAISELFISZ, Julio Jacobo. Mapa da violência 2013: mortes matadas por armas de fogo. Centro Brasileiro de Estudos Latino-Americanos: 2013. 55p.

WARLOW, Tom. Firearms, The Law, And Forensic Ballistics. Second Edition. Flórida: CRC Press LLC, 2005. 476p. 
WILSON, Richard S.; JOPEK, Lukasz; BATES, Christopher D. Sharing Ballistics Data across the European Union. COMPUTATION TOOLS 2010: The First International Conference on Computational Logics, Algebras, Programming, Tools, and Benchmarking. Portugal, 2010. 


\section{ANEXO I: FATORES DE CARGA PARA DIFERENTES CONDIÇÕES DE ENSAIO NOS TESTES DE DUREZA BRINELL}

\begin{tabular}{|c|c|c|c|c|}
\hline $\begin{array}{c}\text { Símbolo da } \\
\text { dureza }\end{array}$ & $\begin{array}{c}\text { Diâmetro da esfera } \\
\text { D } \\
\mathrm{mm}\end{array}$ & $\begin{array}{c}\text { Relação força- } \\
\text { diâmetro } \\
0,102 \times \mathrm{x}^{2} \mathrm{D}^{2} \\
\mathrm{~N} / \mathrm{mm}^{2}\end{array}$ & $\begin{array}{r}\text { Valor no } \\
\text { de }\end{array}$ & la força \\
\hline HBW 10/3000 & 10 & 30 & 29,42 & $\mathrm{KN}$ \\
\hline HBW 10/1500 & 10 & 15 & 14,71 & $\mathrm{KN}$ \\
\hline HBW 10/1000 & 10 & 10 & 9,807 & $\mathrm{KN}$ \\
\hline HBW 10/500 & 10 & 5 & 4,903 & $\mathrm{KN}$ \\
\hline HBW 10/250 & 10 & 2,5 & 2,452 & $\mathrm{KN}$ \\
\hline HBW 10/100 & 10 & 1 & 980,7 & $\mathrm{~N}$ \\
\hline HBW 5/750 & 5 & 30 & 7,355 & $\mathrm{KN}$ \\
\hline HBW 5/250 & 5 & 10 & 2,452 & $\mathrm{KN}$ \\
\hline HBW 5/125 & 5 & 5 & 1,226 & $\mathrm{KN}$ \\
\hline HBW 5/62,5 & 5 & 2,5 & 612,9 & $\mathrm{~N}$ \\
\hline HBW 5/25 & 5 & 1 & 245,2 & $\mathrm{~N}$ \\
\hline HBW 2,5/187,5 & 2,5 & 30 & 1,839 & $\mathrm{KN}$ \\
\hline HBW 2,5/62,5 & 2,5 & 10 & 612,9 & $\mathrm{~N}$ \\
\hline HBW 2,5/31,25 & 2,5 & 5 & 306,5 & $\mathrm{~N}$ \\
\hline HBW 2,5/15,625 & 2,5 & 2,5 & 153,2 & $\mathrm{~N}$ \\
\hline HBW $2,5 / 6,25$ & 2,5 & 1 & 61,29 & $\mathrm{~N}$ \\
\hline HBW 1/30 & 1 & 30 & 294,2 & $\bar{N}$ \\
\hline HBW 1/10 & 1 & 10 & 98,07 & $\mathrm{~N}$ \\
\hline HBW $1 / 5$ & 1 & 5 & 49,03 & $\mathrm{~N}$ \\
\hline HBW $1 / 2,5$ & 1 & 2,5 & 24,52 & $\mathrm{~N}$ \\
\hline HBW 1/1 & 1 & 1 & 9,807 & $\mathrm{~N}$ \\
\hline
\end{tabular}

Fonte: NBR ISO 6506-1:2010, p. 6. 


\section{APÊNDICE I: RELAÇÃO DE ARMAS UTILIZADAS}

Tabela 36 - Relação de armas de calibre .38 SPL.

\begin{tabular}{|c|l|l|c|c|}
\hline & \multicolumn{1}{|c|}{ Arma } & Numeração & Raiamento & Tipo raiamento \\
\hline $\mathbf{1}$ & Revólver Taurus & 133291 & $6 \mathrm{D}$ & Retangular \\
\hline $\mathbf{2}$ & Revólver Taurus & 466573 & $6 \mathrm{D}$ & Retangular \\
\hline $\mathbf{3}$ & Revólver Taurus & 466568 & $6 \mathrm{D}$ & Retangular \\
\hline $\mathbf{4}$ & Revólver Taurus & 409467 & $6 \mathrm{D}$ & Retangular \\
\hline $\mathbf{5}$ & Revólver Rossi & F013615 & 6D & Retangular \\
\hline $\mathbf{6}$ & Revólver Rossi & F013616 & 6D & Retangular \\
\hline $\mathbf{7}$ & Revólver Rossi & F013058 & 6D & Retangular \\
\hline $\mathbf{8}$ & Revólver Rossi & F054100 & 6D & Retangular \\
\hline $\mathbf{9}$ & Revólver Rossi & F054120 & 6D & Retangular \\
\hline $\mathbf{1 0}$ & Revólver Taurus & IE162224 & 5D & Retangular \\
\hline $\mathbf{1 1}$ & Revólver Taurus & IE162265 & 5D & Retangular \\
\hline $\mathbf{1 2}$ & Revólver Taurus & IE162221 & 5D & Retangular \\
\hline $\mathbf{1 3}$ & Revólver Taurus & IE162222 & 5D & Retangular \\
\hline $\mathbf{1 4}$ & Revólver Taurus & 2031906 & 5D & Retangular \\
\hline $\mathbf{1 5}$ & Revólver Taurus & IE162219 & 5D & Retangular \\
\hline $\mathbf{1 6}$ & Revólver Taurus & IE162267 & 5D & Retangular \\
\hline
\end{tabular}

Tabela 37 - Relação de armas de calibre 9mm Luger.

\begin{tabular}{|c|l|l|c|c|}
\hline & \multicolumn{1}{|c|}{ Arma } & Numeração & Raiamento & Tipo raiamento \\
\hline $\mathbf{1 8}$ & Pistola Taurus & TOA 31285 & 6D & Retangular \\
\hline $\mathbf{1 9}$ & Pistola FN & T 345252 & 6D & Retangular \\
\hline $\mathbf{2 0}$ & Pistola Taurus & TNL 30638 & 6D & Retangular \\
\hline $\mathbf{2 1}$ & Pistola Taurus & TOG 08513 & 6D & Retangular \\
\hline
\end{tabular}




\begin{tabular}{|c|c|c|c|c|}
\hline & Arma & Numeração & Raiamento & Tipo raiamento \\
\hline 22 & Pistola Taurus & TNL 30637 & $6 \mathrm{D}$ & Retangular \\
\hline 23 & Pistola Taurus & TOA 31246 & $6 \mathrm{D}$ & Retangular \\
\hline 24 & Pistola Taurus & TOA 31184 & $6 \mathrm{D}$ & Retangular \\
\hline 25 & Pistola Taurus & TOA 31098 & $6 \mathrm{D}$ & Retangular \\
\hline 26 & Pistola Taurus & TSI 11122 & $6 \mathrm{D}$ & Retangular \\
\hline 27 & Pistola Taurus & TVE 04539 & $6 \mathrm{D}$ & Retangular \\
\hline 28 & Pistola Taurus & TOA 31238 & $6 \mathrm{D}$ & Retangular \\
\hline 29 & Pistola Taurus & TOA 31288 & $6 \mathrm{D}$ & Retangular \\
\hline 30 & Pistola Nurico & 303143 & $6 \mathrm{D}$ & Retangular \\
\hline 31 & Pistola Jerico & 151734 & $6 \mathrm{D}$ & Poligonal \\
\hline 32 & Pistola Jerico & 151715 & $6 \mathrm{D}$ & Poligonal \\
\hline 33 & Pistola S\&W & A 352177 & $6 D$ & Retangular \\
\hline
\end{tabular}




\section{APÊNDICE II: RESULTADOS DOS TESTES DE DUREZA BRINELL}

Tabela 38 - Resultados dos testes de dureza Brinell em projéteis .38SPL.

\begin{tabular}{|c|c|c|c|c|c|c|c|}
\hline & Ponta (mm) & 1 & 2,5 & 2,5 & 2,5 & 2,5 & 2,5 \\
\hline & Carga (kgf) & 2,5 & 15,625 & 15,625 & 15,625 & 15,625 & 15,625 \\
\hline & $F / D^{2}$ & 2,5 & 2,5 & 2,5 & 2,5 & 2,5 & 2,5 \\
\hline \multirow{20}{*}{ 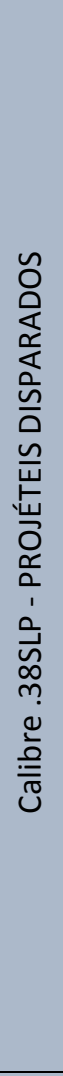 } & Projéteis & PP1 & PP2 & PP3 & PP4 & PP5 & PP6 \\
\hline & \multirow{7}{*}{ Medições } & 5,2 & 86,5 & 110,1 & 114,4 & 122,3 & 114,5 \\
\hline & & 5,2 & 92,2 & 107,2 & 90,6 & 124,9 & 116,9 \\
\hline & & 4,9 & 95,5 & 104,6 & 98,5 & 119,7 & 107 \\
\hline & & 4,9 & 86,3 & 99,7 & 98 & 108,1 & 109,5 \\
\hline & & 5,2 & 89,1 & 92,6 & 93,7 & 123,7 & 108,7 \\
\hline & & 4,8 & 93,9 & 105,2 & 95,5 & 114,7 & 105,3 \\
\hline & & 4,6 & 88,3 & 107 & 110,8 & 112,9 & 111,9 \\
\hline & Média & 5,0 & 90,3 & 103,8 & 100,2 & 118,0 & 110,5 \\
\hline & DP & 0,2 & 3,6 & 5,9 & 8,9 & 6,3 & 4,1 \\
\hline & \multirow[t]{4}{*}{ Projéteis } & PP1 & PP2 & PP3 & PP4 & PP5 & PP6 \\
\hline & & 4,6 & 81,2 & 105,2 & 79,1 & 112,4 & 107,8 \\
\hline & & 5,1 & 94,7 & 111,7 & 84,4 & 110,3 & 104,2 \\
\hline & & 4,9 & 99,1 & 96,4 & 95,6 & 119,5 & 103,1 \\
\hline & \multirow[t]{4}{*}{ Medições } & 4,9 & 91,2 & 92,9 & 97,1 & 101,5 & 109,7 \\
\hline & & 5,7 & 88,7 & 100 & 97,5 & 111 & 106,2 \\
\hline & & 5,4 & 88,6 & 111,3 & 96,6 & 124,3 & 115,5 \\
\hline & & 5,2 & 95,5 & 100,1 & 80,3 & 122,1 & 98,2 \\
\hline & Média & 5,1 & 91,3 & 102,5 & 90,1 & 114,4 & 106,4 \\
\hline & DP & 0,4 & 5,9 & 7,2 & 8,4 & 8,0 & 5,5 \\
\hline \multirow{17}{*}{ 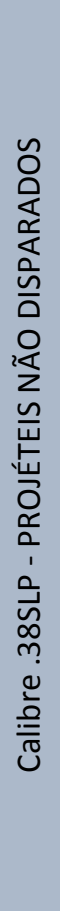 } & \multirow[t]{8}{*}{ Projéteis } & PP1 & PP2 & PP3 & PP4 & PP5 & PP6 \\
\hline & & 6,1 & 84,8 & 106,2 & 93,3 & 115,5 & 108,3 \\
\hline & & 6,1 & 84,4 & 100,4 & 98,9 & 115 & 102,1 \\
\hline & & 5,6 & 84,9 & 93,1 & 100,4 & 107,4 & 100 \\
\hline & & 6,7 & 95,3 & 91,2 & 102,8 & 115,4 & 111,1 \\
\hline & & 5,4 & 95,2 & 89,9 & 98,7 & 120,8 & 108,2 \\
\hline & & 5,7 & 88,2 & 87,5 & 105,7 & 126,8 & 103,8 \\
\hline & & 5,8 & 88,6 & 93,2 & 102,6 & 122,8 & 105,7 \\
\hline & Média & 5,9 & 88,8 & 94,5 & 100,3 & 117,7 & 105,6 \\
\hline & DP & 0,4 & 4,7 & 6,5 & 4,0 & 6,3 & 3,9 \\
\hline & \multirow[t]{3}{*}{ Projéteis } & PP1 & PP2 & PP3 & PP4 & PP5 & PP6 \\
\hline & & 5,6 & 98,6 & 103,3 & 73,5 & 109,8 & 115,8 \\
\hline & & 6,1 & 88,8 & 104,1 & 73,3 & 106,6 & 104,5 \\
\hline & \multirow{4}{*}{ Medições } & 6,1 & 88,8 & 97,6 & 77,3 & 118,9 & 108 \\
\hline & & 5,5 & 85,8 & 100,6 & 87,7 & 118 & 118,1 \\
\hline & & 5,1 & 86,2 & 103,4 & 98,4 & 114,6 & 120,9 \\
\hline & & 6,5 & 87,1 & 98,6 & 89,4 & 101,8 & 100,8 \\
\hline
\end{tabular}




\begin{tabular}{|c|c|c|c|c|c|c|}
\hline & PP1 & PP2 & PP3 & PP4 & PP5 & PP6 \\
\hline & 5,6 & 90,4 & 96,5 & 97 & 108,7 & 100,3 \\
\hline Média & 5,8 & 89,4 & 100,6 & 85,2 & 111,2 & 109,8 \\
\hline DP & 0,5 & 4,4 & 3,1 & 10,6 & 6,3 & 8,5 \\
\hline Média disparados & 5,0 & 90,8 & 103,1 & 95,2 & 116,2 & 108,5 \\
\hline Desvio padrão & 0,3 & 4,7 & 6,3 & 9,9 & 7,1 & 5,1 \\
\hline Média não disparados & 5,9 & 89,1 & 97,5 & 92,8 & 114,4 & 107,7 \\
\hline Desvio padrão & 0,4 & 4,4 & 5,8 & 11,0 & 6,9 & 6,7 \\
\hline Média global & 5,4 & 89,9 & 100,3 & 94,0 & 115,3 & 108,1 \\
\hline Desvio padrão & 0,6 & 4,6 & 6,6 & 10,3 & 7,0 & 5,9 \\
\hline
\end{tabular}

Tabela 39 - Resultados dos testes de dureza Brinell em projéteis 9mm Luger.

\begin{tabular}{|c|c|c|c|c|c|}
\hline & Ponta $(\mathrm{mm})$ & 1 & 1 & 1 & 1 \\
\hline & Carga (kgf) & 10 & 10 & 10 & 10 \\
\hline & $F / D^{2}$ & 10 & 10 & 10 & 10 \\
\hline \multirow{20}{*}{ 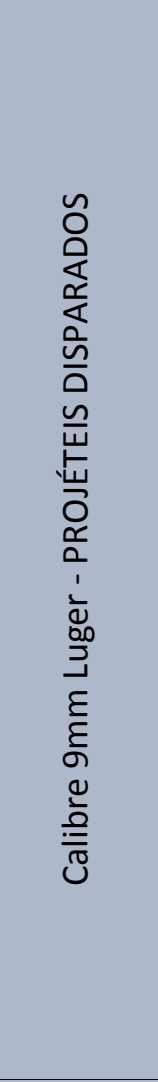 } & \multirow[t]{4}{*}{ Projéteis } & PP1 & PP2 & PP3 & PP4 \\
\hline & & 140,4 & 138,2 & 149,9 & 67 \\
\hline & & 118,2 & 131 & 142,4 & 66,2 \\
\hline & & 144,8 & 142,8 & 136,5 & 67,7 \\
\hline & \multirow[t]{4}{*}{ Medições } & 140,4 & 152 & 138,1 & 73,4 \\
\hline & & 133,9 & 143,7 & 156,6 & 72,8 \\
\hline & & 120,7 & 143,2 & 141 & 72,2 \\
\hline & & 160,1 & 148,3 & 145,2 & 75,1 \\
\hline & Média & 136,9 & 142,7 & 144,2 & 70,6 \\
\hline & DP & 14,4 & 6,8 & 7,0 & 3,6 \\
\hline & \multirow[t]{4}{*}{ Projéteis } & PP1 & PP2 & PP3 & PP4 \\
\hline & & 146,1 & 144,2 & 136 & 70,2 \\
\hline & & 146,2 & 139,7 & 137 & 69 \\
\hline & & 152,1 & 160,4 & 137,6 & 67,2 \\
\hline & \multirow[t]{4}{*}{ Medições } & 129,5 & 149,4 & 134 & 72,3 \\
\hline & & 138,3 & 138,9 & 134,2 & 68,7 \\
\hline & & 135,8 & 125,6 & 131,5 & 77,4 \\
\hline & & 134,5 & 154,6 & 143 & 73,8 \\
\hline & Média & 140,4 & 144,7 & 136,2 & 71,2 \\
\hline & DP & 8,0 & 11,5 & 3,6 & 3,5 \\
\hline \multirow{8}{*}{ 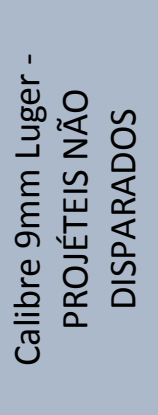 } & \multirow[t]{4}{*}{ Projéteis } & PP1 & PP2 & PP3 & PP4 \\
\hline & & 133,5 & 130,4 & 131,8 & 68,2 \\
\hline & & 147,6 & 135 & 133,5 & 69,7 \\
\hline & & 146,1 & 136,7 & 142,9 & 69,6 \\
\hline & \multirow[t]{4}{*}{ Medições } & 139,7 & 130,5 & 139,9 & 71,2 \\
\hline & & 135,4 & 136 & 145,8 & 67,7 \\
\hline & & 146,5 & 133,9 & 132,9 & 75,6 \\
\hline & & 137,4 & 133,5 & 137,8 & 67,8 \\
\hline
\end{tabular}




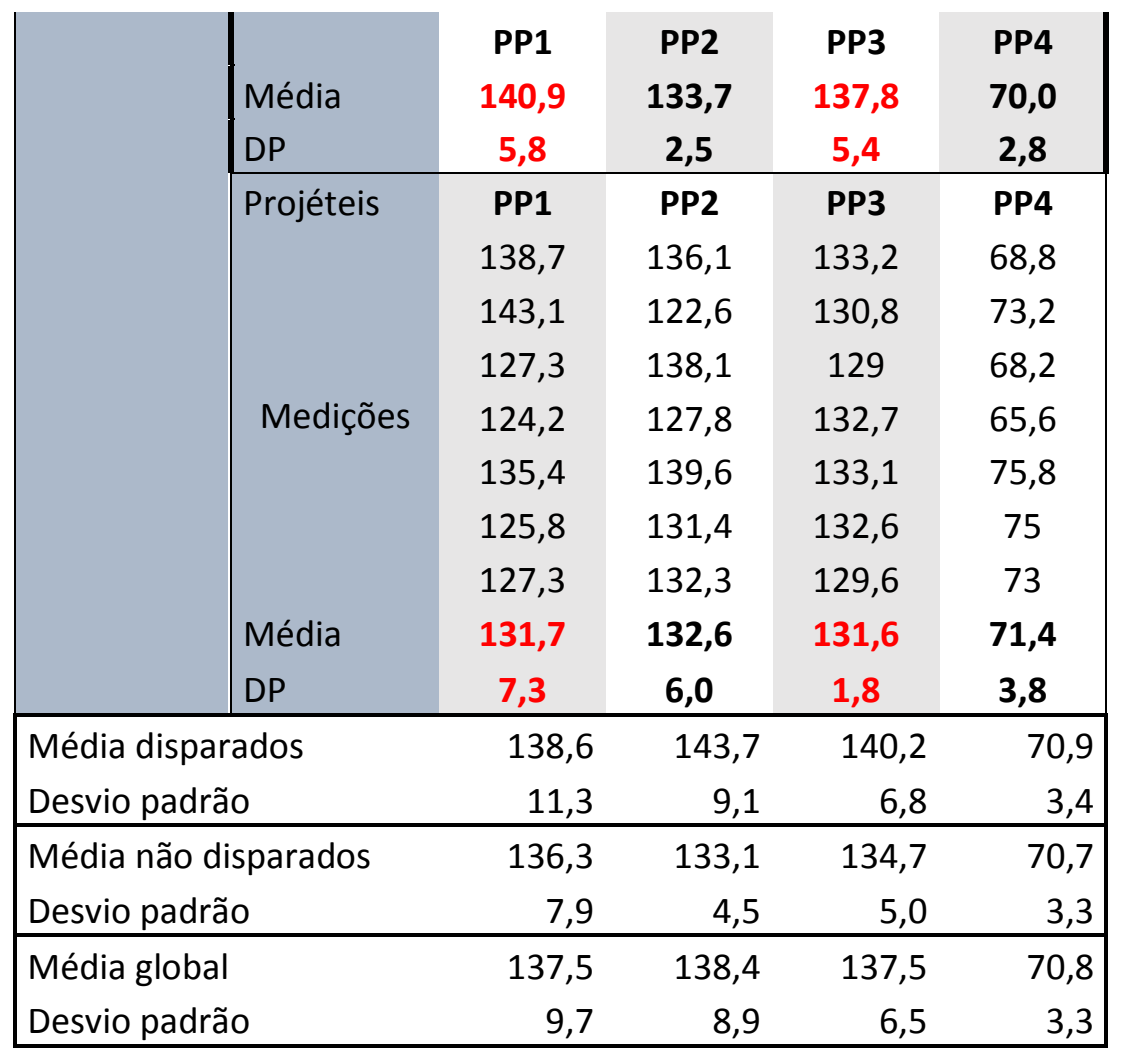




\section{APÊNDICE III: RESULTADOS DOS TESTES DE RUGOSIDADE}

Tabela 40 - Resultados dos testes de rugosidade em projéteis disparados .38SPL.

\begin{tabular}{|c|c|c|c|c|c|c|}
\hline Projétil & PP1 & PP2 & PP3 & PP4 & PP5 & PP6 \\
\hline \multirow{3}{*}{ 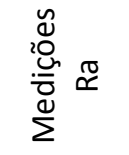 } & 14,3 & 13,6 & 14,8 & 13,3 & 13,8 & 13,6 \\
\hline & 12,8 & 13,1 & 14,5 & 13,5 & 12,7 & 11,8 \\
\hline & 13,4 & 14,6 & 15,8 & 13,6 & 14,5 & 14,2 \\
\hline Média & 13,5 & 13,8 & 15,0 & 13,5 & 13,7 & 13,2 \\
\hline DP & 0,8 & 0,8 & 0,7 & 0,2 & 0,9 & 1,2 \\
\hline \multirow{3}{*}{ 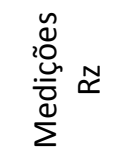 } & 89,9 & 167,5 & 165,2 & 113,6 & 169,9 & 118,7 \\
\hline & 107,6 & 122,4 & 124,6 & 153,4 & 97,4 & 127,6 \\
\hline & 74,7 & 150,9 & 200,5 & 126,9 & 151,0 & 118,8 \\
\hline Média & 90,7 & 146,9 & 163,4 & 131,3 & 139,4 & 121,7 \\
\hline DP & 16,5 & 22,8 & 38,0 & 20,3 & 37,6 & 5,1 \\
\hline
\end{tabular}

Tabela 41 - Resultados dos testes de rugosidade em projéteis disparados 9mm Luger.

\begin{tabular}{|c|c|c|c|c|}
\hline Projétil & PP1 & PP2 & PP3 & PP4 \\
\hline \multirow{3}{*}{ 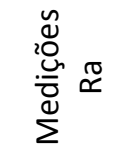 } & 13,3 & 11,7 & 12,5 & 16,8 \\
\hline & 12,9 & 11,7 & 13,9 & 15,0 \\
\hline & 13,1 & 13,4 & 13,9 & 14,9 \\
\hline Média & 13,1 & 12,3 & 13,4 & 15,5 \\
\hline DP & 0,2 & 1,0 & 0,8 & 1,1 \\
\hline \multirow{3}{*}{ 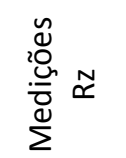 } & 204,0 & 89,0 & 133,5 & 257,8 \\
\hline & 93,9 & 109,6 & 186,7 & 163,7 \\
\hline & 76,7 & 133,4 & 133,4 & 150,5 \\
\hline Média & 124,9 & 110,7 & 151,2 & 190,7 \\
\hline $\mathrm{DP}$ & 69,0 & 22,2 & 30,8 & 58,5 \\
\hline
\end{tabular}

